\title{
AN EVALUATION OF MERCURY COOLED BREEDER REACTORS
}

\author{
Prepared Under \\ Contract No. AT(04-3)-109 \\ Project Agreement No. 4 \\ for the U. S. Atomic Energy Commission \\ Division of Reactor Development
}

ATL Job C-42

\section{October 1959}

John O. Bradfute, Project Engineer

\author{
Donald W. Battles \\ George S. Clark \\ Robert E. Corridan \\ Edward T. Gellenbeck \\ Devereux L. Kavanagh \\ Donald R. Mash \\ Fred E. Romie \\ Roger H. Whitlock \\ Approved by: \\ David P. Herron, Director \\ Nuclear Development Group
}

\section{ADVANCED TECHNOLOGY LABORATORIES \\ A Division of American-Standard \\ 369 Whisman Road \\ Mountain View, California}




\section{DISCLAIMER}

This report was prepared as an account of work sponsored by an agency of the United States Government. Neither the United States Government nor any agency Thereof, nor any of their employees, makes any warranty, express or implied, or assumes any legal liability or responsibility for the accuracy, completeness, or usefulness of any information, apparatus, product, or process disclosed, or represents that its use would not infringe privately owned rights. Reference herein to any specific commercial product, process, or service by trade name, trademark, manufacturer, or otherwise does not necessarily constitute or imply its endorsement, recommendation, or favoring by the United States Government or any agency thereof. The views and opinions of authors expressed herein do not necessarily state or reflect those of the United States Government or any agency thereof. 


\section{DISCLAIMER}

Portions of this document may be illegible in electronic image products. Images are produced from the best available original document. 


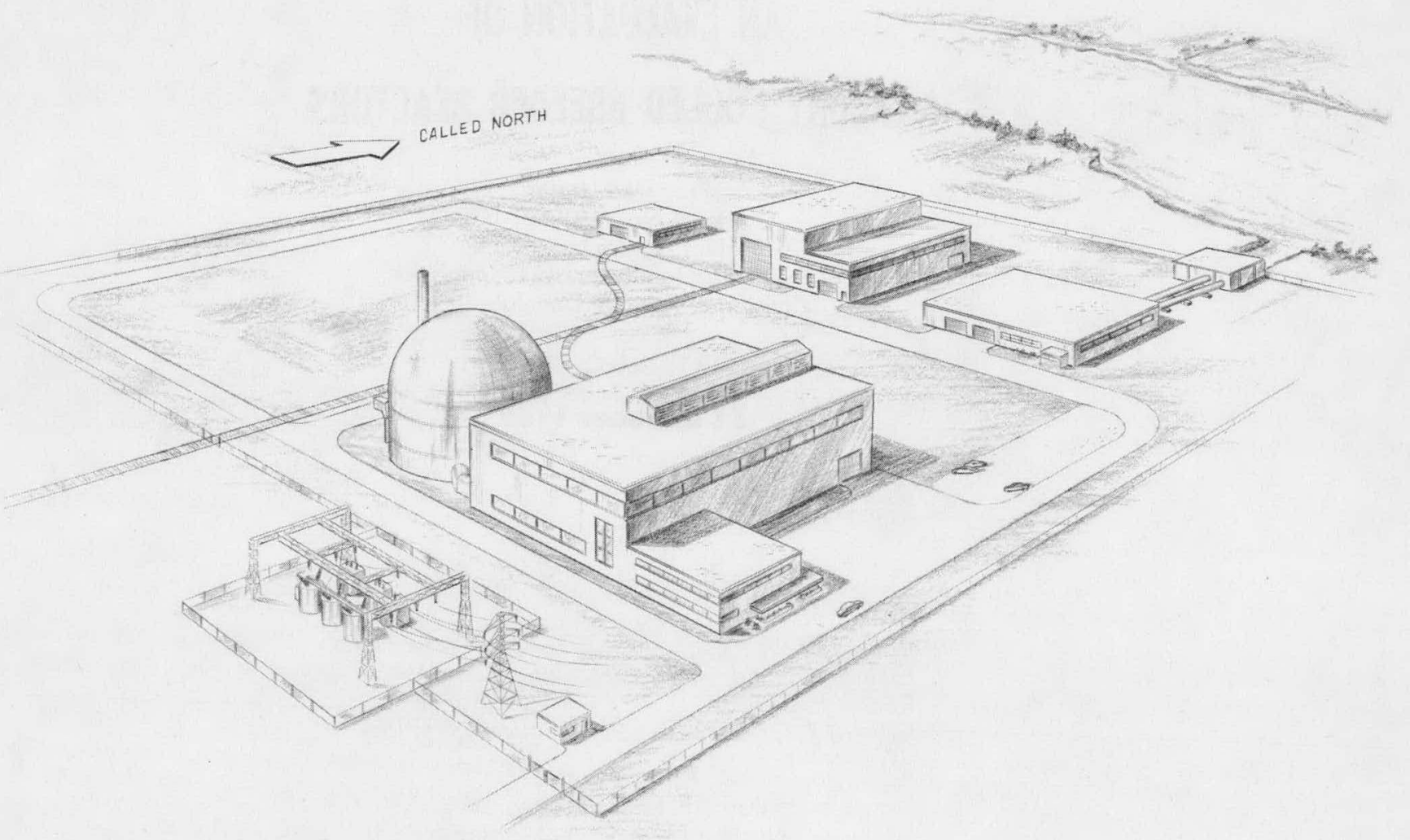

MERCURY COOLED BREEDER REACTOR PLANT ( 100 EMW) 


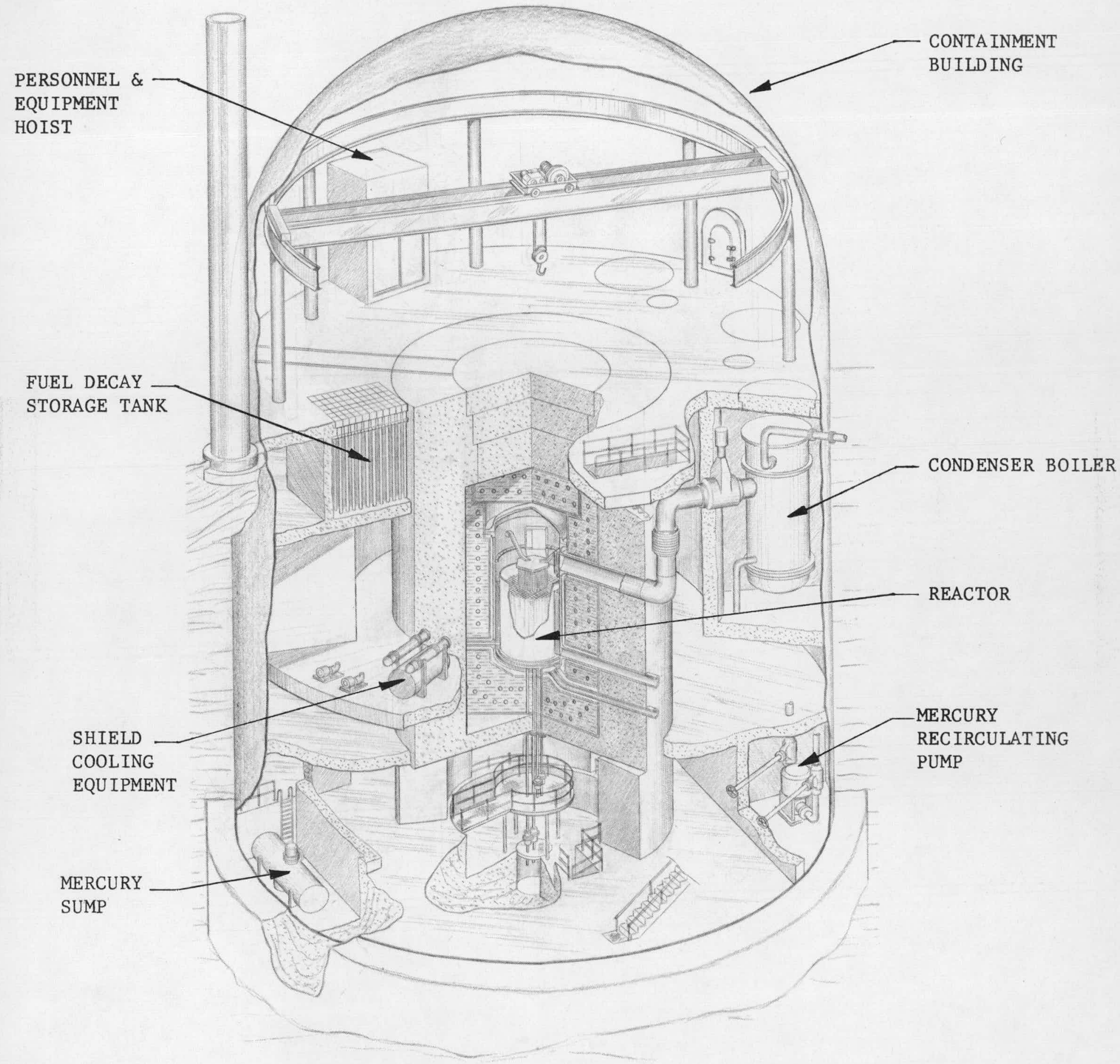

MERCURY COOLED BREEDER REACTOR (100 EMW) 


\section{CONTENTS}

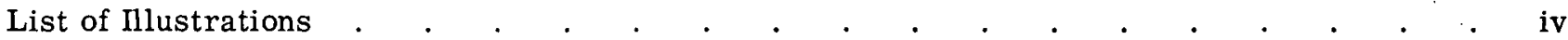
List of Tables

Foreword

Abstract

Summary and Conclusions

Introduction

Mercury as a Reactor Coolant

A. General Characteristics of Mercury

B. Characteristics of Boiling Mercury

C. Comparison of Boiling Mercury with Sodium as a Coolant

Technical Basis for Feasibility Evaluation

A. Fluid Flow and Heat Transfer

1. Head Loss Across Core

2. Permissible Maximum Heat Flux

3. Power Density

4. Inlet Subcooling and Pressure Drop

5. Initial Estimate of Attainable Power Densities

B. Reactor Physics

1. Core Configuration

2. Blanket Configuration

C. Reactor Plant Materials

Selection of Parameters for Conceptual Core Design

B. Optimum Pressure Drop and Exit Saturation Temperature _ . . . . . . . 42

C. Power Level

D. Core Size and Configuration

E. Blanket Thickness

Economic Analysis of MCBR Power Plant System

A. Capital Costs and Fixed Charges

B. Fuel Cost Estimate

C. Annual Operating and Maintenance Costs

D. Comparisons with Other Reactors

Conceptual MCBR Power Plant Design

A. Nuclear Characteristics of Reference Core

1. Reactor Statics

2. Temperature Effects

3. Fuel Burnup

4. Mercury Activation

5. Shielding

a. Primary Neutron and Gamma Shielding

b. Mercury Pipe Shielding

c. Shutdown Shielding

d. Thermal Shielding

B. Reactor Plant Description

1. Reactor

a. Core and Blanket Element Assemblies

b. Control and Safety Rods 


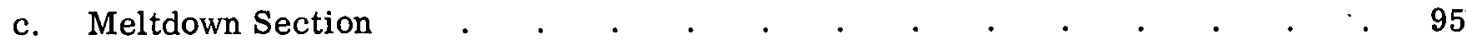

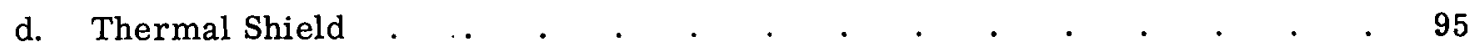

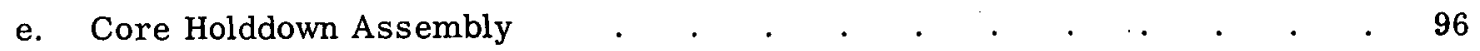

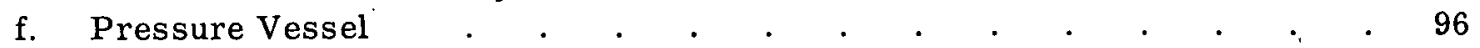

2. Primary Mercury Coolant System _ . . . . . . . . . . . . . 97

3. Condenser-Boilers . . . . . . . . . . . . . . . . . . . . . . 99

4. Steam and Feedwater Systems . . . . . . . . . . . . . . . 100

5. Auxiliary Mercury Systems . . . . . . . . . . . . . 101

a. Cleanup and Additive Injection System $\quad . \quad$. $\quad . \quad$. $\quad . \quad$. $\quad . \quad$. 101

b. Startup System . . . . . . . . . . . . . . 102

c. Shutdown Cooling System + . . . . . . . . . . . . . 102

d. Sump System . . . . . . . . . . . . . . . 103

e. Mercury Recovery System . . . . . . . . . . . . . 103

f. Water-Removal System . . . . . . . . . . . : 104

6. Relief-Valve Blowdown System . . . . . . . . . . . . . . $\quad . \quad 104$

7. Reactor Evacuation System . . . . . . . . . . . . . . . 104

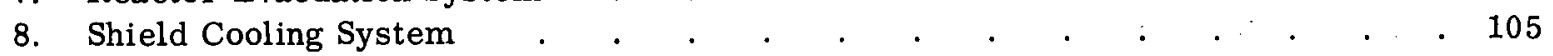

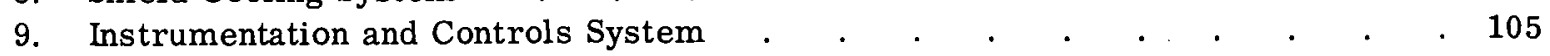

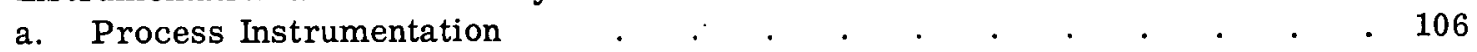

b. Nuclear Instrumentation . . . . . . . . . . . . . . . . . 106

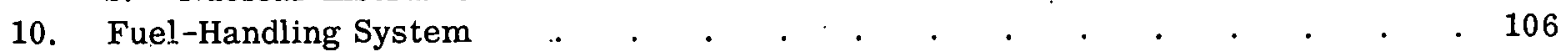

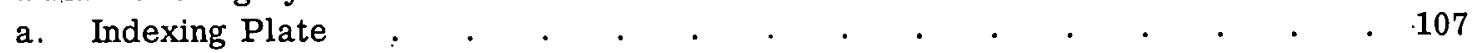

b. Fuel-Transfer Cask

c. Fuel-Decay Storage Tank

11. Reactor Containment Vessel

C. Power-Generation Plant Description

D. Plant Site

E. Plant Layout

1. Reactor Containment Building

a. Operating Floor

b. First Basement

c. Second Basement

d. Third Basement

e. Fourth Basement

2. Turbine-Generator Building $\quad \cdot 112$

3. Water-Treatment Building . . . . . . . . . . . . . . . 112

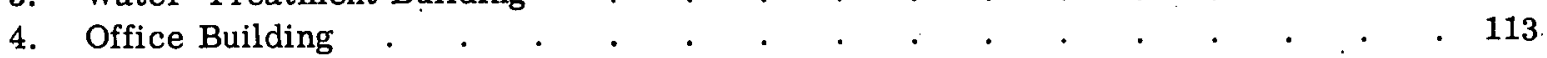

5. Maintenance Shop . . . . . . . . . . . . . . . . . . . $\quad . \quad 113$

6. Waste-Disposal Building . . . . . . . . . . . . . . . . 113

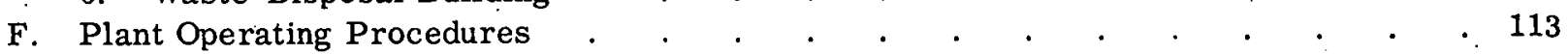

1. Startup Procedure . . . . . . . . . . . . . . . . . . . . .

2. Normal Operation . . . . . . . . . . . . . . . . . . . 115

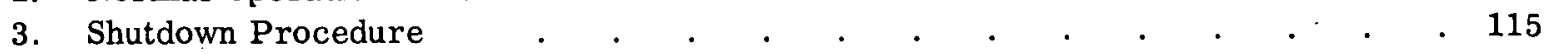

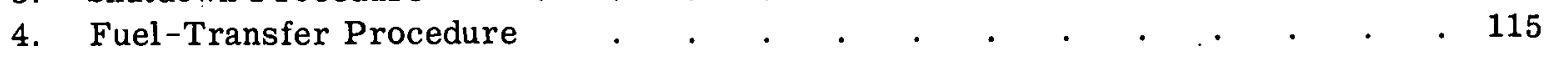




\section{MERCURY COOLED BREEDER REACTOR}

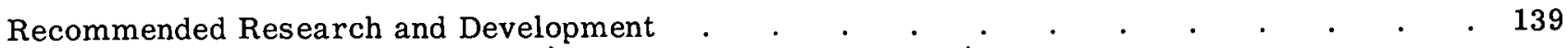

Phase 1 - Preliminary Design of MCBR Power-Producing System _ . . . . . . 140

Task 1 - Preliminary Design of a MCBR Power-Producing System with a Cylindrical Core

Task 2 - Design Evaluation of Improved MCBR Concepts $\quad$. . . . . . . . 142

Phase II - Preconstruction Test Program .

Task 1 - Heat Transfer and Fluid Flow

Task 2 - Sludge Removal, Corrosion, and Other System Tests _ . . . . . . 145

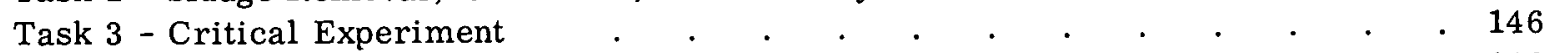

Phase III - Reactor Test . . . . . . . . . . . . . . . . . . . . . . . 146

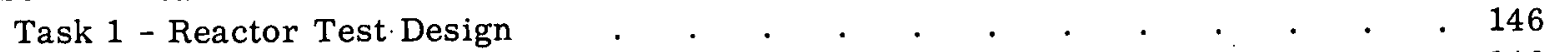

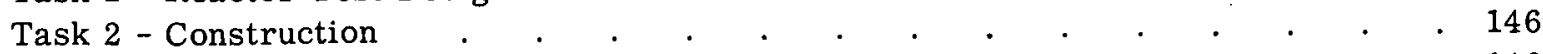

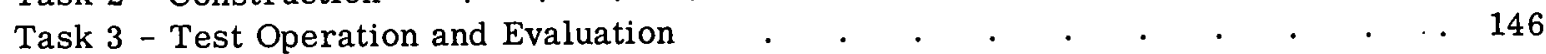

Phase IV - Final Design of MCBR Power-Producing System . . . . . . . . . 146

Boiling Mercury Heat Transfer Experiment . . . . . . . . . . . . . . . . 149

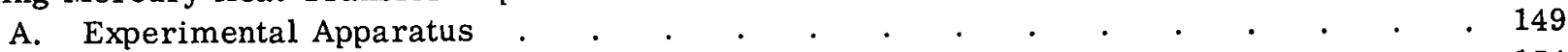

B. Results. . . . . . . . . . . . . . . . . . . . 154

C. Discussion . . . . . . . . . . . . . . . . . . . . . . . . .

Appendix

Appendix $A_{-=}=$Sropenf $=$Sentraot

Appendix B - Physical Properties of Mercury

Appendix C - Mercury Heat Transfer and Fluid Flow

Appendix D - Derivation of Pressure Drop Equations

Appendix E - MCBR' Physics Calculations and Data

Appendix F - Basis for MCBR Materials Selection

Appendix G - Preliminary Economic Evaluation

Appendix $\mathrm{H}$ - Capital Cost Estimate

Appendix J ,-Mercury Availability and Price.

Appendix K - Equipment Design Data - Reactor Plant

Nomenclature

References

Distribution 


\section{LIST OF ILLUSTRATIONS}

Figure No.

Frontispiece

1

22

3

4

5

6

7

8

9

10

11

12

13

14

15

16

17

18

19

20

21

22

23

24

25

26

27

28

29

30

31

32

33

34

35
Title

Mercury Cooled Breeder Reactor Plant (100 emw)

Mercury Cooled Breeder Reactor (100 emw)

Surface Heat Flux for Attainment of $1112^{\circ} \mathrm{F}\left(600^{\circ} \mathrm{C}\right)$ Fuel-Pin

Centerline Temperature

Effect of Mercury Saturation Temperature on Average Power

Density in MCBR Core

Element Temperature Distribution

Length-Average Power Density for Central Channel in Core

(Head Loss Across Blanket not Included)

Critical Mass versus Coolant Volume Fraction in Core

Breeding Ratio versus Coolant Volume Fraction in Core

Breeding Ratio versus Structure-Fuel Alloy Volume Ratio

Breeding Ratio versus Average Coolant $(\mathrm{Hg})$ Density in Core

Critical Mass versus Average Coolant (Hg) Density in Core

Critical Mass versus Structure-Fuel Alloy Volume Ratio

Breeding Ratio versus Blanket Thickness

Leakage out of Blanket versus Blanket Thickness

Total Breeding Ratio versus Average Coolant $(\mathrm{Hg})$ Density in Blanket

Total Breeding Ratio versus Coolant Volume Fraction in Blanket .

Total Breeding Ratio versus Structure-Fuel Alloy Volume Ratio in Blanket

Fuel-Element Temperature Distribution

Mercury Saturation Temperature for Maximum Net Revenue

Inventory and Working Capital Costs Typical MCBR Core

Required Uranium Mass versus Fuel-Element Outer Diameter

Coolant Volume Fraction versus Fuel-Element Outer Diameter

Mass of Uranium versus Coolant Volume Fraction

Required Enrichment versus Fuel-Element Diameter

Net Cost of Maintaining a Uranium Blanket Around a Typical MCBR Core

MCBR Neutron Flux Distribution

Radial Power Density Distribution in Core

Axial Power Density Distribution in Core

Power Density Distribution in Blanket

Integrated Flux Spectrum

Reactivity Change for Fractional Changes in Total Mass of Uranium

Plutonium Buildup in Core versus Integrated Flux

Mercury Activation Due to $\mathrm{n} \gamma$ Reactions

Sources of Radiation Leaving Outer Blanket Surface

Dose Rate for Various Depths of Mercury above Blanket

Over-all Schedule of Development Program, Mercury Cooled

Breeder Reactor

Schematic of Boiling Mercury Test Loop $\underline{\text { Page }}$

14

16

18

19

24

25

26

. 27

28

29

30

31

32

33

34

39

43

46

50

51

52

53

56

71

72

73

74

75

79

80

82

85

87

141

150 
B-1

B-2

B-3

B-4

B-5

B-6

B-7

B-8

B-9

B-10

B-11

$\mathrm{C}-1$

$\mathrm{C}-2$

$\mathrm{C}-3$

C-4

C -5

C -6

$\mathrm{C}-7$

$\mathrm{C}-8$

D-1

$\therefore \mathrm{D}-2$

D-3

$\mathrm{D}-4$

$\mathrm{F}-1$

F-2

$\mathrm{F}-3$

$\mathrm{F}-4$

F-5

F-6
Mercury Saturation Pressure

164

165

166

Surface Tension of Mercury

$\begin{array}{ll}\text { Thermal Conductivity of Liquid Mercury } & 167 \\ \text { Electrical Resistivity of Liquid Mercury } & 168\end{array}$

Density of Liquid Mercury

Mercury Vapor Density at Saturation Conditions

169

170

171

Heat Capacity of Liquid Mercury

172

173

174

180

181

Peak Nucleate Boiling Heat Flux for Mercury-Magnesium Mixtures

183

Titanium Added

Heat Transfer to Mercury Liquid-Vapor Mixtures Flowing in a Pipe $\left(D_{i}=0.20\right.$-inch Diameter $)$

186

Maximum Nucleate Boiling Heat Flux for Mercury at or Below Saturation Temperature

Maximum Nucleate Boiling Heat Flux for Flowing Subcooled Mercury (According to Zuber and Tribus)

Nusselt Modulus for Liquid Metals - Uniform Heat Input

Two-Phase Friction Multipliers for Mercury at $1000^{\circ} \mathrm{F}$ Saturation Temperature

Length-Average Mixture Density of Liquid-Vapor Mercury for Sinusoidal Heat Input

Length-Average Mixture Density of Liquid-Vapor Mercury for Uniform Heat Input

Density Distribution of Liquid-Vapor Mercury Mixture for Various Slip Ratios

Acceleration Pressure Drop Multiplier for Mercury at $1000^{\circ} \mathrm{F}$ Saturation Temperature

Effect of Radiation on the Density of Uranium at Irradiation Temperatures Below $400^{\circ} \mathrm{C}$

Density Change of Uranium-Molybdenum Alloys Due to Irradiation in Various Temperature Ranges

Effect of Irradiation Temperature on Stability of Unalloyed Uranium

Rate of Decrease in Density of Uranium-2 w/o Zirconium Alloys

Rate of Density Decrease of Uranium-10 w/o Molybdenum Alloys. at Various Irradiation Temperatures

Density Change of Uranium-10 w/o Molybdenum Alloy Irradiated at Various Temperatures and to Various Exposure Levels 


\section{MERCURY COOLED BREEDER REACTOR}

Figure No.

$\underline{\text { Title }}$

$\underline{\text { Page }}$

$\mathrm{F}-7$

Thermal Conductivity of Uranium-10 w/o Molybdenum Alloy and Alpha Uranium

$\mathrm{G}-1$

MCBR Fuel-Cycle Costs at Various Power Levels (Preliminary Estimate) (Plutonium Credit at $\$ 12$ per Gram)

$\mathrm{J}-1$

Mercury Prices in New York and London 1946-1958

Dwg. No.

Title

$\underline{\text { Page }}$

$\mathrm{D}-180$

Simplified Flow and Reactor Heat Balance Diagram, $100 \mathrm{emw}$ Mercury Cooled Breeder Reactor

$\mathbf{R - 1 8 1}$

Piping \& Instrument Diagram - Reactor Plant, 100 emw Mercury Cooled Breeder Reactor

121

$\mathrm{F}-182$

Assembly - Reactor Vessel, 100 emw Mercury Cooled Breeder Reactor

$\mathbf{F}-183$

D-184

$\mathrm{F}-185$

F-186

$\mathrm{F}-187$

C-188

$\mathrm{D}-189$

$\mathrm{B}-179$

$\mathrm{F}-53$

Details \& Sections - Fuel \& Axial Blanket Element Assembly, 100 emw Mercury Cooled Breeder Reactor

Details \& Section - Radial Blanket Element Assembly, $100 \mathrm{emw}$ Mercury Cooled Breeder Reactor

Sections - Reactor Containment Building, 100 emw Mercury Cooled Breeder Reactor

Plans I, II, \& III - Reactor Containment Building, $100 \mathrm{emw}$ Mercury Cooled Breeder Reactor

Plans IV \& V - Reactor Containment Building, 100 emw Mercury Cooled Breeder Reactor

Schematic Diagram; Nuclear Instrumentation, $100 \mathrm{emw}$ Mercury Cooled Breeder Reactor

Plant Arrangement, 100 emw Mercury Cooled Breeder Reactor

Preliminary Flow Diagram, Mercury Heat Transfer. Experiment 


\section{LIST OF TABLES}

Table No.

I

II

III

IV

$\mathrm{V}$

VI

VII

VIII

IX

$\mathrm{X}$

XI

XII

XIII

$\mathrm{XIV}$

$\mathrm{XV}$

XVI

XVII

XVIII

XIX

$\mathrm{XX}$

XXI

XXII

XXIII

XXIV

XXV

B-I

B-II

C-I

E-I

E-II

E-III

E-IV

E-V

E-VI

E-VII

E-VIII

E-IX

E-X
Title

Page

Comparison of Saturated Specific Volume Ratios for Water and Mercury

MCBR Thermal Characteristics

8

20

23

37

58

Unit Power Costs, $100 \mathrm{mw}(\mathrm{e}) \mathrm{MCBR}$ Power Plant (1959 basis)

59 Breeder Reactor Plant

62

63

63

Fuel-Cycle Cost Estimate, 100-mw(e) MCBR Power Plant

Core and Blanket Assembly Fabrication Costs, 100-mw(e) MCBR Power Plant

Annual Operating and Maintenance Costs, 100-mw(e) MCBR Power Plant

Estimated Staff Requirements, 100-mw(e) MCBR Power Plant

Comparison of Power Costs, Large United States Nuclear Power Stations

Summary of Core and Blanket Specifications

Neutron Balance, 100-mw(e) MCBR

Disposition of a Fission Neutron, 100-mw(e) MCBR

Average Cross Sections

Mercury Activation Reactions

MCBR Activation Datá

Mercury Pipe Shielding Thickness for Surface Dose Rate of $5 \mathrm{mr} / \mathrm{hr}$

.66

69

76

77

77

81

83

84

$\begin{array}{lr}\text { Plant and Reactor Design and Performance Characteristics } & 89 \\ \text { Results of Mercury Experiment } & 156\end{array}$

Performance Characteristics $\quad 156$

Conversion Table 162

Other Properties of Mercury

Predictions of Maximum Nucleate Heat Flux in Pool Boiling of $\begin{array}{ll}\text { Mercury at } 1000^{\circ} \mathrm{F} \text { Saturation Temperature } & 187\end{array}$

Neutron Energy Grouping $\quad 208$

Uranium-235 210

\begin{tabular}{ll} 
Uranium -238 & 211 \\
\hline & 212
\end{tabular}

$\begin{array}{ll}\text { Plutonium-239 } & 212\end{array}$

Molybdenum $\quad 213$

$\begin{array}{ll}\text { Iron } & 214 \\ & \end{array}$

$\begin{array}{ll}\text { Mercury } & 215\end{array}$

MCBR Core Parameters $\quad 218$

MCBR Blanket Parameters $\quad \cdot 218$

MCBR Neutron-Balance Analysis $\quad 219$ 


\section{MERCURY COOLED BREEDER REACTOR}

Table No.

$\underline{\text { Title }}$

Page

$\mathrm{E}-\mathrm{XI}$

Enrico Fermi Reactor

E-XII

MCBR Neutron-Balance Analysis, Variations in Blanket Composition

221

F-I

F-II

F-III

Approximate Temperature and Burnup Limitations of Uranium Alloys

Comparison of Radiation Stability of Metallic Uranium Fuels

(Typical Data)

G-I

G-II

$\mathrm{H}-\mathrm{I}$

H-II

$\mathrm{H}-\mathrm{III}$

Comparison of Unit Fuel-Cycle Costs

237

Case Studies - Various MCBR Core Configurations

238

Detailed Breakdown Federal Power Commission Account Number 311

246

247

-Detailed Breakdown Federal Power Commission Account Number 312

249

Detailed Breakdown Federal Power Commission Account Numbers 314 , 315,316 , and Portions of 311

$\mathrm{J}-\mathrm{I}$

Primary Mercury: United States and World Production, Selected Years 1877 to 1957

$\mathrm{J}-\mathrm{II}$

$\mathrm{K}-\mathrm{I}$

Mercury Price Quotations

252

K-II

Vessels Design Data

256

Heat Exchangers Design Data

260

262

Pumps and Drivers Design Data

263

Heaters Design Data

264

265 


\section{FOREWORD}

Under the New Reactor Concepts Evaluation Program sponsored by the United States Atomic Energy Commission, Advanced Technology Laboratories (a Division of American Radiator \& Standard Sanitary Corporation) has undertaken an investigation of the technical feasibility and economic potential of the use of boiling mercury as a coolant for fast breeder reactors. The investigation was performed between 1 January 1959 and 31 October 1959. This is the final report on that investigation and is submitted in compliance with the terms of the program authorization, Contract Number AT(04-3)-109, Project Agreement Number 4. 


\title{
MERCURY COOLED BREEDER REACTOR
}

\begin{abstract}
The technical feasibility and economic potential of fast breeder power reactor systems cooled with boiling mercury have been investigated by American-Standard under the United States Atomic Energy Commission's New Reactor Concepts Evaluation Program.

The mercury cooled breeder reactor concept was found to be technically feasible insofar as the system was analyzed. At $1000^{\circ} \mathrm{F}$ maximum mercury vapor temperature (as employed in conventionally fueled mercury power plants), the core pressure drop limits thermal performance to about 100 kilowatts per liter, which corresponds to an average heat flux of $119,000 \mathrm{Btu} / \mathrm{hr}-\mathrm{ft}^{2}$. Operation at higher temperatures, for example $1300^{\circ} \mathrm{F}$, would permit about an $80 \%$ increase in power density and average heat flux.

The MCBR system was found to show economic advantages in comparison with sodium-cooled fast breeder reactors. Fuel costs are comparable to those of equivalent sodium-cooled systems, and capital costs are substantially less.

Capital costs of an initial $100 \mathrm{mw}(\mathrm{e}) \mathrm{MCBR}$ based on presentday technology were estimated at $\$ 32,815,000$ or $\$ 328$ per kilowatt, and total power costs including uranium inventory were estimated at 21.4 mils per kilowatt-hour.

A research and development program embracing a detailed plant design, and including reactor kinetics investigations and heat transfer and fluid flow experimentation, is recommended.
\end{abstract}




\section{SUMMARY AND CONCLUSIONS}

Evaluation of the Mercury Cooled Breeder Reactor concept was guided by two primary objectives: 1) to evaluate the technical feasibility of boiling mercury as a coolant for fast breeder power reactors and, upon reasonable assurance that such a reactor system could be designed and built, 2) to evaluate the reactor-power plant system economics.

The technical feasibility portion of the investigation included evaluation of mercury heat transfer and fluid flow, fast breeder reactor physics, and appropriate reactor and containment materials. The economic considerations required the conceptual design of a reactor-power plant system to serve as a basis for capital, fuel-cycle, and operating cost estimates and analyses.

It was determined that fast breeder reactors cooled with boiling mercury are technically feasible insofar as their characteristics were examined under the rules and scope of the program. The literature regarding the maximum permissible heat flux sustainable in nucleate boiling of mercury presents data as high as $200,000 \mathrm{Btu} / \mathrm{hr}-\mathrm{ft}^{2}$, with no indication that higher values cannot be attained. Nucleate boiling fluxes as high as $1,000,000 \mathrm{Btu} / \mathrm{hr}-\mathrm{ft}^{2}$ are theoretically predicted.

The upper limit of performance on reactors with conventional coolant-channel arrangements is imposed not by heat flux but by the pressure drop associated with boiling two-phase mercury flow because of the large mercury volume change upon vaporization. An MCBR core consisting of $a^{\circ}$ cluster of straight circular fuel pins of optimum diameter and spacing with boiling mercury coolant (at a maximum temperature of $1000^{\circ} \mathrm{F}$ ) flowing axially through them can sustain an average power density of approximately 100 kilowatts per liter without inordinately high pressure drops. Higher power densities are possible if higher temperatures are permitted.

Critical mass of uranium-235 is relatively high for mercury cooled power reactor cores, approximately 2300 kilograms for a 100 -megawatt (electrical) plant, because of the relatively low power density imposed by the coolant hydrodynamic characteristics. A means of improving performance and thereby reducing the critical mass is available, but it involves the fabrication of tapered fuel elements and the development of new handling techniques. Loss of neutrons by capture in the mercury coolant is almost negligible in spite of the high cross section, because boiling permits a low average mercury density in the reactor core.

Breeding is readily achieved, but thick blankets of depleted uranium are required. Conversion ratios as high as 1.3 atoms of plutonium produced per atom of uranium-235 destroyed are calculated. Breeding plutonium with uranium-235 fuel cannot be justified on a presentday economic basis, with plutonium valued at $\$ 12$ per gram and uranium-235 at $\$ 16$, but the economics of breeding with 


\section{MERCURY COOLED BREEDER REACTOR}

uranium-235 fuel are not particularly important, since projected fuel cycles will involve plutonium fuel rather than uranium.

Fuel-cycle economics of MCBR systems compare favorably with those of sodium-cooled fast reactor systems. Estimated capital costs of $\$ 32,815,000$ for a $100-\mathrm{mw}(\mathrm{e})$ plant are appreciably lower than for the equivalent-size sodium-cooled Enrico Fermi reactor. A total power cost of 21.4 mils per kilowatt-hour is estimated. Fuel costs, including uranium inventory charges, of 13. 3 mils per kilowatt-hour are comparable to the initial fuel-cycle cost of the sodium-cooled fast breeder reactor. The inventory charge accounts for 4.0 mils per kilowatt-hour. These estimates are based on a plant having a conventional core configuration and with plutonium valued at $\$ 12$ per gram. The cost is reduced to 11.3 mils per kilowatt-hour for plutonium valued at $\$ 30$ per gram. These fuel costs may be compared with, respectively, 12 and 10 mils per kilowatt-hour for the Enrico Fermi sodium-cooled fast breeder reactor plant.

Mercury activation by fast neutrons is appreciable; however, the photon energies of the mercury isotope decay gammas are less than $0.4 \mathrm{Mev}$, and these low-energy gamma photons are easily shielded. The high density of liquid mercury provides a great deal of self-shielding, and the low mercury density in the high-neutron-flux regions mitigates the radiation hazard due to activated mercury.

Containment materials for mercury are available at low cost, and much experience in welding and fabricating the material has accumulated in numerous commercial shops. A $5 \%$ chromium steel is usable at temperatures up to $1000^{\circ} \mathrm{F}$ with no corrosion anticipated, as evidenced by many years of experience in conventionally fired mercury power plants.

The research and development necessary to advance the MCBR program is relatively small by virtue of the availability of corrosion-resistant materials and commercial experience with the use of mercury as a heat transfer medium and a turbine working fluid. On the basis of these considerations and the conclusions reached as a result of the mercury cooled breeder reactor evaluation reported here, it is recommended that a detailed plant design be undertaken. This effort would include an investigation of the kinetic behavior of the system and an experimental investigation of the two-phase mercury flow; pressure drop, and heat transfer characteristics in the appropriate vapor quality and heat transfer ranges. 


\section{INTRODUCTION}

Two principal objectives based on the scope of the authorizing contract ${ }^{*}$ have guided these investigations and evaluations of the practicality of boiling mercury cooled breeder reactors. These objectives are:

1) To explore and evaluate the technical feasibility of mercury as a coolant for fast breeder reactors.

2) Upon establishment of technical feasibility, to evaluate the economic characteristics and potential of such nuclear power plant systems.

The approach to the evaluation of technical feasibility is outlined below.

1. The potential advantages of the boiling mercury coolant were examined as a guide to the type of design that would be most economic.

2. Information was obtained on heat transfer, fluid dynamics, fast reactor physics, materials, and plant operating experience with boiling mercury. Several power stations that use the mercury cycle were visited, and discussions were held with the responsible design engineers and plant operators.

3. Based on this information, calculations were made for a number of core designs. Core presșure drop, heat flux, fuel-element centerline and surface temperatures, operating pressure, .. critical mass, and breeding gain were the principal technical considerations.

$\because \quad$ Once technical feasibility is established with reasonable confidence, the economic feasibility of the mercury cooled breeder reactor system becomes of paramount interest. The economic evaluation is based upon a conceptual plant design carried out in sufficient detail to permit the estimation of capital, fuel-cycle, and operating and maintenance costs. This first conceptual design is deliberately conservative to avoid the uncertainty and high development costs associated with unproved designs and also to provide a realistic basis for the cost estimates. The principal features of this plant design are:

1. Use of an indirect power cycle involving a mercury condenser-water boiler followed by a conventional steam plant, even though this approach eliminates, in this initial study, the directcycle potentialities of the mercury system.

2. The capability of producing more fissionable material than is consumed.

* The full scope is included in this report as Appendix A. 


\section{MERCURY COOLED · BREEDER REACTOR}

3. A useful reactor lifetime of the order of 20 years.

4. The possibility of a prototype reactor construction in the early 1960 's .

5. The use of a metallic uranium fuel element similar to the design for the first core of the Enrico Fermi plant, although it is recognized that the eventual system will involve a plutonium fuel cycle.

On the basis of this conceptual design, a detailed capital cost estimate was made. Fuel costs and operating and maintenance costs were estimated to provide an over-all estimate of the power cost, as well as a basis for an economic evaluation of the production of power by a Mercury Cooled Breeder Reactor. 


\section{MERCURY AS A REACTOR COOLANT}

\section{A. GENERAL CHARACTERISTICS OF MERCURY}

Mercury owes its attractiveness as a thermodynamic and heat transfer medium primarily to five attributes:

1) It is an element and thus not subject to thermal or radiological decomposition.

2) It exhibits high saturation temperatures at low pressures, e.g., $1000^{\circ} \mathrm{F}$ at 180 psia; thus, high thermal efficiencies are possible without high pressures.

3) Its freezing point is $-38^{\circ} \mathrm{F}$; provisions for avoiding solidification are not required in normal circumstances.

4) It is chemically inert to air and water.

5) It possesses, in common with other liquid metals, good heat transfer properties.

For power plant applications, the high density of liquid mercury is also an asset in that natural circulation is an attractive possibility, with a consequent elimination of mercury feed pumps as well as circulation pumps.

Mercury has the disadvantages of expense, toxicity, and high neutron cross sections for inelastic scattering and absorption. However, problems introduced by mercury vapor toxicity have been satisfactorily met in many mercury applications, and the means for containment and detection are well developed. Mercury is handled in safety by several thousand industrial plants, mercury distillation plants, and mines throughout the world. Although there appears to be a widespread belief that the toxicity of mercury vapor has been a deterrent to adoption of the mercury binarycycle power plant, this belief is belied by an excellent safety record in such power stations. The disadvantage of high neutron absorption is greatly reduced in fast reactors because of the crosssection dependence on neutron energy. The difficulties associated with both neutron absorption and neutron energy degradation by inelastic scattering are substantially mitigated by allowing the mercury coolant to boil, thereby reducing its effective density in the core. .

\section{B. CHARACTERISTICS OF BOILING MERCURY}

The evaporation of mercury is accompanied by a very large change in volume relative to that accompanying the evaporation of water. For a unit mass of liquid vaporized, the ratio of vapor volume to initial liquid volume is shown in Table I for water and mercury at conditions of interest in reactor applications. 
TABLE I

Comparison of Saturated Specific Volume

$\underline{\text { Ratios for Water and Mercury }}$

\begin{tabular}{|c|c|c|c|c|c|}
\hline \multicolumn{3}{|c|}{ Water } & \multicolumn{3}{|c|}{ Mercury $^{*}$} \\
\hline $\begin{array}{c}\text { Temperature } \\
\left({ }^{\circ} \mathrm{F}\right)\end{array}$ & $\begin{array}{c}\text { Pressure } \\
\text { (psia) }\end{array}$ & $\frac{v_{\text {vapor }}}{v_{\text {liquid }}}$ & $\begin{array}{c}\text { Temperature } \\
\left({ }^{\circ} \mathrm{F}\right)\end{array}$ & $\begin{array}{c}\text { Pressure } \\
\text { (psia) }\end{array}$ & $\frac{v_{\text {vapor }}}{v_{\text {liquid }}}$ \\
\hline 486 & 600 & 38.3 & 800 & 41 & 1175 \\
\hline & & & 900 & 90 & 598 \\
\hline 545 & 1000 & 25.4 & & & \\
\hline . & & & 1000 . & 180 & 334 \\
\hline
\end{tabular}

It is of interest to compare a water-cooled reactor.operating at 600 psia $\left(486^{\circ} \mathrm{F}\right)$ with a mercurycooled reactor operating at $90 \mathrm{psia}\left(900^{\circ} \mathrm{F}\right)$, both reasonably close to the limit of existing technology. The comparison from Table I reveals that for the same mass fraction vaporized, the volume change of mercury is about sixteen times that of water. Because of this relatively large volume of vapor, the two-phase mixture of mercury (in quality ranges of interest for reactor applications) can be visualized as one in which the liquid phase occupies a small volume and is distributed within a large volume of vapor. The high surface tension exhibited by liquid mercury makes it probable that the liquid portion of a turbulent two-phase mixture of mercury will form and exist in small droplets, rather than as a froth-type of mixture as would be expected and is frequently observed with boiling liquids of low surface tension such as water. A small volume of liquid existing as small droplets thinly dispersed in a large volume of vapor has the character of a "fog."

The requirement for the production of mercury fog is the addition of heat to the confined saturated liquid at a rate sufficient to create an appreciable volume fraction of mercury vapor and a vapor velocity sufficient to entrain the liquid droplets that are formed. No evidence has been found to indicate that mercury boiling phenomena are qualitatively different from those exhibited in other fluids such as water; however, no direct visual observations of the two-phase flow of mercury are reported in the literature.

* A summary of mercury physical properties data is presented in Appendix B.

** See Appendix C for a review of the mercury heat transfer literature. 
In the process of developing mercury boilers for binary mercury-steam power plants, it was found by experiment that high-vapor-quality liquid-vapor mixtures could sustain the heat flux encountered in conventionally fueled furnaces as long as sufficient liquid was present to replenish that removed from the walls by evaporation. This discovery (together with the development of mercury additives) permitted the design of boilers in which the volume available to the mercury was several times the volume of liquid mercury, with a consequent savings in mercury inventory. Calculated mixture densities as low as $2.5 \mathrm{lb} / \mathrm{ft}^{3}$ are claimed to be attainable in mercury boilers without producing excessive tube wall temperatures. 1

\section{COMPARISON OF BOILING MERCURY WITH SODIUM AS A COOLANT}

Sufficient work on the MCBR concept has now been completed to permit a general comparison between mercury and sodium as fast reactor coolants. Probably the most significant difference between the two with respect to their use in small as well as large power reactors is the applicability of the mercury vapor as the working fluid for the turbine. Many large mercury turbines have been designed and successfully operated over the past 30 years, and no formidable problems appear to exist. Low-power mercury turbines have been designed and tested recently by. Thompson RamoWooldridge (Cleveland, Ohio); consequently, a rather broad range of reactor power levels appears to be well adapted to a direct-cycle mercury-cooled system. It is anticipated that this system will operate at significantly higher thermal efficiencies than equivalent indirect-cycle mercury or sodiumcooled systems.

Because of the explosion hazard associated with the use of sodium and water, particularly with radioactive sodium, sodium-cooled reactors are invariably equipped with a secondary heat exchanger to prevent the remotest possibility of contact between the water on the steam side of the plant and the radioactive sodium. Additional capital costs are thus incurred, and lowered steam temperatures and efficiency are suffered. Mercury coolant, on the other hand, largely eliminates the need for this complication. It should be noted, however, that double-walled tubes in the condenser-boiler, whether the cycle is direct or indirect, probably are needed to prevent the leakage of water or steam into the fast reactor core in the event of a tube rupture. The double-walled tubes entail additional expense, which partially offsets the advantage of a non-reactive (chemically) coolant.

1. Superscripts refer to items in list of References appended. 


\section{MERCURY COOLED BREEDER REACTOR}

Neutron activation of the coolant is a serious problem for both sodium and mercury, even in fast reactors. While the activation cross section for sodium is very much smaller than for mercury, the photon energies of the decay gammas are 2.7 and $1.4 \mathrm{Mev}$ for sodium but only $0.37,0.16,0.13$, and $0.08 \mathrm{Mev}$ for the activated mercury isotopes. In addition, the quantity of mercury exposed to the neutron flux is low because the density of the boiling coolant in the reactor is low. The low density of mercury in the core and the low energy of the decay gamma radiation, although offset by the higher mercury cross section, produce shielding requirements that are substantially reduced from those of a sodium-cooled system.

Higher power densities are achievable for sodium-cooled systems than for boiling-mercurycooled systems because of the large pressure drop produced by the mercury phase change.

The relationships between pressure drop and thermal performance (expressed as power density or heat flux) are examined in detail in the following section on Fluid Flow and Heat Transfer.

Initial fuel-element fabrication costs for sodium-cooled plants (viz. the Enrico Fermi plant) are quite high, as a result of the requirement for a metallurgical bond between the uranium fuel and its cladding. (Zirconium is presently specified as the cladding material in the Enrico Fermi core.) The lower heat flux in the MCBR core obviates the need for a metallurgical bond, thus permitting the use of less expensive materials, with resultant lower fabricating costs. In the long run, however, no clear advantage with respect to fuel-element fabrication appears for either coolant system, because the basic problems are similar; consequently, their solutions will be similar and of equivalent cost. 


\section{TECHNICAL BASIS FOR FEASIBILITY EVALUATION}

\section{A. FLUID FLOW AND HEAT TRANSFER}

The upper limit of thermal performance of MCBR cores is limited by an excessive heat flux or by excessive pressure drop across the boiling channel. The heat flux limitation is imposed either by the well known burnout phenomenon, that is, the transition from nucleate to film boiling with its concomitant increase in surface temperature, or by an excessive fuel-pin centerline temperature.

The pressure drop limitation stems from the very large increase in volume associated with the vaporization of liquid mercury. This large change in volume implies a large increase in velocity within a coolant channel of constant flow area. Since friction and acceleration head losses are approximately proportional to the square of velocity, large pressure drops may be encountered.

These limiting conditions are virtually independent, and in any core design both must be considered until one is established as the more severe.

\section{Head Loss Across Core}

The total difference in head between the top and bottom of the core and blanket is expressed as the sum of three independent head changes: flow friction head difference of the liquid-vapor mixture in the boiling portion of the core channel, flow friction head loss in the upper blanket, and acceleration head difference. The friction head loss in the liquid-filled lower blanket and non-boiling portion of the core is negligibly small. Expressions for each of these contributions are derived (see Appendix D) and combined to yield an equation which represents the pressure drop across a fuel and blanket combination element of a conventional-type cylindrical core:

$$
\Delta \mathrm{h}=\frac{(\mathrm{q} / \mathrm{A})^{2} \text { avg } 16\left(\mathrm{~L}_{\mathrm{c}} / \mathrm{D}_{\mathrm{h}}\right)^{2}}{\chi_{\mathrm{e}} \lambda^{2} \rho_{\ell} \rho_{\mathrm{v}} 2 \mathrm{~g}}\left\{\left[2.76 \frac{\mathrm{fL}_{\mathrm{c}}}{\mathrm{D}_{\mathrm{h}}}+6.52 \frac{\mathrm{fL}_{\mathrm{b}}}{\mathrm{D}_{\mathrm{h}_{\mathrm{b}}}}\right] \chi_{\mathrm{e}}^{\frac{1}{2}+2}\right\}
$$

where $\Delta \mathrm{h}=$ head loss across core and blanket ( $\mathrm{ft}$ of liquid $\mathrm{Hg}$ ),

$(\mathrm{q} / \mathrm{A})_{\text {avg }}=$ average heat flux in channel $\left(\mathrm{Btu} / \mathrm{hr}-\mathrm{ft}^{2}\right)$,

$\mathrm{L}_{\mathrm{c}}=$ boiling length of core $(\mathrm{ft})$,

$\mathrm{L}_{\mathrm{b}}=$ thickness of upper blanket (ft),

$D_{h}=$ equivalent diameter of coolant channel in core (ft),

$\mathrm{D}_{\mathrm{h}_{\mathrm{b}}}=$ equivalent diameter of coolant channel in upper blanket (ft), 


\section{MERCURY COOLED BREEDER REACTOR}

$\chi_{\mathrm{e}}=$ exit quality (quality is defined as the ratio of the mass flow rate of vapor to the total mass flow rate of coolant),

$\lambda=$ latent heat of vaporization $(\mathrm{Btu} / \mathrm{lb})$,

$\rho_{\ell}=$ liquid density $\left(\mathrm{lb} / \mathrm{ft}^{3}\right)$,

$\rho_{\mathrm{v}}=$ vapor density $\left(\mathrm{lb} / \mathrm{ft}^{3}\right)$,

$\mathrm{f} \quad=$ fluid friction factor,

$\mathrm{g}=$ acceleration of gravity $\left(\mathrm{ft} / \mathrm{hr} \mathrm{r}^{2}\right)$.

The first term of the bracketed quantity represents the pressure drop through the core, the second represents pressure drop through the blanket, and the last term (the factor 2) accounts for the resistance due to acceleration of the flowing mercury. For practical design ranges, all three terms are found to be of comparable magnitude.

Pressure drop is seen to be governed by a coefficient that is proportional to the square of the heat flux and the square of the boiling channel length-to-diameter ratio, and inversely proportional to exit quality. The equation reveals the severe influence on pressure drop of heat flux and hydraulic diameter by virtue of the squared relationships. To minimize pressure drop, large hydraulic diameters and/or low heat fluxes are required, but both these requirements will reduce the core thermal performance. An optimization study to permit operation at least cost for each reactor core design is thereby dictated.

An additional influence on over-all pressure drop of the ratio of boiling core length to fuelelement diameter, the ratio of blanket thickness to blanket-element diameter, and exit quality exists in the bracketed term of equation 1 ; :but the sensitivity is low because the second appearances of these quantities are in additive terms.

\section{Permissible Maximum Heat Flux}

The maximum heat flux will be limited by one of two restrictions: either the maximum permissible fuel temperature will be exceeded or the maximum nucleate boiling heat flux will be reached. Heat fluxes up to $600,000 \mathrm{Btu} / \mathrm{hr}-\mathrm{ft}^{2}$ have been measured for boiling mercury (see Appendix C). There are no experimental data that can be used to estimate the maximum nucleate boiling flux, but various theories and data correlations based on other fluids make it appear that a flux in excess of $1,000,000 \mathrm{Btu} / \mathrm{hr}-\mathrm{ft}^{2}$ is below the maximum. 
The fuel temperature limitation on the heat flux can be derived from the equation

$$
q / A_{\max }=\frac{T_{C L}-T_{\text {sat }}-20}{\frac{t}{k_{c}}+\frac{D_{f}}{4 k_{f}}},
$$

where $\mathrm{q} / \mathrm{A}_{\max }=\operatorname{maximum}$ heat flux, $\mathrm{T}_{\mathrm{CL}}=$ fuel-pin centerline temperature, $\mathrm{T}_{\text {sat }}=$ saturation temperature, $t=$ cladding thickness, $D_{f}=$ fuel-pin outside diameter, $k_{c}$ and $k_{f}=$ thermal conductivity of cladding and fuel.

The heat flux which will produce a maximum fuel alloy temperature of $1112^{\circ} \mathrm{F}\left(600^{\circ} \mathrm{C}\right)^{*}$ is shown as a function of fuel-element diameter in Figure 1. Inspection of the graph reveals that the higher saturation temperatures, which are desirable for high electric power generation efficiency, are purchased at the cost of lower permissible heat flux.

If, as assumed, the permissible maximum nucleate boiling heat flux is of the order of $10^{6}$ $\mathrm{Btu} / \mathrm{hr}-\mathrm{ft}^{2}$, it can be concluded that for saturation temperatures above $900^{\circ} \mathrm{F}$ the permissible heat flux will be determined by maximum fuel-temperature considerations rather than by burnout considerations, since the heat fluxes shown on Figurc 1 for these saturation temperatures are considerably below the probable burnout values.

If it may be presumed that future alloy development will permit operation at higher maximum fuel temperatures than the present limit of $1112^{\circ} \mathrm{F}\left(600^{\circ} \mathrm{C}\right)$, it is of interest to examine the resultant effect on thermal performance. Since the fuel-element surface heat flux is proportional to the temperature difference between the pin centerline and the surface, and since that temperature difference is only $112^{\circ} \mathrm{F}$ for a surface temperature of $1000^{\circ} \mathrm{F}$, relatively small increases in the allowable centerline temperature will yield significant increases in surface heat flux. For example, an increase of $100^{\circ} \mathrm{F}$ in centerline temperature displaces the curves in Figure 1 by an amount equal to the existing spacing between the curves. For example, the curve labeled $900^{\circ} \mathrm{F}$ represents the heat flux versus element diameter for $1000^{\circ} \mathrm{F}$ saturation temperature.

Associated with this increase in heat flux is an even greater increase in pressure drop, since pressure drop is proportional to heat flux squared (see equation 1). Therefore, improvement in performance due to an increase in centerline temperature is significant but is not as great as would appear for a core that is limited by pressure drop, although the temperature increase does permit a larger diameter fuel pin with attendant fabrication and physics advantages.

* The limiting centerline temperature is specified by radiation damage criteria; see "Reactor Plant Materials" (section C below). 


\section{MERCURY COOLED. BREEDER REACTOR}

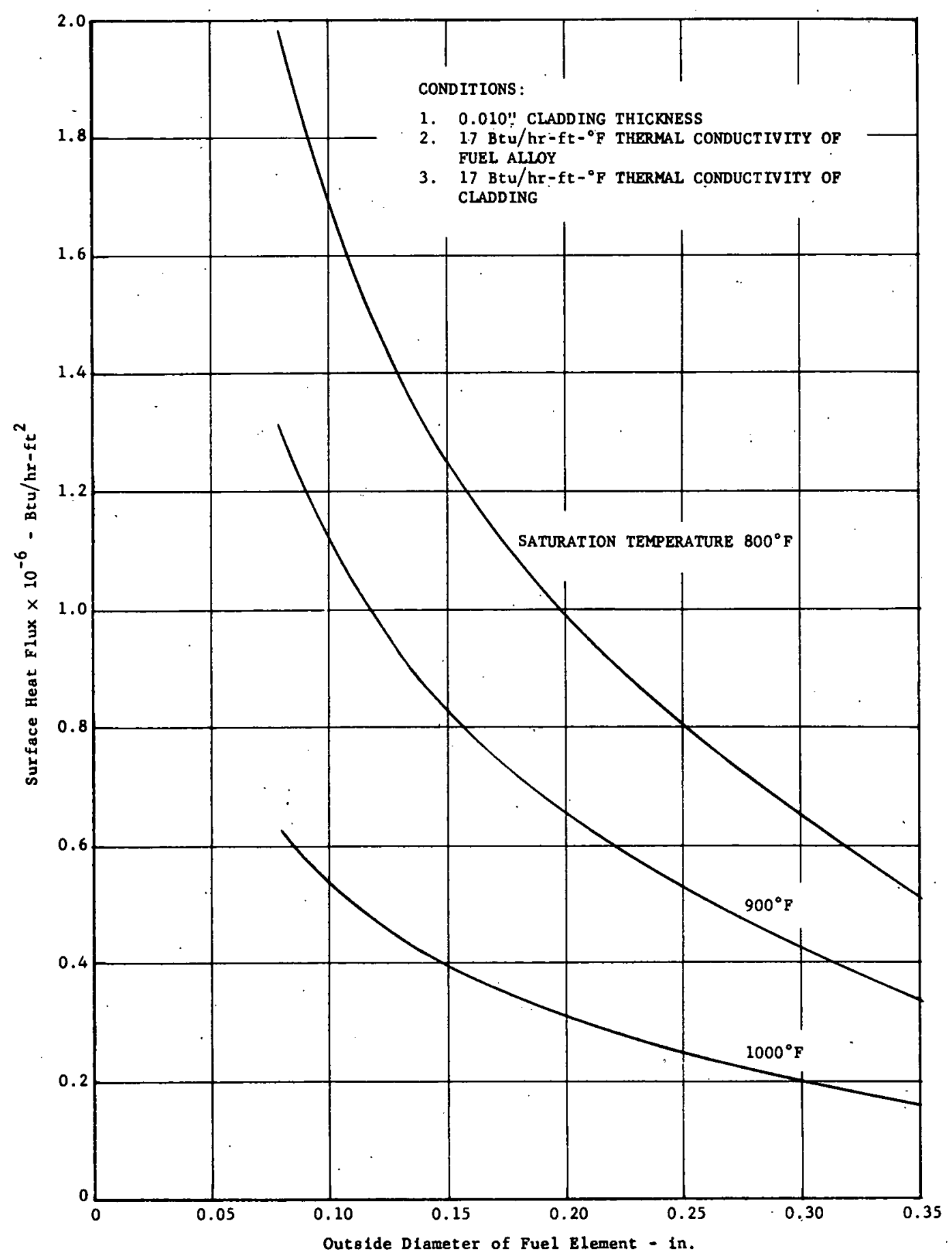

SURFACE HEAT FLUX FOR

ATTAINMENT OF $1112^{\circ} \mathrm{F}\left(600^{\circ} \mathrm{C}\right)$ FUEL-PIN CENTERLINE TEMPERATURE

FIGUR E 1 


\section{Power Density}

The high fuel mass per unit core volume that is characteristic of fast breeder reactors places a high economic premium on attaining high power output per unit core volume. The power density is expressed in terms of heat flux and fuel-element dimensions by the equation

$$
P_{d}=\frac{4 q / A}{D_{0}+D_{h}}
$$

where $D_{0}$ is the outside diameter of the fuel element and $D_{h}$ is the equivalent diameter of the flow channel. Attainment of high power densities by incorporating small closely packed fuel elements is opposed by excessive pressure difference across the core, as well as by considerations of fabrication cost and mechanical rigidity.

If allowable surface temperature is increased, the saturation temperature and vapor density are increased, allowing a significant increase in heat flux for a given configuration and pressure drop. Other factors, i.e., heat of vaporization and liquid density, affect performance, but their effect is small compared to the changes brought about by changes in vapor density. The relationships among all these parameters may be inferred from equation 1 (neglecting, for this purpose, the pressure drop through the upper blanket) by rearrangement and substitution to yield

$$
\mathrm{P}_{\mathrm{d}}=\sqrt{\frac{\chi_{\mathrm{e}} \lambda^{2} \rho_{l} \rho_{\mathrm{v}} 2 \mathrm{~g} \mathrm{v}_{\mathrm{c}}{ }^{2} \Delta \mathrm{h}}{\mathrm{L}_{\mathrm{c}}{ }^{2}\left[2.76 \frac{\mathrm{fL}}{\mathrm{D}} \mathrm{D}_{\mathrm{h}} \chi_{\mathrm{e}}{ }^{\frac{1}{2}}+2\right]}}
$$

where $\mathrm{V}_{\mathrm{c}}=$ coolant volume fraction

$$
\begin{aligned}
& =1-\frac{\pi \sqrt{3}}{6}\left(\frac{\mathrm{s}}{\mathrm{D}_{\mathrm{o}}}\right)^{-2}, \\
\mathrm{D}_{\mathrm{h}} & =\left(\frac{\mathrm{V}_{\mathrm{c}}}{1-\mathrm{V}_{\mathrm{c}}}\right) \mathrm{D}_{\mathrm{o}} .
\end{aligned}
$$

Note that power density is proportional to $\sqrt{\lambda \rho_{\ell} \rho_{\mathrm{v}}}$, which is expressible as a function of saturation temperature (or pressure) only. Figure 2 presents the relationship graphically and shows the advantage of operation at high temperatures. A $300^{\circ} \mathrm{F}$ increase in mercury saturation temperature allows an $80 \%$ increase in power density for a fixed geometry, pressure drop, and exit quality. The increased performance is achieved by a proportional increase in fuel-centerline-to-surfacetemperature difference. 


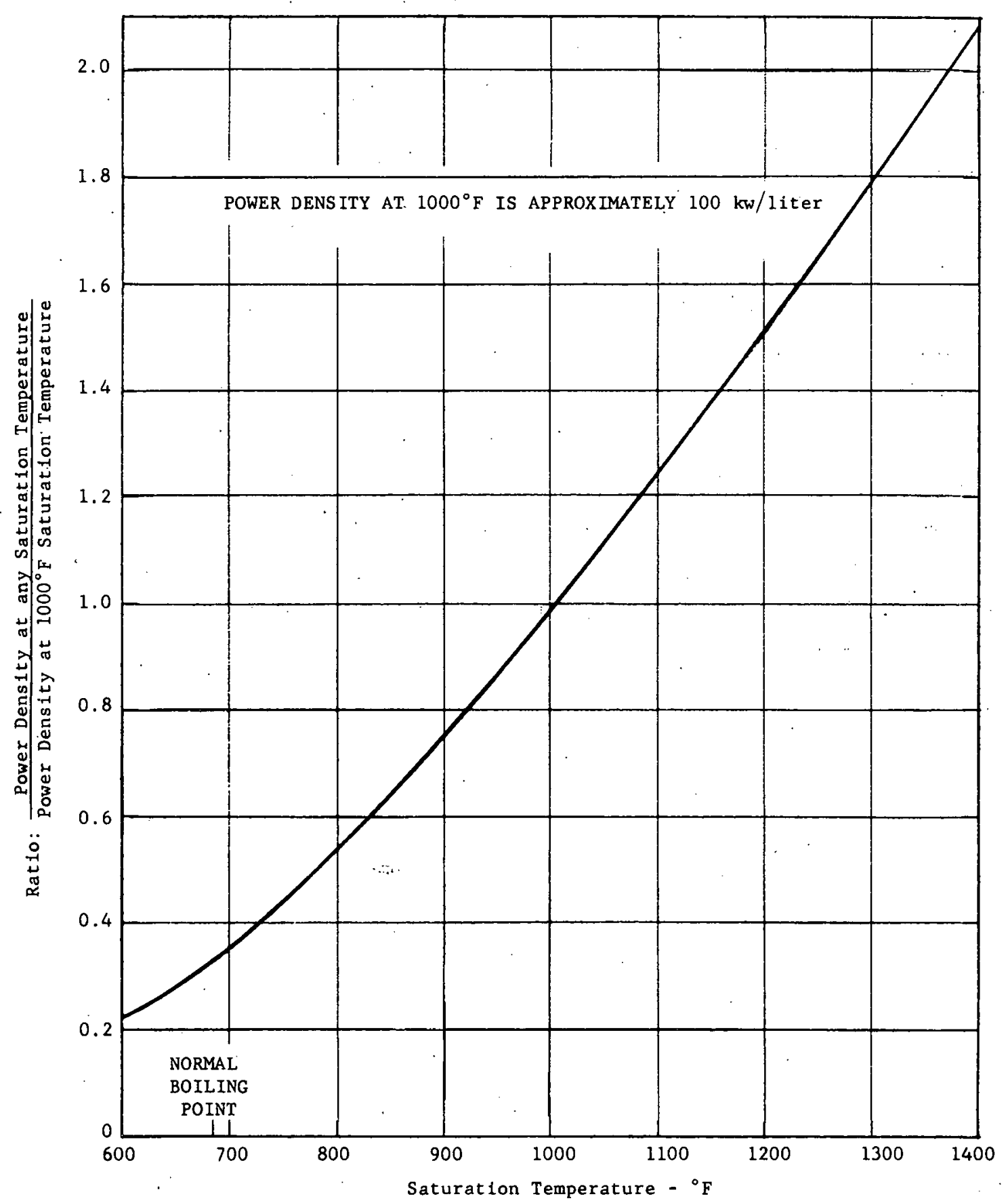

EFFECT OF MERCURY SATURATION TEMPERATURE ON AVERAGE POWER DENSITY IN MCBR CORE

FIGURE 2 


\section{MERCURY COOLED BREEDER REACTOR}

\section{Inlet Subcooling and Pressure Drop}

The saturation temperature distribution along a fuel element is fixed by the corresponding pressure at any point. If a maximum allowable mercury temperature of $1000^{\circ} \mathrm{F}$ is assumed because of materials considerations, this temperature sets the pressure at the maximum temperature point in the core, i.e., at the point where the liquid mercury first starts to boil.

A large pressure drop across the core results in a large decrease in exit saturation temperature, thus reducing the exit vapor temperature and lowering the thermal efficiency of the power cycle.

Figure 3 shows typical temperature variations along the length of the core and implies a saturation pressure distribution similar to the bulk mercury temperature. It is seen that a high pressure drop across the core causes the condensing temperature in the condenser-boiler to be considerably below the saturation temperature at the point where boiling first occurs. Since the temperature of the liquid mercury returning to the core is at or below the condensing temperature, there will be considerable subcooling of the entering liquid mercury if the core pressure drop is large. This is undesirable, since it increases the amount of mercury in the non-boiling length of the core, thus raising critical mass and reducing breeding gain. Hence, inlet subcooling should be minimized consistent with the core pressure drop needed to remove reactor heat. From the standpoints of power density, critical mass, and breeding ratio, however, a small coolant volume fraction and correspondingly high pressure drops are desirable. Thus, for a given fuel-element type, a minimum-cost pressure drop must occur.

\section{Initial Estimate of Attainable Power Densities}

The information presented above has been assembled in Figure 4 to give the length-average power density in the central channel as a function of fuel-element diameter and the ratio of element pitch to outside diameter $\left(S / D_{0}\right)$ for a fixed head difference across the core proper and for a maximum saturation temperature of $1000^{\circ} \mathrm{F}$. These relationships are expressed in equations 4 , 5, and 6 . Inspection of the curves reveals that, with the stated restrictions, the power density increases with increasing element diameter and pin spacing. A limit on increasing these two variables is imposed by attainment of excessive fuel temperature (i.e., greater than $1112^{\circ} \mathrm{F}$ ), as given by equation 2 . It may be noted additionally that large pin spacing produces a large coolant volume fraction, to the detriment of neutron economy.

Table II summarizes the major conclusions revealed by Figure 4 and presents additional information on the length-average mercury density and the maximum heat flux in the central channel. The maximum heat fluxes are seen to be considerably below the estimated magnitude for burnout 


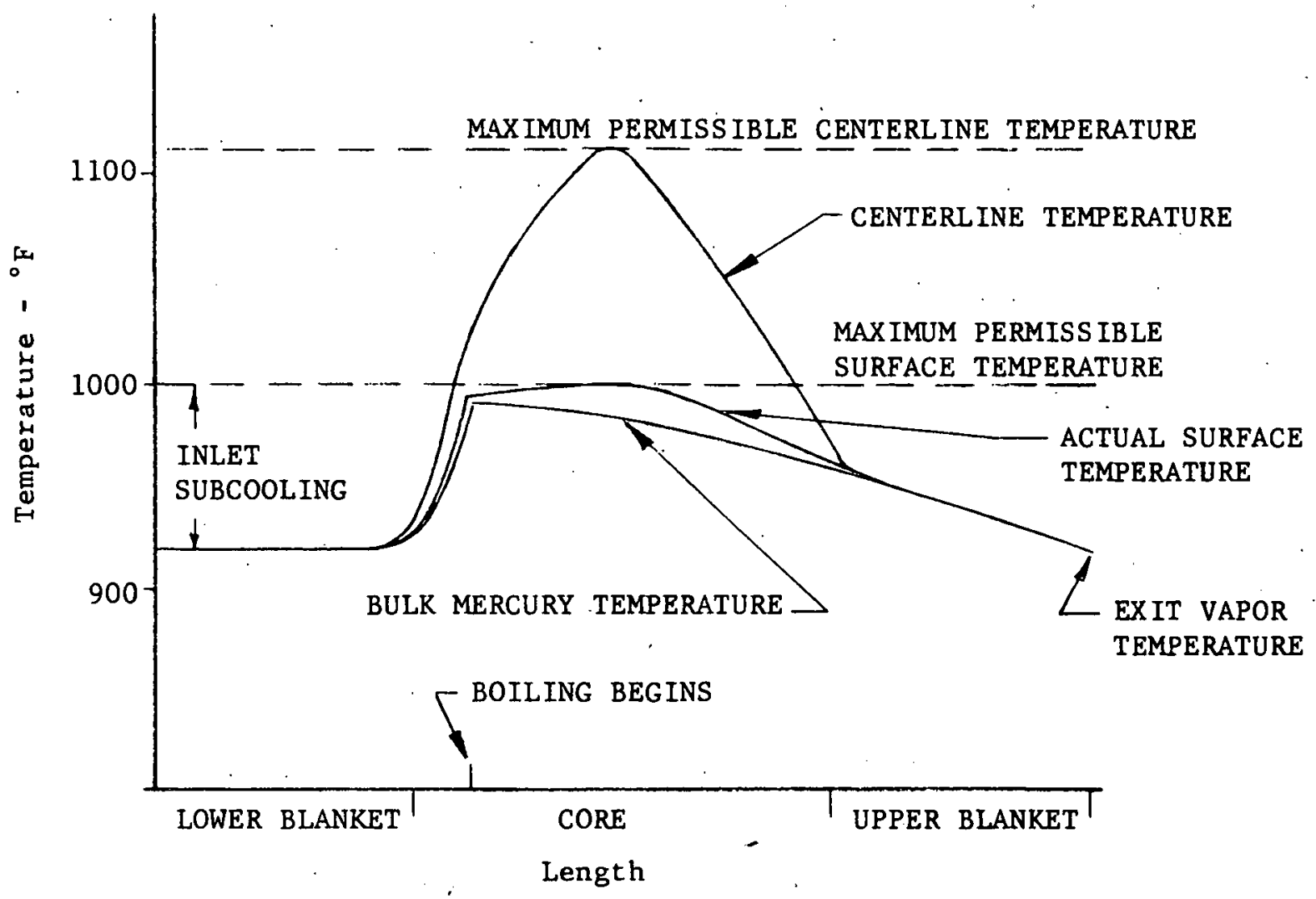

ELEMENT TEMPERATURE DISTRIBUTION

FIGURE 3 


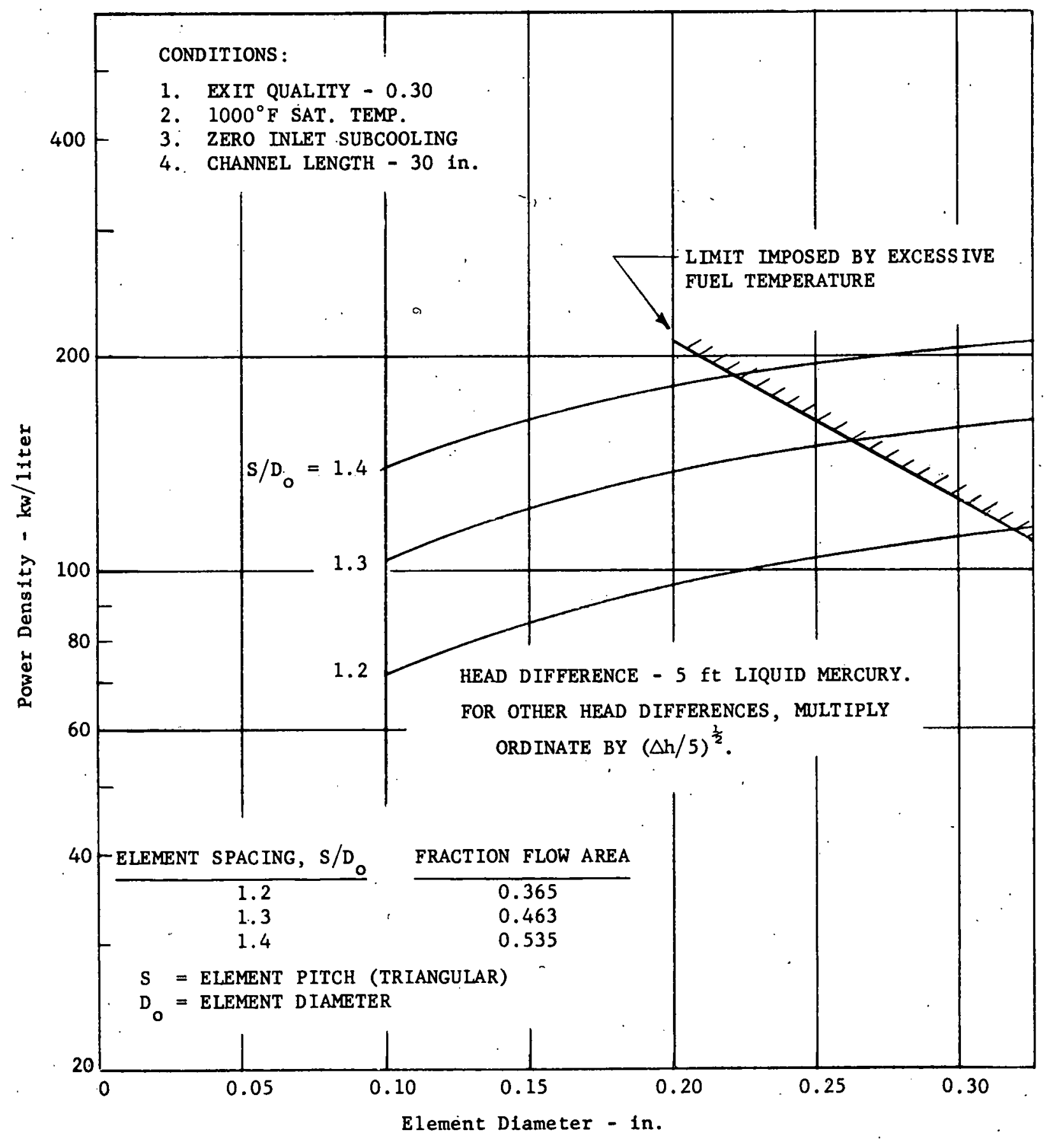

LENGTH-AVERAGE POWER DENSITY FOR.

CENTRAL CHANNEL IN CORE

(HEAD LOSS ACROSS BLANKET NOT INCLUDED)

FIGURE 4 
flux and thus do not represent a design limitation. It appears probable that the pressure drop through the core will limit power densities to about $100 \mathrm{kw} /$ liter in the cylindrical-core designs considered for the limitation of $1000^{\circ} \mathrm{F}$ saturation temperature. Since pressure drop is shown to be a key design parameter in these studies, and since data on two-phase flow of mercury are inadequate, an experimental investigation of two-phase flow friction with mercury is recommended (see "Recommended Research and Development Program").

TABLE II

MCBR Thermal Characteristics

\begin{tabular}{|c|c|c|c|c|}
\hline Fuel-element pitch-to-diameter ratio & 1.2 & 1.3 & 1.4 & 1.3 \\
\hline Coolant volume fraction & 0.365 & 0.463 & 0.535 & 0.463 \\
\hline Exit quality & 0.30 & 0.30 & 0.30 & 0.30 \\
\hline \multicolumn{5}{|l|}{ Average coolant $(\mathrm{Hg})$ density: } \\
\hline$\left(\mathrm{gm} / \mathrm{cm}^{\circ}\right)$ & 0.56 & 0.56 & 0.56 & 0.56 \\
\hline $\begin{array}{l}\text { Fuel-element outside diameter (in.) } \\
\text { Head loss across core }\end{array}$ & 0.322 & 0.263 & 0.222 & 0.165 \\
\hline $\begin{array}{l}\text { (ft liquid } \mathrm{Hg} \text { ) } \\
\text { Power density, centerline fuel } \\
\text { temp. limiting (kw/liter) }\end{array}$ & 5 & 5 & 5 & 20 \\
\hline Maximum & 171 & 240 & 294 & 396 \\
\hline $\begin{array}{c}\text { Average } \\
\text { Heat flux }\left(\mathrm{Btu} / \mathrm{hr}^{-\mathrm{ft}^{2}}\right)\end{array}$ & 47 & 66 & 81 & 109 \\
\hline Maximum & 176,000 & 237,000 & 284,000 & 246,000 \\
\hline Average & 48,400 & 65,300 & 78,400 & 67,500 \\
\hline
\end{tabular}

\section{B. REACTOR PHYSICS}

A parametric study of the effects on critical mass and breeding ratio of various geometrical and performance characteristics was conducted. The purpose of the investigation was to establish the ranges of these variables over which MCBR cores might be found feasible. The calculations were performed with the standard physics codes PROD II and a more convenient modification of PROD, VAL PROD, using ATL'S IBM 650 computer. These codes represent multigroup, multiregion, diffusion equations that can be shown to be applicable to large fast reactor cores (see Appendix E).

\section{Eore Configuration}

Variations in core composition with a fixed blanket composition were evaluated, with results as shown in Table III and Figures 5 through 10. The constant blanket composition maintained in this study had the following properties: 


\section{MERCURY COOLED BREEDER REACTOR}

$\begin{array}{ll}\text { Thickness } & =80 \mathrm{~cm} \\ \text { Uranium enrichment } & =0.36 \% \text { U } 235 \text { (depleted uranium) } \\ \text { Average coolant }(\mathrm{Hg}) \text { density } & =2.0 \mathrm{gm} / \mathrm{cm}^{3} \\ \text { Coolant volume fraction } & =0.2 \\ \text { Structure-fuel alloy volume ratio } & =0.2\end{array}$

Since the assumed blanket thickness is large, neutron leakage is small and changes in core size do not materially affect total breeding ratio for any case considered. The distribution of breeding between blanket and core does vary with core size, as illustrated in Table III. The larger the core, the lower is the blanket contribution to total breeding ratio, because of the reduced leakage from the core. Breeding in the core itself is quite insensitive to all variables except enrichment. To a first approximation, breeding ratio in the core may be shown to be proportional to the ratio of the macroscopic capture cross section in U 238 to the macroscopic absorption cross section in U 235. A flux-weighted average of the ratios for the various neutron energy groups gives the actual value of breeding ratio contributed by the core (see Table III).

Figure 5 shows the relationship between critical mass of $U 235$ and coolant volume fraction in the core for several enrichments. Note that the critical mass is quite sensitive to coolant volume fraction. This sensitivity is due to the increased capture in the mercury compared with the fission absorptions in the $U 235$ and the softening of the neutron energy spectrum due to the large $U 238$ and mercury content. This effect is more pronounced at low enrichments. With an enrichment of $15 \%$ and a coolant volume fraction of much above 0.5 , it is doubtful that the system could attain criticality. At the higher enrichment of $30 \%$, the amount of $U 235$ is sufficient that the increase in mercury coolant fraction to 0.5 does not seriously reduce the reactivity.

Sensitivity of critical mass to enrichment is also apparent from Figure 5, which shows very much higher critical masses at $15 \%$ enrichment than at $30 \%$. This increase in critical mass as the enrichment is reduced is due to the increased capture in $U$ 238. Also, the degradation of neutron energy due to inelastic scattering reduces the fast fission effect. in $\mathrm{U} 238$.

Breeding ratio is affected by core enrichment, as illustrated in Figures 6 and 7 , but note that it is fairly insensitive to coolant volume fraction and to structure-fuel alloy volume ratio.

Mercury coolant density affects breeding ratio and critical mass very significantly at low enrichments (see Figures 8 and 9), which illustrates the requirement for operation at low mercury densities. 


\section{MERCURY COOLED BREEDER REACTOR}

The effect on critical mass of structure in the core is shown in Figure 10, and of mercury density in the coolant region in Figure 9. Both graphs show the same trends observed for variations in coolant volume fraction (Figure 5), although the effects are less pronounced over the ranges of interest because the total cross sections of the variable materials are low compared to the total core cross sections. Thus, large percentage variations in quantities which are themselves small have - relatively little over-all effect.

\section{Blanket Configuration}

The effect of changes in blanket thickness on critical mass and breeding ratio, with the same blanket composition used in the core studies, was determined. The effect on multiplication over the thickness range of 45 to $95 \mathrm{~cm}$ was found to be small, about $0.07 \%$; the effect on breeding ratio is shown in Figure 11. A plot of leakage out of the blanket versus blanket thickness, Figure 12, shows the expected exponential decrease. For the blanket composition used, Figures 11 and 12 indicate that blanket thicknesses of around 80 to $100 \mathrm{~cm}$ may be considered essentially infinite.

The effects of variations in blanket composition on critical mass and breeding ratio were investigated. The core used in this portion of the analysis was the same as that used previously in Case 2002 (see Table III). The effect on multiplication or critical mass for all variations in the blanket is negligible. The effect on breeding ratio is almost negligible for changes in blanket coolant density and volume fraction (see Figures 13 and 14), while blanket structure has a small but somewhat greater effect.on breeding ratio, as may be observed in Figure 15.

The neutron-balance analyses of this series of calculations are shown in Table E-XII (Appendix E). 
TABLE III

REACTOR PHYSICS PARAMETERS

\begin{tabular}{|c|c|c|c|c|c|c|c|c|}
\hline \multirow{2}{*}{$\begin{array}{l}\text { Case } \\
\text { No. }\end{array}$} & \multirow{2}{*}{$\begin{array}{l}\text { Coolant } \\
\text { Volume } \\
\text { Fraction }\end{array}$} & \multirow{2}{*}{$\begin{array}{c}\text { Average } \\
\text { Coolant }(\mathrm{Hg}) \\
\text { Density } \\
(\mathrm{gm} / \mathrm{cm}) \\
\end{array}$} & \multirow{2}{*}{$\begin{array}{c}\text { Structure-Fuel } \\
\text { Alloy Volume } \\
\text { Ratio } \\
\end{array}$} & \multirow{2}{*}{$\begin{array}{c}\text { Critical } \\
\text { Mass } \\
(\mathrm{kg} \text { U 235) }\end{array}$} & \multirow{2}{*}{$\begin{array}{c}\text { Core } \\
\text { Volume } \\
\text { (liters) }\end{array}$} & \multicolumn{3}{|c|}{ Breeding Ratio } \\
\hline & & & & & & Core & Blanket & Total \\
\hline \multicolumn{9}{|c|}{$15 \%$ Enriched Core } \\
\hline 1501 & 0.1 & 2.0 & 0.2 & 728.0 & 435 & 0.5781 & 0.6384 & 1.2165 \\
\hline 1502 & 0.3 & 2.0 & 0.2 & 1170.0 & 905 & 0.5795 & 0.6129 & 1. 1924 \\
\hline 1503 & 0.5 & 2.0 & 0.2 & 2310.0 & 2483 & 0.5814 & 0.5765 & 1.1579 \\
\hline 1504 & 0.3 & 2.0 & 0.1 & 987.0 & 697 & 0.5760 & 0.6514 & 1.2274 \\
\hline 1505 & 0.3 & 2.0 & 0.2 & 1170.0 & 905 & 0.5795 & 0.6129 & 1. 1924 \\
\hline 1506 & 0.3 & 2.0 & 0.3 & 1510.0 & 1260 & 0.5840 & 0.5573 & 1. 1413 \\
\hline 1507 & 0.3 & 0.5 & 0.2 & 1150.0 & 875 & 0.5782 & 0.6282 & 1.2064 \\
\hline 1508 & 0.3 & 2.0 & 0.2 & 1170.0 & 905 & 0.5795 & 0.6129 & 1. 1924 \\
\hline 1509 & 0.3 & 4.0 & 0.2 & 1430.0 & 1098 & 0.5815 & 0.5394 & 1. 1209 \\
\hline 1510 & 0.3 & 13.6 & 0.2 & 4320.0 & 3424 & 0.5896 & 0.2464 & 0.837 \\
\hline \multicolumn{9}{|c|}{$20 \%$ Enriched Core } \\
\hline 2001 & 0.1 & 2.0 & 0.2 & 374.0 & 168 & 0.3978 & 0.8682 & 1.266 \\
\hline 2002 & 0.3 & 2.0 & 0.2 & 578.0 & 333 & 0.3987 & 0.8373 & 1.236 \\
\hline 2003 & 0.5 & 2.0 & 0.2 & 1275.0 & 1033 & 0.4013 & 0.7807 & 1.182 \\
\hline 2004 & 0.3 & 2.0 & 0.1 & 507.0 & .268 & 0.3961 & 0.8689 & 1.265 \\
\hline 2005 & 0.3 & 2.0 & 0.2 & 578.0 & 333 & 0.3987 & 0.8373 & $1: 236$ \\
\hline 2006 & 0.3 & 2.0 & 0.3 & 748.0 & 469 & 0.4026 & 0.7604 & 1. 163 \\
\hline 2007 & 0.3 & 0.5 & 0.2 & 562.0 & 324 & 0.3977 & 0.8733 & 1. 271 \\
\hline 2008 & $0: 3$ & 2.0 & 0.2 & 578.0 & 333 & 0.3987 & 0.8373 & 1. 236 \\
\hline 2009 & 0.3 & 4.0 & 0.2 & 636.0 & 367 & 0.4001 & 0.7709 & 1.171 \\
\hline 2010 & 0.3 & 13.6 & 0.2 & 906.0 & 524 & 0.4059 & 0.5481 & 0.954 \\
\hline \multicolumn{9}{|c|}{ 30\% Enriched Core } \\
\hline 3001 & 0.1 & 2.0 & 0.2 & 205.0 & 62 & 0.2231 & 1.0862 & 1.310 \\
\hline 3002 & 0.3 & 2.0 & 0.2 & 294.0 & 113 & 0.2239 & 1. 0628 & 1. 286 \\
\hline 3003 & 0.5 & 2.0 & 0.2 & 535.0 & 289 & 0.2251 & 1.0049 & 1.230 \\
\hline 3004 & 0.3 & 2.0 & 0.1 & 275.0 & 97 & 0.2224 & 1.0756 & 1. 298 \\
\hline 3005 & 0.3 & 2.0 & 0.2 & 294.0 & 113 & 0.2239 & 1.0628 & 1. 286 \\
\hline 3006 & 0.3 & 2.0 & 0.3 & 344.0 & 144 & 0.2259 & 1.0141 & 1. 240 \\
\hline 3007. & 0.3 & 0.5 & 0.2 & 282.0 & 109 & 0.2193 & 1. 1087 & 1. 328 \\
\hline 3008 & 0.3 & 2.0 & 0.2 & 294.0 & 113 & 0.2239 & 1. 0628 & 1.286 \\
\hline 3009 & 0.3 & 4.0 & 0.2 & 333.0 & 128 & 0.2249 & 0.9731 & 1. 198 \\
\hline 3010 & 0.3 & 13.6 & 0.2 & 391.6 & 151 & 0.2281 & 0.7969 & 1. 025 \\
\hline
\end{tabular}




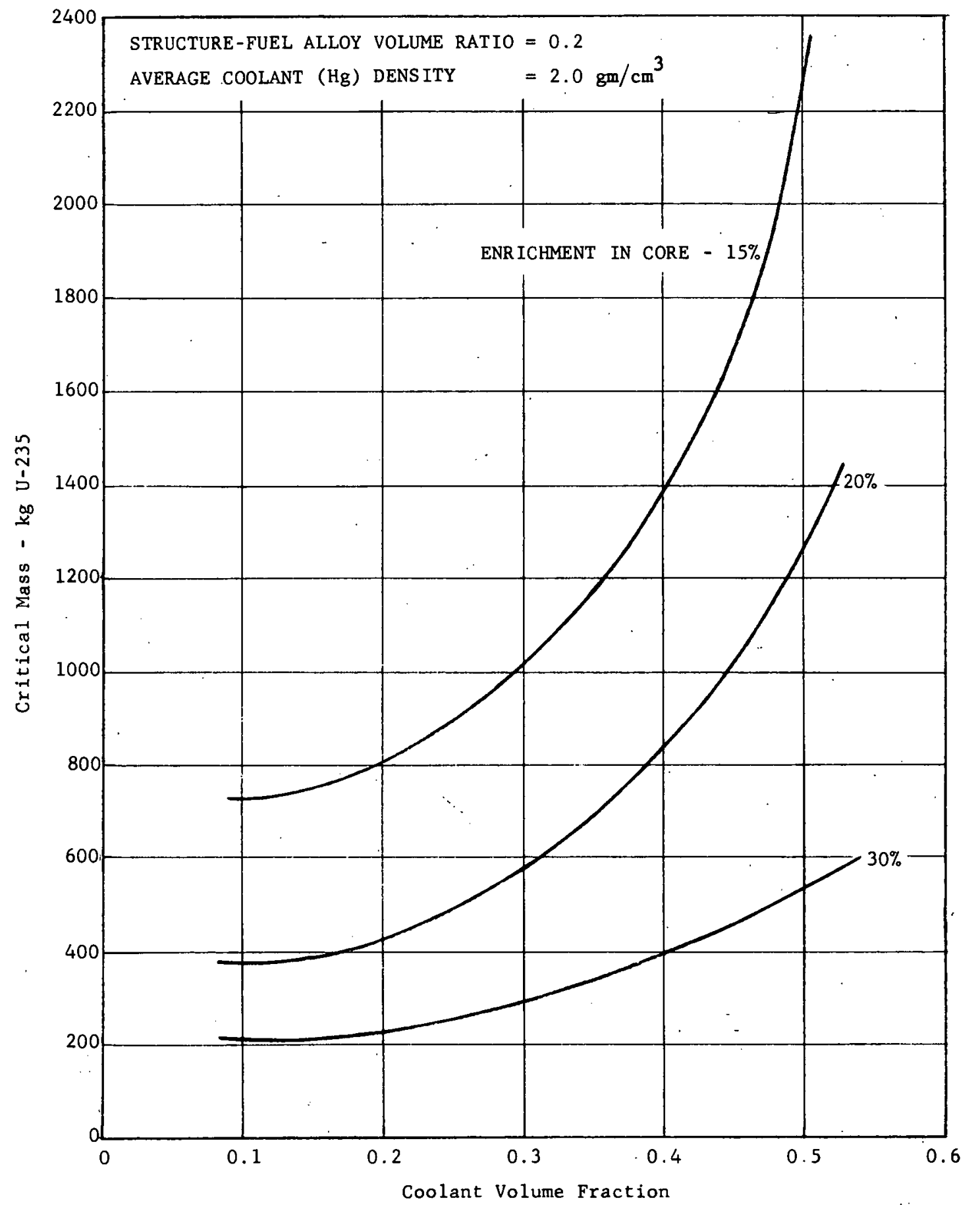

CRITICAL MASS VERSUS COOLANT VOLUME FRACTION IN CORE

FIGURE 5 


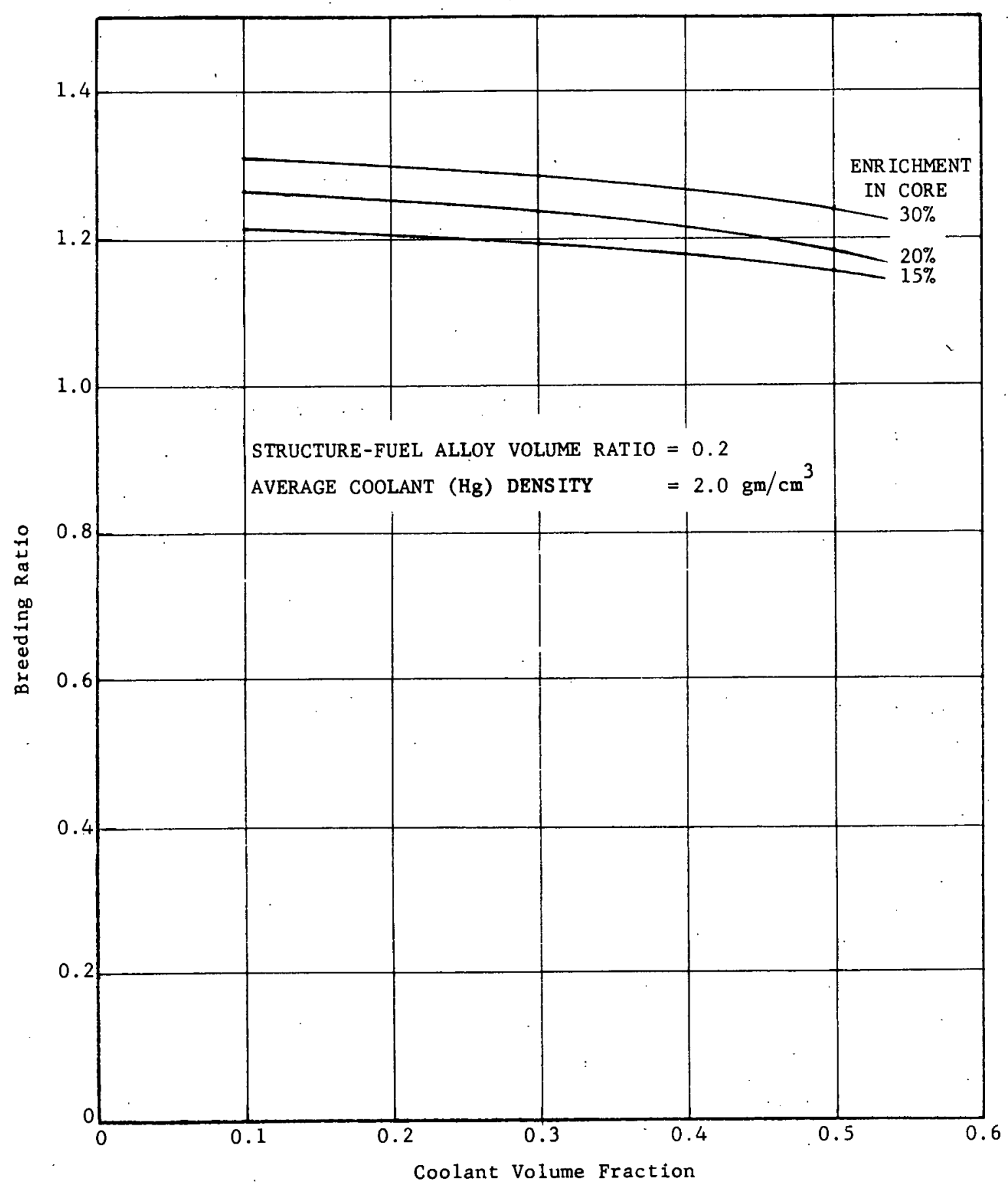

BREEDING RATIO VERSUS COOLANT VOLUME FRACTION IN CORE

FIGURE 6 


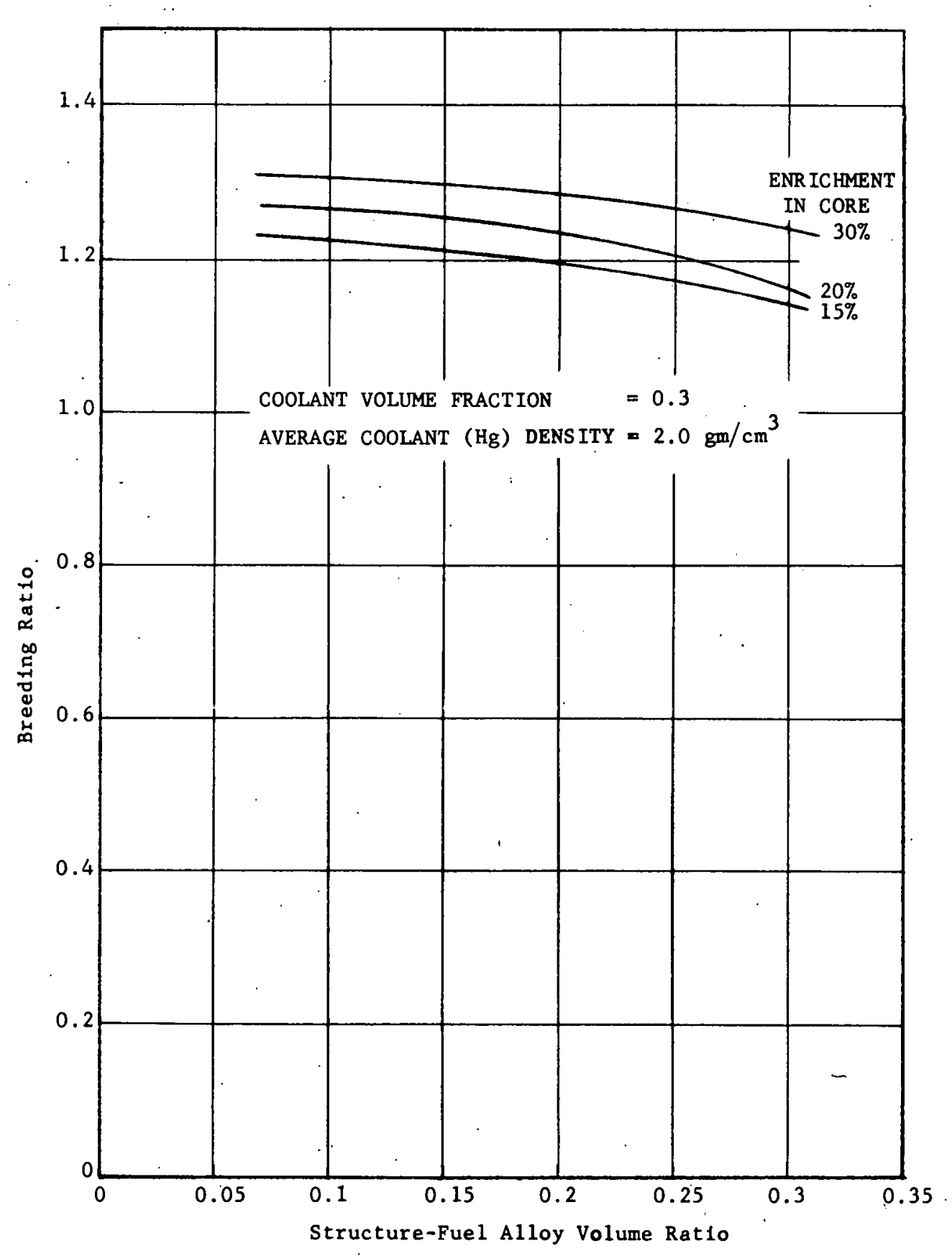

BREEDING RATIO VERSUS STRUCTURE-FUEL ALLOY VOLUME RATIO

FIGURE 7 


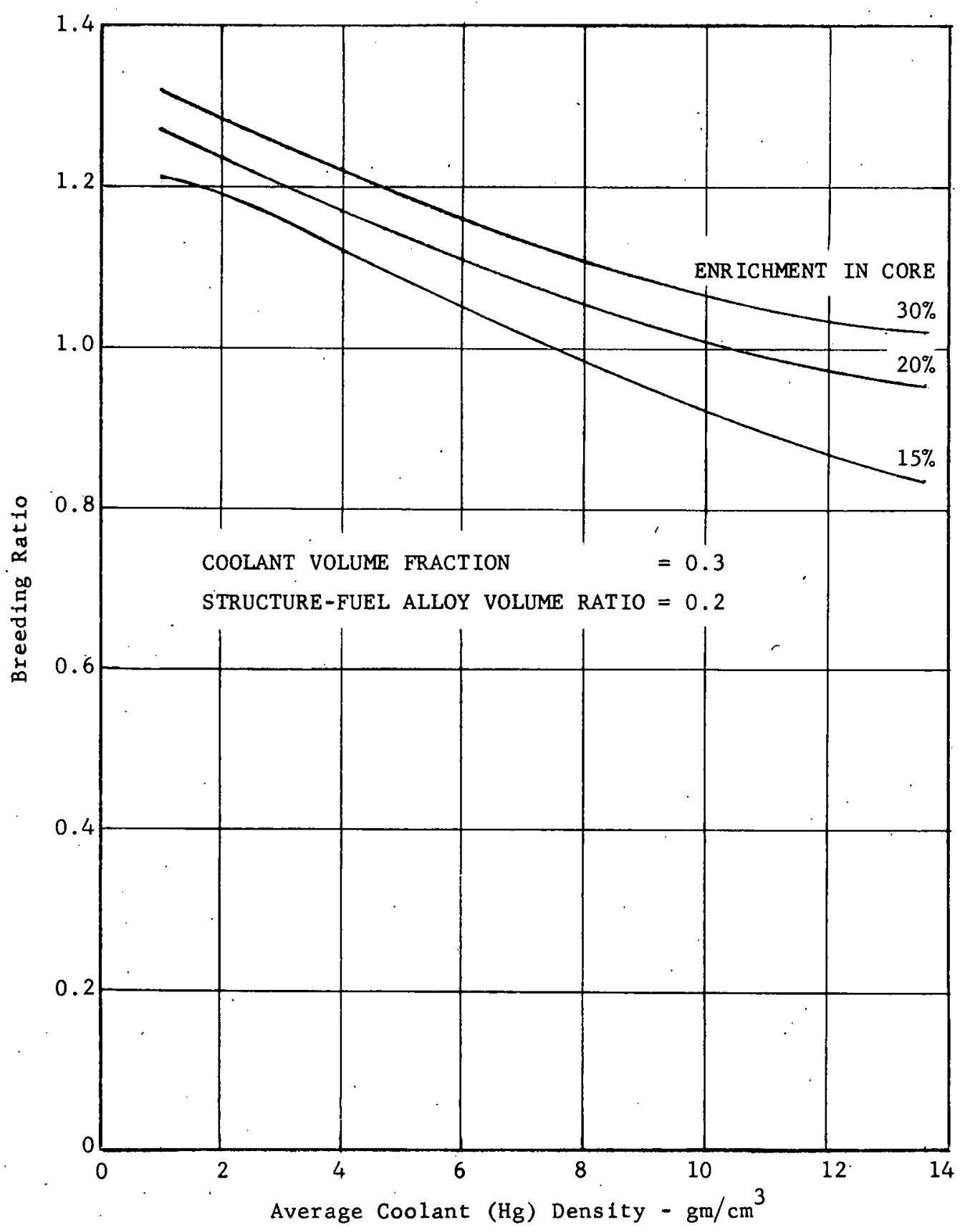

BREEDING RATIO VERSUS AVERAGE COOLANT (Hg) DENSITY IN CORE FIGURE 8 


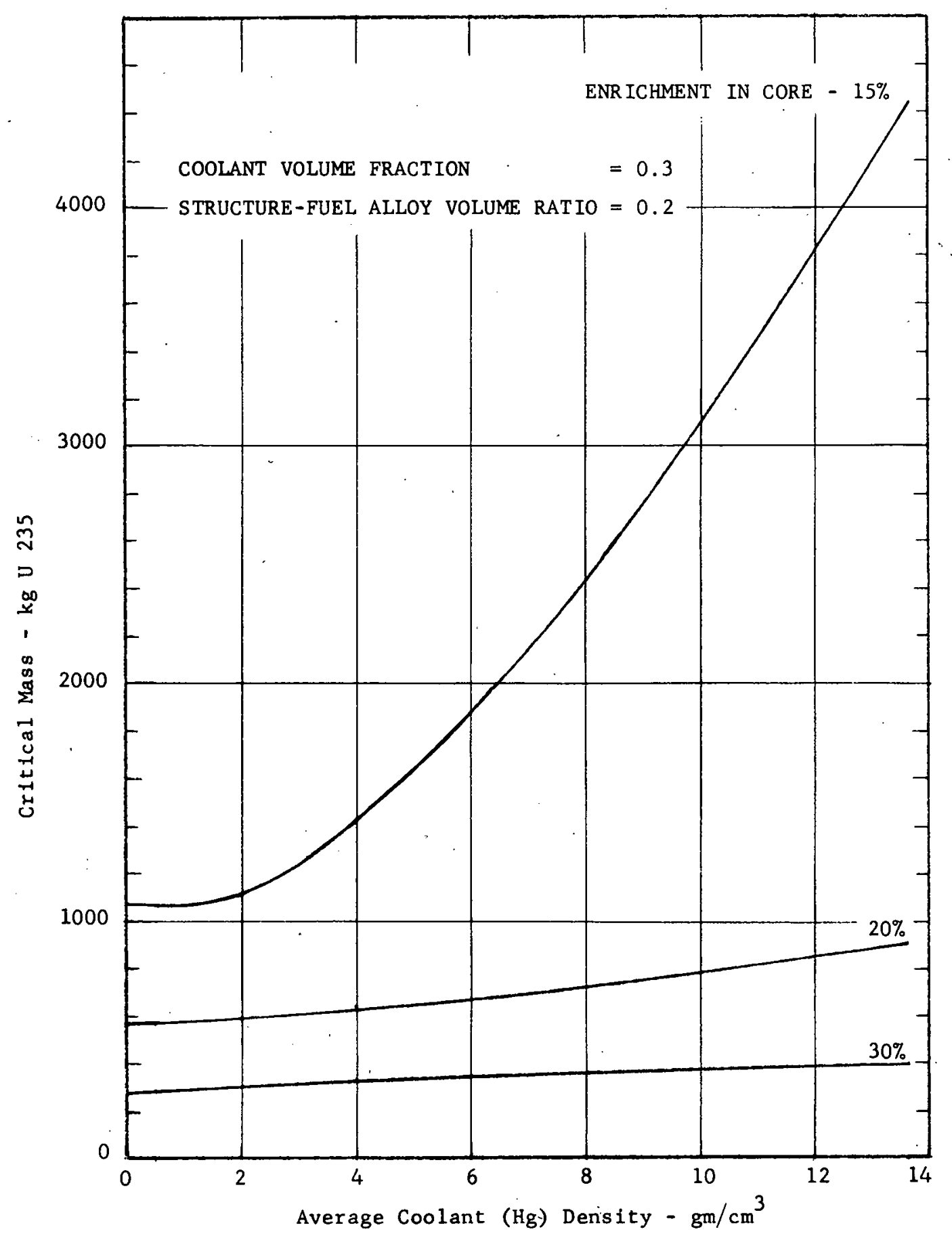

CRITICAL MASS VERSUS AVERAGE COOLANT (Hg) DENSITY IN CORE FIGURE 9 


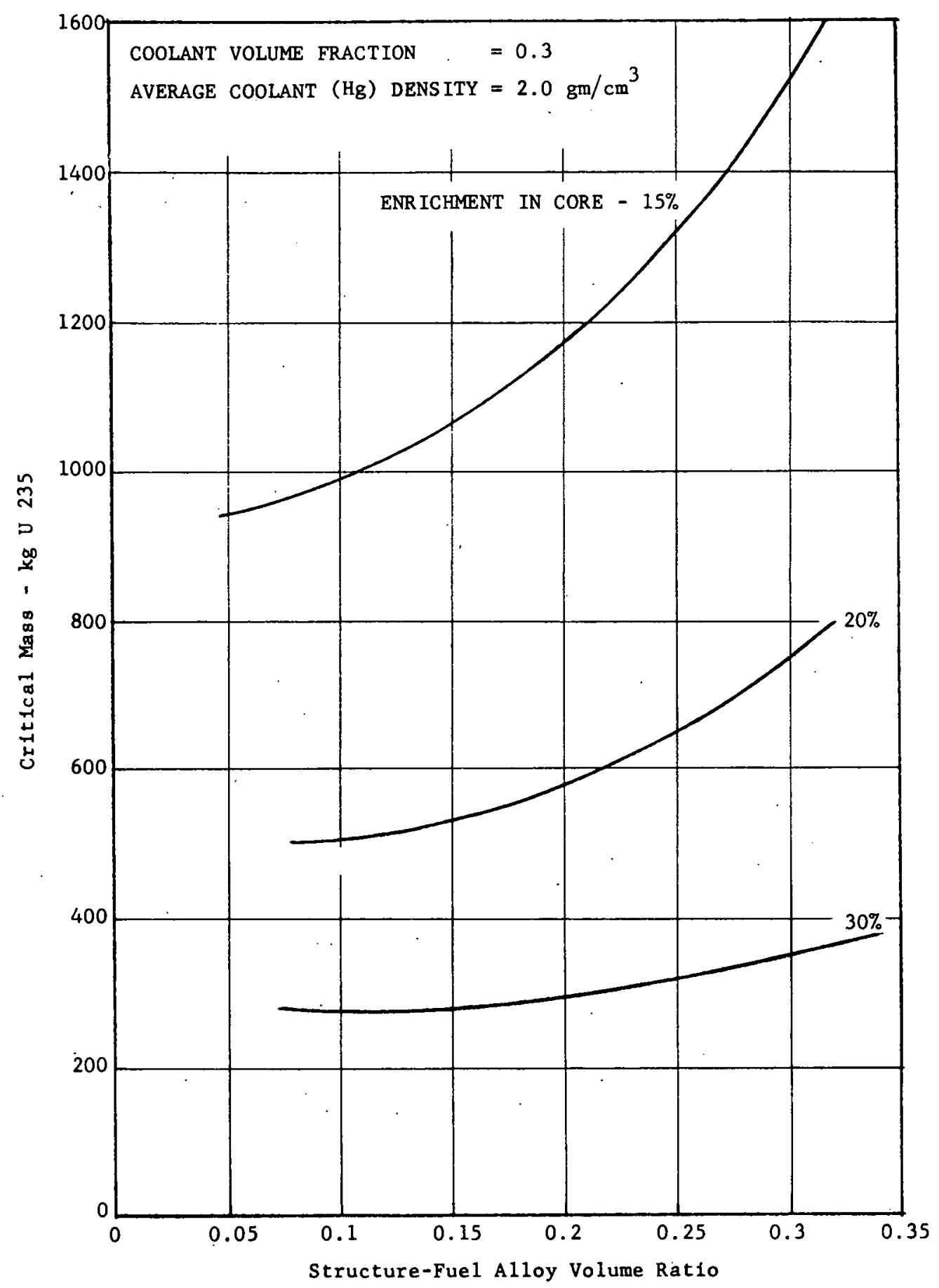

CRITICAL MASS VERSUS STRUCTURE-FUEL ALLOY VOLUME RATIO

FIGURE 10 


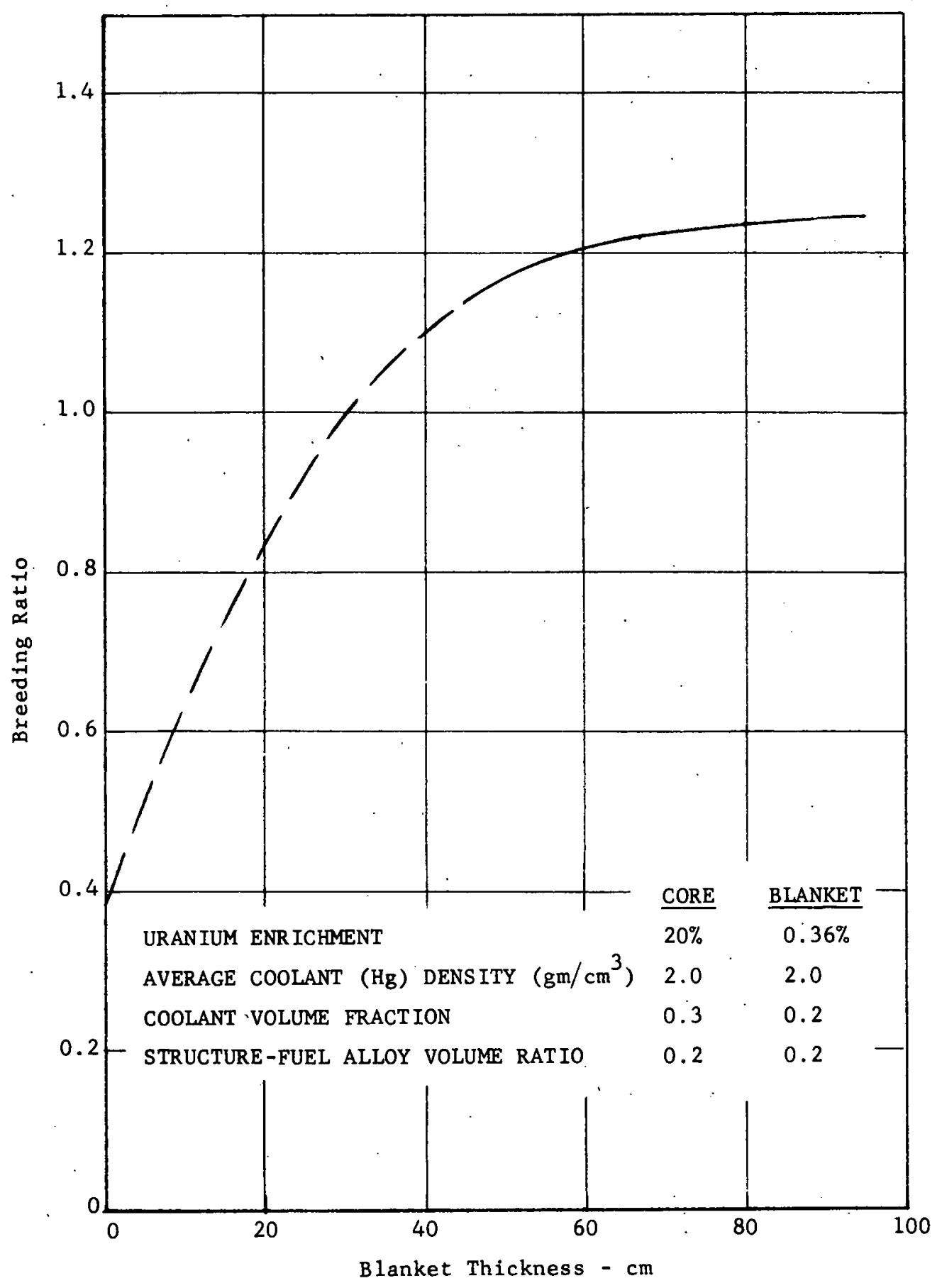

BREEDING RATIO VERSUS BLANKET THICKNESS

FIGURE 11 


$$
\text { 践 }
$$




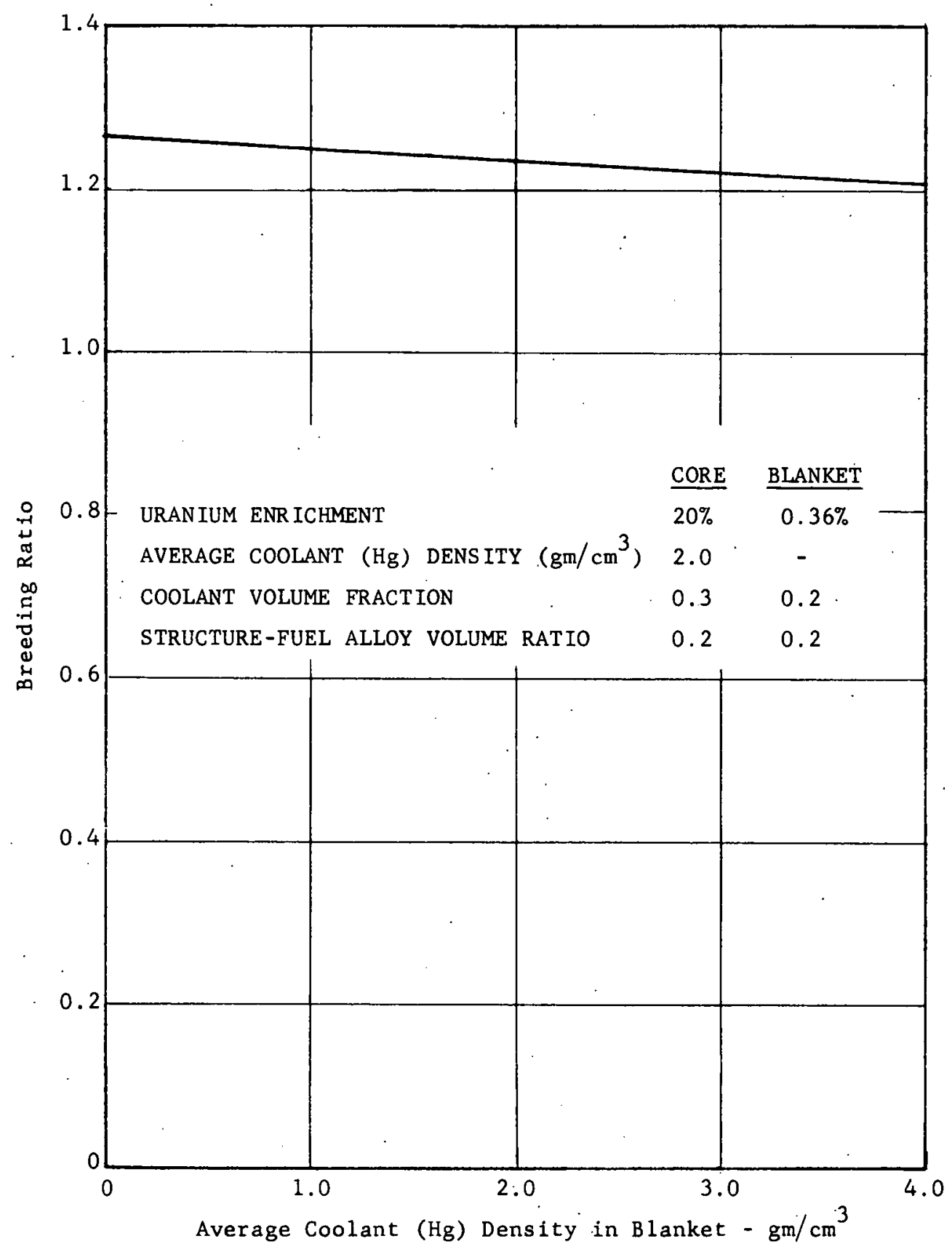

TOTAL BREEDING RATIO VERSUS AVERAGE COOLANT (Hg) DENSITY IN BLANKET FIGURE 13 


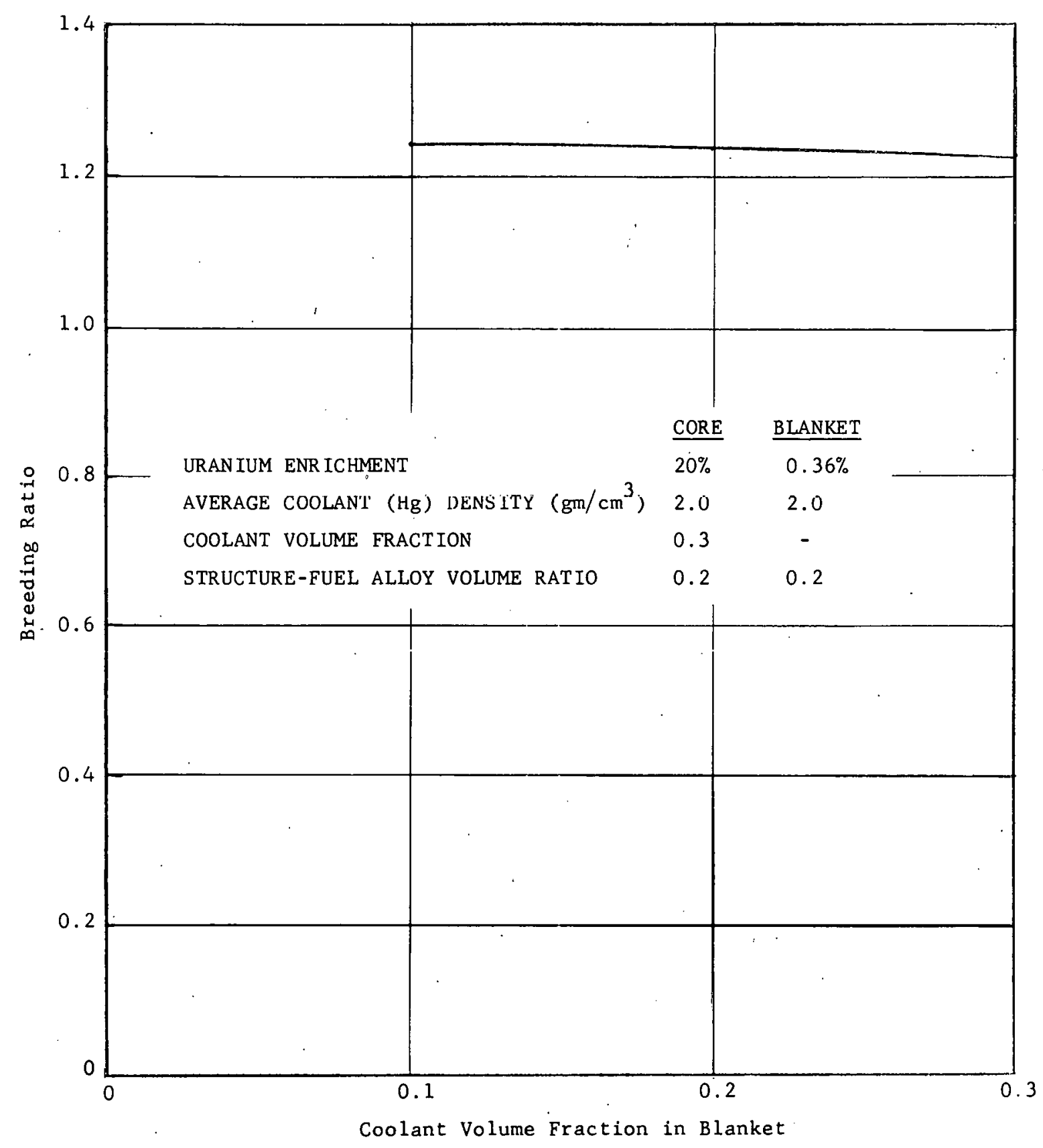

TOTAL BREEDING RATIO VERSUS COOLANT VOLUME FRACTION IN BLANKET

FIGURE 14 


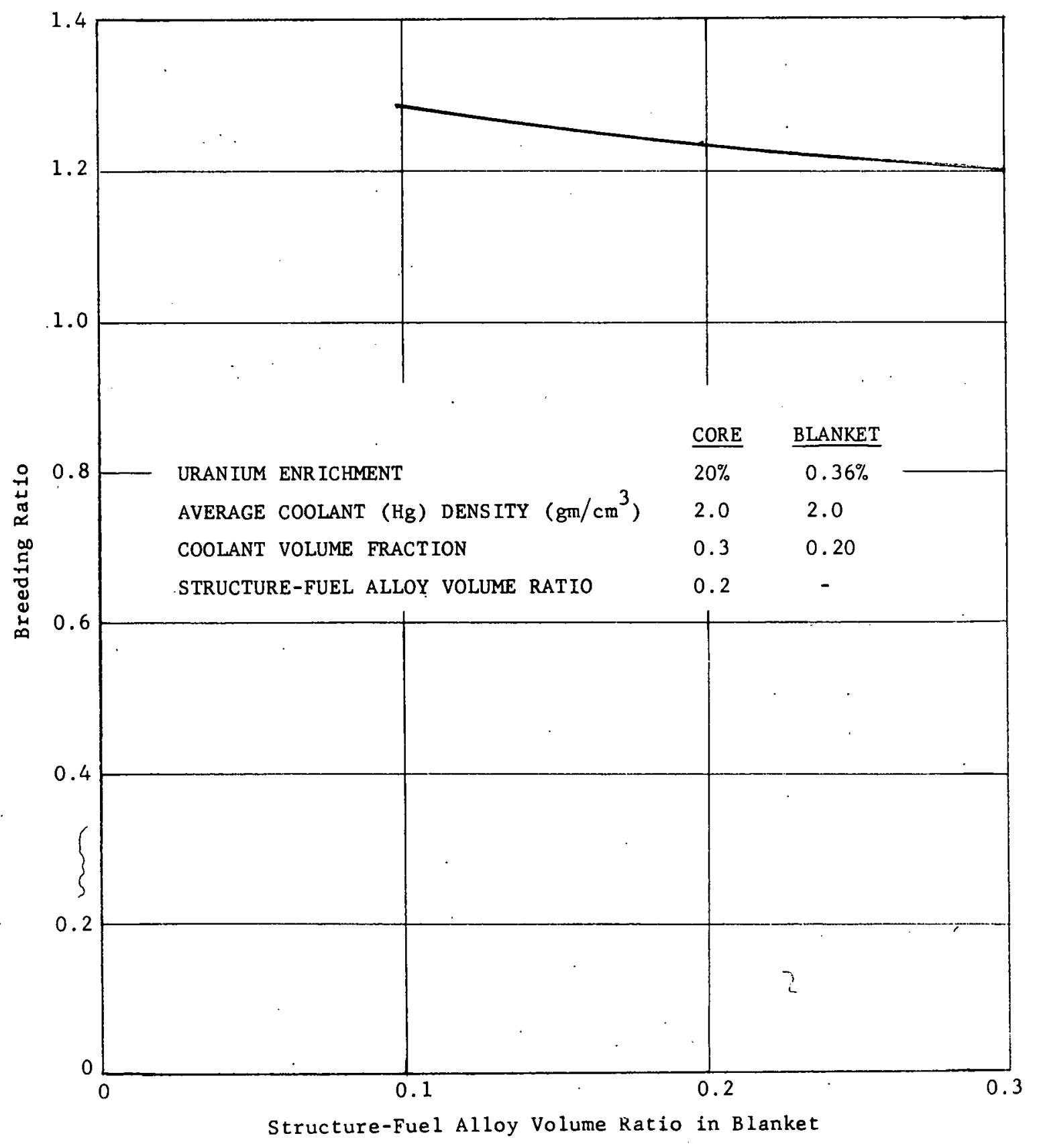

TOTAL BREEDING RATIO VERSUS

STRUCTURE-FUEL ALLOY VOLUME RATIO IN BLANKET

FIGURE 15 


\section{REACTOR PLANT MATERIALS}

Selection of materials for a reactor plant involves consideration of many factors affecting performance under the specific reactor service conditions. (See Appendix F for a detailed review.) The following important materials considerations enter into the MCBR design:

1) Compatibility of fuel and blanket element materials.

2) Corrosion-erosion of materials to the mercury coolant.

3) Physical and mechanical properties of materials.

4) Radiation stability of materials in the reactor systems.

5) Nuclear properties of materials in the core and blanket.

Although all of these factors influence the performance of the MCBR system, the radiation stability of the fuel material represents the major technical and economic limitation, since it determines fuel lifetime for realistic temperatures and burnup levels.

In common with other liquid-metal-cooled fast reactors, the MCBR requires a fuel element that is capable of achieving extensive burnup lifetime. High burnup must be attained with minimum penalty to neutron economy. The technology developed in connection with the EBR-II and the Enrico Fermi reactors is applicable to the MCBR fuel and blanket element design and performance evaluation.

Clad fuel and blanket elements are required for the MCBR because of the incompatibility of mercury and uranium, as well as the requirement for fission product retention. It is impractical to consider fabrication of a coextruded metallurgically bonded fuel element for the MCBR because of the low melting $\left(725^{\circ} \mathrm{C}\right)$ eutectic formed between uranium and the $5 \mathrm{w} / \mathrm{O} \mathrm{Cr}, \frac{1}{2} \mathrm{w} / \mathrm{o}$ Mo steel cladding selected. A "canned slug" type element similar to that utilized in the EBR-II reactor has therefore been selected rather than the coextruded type element used in the Enrico Fermi reactor. The fuel and blanket elements will consist of uranium pins inside a thin-walled can with a thermal bonding medium in the space between the pin and the cladding.

The selection of fuel element and other core materials is based on the following ground rules and assumptions which are appropriate for a reactor to be built in the early 1960 's.

1) Materials selection must be based on currently available technology, with little or no extrapolation to future developments.

2) Exposure level and temperature are assumed to be more important economic factors than breeding ratio; consequently, uranium alloy composition is relatively free of restrictions as to type and concentration of alloying elements. 


\section{MERCURY COOLED BREEDER REACTOR}

3) Although the "metallic uranium fuel" required by the project scope is interpreted to include uranium alloys containing plutonium as the fissionable material, as well as those containing $\mathrm{U} 235$, insufficient information is available to warrant the selection of Pu-bearing alloys at this time. Moreover, the MCBR initial fuel loading would include uranium only.

4) Only a small proportion (less than $10 \%$ ) of total reactor power is generated in the blanket regions.

A discussion of the basis for the selection of materials for the core and blanket elements is presented in Appendix F.

The selection of materials for other reactor plant equipment, piping, and structures is governed by corrosion-erosion resistance to fluids handled and to physical and mechanical properties of the materials at the operating conditions employed. A discussion of the basis for the selection of these materials is presented in the Power Generation Plant Description section. The selected materials and some of their important characteristics are listed in Table IV. 


\section{MERCURY COOLED BREEDER REACTOR}

TABLE IV

REACTOR PLANT MATERIALS

Fuel Material - Enriched Uranium + 10 w/o Molybdenum Alloy

Maximum burnup

Average burnup expected

Maximum temperature

Thermal conductivity

Mean coefficient of expansion (linear)

Structure

Fabrication method
$2 \%$ of total atoms (approx. $20,000 \mathrm{mwd} /$ metric ton) $1 \%$ of total atoms (approx. $10,000 \mathrm{mwd} /$ metric ton) $600^{\circ} \mathrm{C}\left(1112^{\circ} \mathrm{F}\right)$

See Figure $F-7$

$10 \times 10^{-6} \circ \mathrm{F}^{-1}$ (70 to $\left.1200^{\circ} \mathrm{F}\right)$

Gamma-quenched (retained metastable, gamma phase)

Cast or wrought, heat treated (gamma-quenched)

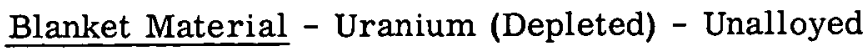

Maximum burnup

Average burnup expected

Maximum temperature

Thermal conductivity

Mean coefficient of expansion (linear)

Structure

Fabrication method
$0.2 \%$ of total atoms (approx. $2,000 \mathrm{mwd} /$ metric ton) $0.1 \%$ of total atoms (approx. 1,000 mwd/metric ton) $600^{\circ} \mathrm{C}\left(1112^{\circ} \mathrm{F}\right)$

See Figure F-7

$13.3 \times 10^{-6} \circ \mathrm{F}^{-1} \quad\left(70\right.$ to $\left.1200^{\circ} \mathrm{F}\right)$

Beta-quenched (fine-grained, alpha phase)

Cast or wrought, heat treated (beta-quenched)

Element Cladding Material - $5 \mathrm{w} / \mathrm{o} \mathrm{Cr}, \frac{1}{2}$ w/o Mo Steel

Material specification

Corrosion rate

Maximum temperature

Thermal conductivity

Mean coefficient of expansion (linear)

Thickness

Element Thermal Bonding Material - Sodium

Interaction with fuel and cladding

Mean coefficient of expansion (volumetric)

Annulus width
ASME Specification SA-199, Grade T-5

Nil (using magnesium, titanium additives)

$538^{\circ} \mathrm{C}\left(1000^{\circ} \mathrm{F}\right)$

15. $8 \mathrm{Btu} / \mathrm{hr}-\mathrm{ft}^{2}-^{\circ} \mathrm{F}$ (practically independent of temperature)

$7.38 \times 10^{-6} \circ \mathrm{F}^{-1}$ (70 to $\left.1200^{\circ} \mathrm{F}\right)$

$\sim 0.008$ inch

Nil $-600^{\circ} \mathrm{C}\left(1112^{\circ} \mathrm{F}\right)$ maximum

$216 \times 10^{-6} \circ \mathrm{F}^{-1}\left(70\right.$ to $\left.1200^{\circ} \mathrm{F}\right)$

0.005 inch 


\section{MERCURY. COOLED BREEDER REACTOR}

TABLE IV

(Concluded)

Mercury Systems Materials - $5 \mathrm{w} / \mathrm{o} \mathrm{Cr}, \frac{1}{2}$ w/o Mo Steel

Material specifications:

Vessels

Castings

Pipe

Tubing

Fittings and valves

Corrosion rate

Maximum temperature

Thermal conductivity

Mean coefficient of expansion (linear)
ASME Specification SA-357

ASME Specification SA-217, Grade C-5

ASME Specification SA-335, Grade P-2

ASME Specification SA-199, Grade T-5

ASME Specification SA-182, Grade F-5

Nil (using magnesium and titanium additives) $538^{\circ} \mathrm{C}\left(1000^{\circ} \mathrm{F}\right)$

15. $8 \mathrm{Btu} / \mathrm{hr}-\mathrm{ft}^{2}-{ }^{\circ} \mathrm{F}$ (practically independent of temperature)

$7.38 \times 10^{-6}{ }^{\circ} \mathrm{F}^{-1}$ (70 to $\left.1200^{\circ} \mathrm{F}\right)$

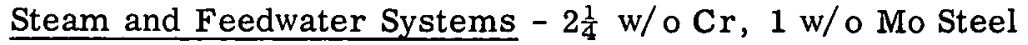

Material specifications:

Steam piping

Feedwater piping

Fittings and valves

Maximum temperature

Reactor Containment Vessel - Carbon Steel

Material specification
ASME Specification SA-369, Grade FP-22

ASME Specification SA-335, Grade P-22

ASME Specification SA-182, Grade F-22

$538^{\circ} \mathrm{C}\left(1000^{\circ} \mathrm{F}\right)$

ASME Specification SA-201, Grade B steel, in accordance with ASME Specification SA-300 


\section{SELECTION OF PARAMETERS FOR CONCEPTUAL CORE DESIGN}

\section{A. OPTIMUM OPERATING TEMPERATURE}

Materials properties impose two independent limitations on fuel-element temperatures. The centerline temperature is limited to about $600^{\circ} \mathrm{C}\left(1112^{\circ} \mathrm{F}\right)$ to avoid excessive radiation damage at economic exposure levels (see Appendix F), and the cladding surface temperature is limited to about $538^{\circ} \mathrm{C}\left(1000^{\circ} \mathrm{F}\right)$ to prevent corrosion and mass transfer. Since the aim of the reactor design is to maximize the financial return on the invested capital, operating conditions and configuration parameters are chosen to maximize the revenue obtained from the operation of the reactor system without exceeding design limitations.

While two temperature limitations are specified, it is not clear at first glance that both will control the design. For example, in a given fuel element and for a centerline temperature equal to the allowable limit, the cladding surface heat flux, consequently the reactor power level, is controlled hy the operating surface temperature. For high surface temperatures the heat flux is low, and for low surface temperatures (for a given centerline temperature) the heat flux is high.

Figure 16 shows a typical temperature distribution in a fuel element. Note that heat flux is proportional to the slope of the temperature distribution, so that with reduction of $T_{\text {wall }}$ for a fixed $T_{C L}$ ' heat flux at the cladding surface must increase.

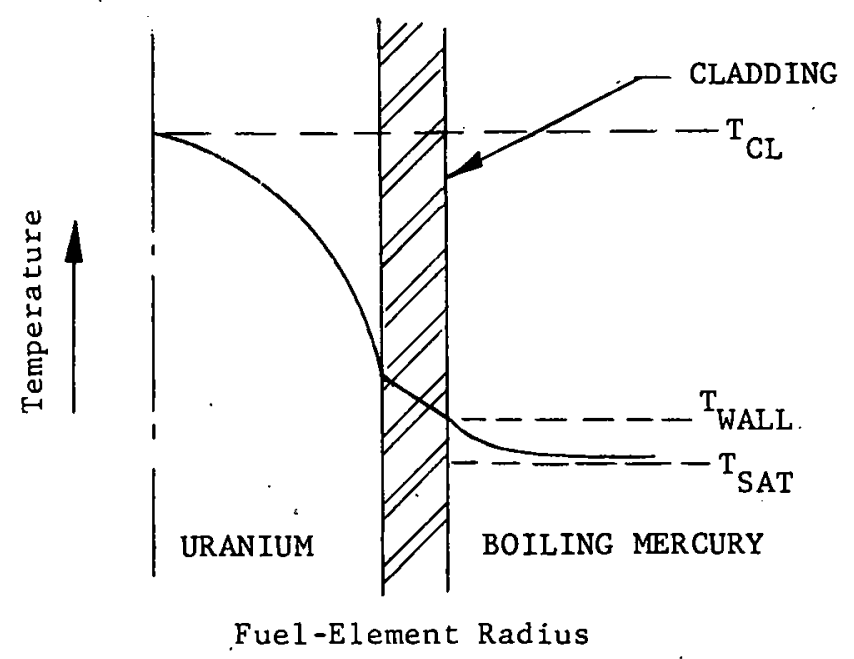

FUEL-ELEMENT TEMPERATURE DISTRIBUTION

FIGURE 16 


\section{MERCURY COOLED BREEDER REACTOR}

Net station efficiency is governed by the mercury saturation temperature. Reducing the saturation temperature (hence the surface temperature) for a fixed centerline temperature increases thermal power output by a factor very nearly proportional to ( $\mathrm{T}_{\mathrm{CL}}-\mathrm{T}_{\text {sat }}$ ), but net (electrical) power output is not increased proportionally because the saturation temperature is reduced.

Assuming revenue is proportional to net power output (this is not true if the rejected heat has value, in a process for example, but is true in electrical power plants), the saturation temperature should be chosen so as to maximize net power output rather than thermal power output.

An elementary analysis gives

$$
q / A_{0}=\frac{T_{C L}-T_{\text {sat }}}{R}
$$

where $\quad \mathrm{g} / \mathrm{A}_{\mathrm{o}}=$ cladding outside surface heat flux $\left(\mathrm{Btu} / \mathrm{hr}-\mathrm{ft}^{2}\right)$,

$$
\begin{aligned}
\mathrm{R}= & \text { thermal resistance (approximately constant for a given fuel-element } \\
& \text { configuration) }\left[\left(\mathrm{Btu} / \mathrm{hr}-\mathrm{ft}^{2}-{ }^{\circ} \mathrm{F}\right)^{-1}\right] \\
\mathrm{T}_{\mathrm{CL}}= & \text { fuel-pin centerline temperature }\left({ }^{\circ} \mathrm{R}\right) \\
\mathrm{T}_{\text {sat }}= & \text { boiling mercury coolant saturation temperature }\left({ }^{\circ} \mathrm{R}\right) .
\end{aligned}
$$

Power density in the core is related to heat flux with a simple geometry term

$$
P_{d}=G_{f} q / A_{0} \text {, }
$$

where,$P_{d}=$ power density (kw/liter),

$\mathrm{G}_{\mathrm{f}}$ = a fuel-element geometry factor (for cylindrical elements in a triangular array),

$$
G_{f}=\frac{2 \pi}{\sqrt{3} D_{0}\left(\frac{S}{D_{0}}\right)^{2}}
$$

The net station power is given by

$$
P_{\mathrm{e}}=\eta_{\text {net }} \mathrm{P}_{\mathrm{t}}
$$

where $\quad \mathrm{P}_{\mathrm{e}}=$ net station power $[\mathrm{kw}(\mathrm{e})]$,

$\mathrm{P}_{\mathrm{t}} \quad=$ reactor thermal power $[\mathrm{kw}(\mathrm{t})]$,

$\eta_{\text {net }}=$ net station efficiency. 
The net station efficiency is related to the Carnot efficiency:

$$
\eta_{\text {net }}=B \eta_{\text {Carnot }}=\mathrm{B}\left(\frac{\mathbf{T}_{\text {sat }}-\mathbf{T}_{\text {water }}}{\mathrm{T}_{\text {sat }}}\right),
$$

where $\eta_{\text {Carnot }}=$ Carnot efficiency,

$$
\begin{aligned}
\mathrm{T}_{\text {water }}= & \text { temperature of cooling water (approximately constant over the range of } \\
& \text { interest) }\left({ }^{\circ} \mathrm{R}\right)
\end{aligned}
$$

The return on invested capital may be approximated by

$$
I_{r}=P_{e} C_{r}-P_{t} C_{c}^{\prime}-I_{f c}
$$

where $I_{r}=$ rate of return on investment $(\$ /$ unit time),

$$
\begin{aligned}
& C_{r}=\text { unit revenue rate }[\mathrm{mils} / \mathrm{kwh}(\mathrm{e})], \\
& \mathrm{C}_{\mathrm{c}}^{\prime}=\text { unit fuel cost }[\mathrm{mils} / \mathrm{kwh}(\mathrm{t})] \\
& \mathrm{I}_{\mathrm{fc}}=\text { sum of all fixed charges }(\$ / \text { unit time) } .
\end{aligned}
$$

Using the conventional technique of setting the derivative of $I_{r}$ with respect to $T_{\text {sat }}$ equal to zero to obtain the value of $T_{\text {sat }}$ associated with $\mathrm{I}_{\mathbf{r}}(\max )$ :

$$
\text { Optimum } T_{\text {sat }}=\sqrt{\frac{T_{C L}-T_{\text {water }}}{1-\frac{C_{C}^{\prime}}{B_{:}}}} \text {. }
$$

Substituting the following temperature values:

$$
\begin{aligned}
& \mathrm{T}_{\mathrm{CL}}=600^{\circ} \mathrm{C}=1572^{\circ} \mathrm{R}, \text { and }, \\
& \mathrm{T}_{\text {water }}=70^{\circ} \mathrm{F}=530^{\circ} \mathrm{R},
\end{aligned}
$$

and an equivalent expression for $\mathrm{C}_{\mathrm{c}}^{\prime}$ :

$$
\mathrm{C}_{\mathrm{c}}^{\prime}=\eta_{\text {net }} \mathrm{C}_{\mathrm{c}}=\mathrm{B} \eta_{\text {Carnot }} \mathrm{C}_{\mathrm{c}}
$$

where $\quad \mathbf{C}_{\mathbf{c}}=$ unit fuel cost $[\mathrm{mils} / \mathrm{kwh}(\mathrm{e})]$, reduces the equation to.

$$
\text { Optimum } T_{\text {sat }}=\frac{913}{\sqrt{1-\eta_{\text {net } \frac{C_{c}}{C_{r}}}}}
$$




\section{MERCURY COOLED BREEDER REACTOR}

From equation 13, several implications are apparent, namely:

1) For very low fuel costs, $\mathrm{C}_{\mathrm{c}}<<\mathrm{C}_{\mathrm{r}}$, the optimum mercury saturation temperature is quite low but approaches $913^{\circ} \mathrm{R}\left(453^{\circ} \mathrm{F}\right)$ as a lower limit.

2) For values of fuel costs which may become realistic, say $C_{c}=0.3 C_{r}$, the optimum $T_{\text {sat }}$ is found to be about $520^{\circ} \mathrm{F}$, which corresponds to a surface temperature appreciably less than the maximum allowable.

3) For reactor systems in which other revenues are significant and large values of fuel cost are expected, the optimum saturation temperature will approach or exceed the $1000^{\circ} \mathrm{F}$ limitation; consequently, the design value will be set by the materials limitation rather than by an economic consideration.

Figure 17 shows the optimum saturation temperature as a function of the ratio of fuel cost to the unit value of electrical energy delivered at the generator terminals.

Since fuel costs for fast breeder reactors are characteristically high, approaching or exceeding the value of the salable power before a plutonium credit is taken, it is concluded that operation of the reactor at a maximum fuel-element surface temperature of $1000^{\circ} \mathrm{F}$ will permit the production of power such that revenue is maximized. This temperature of $1000^{\circ} \mathrm{F}$ is the safe upper limit allowed by the mass transport and corrosion characteristics of $5 \%$ chromium steels. A maximum fuelelement surface temperature of $1000^{\circ} \mathrm{F}$ is thus selected as a design criterion.

It may be noted that the basis for selection is predicated on fixed fuel-pin centerline and coolingwater temperatures. The selection of a design value would be reconsidered in the event that either these temperatures or the ratio of unit fuel cost to power revenue is altered.

\section{B. OPTIMUM PRESSURE DROP AND EXIT SATURATION TEMPERATURE}

With the maximum surface temperature determined at $1000^{\circ} \mathrm{F}$ by the materials limitation, a pressure drop across the core and blanket can be established such that electrical power can be produced by the reactor-power plant system at least cost.

The direct annual costs associated with an installed reactor core are virtually independent of the power level at which the core is operated. These costs are functions only of the mass of uranium in the core and the interest rates on the funds associated with the uranium inventory and the fabricated fuel elements. The unit cost of the energy produced then is affected by the rate at which electrical energy is produced, since revenue is proportional to power level and costs are fixed. Other unit power costs associated with the fuel cycle are not sensitive to power level alone but are proportional to the integrated exposure level of the fuel elements at the time of discharge. Still other unit costs, 


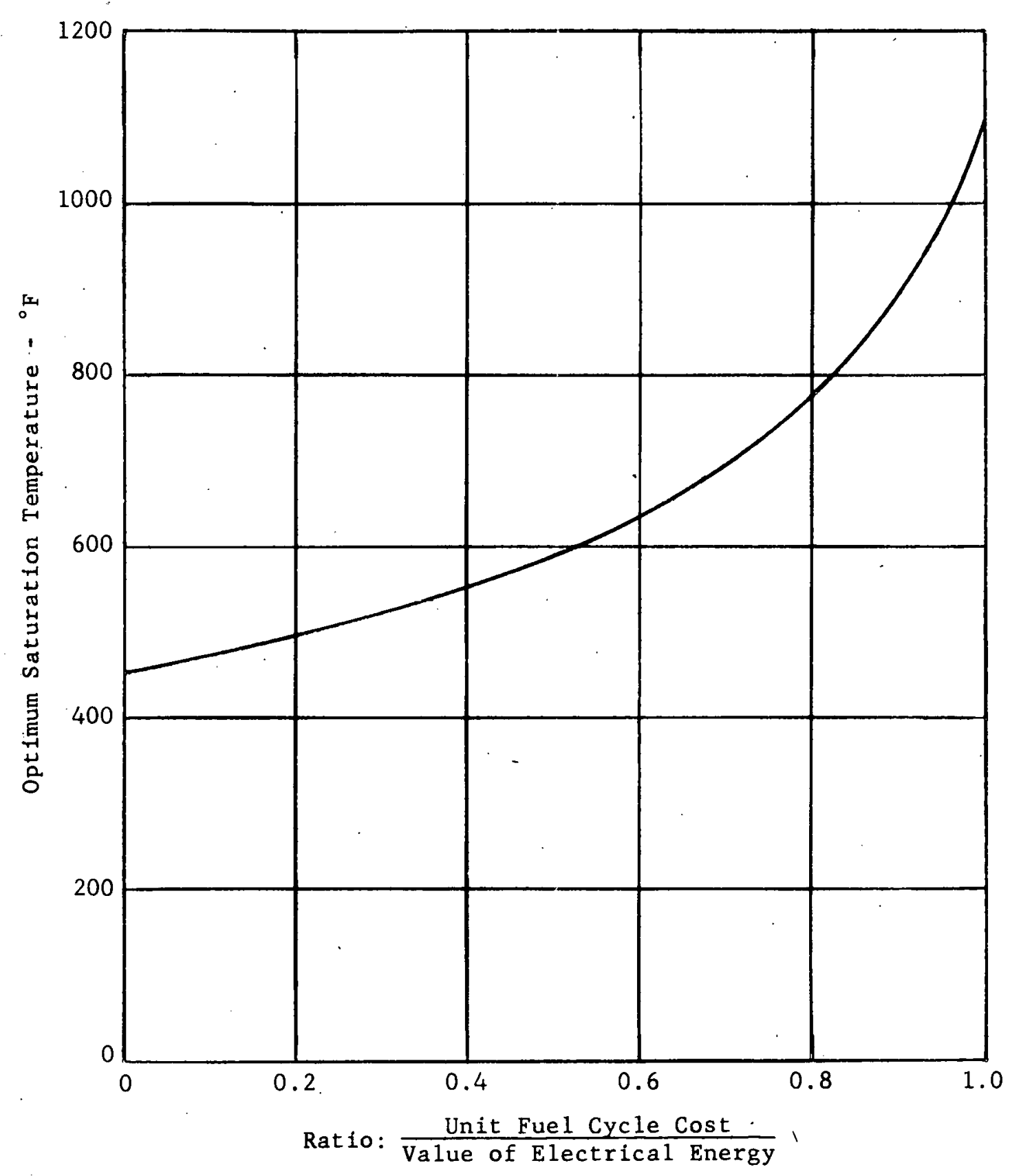

MERCURY SATURATION TEMPERATURE FOR MAXIMUM NET REVENUE

FIGURE 17 
for example capital costs, are functions of over-all power level but are not affected by the mass of fuel required, or the exposure level.

The power produced by a given core depends on the allowable pressure drop, and since the overall reactor power level is an independent and fixed design parameter, the amount of fuel required may be related to the allowable pressure drop. Increasing pressure drop reduces the fuel requirement and the related inventory costs by reducing the amount of fuel required; however, the increased pressure drop also forces a reduction in the exit saturation temperatures, consequently a reduction in plant efficiency, with a concomitant cost increase.

The opposing cost trends associated with allowable pressure drop suggest that a pressure drop exists which is optimum with respect to cost. This optimum pressure drop may be determined by computing the portion of the fuel costs associated with the uranium inventory and the fuel fabrication working capital as a function of pressure drop:

$$
\mathrm{C}_{i}=\mathrm{M}_{\mathrm{c}}\left(\frac{\mathrm{M}_{\mathrm{t}}}{\mathrm{M}_{\mathrm{c}}}\right)\left(\frac{\mathrm{i}_{\mathrm{i}} \mathrm{S}_{\mathrm{i}}}{\mathrm{F}_{\mathrm{l}} \eta_{\text {net }} \text { e } \mathrm{P}_{\mathrm{t}}}\right) \text {, }
$$

where $\quad C_{i}=$ unit power cost associated with uranium inventory [mils/kwh(e)],

$$
M_{c}:=\text { mass of U } 235 \text { in core, }
$$

$M_{t}=$ total mass of $U 235$ required for operation of reactor (includes uranium in storage and in process of fabrication),

$i_{i} \quad=$ uranium inventory change rate $\left(\right.$ years $^{-1}$ ),

$\mathrm{S}_{\mathrm{i}} \quad=$ value of uranium $(\$ / \mathrm{kg} \mathrm{U})$,

$F_{1}=$ plant load factor,

$\eta_{\text {net }}=$ net station efficiency,

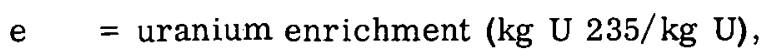

$P_{t}=$ reactor thermal power $[k w(t)]$.

Similarly,

$$
C_{f}=M_{c}\left(\frac{M_{t}}{M_{c}}\right) \quad\left(\frac{i_{f} S_{f}}{F_{1} \eta_{\text {net }} \text { e } P_{t}}\right),
$$


where $\mathrm{C}_{\mathrm{f}}=$ unit power cost associated with the capital required for fuel-element fabrication [mils/kwh(e)], $i_{f}=$ interest on working capital required for fuel-element fabrication (years ${ }^{-1}$ ), and $S_{f}=$ unit fuel-element fabrication cost $(\$ / \mathrm{kg} \mathrm{U})$.

Combining equations 14 and 15 and noting that

$$
\frac{1000 \mathrm{eP}_{\mathrm{t}}}{\mathrm{M}_{\mathrm{c}}}=\mathrm{P}_{\mathrm{s}}
$$

where $P_{S}=$ average specific power $[\mathrm{kw}(\mathrm{t}) / \mathrm{kg} \mathrm{U}]$,

and that $M_{t} \Theta_{c}=M_{c} \Theta_{c}+n_{s} M_{c} \Theta_{s}+n_{f} M_{c} \Theta_{f}$,

where $\theta_{c}=$ fuel cycle time (years),

$\theta_{S}=$ fuel storage time (years),

$\mathrm{n}_{\mathrm{S}}=$ fraction of fuel in storage,

$\mathrm{n}_{\mathrm{f}}=$ fraction of fuel in fabrication,

$\theta_{s}=$ fuel fabrication time (years),

giveș

$$
C_{i}+C_{f}=\left(1+\frac{n_{s} \theta_{s}}{\theta_{c}}+\frac{n_{f} \theta_{f}}{\theta_{c}}\right) \quad \frac{1000}{F_{l} P_{s} \eta_{n e t}}\left(i_{i} s_{i}+i_{f} s_{f}\right) .
$$

Specific power is shown to be proportional to the square root of $\Delta \mathrm{h}$ (see equation 4 ), fuel-cycle time may be expressed as a function of specific power

$$
\theta_{\mathrm{c}}=\frac{\mathrm{E}}{365 \mathrm{~F}_{1} \mathrm{P}_{\mathrm{S}}}
$$

whère $\mathrm{E}=$ exposure level at discharge $(\mathrm{mwd} / \mathrm{t} \mathrm{U})$,

$F_{1}=$ load factor,

and efficiency may be related to the Carnot efficiency by equation 10. For a maximum surface temperature in the core of $1000^{\circ} \mathrm{F}$, the exit saturation temperature is a function of pressure drop; consequently, the inventory and working capital costs for a given reactor design may be related to pressure drop alone. Figure 18 shows the relationship expressed by equation 18 for a specific core design which is characteristic of an MCBR of 100 electrical megawatts. The curve shows a minimum cost at a pressure drop of about 50 feet of liquid mercury, but it will be noted that the curve is fairly flat in the vicinity of the minimum. An allowable pressure drop of somewhat less than the optimum 


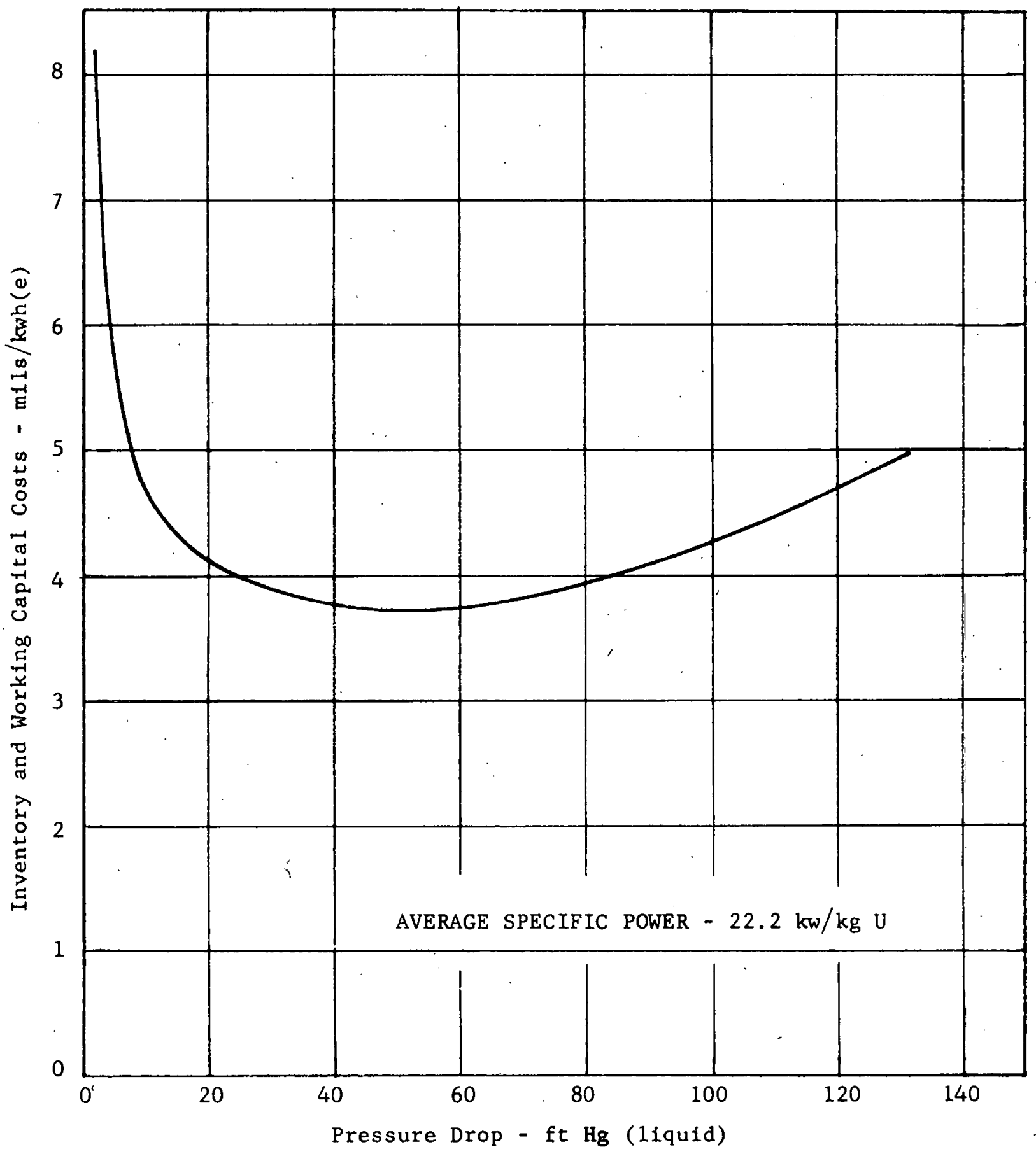

INVENTORY AND WORKING CAPITAL COSTS

TYPICAL MCBR CORE

FIGURE 18 
was selected in order to minimize the mechanical core design problems, which are not quantitatively accounted for in the optimum calculation. Based on these results, a value of 12.5 feet of mercury was specified as the design value for pressure drop (11.5 feet through the reactor and 1 foot through piping, etc.). Although less than that corresponding to the calculated optimum, this value corresponds to an exit saturation temperature of $920^{\circ} \mathrm{F}$, which permits a superheated steam temperature of $900^{\circ} \mathrm{F}$ and allows the selection of a standard steam turbine. Since little cost penalty is incurred, the off-optimum selection is justified.

C. POWER LEVEL

The electrical power capability for which a reactor plant is designed is usually fixed by a specification based on a power requirement. In the case of a general design study, a normal specification is not appropriate, so that another basis for the choice of a power level on which a design may be based must be found.

An operating power level of approximately 100 electrical megawatts is a common size for power plants contemplated for the next few years. It is not unusually large nor unrealistically small. A preliminary evaluation of the MCBR fuel-cycle economics suggests that no major reduction in fuel cost may be achieved by further increases in power output, but that rather large increases would be expected if small plants are considered (see Appendix G). In addition, an MCBR conceptual design based on a power output of $100 \mathrm{mw}(e)$ will permit a direct comparison of performance and cost with the sodium-cooled fast breeder reactor, the Enrico Fermi Atomic Power Plant ${ }^{2}$ now being developed and built by Atomic Power Development Associates and the Power Reactor Development Company near Detroit, Michigan. The nominal power rating of that plant is $100 \mathrm{mw}(\mathrm{e})$.

For these reasons, a nominal operating power level of $100 \mathrm{mw}(e)$ was selected as the size of the plant on which the MCBR conceptual design study would be based.

\section{CORE SIZE AND CONFIGURATION}

A conventional core configuration consisting of bundles of straight metal fuel pins clad with alloy steel cladding and set in a cylindrical array permitted the design study to proceed on a conservative basis. Upper and lower axial blanket elements of steel-clad depleted uranium are presumed to be combined with the fuel elements to form a single fuel and blanket assembly. Radial blanket assemblies are presumed to surround the fuel and axial blanket assemblies, completing the core and blanket. Such a configuration is quite similar to sodium-cooled fast breeder core and blanket arrangements that have been or are being built. 


\section{MERCURY COOLED BREEDER REACTOR}

It is possible that improved thermal performance may be achieved with plate-type or oxide fuel elements or with more complicated and undeveloped configurations and shapes of the fuel elements. However, the purpose of this study is to permit comparisons, both technical and economic, with existing fast breeder reactor concepts. On this basis, selection of the conventional core configuration is justified.

For a specified maximum fuel-element surface temperature, allowable pressure drop across . the core, and blanket and operating power level, there remains the selection of core diameter and length, fuel-element diameter and spacing, and blanket thicknesses, such that operating cost is minimum. The physical properties parameters are fixed by the temperature and pressure specifications, and the quality of the coolant leaving the channel is fixed at 0.30 , a value as large as is conservatively consistent with reported experience in existing mercury power plants and the experimental findings leading to the designs of these plants. Substitution of these values in the pressure drop equation, equation (1) :

$$
\Delta h=\frac{(q / A)^{2} \text { avg } 16\left(L_{c} / D_{h}\right)^{2}}{x_{e} \lambda^{2} \rho_{l} \rho_{v} 2 g}\left\{\left[2.76 \frac{f_{c}}{D_{h}}+6.52 \frac{f L_{b}}{D_{h_{b}}}\right] x_{e}^{\frac{1}{2}}+2\right\}
$$

yields a relationship between average heat flux, core configuration parameters, $L_{c} / D_{h}$ and $L_{b} / D_{h_{b}}$, and the head loss across the core and blanket, which has been specified at 11.5 feet of liquid mercury at the inlet saturation temperature. Average heat flux in the central channel is expressible as a function of element diameter only, since the fuel-pin centerline temperature and the element surface temperature are fixed. This makes it possible and convenient to consider the fuel-element diameter as an independent variable.

Relating the maximum heat flux associated with the maximum allowable temperatures to the average heat flux in the central channel gives the following relationship for average heat flux in the central channel in terms of known quantities and the fuel-element and fuel-pin outer diameters:

$$
q / A_{c_{\text {avg }}}=\left(\frac{\frac{q / A_{\max }}{q / A_{\max }}}{q / A_{c_{\text {avg }}}}\right)=\frac{1}{\left(\frac{q / A_{\max }}{q / A_{c_{\text {avg }}}}\right)} \frac{T_{C L}-T_{\text {wall }}}{\left(\frac{D_{0}}{2}\right)\left(\frac{1}{2 k_{f}}+\frac{1}{k_{c}} \ln \frac{D_{o}}{D_{f}}\right)} .
$$


Combining equations 1 and 20 and incorporating the fixed value of $\Delta \mathrm{h}$ yields the following expression involving the core and blanket configuration parameters only:

$$
28.64 \times 10^{-13}\left(\frac{\mathrm{L}_{\mathrm{c}}}{\mathrm{D}_{\mathrm{h}}}\right)^{2}\left(0.0303 \frac{\mathrm{L}_{\mathrm{c}}}{\mathrm{D}_{\mathrm{h}}}+0.0715 \frac{\mathrm{L}_{\mathrm{b}}}{\mathrm{D}_{\mathrm{h}_{\mathrm{b}}}}+2\right)=\mathrm{D}_{\mathrm{o}}^{2}\left(\frac{1}{2 \mathrm{k}_{\mathrm{f}}}+\frac{1}{\mathrm{k}_{\mathrm{c}}} \ln \frac{\mathrm{D}_{\mathrm{o}}}{\mathrm{D}_{\mathrm{f}}}\right)^{2} .
$$

It may be assumed that the upper blanket length and its equivalent diameter are proportional to the respective quantities.in the core. Including such relationships greatly simplifies the computational procedure, thus justifying the small loss in generality occasioned thereby, provided the resulting $\mathrm{L}_{\mathrm{b}} / \mathrm{D}_{h_{b}}$ is relatively small compared to $\mathrm{L}_{c} / \mathrm{D}_{\mathrm{h}}$. The latter condition is readily met, since it implies low pressure drop.

For various values of fuel-element diameters and fuel-element spacings, which in turn imply a corresponding set of coolant volume fractions, the mass of uranium in the square cylindrical core may be determined. The three curves with the pressure drop notation in Figure 19 depict this relationship for coolant volume fractions in the core of $0.50,0.60$, and 0.70 . Note that these curves correspond to a pressure drop across the core of 11.5 feet of liquid mercury and imply nothing regarding the power output of the core.

The remaining curve in Figure 19 represents the relationship between mass of fuel and element diameter for a plant which will operate at the previously established power level, $100 \mathrm{mw}(\mathrm{e})$. Since both power level and pressure drop are fixed design parameters, a unique relationship between. coolant volume fraction and fuel-element diameter is specified. This relationship is plotted in Figure 20. In addition, the relationship between uranium mass and coolant volume fraction is determined as indicated in Figure 21.

Coupled with these considerations of thermal and hydrodynamic performance are the conditions for criticality, which involve the same configuration parameter, i.e., coolant volume fraction, as well as the additional variable, fuel enrichment.

From the results of the parametric investigation of the nuclear characteristics of the MCBR cores (see "Reactor Physics" section), the mass of uranium required for a neutron multiplication factor of 1.0 is obtained as a function of coolant volume fraction and enrichment. These relationships are also shown in Figure 21. The intersections of these curves with the curve determined by the power requirement and pressure drop characteristics establish a relationship between enrichment and coolant volume fraction, which in turn implies the relationship between enrichment and fuelelement diameter shown in Figure 22. 


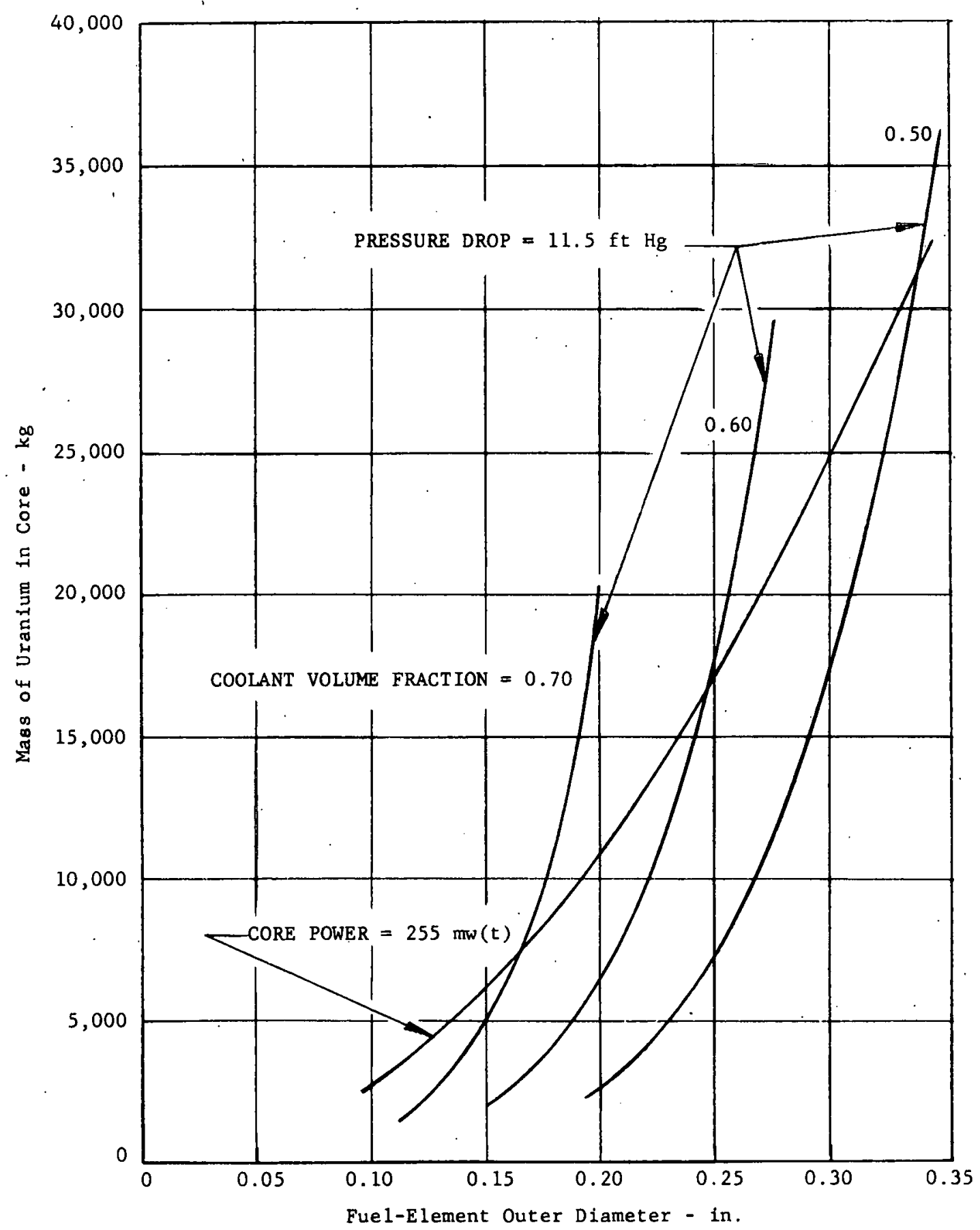

REQUIRED URANIUM MASS VERSUS FUEL-ELEMENT OUTER DIAMETER

FIGURE 19 


\section{MERCURY COOLED BREEDER REACTOR}

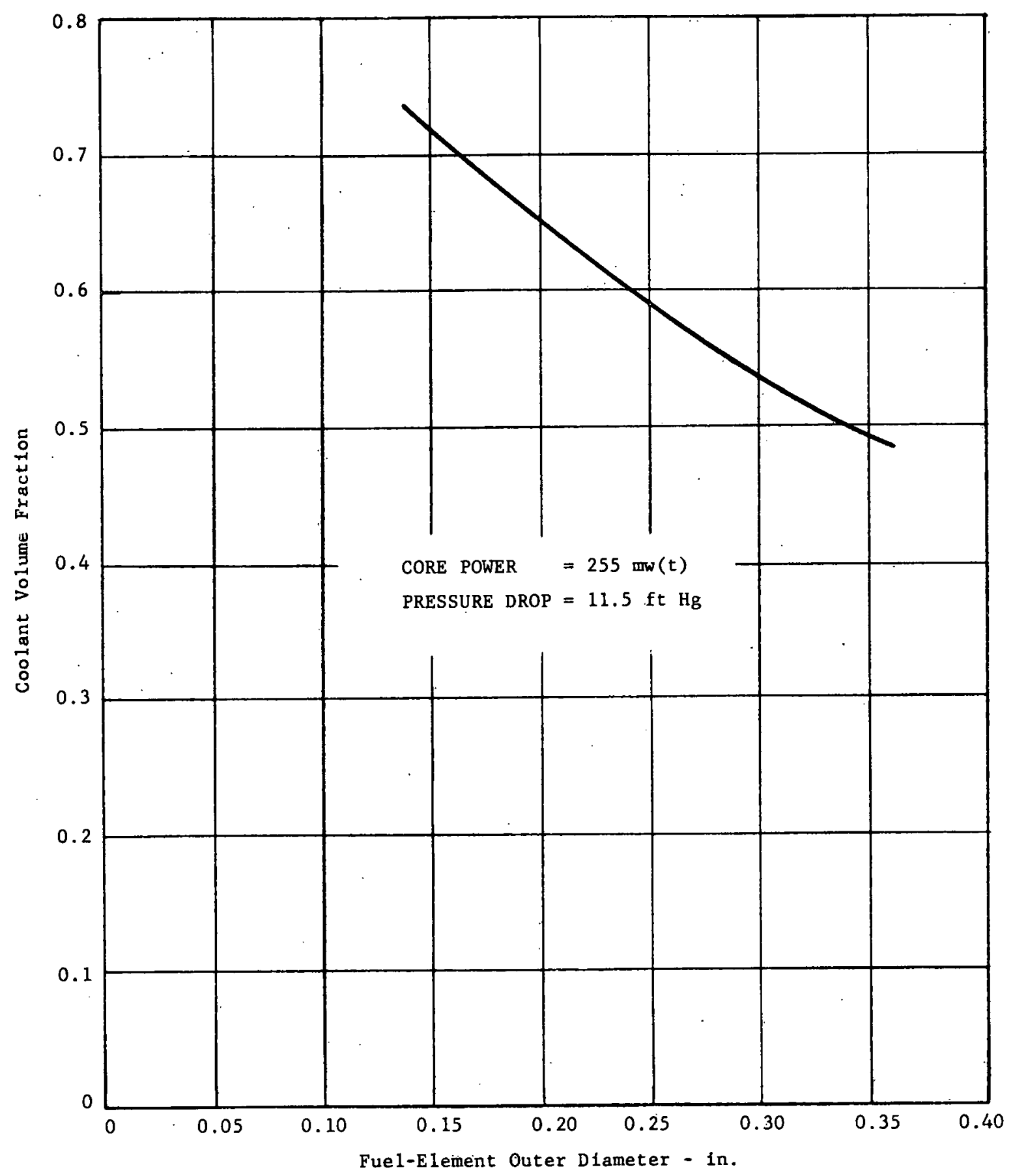

COOLANT VOLUME FRACTION VERSUS FUEL-ELEMENT OUTER DIAMETER

FIGURE 20 


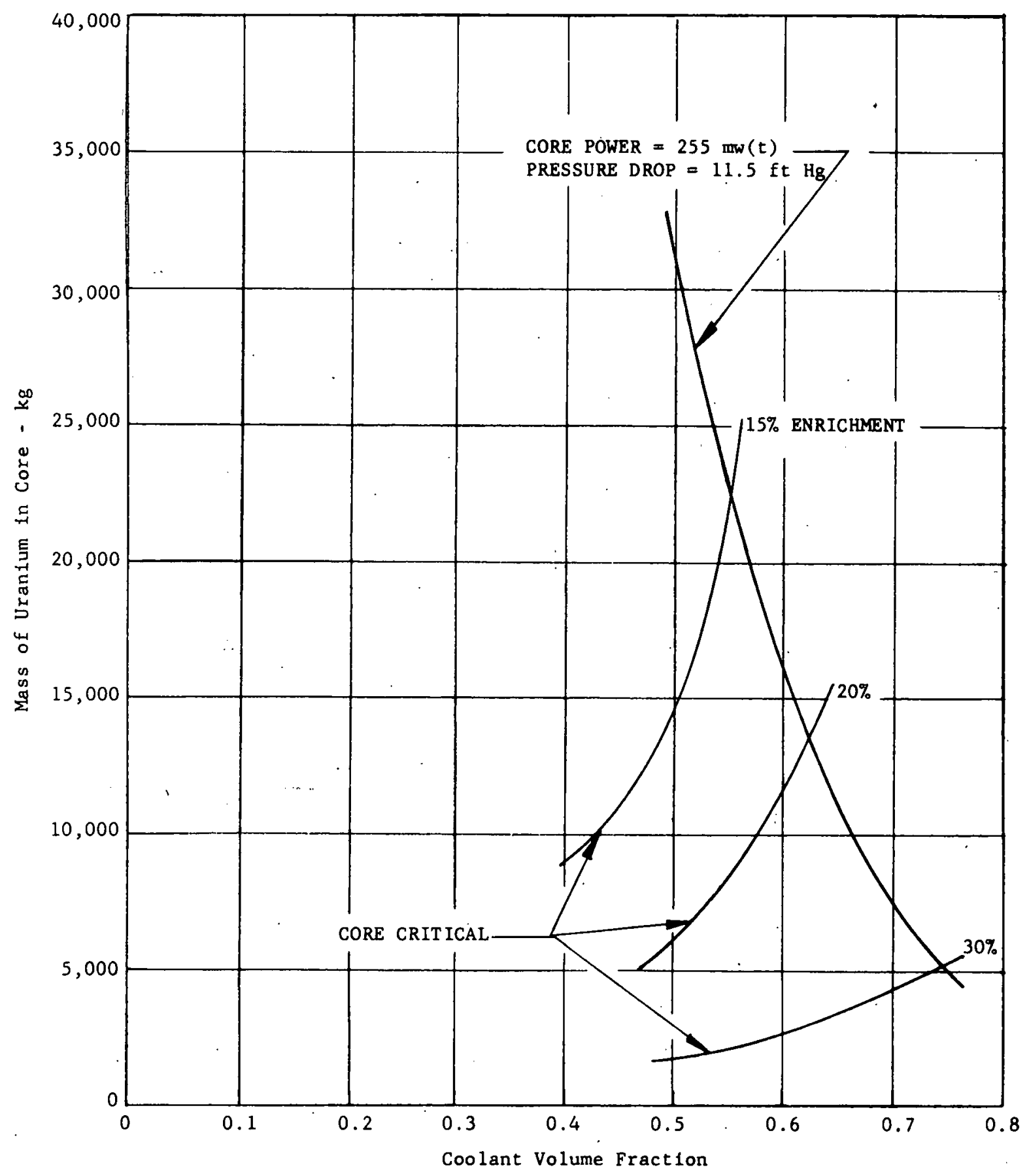

MASS OF URANIUM VERSUS COOLANT VOLUME FRACTION

FIGURE 21 


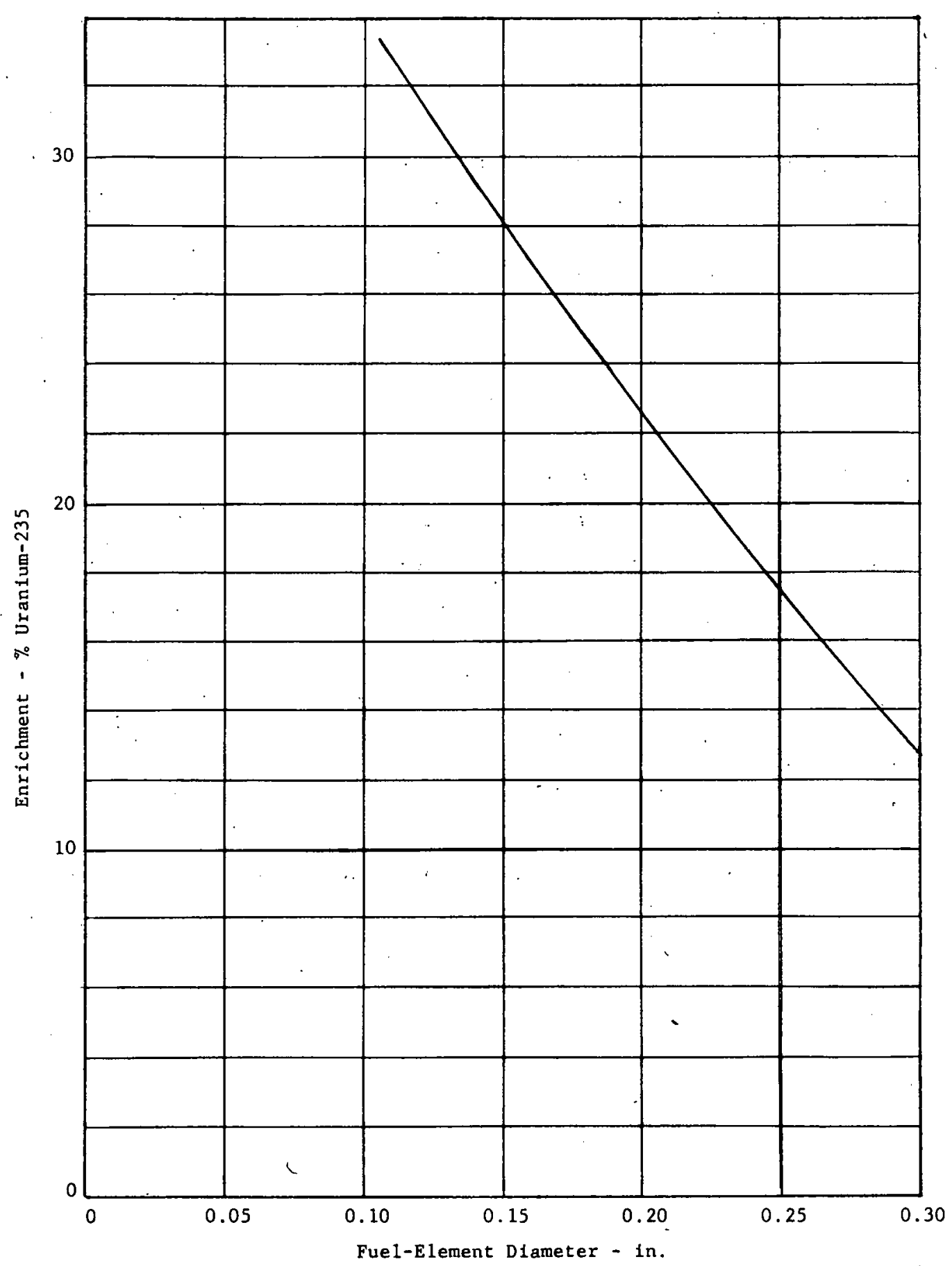

REQUIRED ENRICHMENT VERSUS FUEL-ELEMENT DIAMETER

FIGURE 22 


\section{MERCURY COOLED: BREEDER REACTOR}

An estimate of the fuel cost can be made for the various fuel-element diameters since both enrichment and total mass of uranium are known. The analysis revealed so little change in cost over the range of fuel-element diameters of interest that economics could not be construed as a basis for selection of fuel-element diameter without substantial refinement of the calculations. Rather, the element diameter corresponding to an enrichment high enough to exhibit a relatively small mercury density coefficient of reactivity proved to be a more realistic basis for the determination of fuelelement diameter. This may be inferred from the curves presented in Figure 9, which shows critical mass as a function of mercury density in the core. The flat curves corresponding to high enrichments indicate that relatively little reactivity is associated with the mercury coolant, while the steeper slopes at lower enrichments indicate relatively large reactivity changes associated with changes in mercury density.

A fuel-element diameter of 0.18 .0 inch corresponds to an enrichment of approximately $25 \%$. This value of element diameter was selected for the conceptual design, and the corresponding coolant volume fraction of 0.68 was obtained directly from Figure 20. The approximate mass of uranium required was obtained from Figure 21. From these values, the core dimensions were readily obtained.

This procedure permitted selection of the important design parameters used for the conceptual design and cost evaluation presented here. It should be noted, however, that the procedure is not sufficiently refined to permit the results to be used directly. Rather it permits objective selection of the important values, namely: fuel-element diameter, coolant volume fraction, allowable pressure drop, and over-all core dimensions. The enrichment, breeding ratios, flux distributions, and reactivity coefficients are then developed from additional machine calculations based on the specific input values, which were determined as described. Table XXIII presents the results of the more refined and complete analysis, which represents a slight departure from the values presented here in graphical form, Figures 19 through 22.

\section{E. BLANKET THICKNESS}

The blanket of depleted uranium surrounding the core serves as a neutron reflector for the core. It absorbs the neutrons leaking from the core, thereby producing the fissionable material plutonium, in some cases in quantities greater than are consumed. It generates thermal energy because of the fissioning of the small fraction of $\mathrm{U} 235$, the bred $\mathrm{Pu}$, and the fast fission of $\mathrm{U} 238$. It absorbs gamma photons leaking from the core. Some of these characteristics may be analyzed with respect 
to their effect on the system economics; others are sufficiently complicated or subtle that a quantitative treatment of the associated economics is quite beyond the scope of this investigation.

Considering only the cost of fabricating the blanket elements, the interest on invested capital, and the arbitrary value of the plutonium produced in the blanket, an estimate of the blanket thickness consistent with operation at minimum cost is readily obtained. This thickness appears to be less than one centimeter for plutonium valued at $\$ 12$ per gram and is insufficient for an over-all breeding ratio greater than unity (see Figure 23). A breeding ratio of unity occurs with a blanket approximately $30 \mathrm{~cm}$ thick, which also represents the approximate optimum thickness with plutonium valued at $\$ 30$ per gram.

It may be observed from Figure 23 that a blanket which is appreciably thicker than the economic optimum is neoessary to approach the maximum breeding gain possible for the MCBR core and blanket system. Such a blanket is justified on the basis of the intrinsic value of breeding as a means of conserving the world's energy resources rather than on a purely economic basis. A nominal blanket thickness of $50 \mathrm{~cm}$ is thus justified, corresponding to a breeding ratio that begins to approach the maximum theoretical limit. 


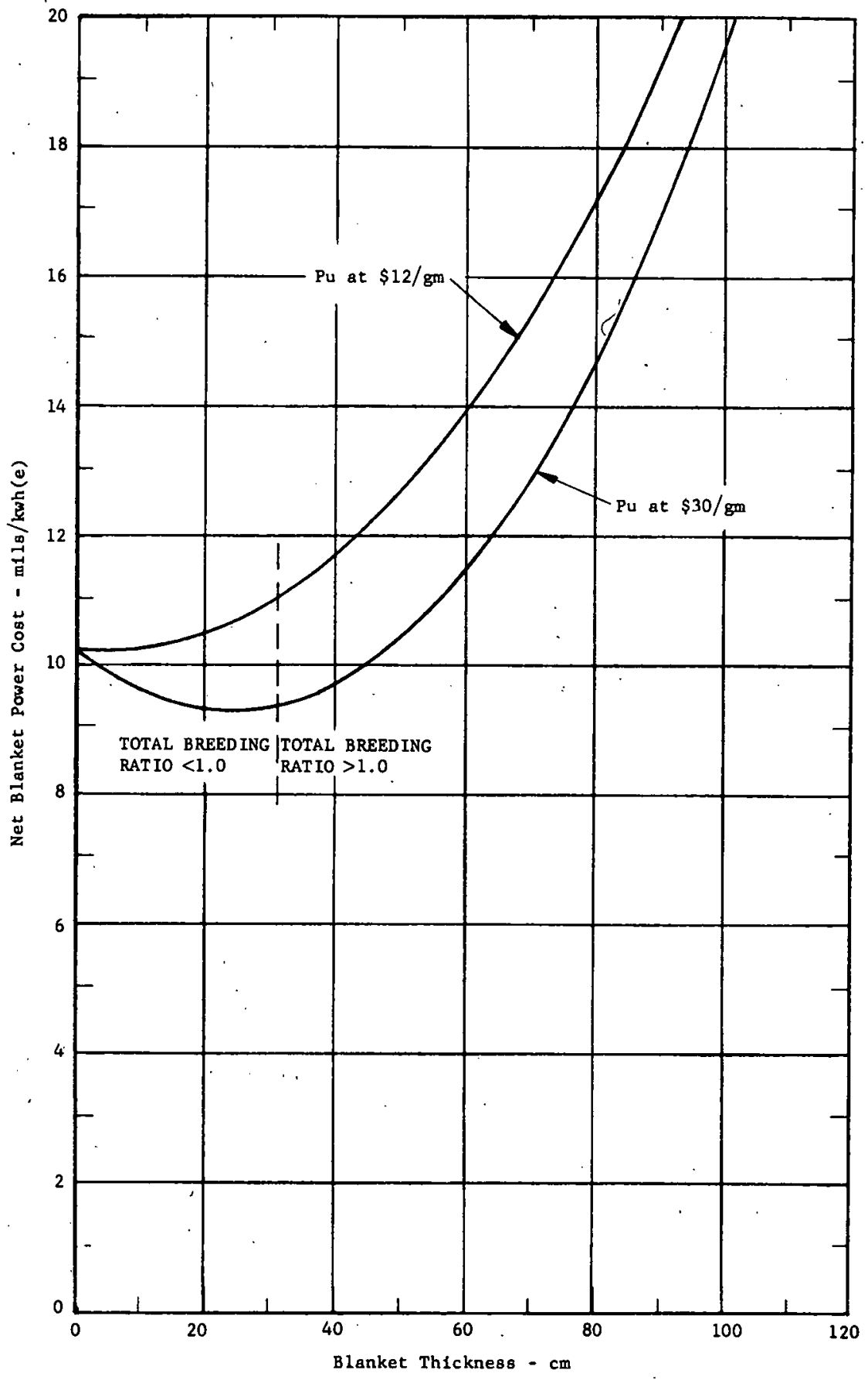

NET COST OF MAINTAINING A URANIUM BLANKET AROUND A TYPICAL MCBR CORE

FIGURE 23 


\section{ECONOMIC ANALYSIS OF MCBR POWER PLANT SYSTEM}

The primary purpose for the conceptual design of a $100 \mathrm{mw}(\mathrm{e}) \mathrm{MCBR}$ power plant is to provide the basis for detailed and realistic cost estimates. A detailed discussion of the reactor plant design is presented in the following section.

Briefly, the reactor core consists of an hexagonal array of hexagonal fuel elements containing Croloy-clad uranium fuel pins arranged vertically. The elements are cooled by a stream of mercury flowing upward through the core such that the mercury is permitted to boil in the core region. Attached to the ends of the fuel elements, and contained within extensions of the steel shrouds that enclose and support the fuel elements, are similar bundles of depleted uranium elements. These assemblies constitute upper and lower axial blanket regions. The lower blanket is cooled by liquid mercury before the mercury reaches the core proper, and the upper blanket is cooled by the liquidvapor mixture that èmerges from the core.

Surrounding the core and its attached upper and lower blankets is a radial blanket region consisting of bundles of depleted uranium elements in hexagonal shrouds of the same dimensions as those enclosing the fuel and axial blanket elements. The radial blanket elements are also cooled by liquid mercury entering from the bottom and boiling as it passes upward through the assembly.

The combined core and radial blanket elements produce a close-packed array approximating a right circular cylinder with its height equal to its diameter.

Mercury vapor produced in the core is separated from entrained liquid mercury and is transported to condenser-boilers, where the mercury is condensed and water is boiled and superheated. The superheated steam drives a turbine in the conventional steam power plant portion of the MCBR power facility. The condensed mercury is combined with the liquid stream from the entrainment separator and is pumped back to the core inlet to complete the cycle.

A small sidestream of liquid mercury is continuously circulated through an auxiliary cleanup system to remove oxygen and other contaminants that might impair the wetting characteristics of the heat transfer surfaces.

Table V presents a gross breakdown of the estimated unit power costs for the $100 \mathrm{mw}(\mathrm{e}) \mathrm{MCBR}$ power plant. 


\title{
MERCURY COOLED BREEDER REACTOR
}

\author{
TABLE V \\ Unit Power Costs \\ $100 \mathrm{mw}(\mathrm{e}) \mathrm{MCBR}$ Power Plant \\ (1959 basis)
}

Fixed charges at $14 \%$ of capital cost

Fuel cost ( $\mathrm{Pu}$ at $\$ 12 / \mathrm{gm})$

Operating and maintenance cost

Total Unit Power Cost

$$
\begin{array}{r}
6.6 \mathrm{mils} / \mathrm{kwh} \\
13.3 \mathrm{mils} / \mathrm{kwh} \\
1.5 \mathrm{mils} / \mathrm{kwh} \\
\hline 21.4 \mathrm{mils} / \mathrm{kwh}
\end{array}
$$

\section{A. CAPITAL COSTS AND FIXED CHARGES}

A summary of the estimated MCBR capital costs are presented in Table VI. The total capital cost, including interest during construction but excluding all research and development costs, is $\$ 32,815,000$. This estimate may be compared with $\$ 54,600,000$, which is the reported capital cost of the Enrico Fermi plant. ${ }^{3}$

Tables VII and VIII show brief summaries of the totals indicated in Table VI for the appropriate Federal Power Commission accounts. A detailed breakdown of the entire capital cost estimate is given in Appendix $\mathrm{H}$.

The capital cost of the MCBR appears to be significantly less than that of the Enrico Fermi reactor, for several reasons.

1) The MCBR system is simple compared to the Enrico Fermi reactor, largely because little hazard results from a leak or spill of the mercury coolant in contrast to the large hazard produced by the reactive character of hot sodium in contact with air or water.

2) The shielding required for the reactor, and more importantly for the activated mercury that is circulated externally, is reduced over that required for sodium because of the low energy of the decay gamma photons.

3) The containment requirements are less severe because more free volume is available within the containment vessel of similar size and because the total energy released in a maximum credible accident is less as a result of the chemical inertness of the mercury coolant.

It is difficult to compare these features quantitatively, because a detailed breakdown of the Enrico Fermi capital costs was not available. 
TABLE VI

ESTIMATED CAPITAL COST SUMMARY

100-MW(E) MERCURY COOLED BREEDER RE ACTOR

Acct.

No. Item

310 Land and land rights

$\$ 186,000$

311 Reactor plant structures and improvements

$\$: 4,772,000$

312 Reactor plant equipment

$12,463,000$

Subtotal - Reactor Portion. of Plant

$\$ 17,235,000$

$314-$

316

Turbine-Generator portion of plant excluding substation

$\$ 12,700,000$

Total - Power Plant With Land

$\$ 30,121,000$

Interest During Construction

$2,694,000$

TOTAL CAPITAL COST

$\$ 32,815,000$ 


\section{MERCURY COOLED BREEDER REACTOR}

TABLE VII

CAPITAL COST BREAKDOWN - ACCOUNT 311 100-MW(E) MCBR POWER PLANT

Structures and Improvements

Material

Labor

Total

(Reactor Plant Items Only)

Containment structure:

Containment vessel

Structural steel

Structural concrete

Foundations

Facilities and other

Other buildings

Yard services and facilities

Direct Field Cost

Field Prorates

Total Field Cost

$\$ 624,000$

61,000

438,000

114,000

70,000

42,100

52,000

$1,401,100$

70,200

$\$ 1,471,300$

Contractor's Fee

Engineering, Purchasing, Inspection, and Hazard Survey

Total Cost Without Contingency

Contingency at $20 \%$

$$
\begin{array}{rrr}
\$ 27,000 & \$ 651,000 \\
24,500 & 85,500 \\
407,000 & & 845,000 \\
230,500 & & 344,500 \\
91,000 & & 161,000 \\
37,900 & 80,000 \\
\quad 54,000 & & 106,000 \\
\hline 871,900 & 2,273,000 \\
697,500 & \\
\hline \$ 1,569,400 & & 3,040,707,700 \\
\hline
\end{array}
$$

219,000

717,100

$3,976,800$

795,200

$\$ 4,772,000$ 


\section{MERCURY COOLED BREEDER REACTOR}

TABLE VIII

CAPITAL COST BREAKDOWN - ACCOUNT 312 100-MW(E) MCBR POWER PLANT
Reactor Plant Equipment

Reactor vessel and auxiliaries

Other vessels

Condensers, coolers, and heaters

Pumps and drivers

Machinery

Instrumentation

Piping - Mercury system

- Water system

- Steam system

Subtotal ,

Other Direct Costs

Insulation

Miscellaneous structural

Electrical

Painting

Sewers and services

Direct Field Cost

Field Prorates

Total Field Cost

Contractor's Fee

Plant Startup

Mercury at $\$ 225 / 76-1 b$ Flask

Engineering, Purchasing, Inspection, and Hazard Survey

Total Cost Without Contingency

Contingency at $20 \%$

TOTAL COST - Account 312

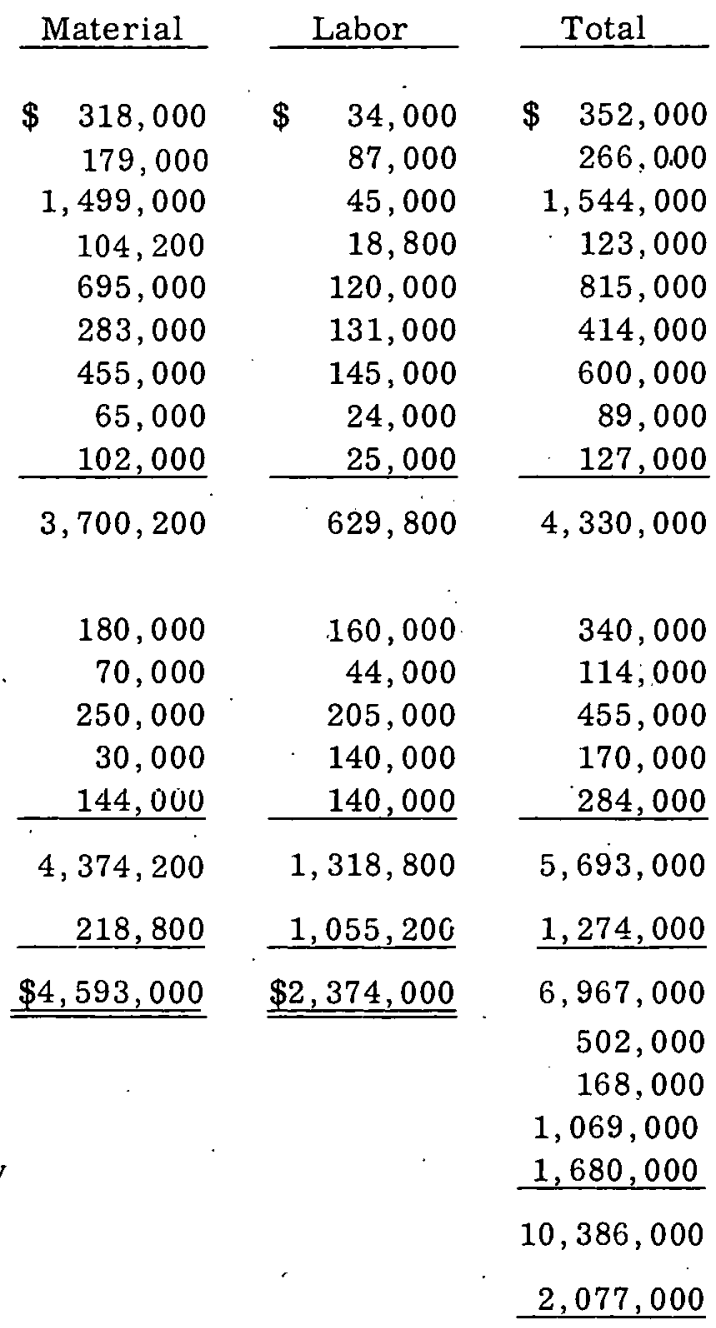

$\$ 12,463,000$ 


\section{MERCURY COOLED: BREEDER REACTOR}

Annual fixed charges are determined as a fraction of the total capital cost, as indicated in Table IX.

\section{TABLE LX ${ }^{*}$ \\ Annual Fixed Charge Rates \\ $100 \mathrm{mw}(\mathrm{e}) \mathrm{MCBR}$ Power Plant}

Over-all return on investment

Bond interest (3.5\% on $50 \%$ of capital)

$1.75 \%$

Preferred stock dividend (5.0\% on $15 \%$ of capital)

0.75

Common stock dividend (10\% on $35 \%$ of capital)

$\underline{3.50}$

Federal income tax (52/48 of return on stock)

$6.00 \%$

Other taxes (real estate, etc.)

4.60

Insurance (other than 3rd party liability)

2.00

Depreciation (sinking fund, 30 years at $6 \%$ )

0.10

Total Fixed Charges

1.30

$\underline{\underline{14.00 \%}}$

Although some variations from this estimate may be found in practice throughout the country, the percentages presented are believed to be typical of current utility company practice for reactor power plants. In addition, since these values were suggested as a ground rule for previous AEC-sponsored reactor cost evaluations, continued usage will tend to maintain cost comparisons on a consistent basis.

\section{B. FUEL COST ESTIMATE}

A summary of the fuel costs required for operation of a $100 \mathrm{mw}(\mathrm{e}) \mathrm{MCBR}$ power plant at an assumed load factor of $80 \%$ is presented in Table $\mathrm{X}$. The Table shows the effect on net annual and unit fuel cost of plutonium credit at $\$ 12$ per gram and $\$ 30$ per gram. It will be noted that the plutonium revenue received from the upper and lower blankets, less than $10 \%$ of total plutonium credit, is insufficient to approach economic justification of the use of those portions of the blanket. The high cost is partially due to the relatively short exposure the blanket receives because the cycle time is governed by the fuel in the core. The blankets are mechanically attached to the fuel in each element (see Dwg. F-183 in following section); consequently, they must be removed and reprocessed on the same schedule as the fuel.

* From Reference 4. 


\section{TABLE $X$}

Fuel-Cost Summary

100-mw(e) MCBR Power Plant

$\underline{\text { Core }}$

Blanket

\begin{tabular}{lcccc} 
& $\underline{\text { Core }}$ & \multicolumn{3}{c}{ Blanket } \\
\cline { 4 - 5 } & & $\underline{\text { Radial }}$ & $\underline{\text { Upper }}$ & $\underline{\text { Lower }}$ \\
Length of cycle (years) & $\$ 10,097,000$ & $\$ 9,002,000$ & $\$ 363,000$ & $\$ 592,000$ \\
Annual Fuel Costs & 1.17 & 12.3 & 1.17 & 1.17. \\
& $\$ 8,615,000$ & $\$ 732,000$ & $\$ 309,000$ & $\$ 505,000$
\end{tabular}

Total Annual Fuel Cost

$\$ 10,161,000$

Annual plutonium credit

$\underline{\mathrm{Pu} \text { at } \$ 12 / \mathrm{gm}}$

Pu at $\$ 30 / \mathrm{gm}$

$\$ 814,000$

$\$ 2,208,000$

Net Annual Fuel Cost

$\$ 9,347,000$

$\$ 7,953,000$

Unit Fuel Cost

$13.3 \mathrm{mils} / \mathrm{kwh}$

$11.3 \mathrm{mils} / \mathrm{kwh}$

Table XI shows a detailed estimate of the unit costs of the various portions of the fuel and blanket fabrication and reprocessing schedule. These unit costs are based on general price quotations for materials, labor estimates, and AEC-published prices for uranium and reprocessing changes.

TABLE XI

Fuel-Cycle Cost Estimate $\underline{100-m w(e) ~ M C B R ~ P o w e r ~ P l a n t ~}$

Unit Fuel and Blanket Element Costs $(\$ / \mathrm{kg}$ U)

\section{$\underline{\text { Core }}$}

Conversion

Fabrication

Reprocessing

Conversion

Shipping

Losses

Burnup

Inventory

Working capital
$\$ 208.54$

$\$ \frac{65.50}{\$ 274.04}$

93.60

32.00

5.00

86.68

$\$ 217.28$

231.00

427.33

6.91

$\$ 1,156.56$
Blanket

Radial Upper L Lower

$\$ 17.30$

24.15

$\$ 41.45$

$\$ 17.30$

$\$ 17.30$

$\frac{77.10}{94.40} \quad 40.36$

16.50

5.60

30.00

$\$ 57.66$

5.00

5.60

30.00

5.00

5.60

$\frac{-}{\$ 27.10}$

$\frac{-}{\$ 40.60}$

$\frac{-}{\$ 40.60}$

3.28

.49

.49

$\frac{26.70}{\$ 97.53}$

$\frac{8.14}{\$ 143.63}$

4.26 


\section{MERCURY COOLED BREEDER REACTOR}

The costs associated.with fabrication of the core and blanket assemblies required for the initial reactor startup are estimated as shown in Table XII.

\section{Table XII}

Core and Blanket Assembly Fabrication Costs 100-mw(e) MCBR Power Plant

Core:

Conversion and fabrication

Use charges during fabrication (6 mo.)

Total Core

Blanket:

Radial

Upper axial

Lower axial

Use charges during fabrication (6 mo.)

Total Blanket
$\$ 2,392,000$

757,000

$\$ 3,149,000$
$\$ 3,830,000$

238,000

332,000

10,000

$\$ 4,410,000$

Total

$\$ 7,559,000$

The first core cost, as well as the costs of additional replacement cores, is reflected in the fuel-cost estimate; the first core cost does not appear as a capital cost item.

\section{ANNUAL OPERATING AND MAINTENANCE COSTS}

The annual operating and maintenance costs are shown in Table XIII. Included are salaries, wages, benefits, and payroll taxes for plant operating personnel; nuclear idemnity insurance; mercury and additives consumed in plant operation; and an over-all allowance for maintenance and supplies.

\section{TABLE XIII}

Annual Operating and Maintenance Costs 100-mw(e) MCBR Power Plant

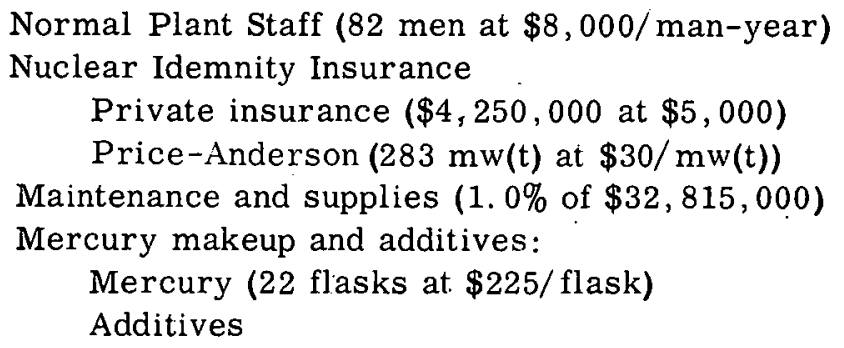

$$
\begin{array}{r}
\$ / \text { Year } \\
\hline \$ 656,000 \\
21,200 \\
8,500 \\
328,200 \\
\\
5,000 \\
300 \\
\hline
\end{array}
$$




\section{MERCURY COOLED BREEDER REACTOR}

It is estimated that a normal plant staff of 82 is required to operate the plant and perform daily maintenance. The personnel needed for major maintenance is included in the maintenance and supplies item, which was estimated at $1.0 \%$ of the total capital costs. A breakdown of the planned staff is shown in Table XIV. The staffing requirements are estimated for a plant operated on a steady routine basis; additional personnel are required for startup and initial operation.

\section{TABLE XIV}

Estimated Staff Requirements $100-\mathrm{mw}(\mathrm{e})$ MCBR Power Plant

$\underline{\text { Per Shift } \quad \text { Total }}$

Supervisory Personnel

Station Superintendent Assistant Superintendent Maintenance Supervisor Health Physics Supervisor Security Officer

Subtotal

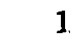

1

1

1

1

Operating Personnel

Shift Supervisor

Senior Operator

Reactor Operator

Assistant Operator

Plant Attendants

Chemists

Health Physicists

Subtotal

Maintenance Personnel

Maintenance Foremen

Mechanics and Electricians

Instrument Technicians

Subtotal

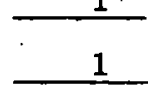

Miscellaneous Service Personnel

Technical Engineers

Secretaries and Clerks

Security Guards

Janitors

Subtotal

4

4

4

5

13

5

4

39

.

Total Employees

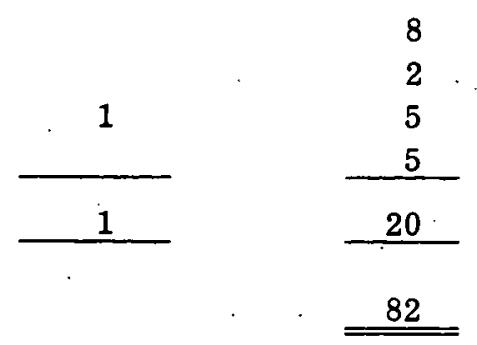




\section{MERCURY COOLED BREEDER REACTOR}

An allowance has been made for nuclear indemnity insurance. The conventional liability insurance is included in fixed charges. Title 10, Code of Federal Regulations, Part 140, requires private nuclear insurance coverage for each reactor in the amount of $\$ 150,000$ per megawatt of thermal power. The Price-Anderson indemnity legislation provides additional liability insurance at an annual premium of $\$ 30$ per thermal megawatt.

\section{COMPARISONS WITH OTHER REACTORS}

The total unit power cost of 21.4 mils per kilowatt-hour (electrical), see Table $V$, may be compared with power costs of other reactors which represent the first large-scale power versions of each reactor type, Table XV.

\section{TABLE XV}

Comparison of Power Costs

Large United States Nuclear Power Stations

\begin{tabular}{|c|c|c|c|c|c|}
\hline Station & Dresden & Yankee & Hallam & Enrico Fermi & MCBR \\
\hline Reactor Type & $\begin{array}{l}\text { Boiling- } \\
\text { Water }\end{array}$ & $\begin{array}{l}\text { Pressurized- } \\
\text { Water* }\end{array}$ & $\begin{array}{l}\text { Sodium } \\
\text { Graphite }\end{array}$ & $\begin{array}{l}\text { Sodium-Cooled } \\
\text { Fast-Breeder }\end{array}$ & $\begin{array}{l}\text { Mercúry-Cooled } \\
\text { Fast-Breeder }\end{array}$ \\
\hline Net Power, mw(e) & 180 & 110 & 75 & 100 & 100 \\
\hline Net Station Efficiency (\%) & 28.7 & 28 & 31.2 & 31.3 & 33.4 \\
\hline Plant Costs (\$/kw) & $400^{\dagger}$ & 470 & 670 & 570 & 328 \\
\hline \multicolumn{6}{|l|}{ Power Cost (mils/kwh) } \\
\hline Capital Charges & 8.0 & 9.4 & 13.3 & 11.3 & 6.6 \\
\hline Fuel Costs & 4.4 & 6.4 & 3.8 & 12.0 & 13.3 \\
\hline Operating \& Maintenance & 2.1 & 2.1 & 1.0 & 2.0 & 1.5 \\
\hline Total & 14.5 & 17.9 & 18.1 & 25.3 & 21.4 \\
\hline
\end{tabular}

* The Shippingport reactor was the first large pressurized-water power reactor installed in the United States, but power costs were so high $(64.4 \mathrm{mils} / \mathrm{kwh})$ that the Yankee reactor at Rowe, Vermont, affords a more realistic cost comparison.

$\dagger$ Estimated.

$\ddagger$ Power costs were calculated from information published in references 5 through 10 .

The estimated total power costs for the two fast breeder reactors are somewhat higher than for most of the thermal reactors at approximately the same stage of development. This is at least partly explained by the relatively lower state of development of fast breeder reactors in general and therefore reflects the uncertainty and conservation in plant design and fuel-cost evaluation. The 
potential for reducing the cost by several mils per kilowatt-hour, as well as the long range attraction of breeding, justifies the apparent higher cost for fast breeders. The difference between the cost of power produced by the sodium-cooled system and by the MCBR is associated with the reduced capital requirement for the $\mathrm{MCBR}$.

The MCBR fuel cost of 13.3 mils per kilowatt-hour may be compared with 12 mils per kilowatthour for the Enrico Fermi Reactor. ${ }^{6}$ The slightly higher MCBR fuel cost is produced by larger use charges on the substantially larger uranium inventory. A higher use charge rate which might be applied in the future will accentuate the difference, while a reduced evaluation of the contained uranium will reduce both the inventory cost and the difference between the fuel costs of the two reactor systems.

In summary, the net cost of producing power from an indirect-cycle, boiling-mercury-cooled breeder reactor is comparable to the net cost of producing power from a sodium-cooled fast breeder. The fuel cost is greater because the average power density in the mercury-cooled system is lower; consequently, the mass of required uranium is greater than in a sodium-cooled system. Although the higher MCBR uranium inventory cost is partially offset by reduced fabrication costs, the net effect on over-all fuel-cycle cost is a $20 \%$ increase. Capital costs for the MCBR are much less than for an equivalent sodium-cooled system, which results in an over-all MCBR power cost of approximately $85 \%$ of the total estimated power cost for the first sodium-cooled fast power breeder reactor. 


\section{MERCURY COOLED BREEDER REACTOR}

\section{CONCEPTUAL MCBR POWER PLANT DESIGN}

The primary purpose of the conceptual design of the 100 electrical megawatt MCBR power plant is to provide a basis for estimation of capital, fuel-cycle, and operating and maintenance costs, thereby permitting a realistic appraisal of the economic potential of the boiling-mercury-cooled breeder reactor.

A conceptual design study of the reactor and reactor systems was made, but only a broad investigation of the more conventional power-generation facilities was included. The plant has been designed to use an indirect mercury cycle, with mercury vapor condensing to generate the steam fed to a steam-driven turbine. No provision has been made for a direct mercury cycle in which mercury vapor is delivered directly to a mercury turbine, the turbine being followed by a condenserboiler that produces steam for a conventional steam-turbine plant. The plant is designed to produce $100 \mathrm{mw}(\mathrm{e})$, and flexibility to permit a major expansion of plant capacity has not been provided.

Design of the reactor and reactor plant systems and equipment has been predicated on the following over-all design considerations:

1) Available fast breeder reactor and mercury technology is used where possible.

2) A cylindrical-core geometry and conventional fuel elements are employed to permit utilization of available fuel fabrication, handling, shipping, and reprocessing techniques and control rod technology.

3) Selection of core and blanket design parameters is based on the results of the heat transfer, physics, and metallurgical evaluations and the optimization studies presented earlier.

4) All element cladding and structural equipment, and piping materials in contact with mercury are $5 \mathrm{w} / \mathrm{o} \mathrm{Cr}, \frac{1}{2} \mathrm{w} / \mathrm{o}$ Mo steel.

5) Mercury will be inhibited with magnesium and titanium and continuously routed through a cleanup system to remove oxide sludge.

6) Reactor operating temperature is the maximum permitted by cladding and uranium alloy material limitations so as to maximize plant thermal efficiency.

7) Once-through type vertical condenser-boilers are utilized to facilitate control, particularly at low power levels. Double-wall tubes with a mercury thermal bond are employed to prevent water from entering the core in the event of a tube leak.

8). Forced recirculation of the primary mercury coolant is required to insure a constant mercury vapor quality in the core. 
9) Emphasis is placed on minimizing mercury holdup in the system because of the high cost of mercury.

10) All equipment normally containing radioactive mercury is located within the reactor containment vessel. Individual pieces of equipment are located in shielded compartments to permit access for maintenance during operation of the plant.

\section{A. NUCLEAR CHARACTERISTICS OF REFERENCE CORE}

1. Reactor Statics

The reference design system was evaluated by the techniques described in Appendix E. For ease of calculation and analysis, a spherical geometry was used and the equivalent cylindrical core was related to the spherical geometry by equating geometric bucklings. An equivalent blanket was evaluated by weighting the various contributions to account for the relative importance of the upper axial, lower axial, and radial blankets, based on the performance of the reactor. The specifications are given in Table XVI.

\section{TABLE XVI}

\section{Summary of Core and Blanket Specifications}

\begin{tabular}{|c|c|c|c|c|}
\hline & \multirow{2}{*}{ Core } & \multicolumn{3}{|c|}{ Blanket } \\
\hline . & & $\underline{\text { Radial }}$ & $\begin{array}{l}\text { Lower } \\
\text { Axial } \\
\end{array}$ & $\begin{array}{l}\text { Upper } \\
\text { Axial } \\
\end{array}$ \\
\hline Element $O D$ (in.) & 0.18 & 0.424 & 0.424 & 0.424 \\
\hline Element pitch/diameter ratio & 1.68 & 1.03 & 1.31 & 1.81 \\
\hline Equivalent circle diam. $(\mathrm{cm})$ & 156 & 256 & 156 & 156 \\
\hline Blanket thickness $(\mathrm{cm})$ & - & 50 & - & - \\
\hline Length $(\mathrm{cm})$ & 141.5 & 241.5 & 50 & 50 \\
\hline No. of elements per assy. & 127 & 61 & 37 & 19 \\
\hline No. of assemblies & 271 & 462 & 271 & 271 \\
\hline Mass of uranium $(\mathrm{kg})$ & 8,730 & 92,300 & 5,750 & 2,520 \\
\hline Coolant volume $(\%)$ & 62.3 & 16.2 & 47.1 & 71.7 \\
\hline Structure-fuel alloy vol. ratio (\%) & 69.5 & 24.8 & 58.0 & 86.8 \\
\hline Avg. mercury density $\left(\mathrm{gm} / \mathrm{cm}^{3}\right)$ & 0.5 & 0.5 & 12.3 & 0.2 \\
\hline
\end{tabular}

(flux weighted) 


\section{MERCURY COOLED BREEDER REACTOR}

The diffusion theory analysis yielded the basic nuclear characteristics of the system. It was determined that a critical mass of 2314 kilograms of uranium-235 at an enrichment of $26.5 \%$ is required. The associated core volume is 2642 liters.

The neutron flux for each of the eleven energy groups as a function of distance from the center of the equivalent spherical core is shown in Figure 24. Radial and axial power densities in the core are given in Figures 25 and 26; power density distribution in the blanket is given in Figure 27.

The results of the detailed neutron balance evaluation are shown in Table XVII, while Table XVIII shows the over-all neutron balance for the core and blanket combined. Note that the parasitic capture of neutrons in the molybdenum, iron, and mercury are approximately equal and relatively small.

A second result of prime interest in this analysis is the determination of the breeding ratio. As described in Appendix E, two values are given: BRII, a theoretical maximum based on the assumption that there is no loss of neutrons from the system; and BRI, a slightly lower value which accounts for leakage out of the blanket and also the loss of neutrons by scattering into the energy region below the lower boundary of the eleventh group. Since neutrons suffering this energy degradation into the lower energy regions can be assumed to be captured by $U 238$ in the high-resonance region, $B R I$ may be regarded as an underestimate of the actual breeding ratio, while BRII is an overestimate. BRI and BRII thus represent limits which bracket the actual breeding ratio. Since the neutron balance analysis of the design case yielded $\mathrm{BRI}=1.1612$ and $\mathrm{BRII}=1.2268$, the actual breeding ratio of the reference MCBR design may be reported as $1.19 \pm 0.04$.

In Figure 28, the total integrated flux for each of the eleven energy groups in core and blanket is shown as a function of lethargy. The plots of flux and integrated flux demonstrate that the spectrum in the core is peaked in group 5 and yields a mean fission energy between 0.3 and $0.5 \mathrm{Mev}$. In the blanket, the peak of spectrum has shifted down to group 8 as the neutrons slow down in energy in the blanket, and the mean neutron energy is found to be between 0.008 and $0.017 \mathrm{Mev}$.

The average flux in the core was found to be $8.9 \times 10^{14}$ neutrons per $\mathrm{cm}^{2}-\mathrm{sec}$. From an analysis of the flux distribution, the average cross sections for the core and blanket were evaluated and are as given in Table XIX. 


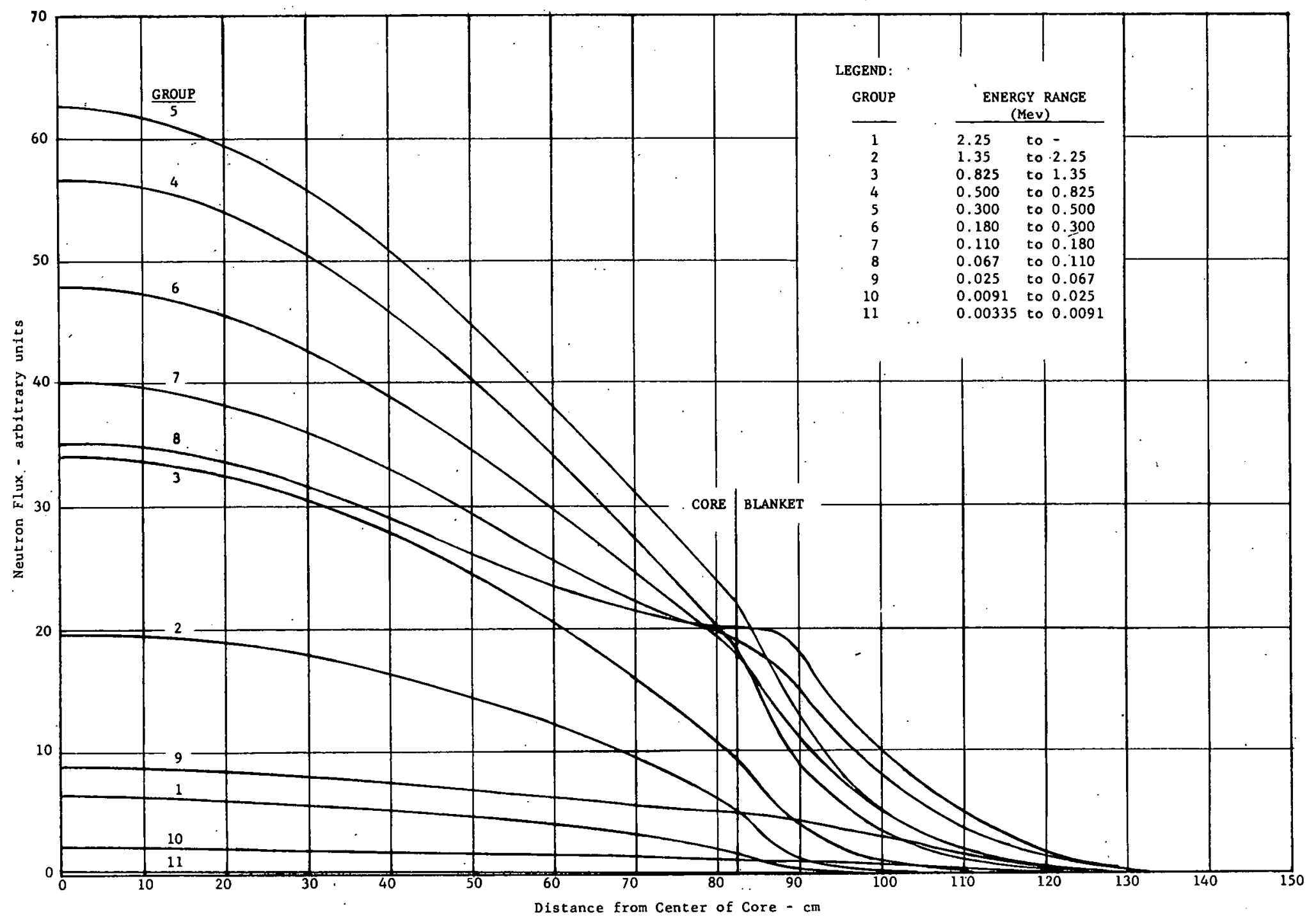

MCBR NEUTRON FLUX DISTRIBUTION

FIGURE 24 


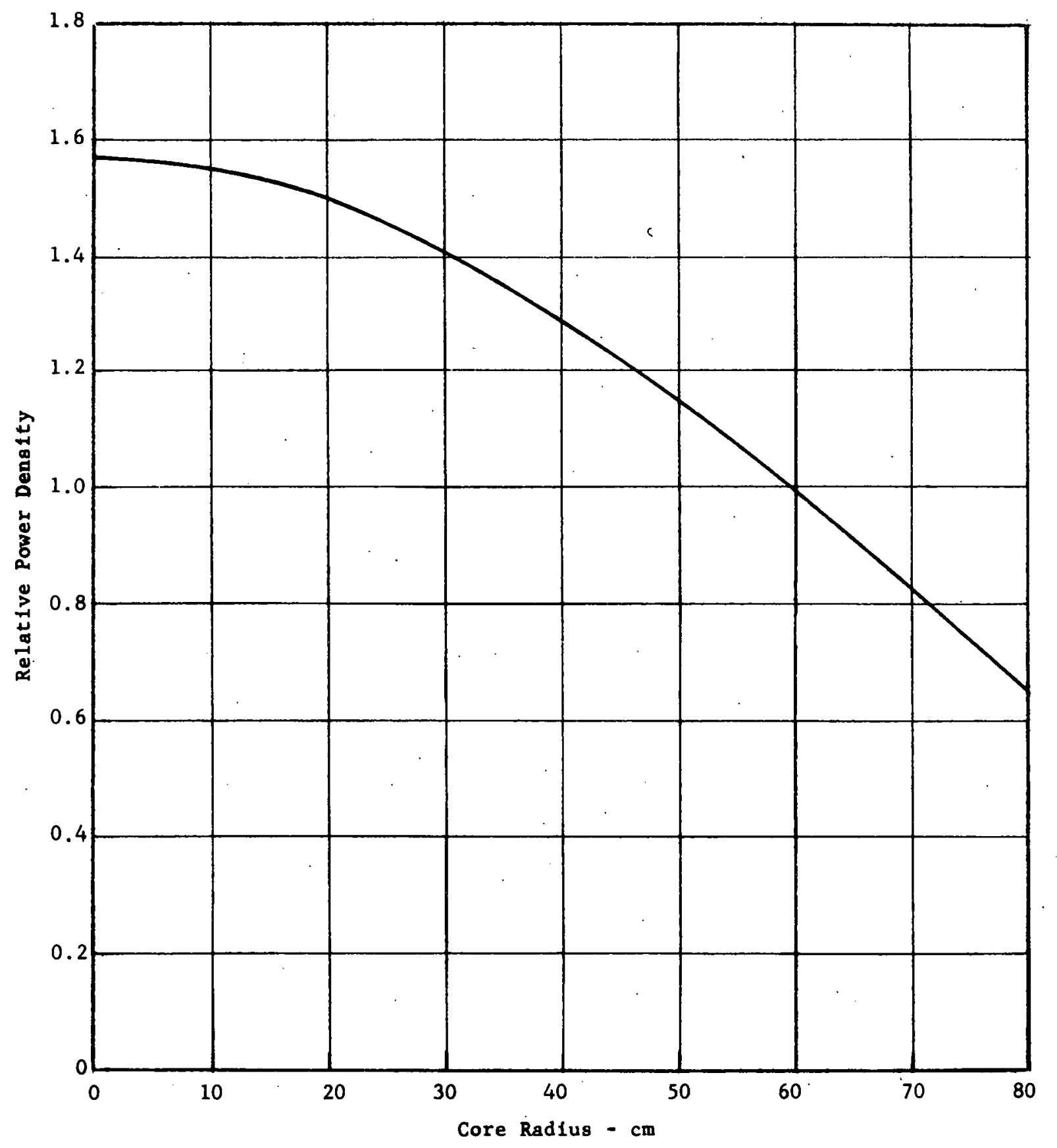

RADIAL POWER DENSITY DISTRIBUTION IN CORE

FIGURE 25 


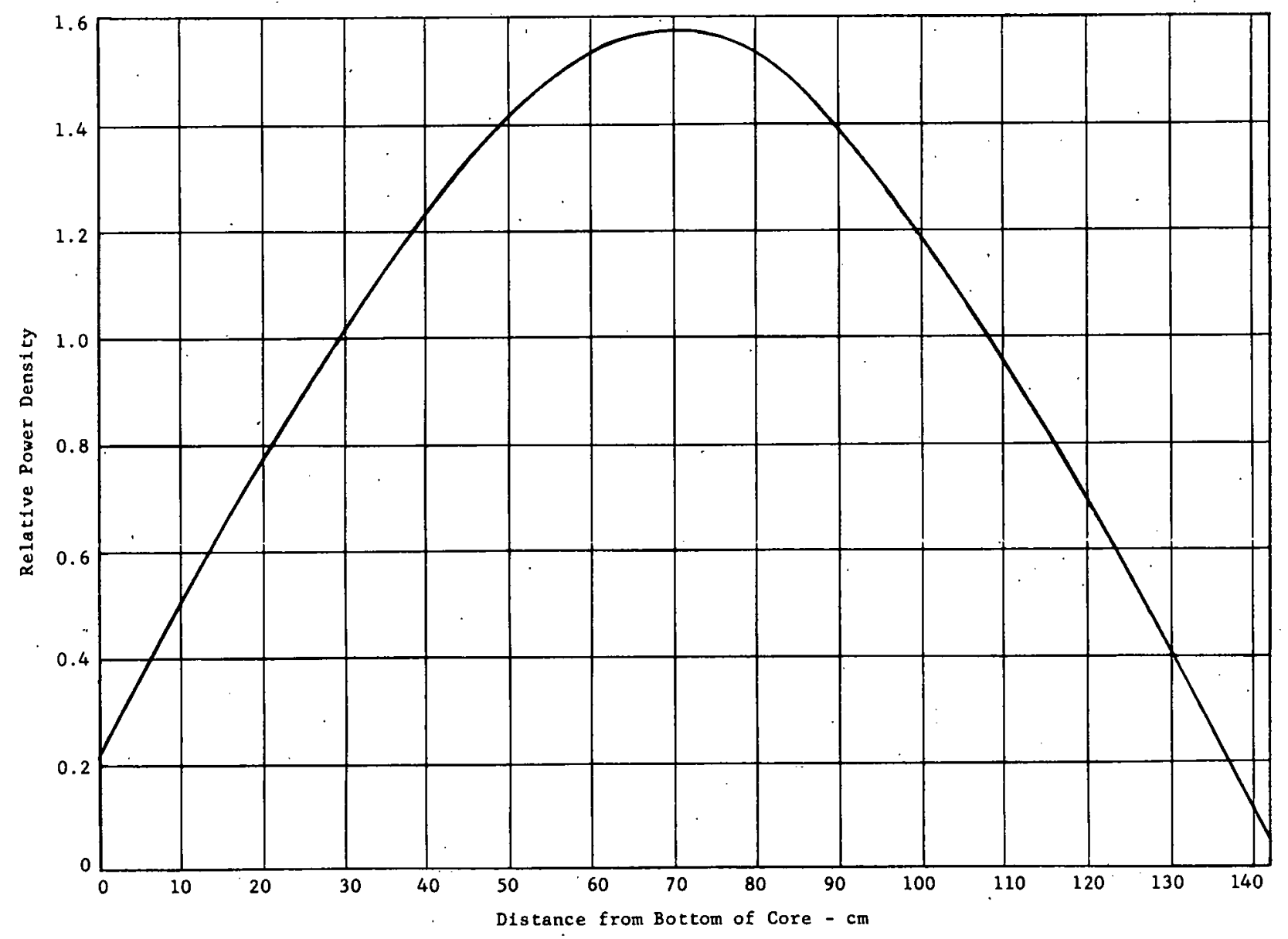

AXIAL POWER DENSITY DISTRIBUTION IN CORE

FIGURE 26 


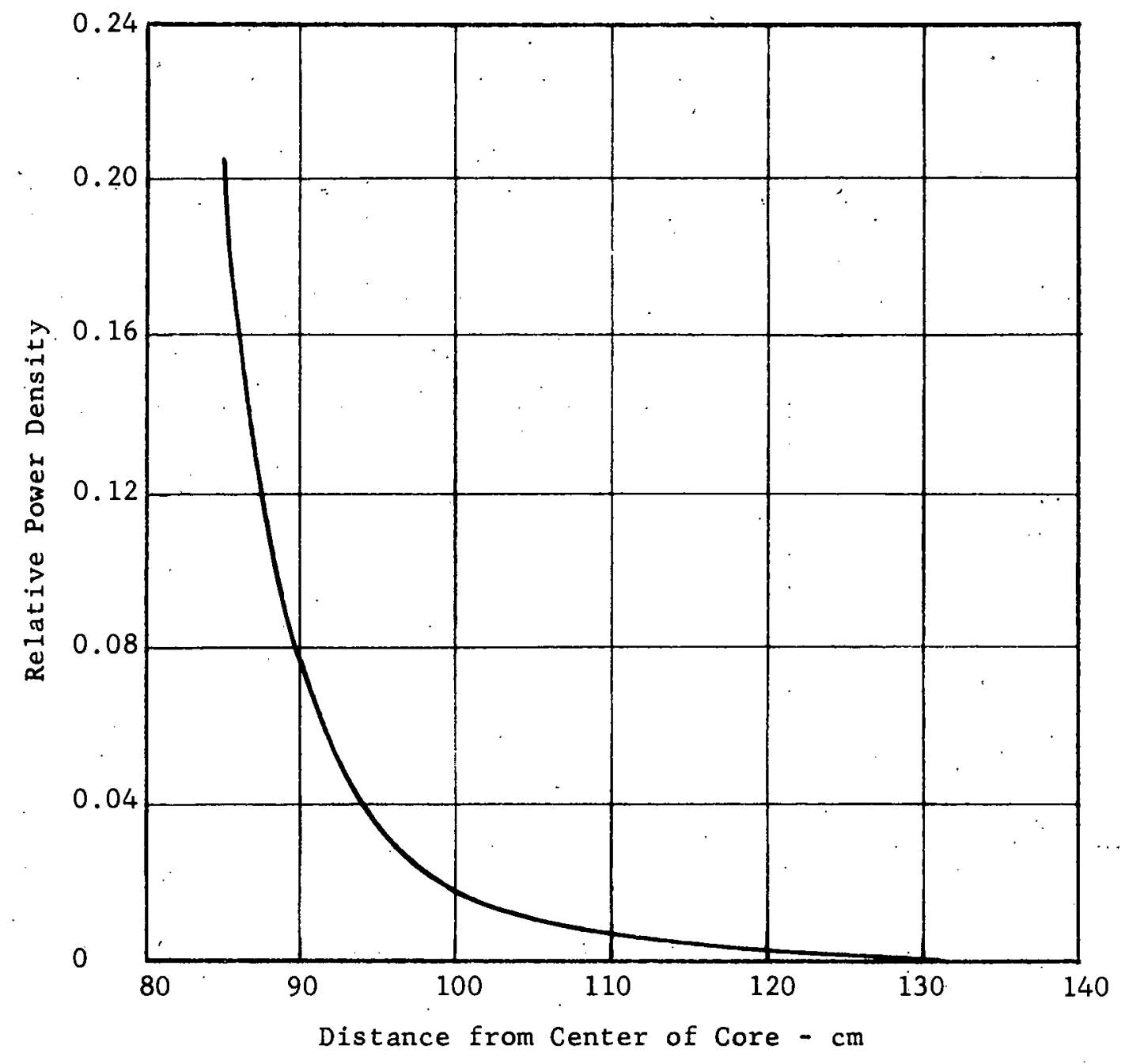

POWER DENSITY DISTRIBUTION IN BLANKETT

FIGURE 27 


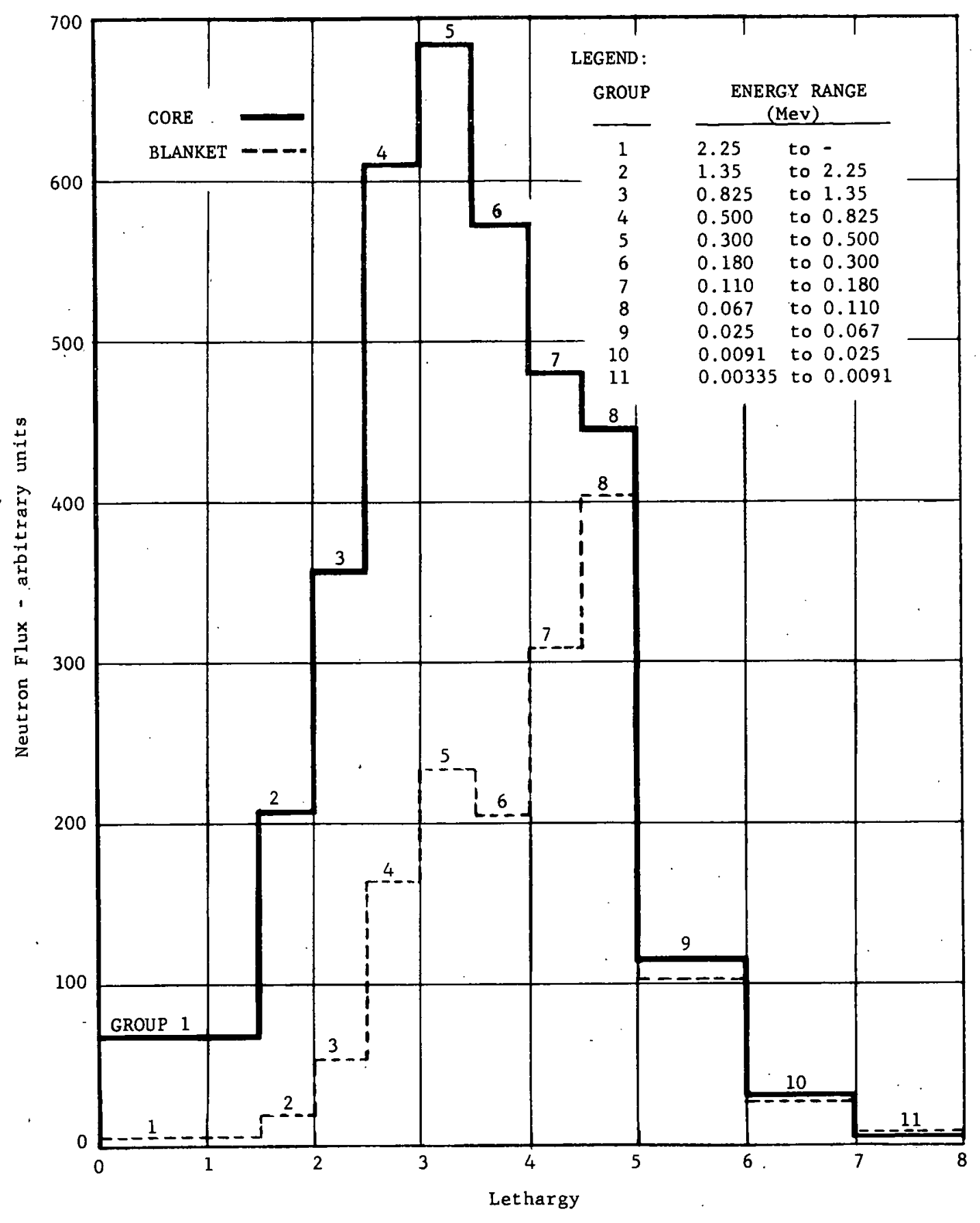

INTEGRATED FLUX SPECTRUM

FIGURE 28 
TABLE XVII

NEUTRON BALANCE

100-MW(E) MCBR

\begin{tabular}{|c|c|c|c|}
\hline & Core & & Blanket \\
\hline$N_{f}(235)$ & 0.3374 & & 0.007859 \\
\hline $\mathrm{N}_{\mathrm{c}}(235)$ & 0.06149 & & 0.001781 \\
\hline$N_{f}(238)$ & 0.03624 & & 0.01389 \\
\hline $\mathrm{N}_{\mathrm{c}}(238)$ & 0.1328 & & 0.3416 \\
\hline $\mathrm{N}_{\mathrm{c}}(\mathrm{Mo})$ & 0.01079 & & \\
\hline $\mathrm{N}_{\mathrm{c}}(\mathrm{Fe})$ & 0.009939 & & 0.005866 \\
\hline $\mathrm{N}_{\mathrm{c}}(\mathrm{Hg})$ & 0.008173 & & 0.005310 \\
\hline$\nu \mathrm{N}_{\mathrm{f}}(235)$ & 0.8500 & & $0: 01956$ \\
\hline$\nu \mathrm{N}_{\mathrm{f}}(238)$ & 0.09444 & & 0.03612 \\
\hline${ }^{\alpha} 235$ & & 0.1832 & \\
\hline${ }^{\alpha}$ Mo & & 0.03125 & \\
\hline${ }^{\alpha} \mathrm{Fe}$ & & 0.04577 & \\
\hline${ }_{-}^{\alpha} \mathrm{Hg}$ & & 0.03905 & \\
\hline$\nu(235)$ & & 2.5180 & \\
\hline$\nu(238)$ & & 2.6043 & \\
\hline$\Delta \nu^{\prime}$ & & 0.2329 & \\
\hline BRII & & 1. 2268 & . \\
\hline k & & 1.0000 & . \\
\hline $\mathrm{L}_{\mathrm{nc}}$ & & 0.3466 & \\
\hline BRI & & 1. 1612 & \\
\hline
\end{tabular}


TABLE XVIII

DISPOSITION OF A FISSION NEUTRON

100-MW(E) MC BR

$\begin{array}{ll}\text { U } 235 \text { fission } & 0.3453 \\ \text { U.235 capture } & 0.0653 \\ \text { U } 238 \text { fission } & 0.0501 \\ \text { U } 238 \text { capture } & 0.4744 \\ \text { Molybdenum capture } & 0.0108 \\ \text { Iron capture } & 0.0158 \\ \text { Mercury capture } & 0.0135 \\ \text { Blanket leakage } & 0.0132 \\ \text { Low energy degradation } & 0.0116 \\ \quad \text { Total } & 1.0000 \text { fission neutron }\end{array}$

TABLE XIX

AVERAGE CROSS SECTIONS (barns)

Cross Section

$$
\begin{aligned}
& \sigma_{\mathrm{c}}(235) \\
& \sigma_{\mathrm{f}}(235) \\
& \sigma_{\mathrm{c}}(238) \\
& \sigma_{\mathrm{f}}(238) \\
& \sigma_{\mathrm{c}}(239) \\
& \sigma_{\mathrm{f}}(239)
\end{aligned}
$$

Core

0.2733

1.5004

0.1784

0.05661

0.2909

1.7680
Blanket

0.3897

1.7195

0.2387

0.0109

0.4297

1. 8082 


\section{MERCURY COOLED BREEDER REACTOR}

\section{Temperature Effects}

Evaluation of the effects on reactivity of the temperature-dependent parameters is necessary to determine the stability of the reactor under operating conditions and to aid in establishing control criteria: By applying the usual technique of change in size and material density with temperature, the temperature coefficient of reactivity due to core expansion was found to be $-13.55 \times 10^{-6} \Delta \mathrm{k} / \mathrm{k}\left({ }^{\circ} \mathrm{C}\right)$. The Doppler coefficient was estimated to be $-3.0 \times 10^{-6} \Delta \mathrm{k} / \mathrm{k}\left({ }^{\circ} \mathrm{C}\right)$, the total blanket-temperature coefficient of reactivity was estimated to be $-1.2 \times 10^{-6} \Delta \mathrm{k} / \mathrm{k}\left({ }^{\circ} \mathrm{C}\right)$, and the effect of mercury density on reactivity was found to be approximately $-0.015 \Delta \mathrm{k} / \mathrm{k} \mathrm{gm} / \mathrm{cm}^{3}$.

\section{Fuel Burnup}

In the course of reactor operation, fuel content decreases as a function of flux and time. A. code to determine fuel burnup via changes in concentration of $\mathrm{U} 235, \mathrm{U} 238$, and $\mathrm{Pu} 239$ as a function of $\phi t$ (the integrated flux) was used. To obtain an average burnup of 10,000 megawatt-days per metric ton, the average core lifetime of the reactor fuel was evaluated to be 443 days and the integrated flux for this operational time was found to be $0.30 \times 10^{23}$ neutrons $/ \mathrm{cm}^{2}$. This burnup code was used to evaluate the changes in concentration and from this the change in $U 235$ content, as shown in Figure 29.

In Figure 30, the buildup of $\mathrm{Pu} 239$ in the core during the lifetime of the system is shown. An end-of-life calculation that takes into account the plutonium present in core and blanket was carried out. This calculation yielded a drop in multiplication of approximately $1 \%$, which appears small but may be reasonable in view of the higher cross section and neutrons per fission of plutonium compared to uranium. The cross sections of plutonium-239 used in the calculation are shown in Table E-IV.

A summary of the reactor physics parameters of the Mercury-Cooled Breeder Reactor is shown in Table XXIII.

\section{Mercury Activation}

The activation of mercury in a fast neutron spectrum cannot be calculated with confidence because of the unavailability of cross section data for the production of radioactive isotopes. However, an estimate of the expected activity has been made.

The reactions considered were of four types: $(n, \gamma) ;(n, p) ;(n, \alpha)$; and $(n, 2 n)$. The nine reactions considered to be significant are listed in Table $\mathbf{X X}$. 


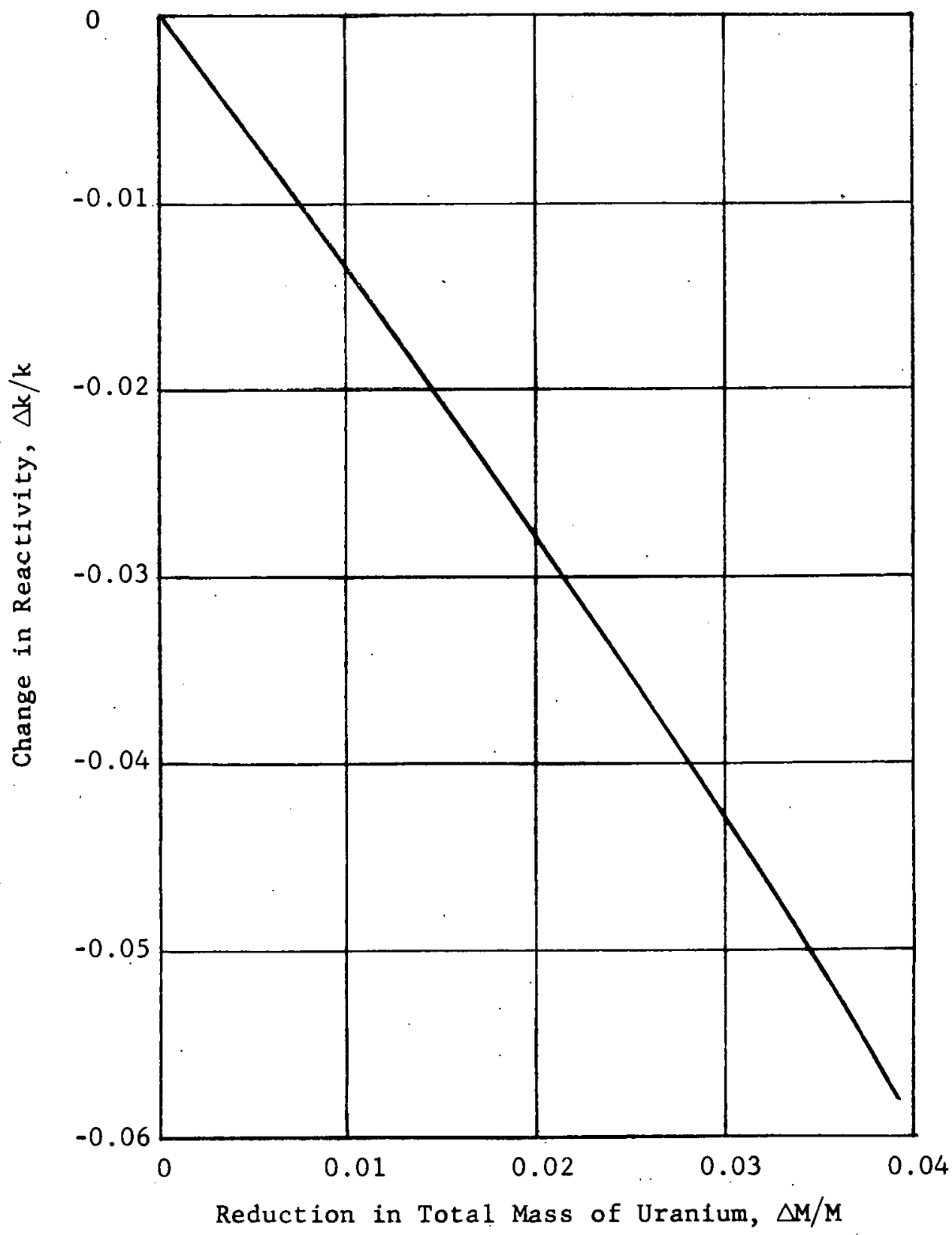

REACTIVITY CHANGE FOR FRACTIONAL CHANGES

IN TOTAL MASS OF URANIUM

FIGURE 29 


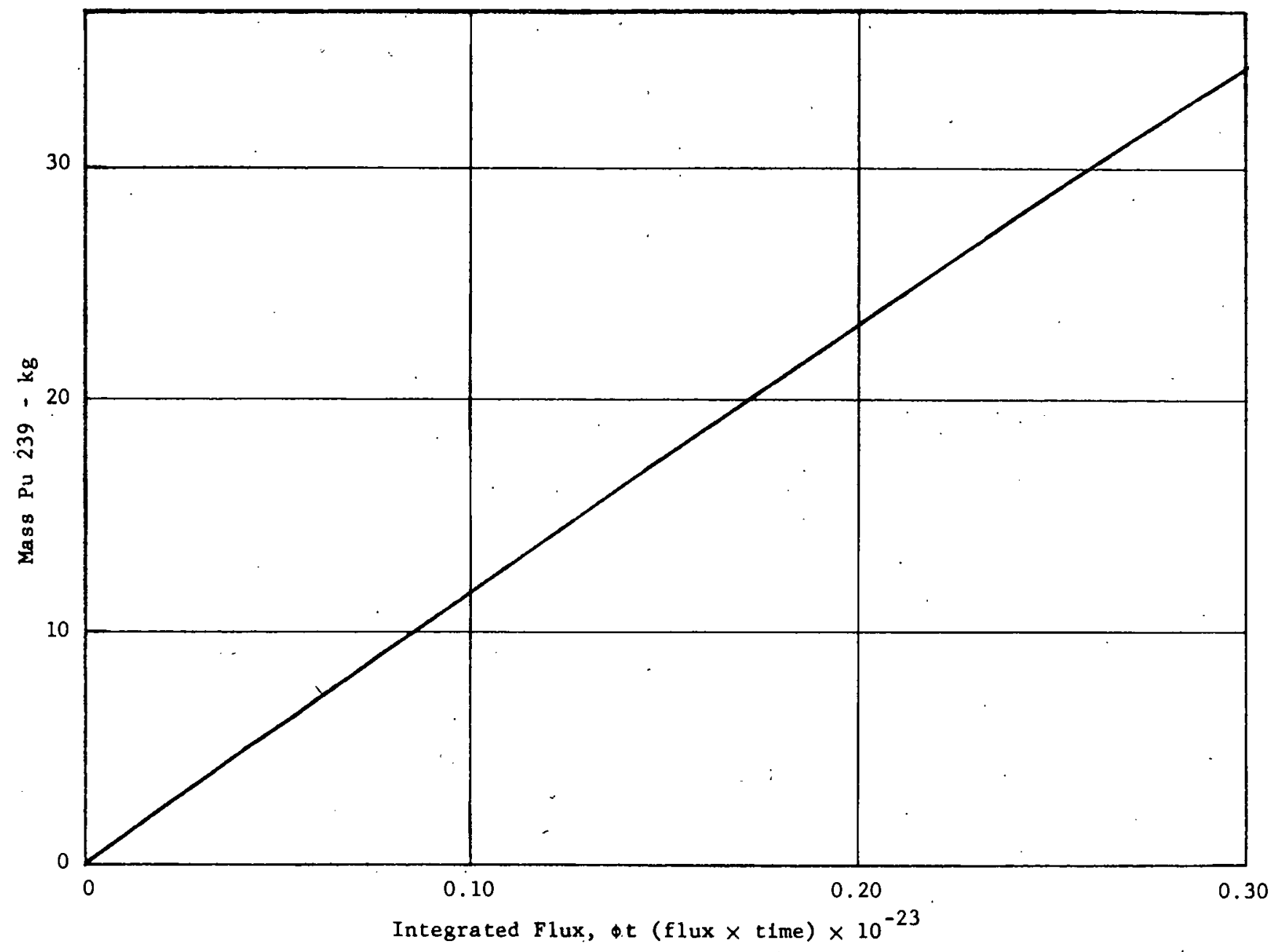

PLUTONIUM BUILDUP IN CORE VERSUS INTEGRATED FLUX

FIGURE 30 
TABLE XX

Mercury Activation Reactions

\section{Reaction}

Hg 196 n $\gamma \mathrm{Hg} 197$

$\mathrm{Hg} 198 \mathrm{n} \gamma \mathrm{Hg} 199$

Hg 198 np Au 198

Hg 198 n $\alpha$ Pt 195

Hg 199 np Ag 199

Hg 200 n $\alpha$ Pt 197

$\mathrm{Hg} 202 \mathrm{n} \gamma \mathrm{Hg} 203$

Hg 204 n, 2n Hg 203
Half Life

$65 \mathrm{hr}$

$42 \mathrm{~min}$

2. 7 days

$80 \mathrm{~min}$

3. 3 days'

$18 \mathrm{hr}$

47 days

47 days
Gamma Ray Energies

(Mev)

$0.077,0.134,0.165$

$0.16,0.37$

0.41

0.34

$25 \% 0.024 \& 0.207$

$30 \% 0.07 \& 0.156$

$45 \% 0.23$

$0.77,0.346$

0.28

0.28

Fast cross sections for the three $\mathrm{n} \gamma$ reactions were estimated by apportioning the mercury total cross sections among the various isotopes in the same ratio as the thermal cross sections. For a particular isotope:

$$
\sigma_{\text {if }}=\frac{\sigma_{\text {ef }} \sigma_{\text {it }} \mathrm{a}}{\sum \sigma_{\text {it }}{ }^{\mathrm{a}}},
$$

where $\sigma_{\text {if }}=$ cross section of isotope for fast neutron capture,

$\sigma_{\text {ef }}=$ cross section of element for fast neutron capture,

$\sigma_{i t}=$ cross section of isotope for thermal neutron capture,

$\mathrm{a}=$ abundance of isotope.

Cross sections for six energy groups were multiplied by the corresponding neutron flux estimates to obtain reaction rates. Results are listed in Table XXI.

This information is presented in Figure 31 in terms of the activity produced in one pound of mercury as a function of the power produced in one liter of reactor core. If the power density is assumed to be 100 kilowatts per liter, the relative fluxes in Table XXI must be multiplied by $5.6 \times 10^{13}$ to obtain absolute fluxes. 


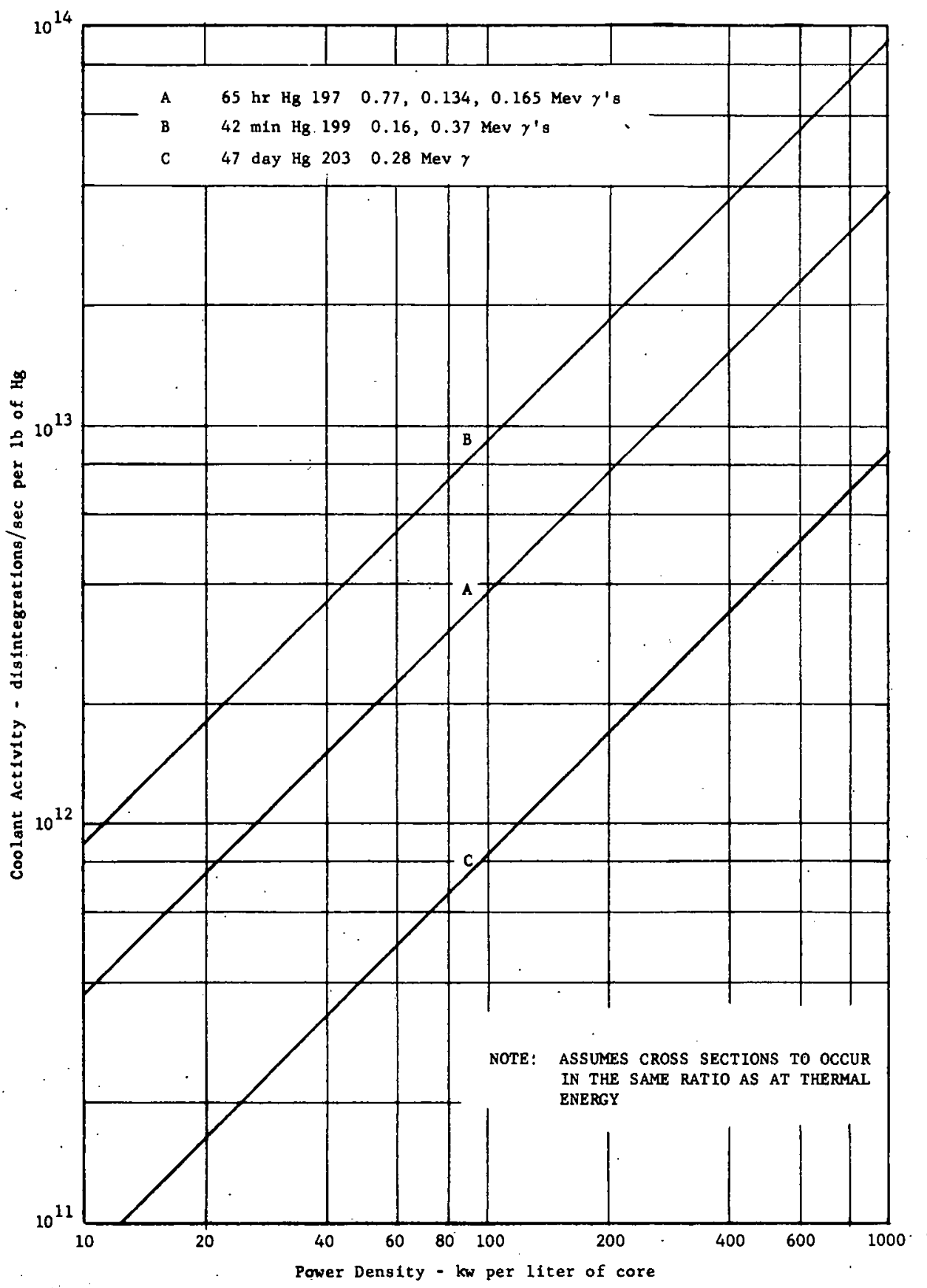

MERCURY ACTIVATION DUE TO n $\gamma$ REACTIONS

FIGURE 31 
TABLE XXI

MCBR Activation Data

\begin{tabular}{|c|c|c|c|}
\hline \multicolumn{2}{|c|}{$\begin{array}{l}\text { Energy } \\
\text { Range } \\
\text { (Mev) } \\
\end{array}$} & $\begin{array}{l}\text { Capture Cross Section } \\
\text { for Mercury } \\
\text { (barns) }\end{array}$ & $\begin{array}{c}\text { Neutron } \\
\text { Flux } \\
\text { (Relative) }\end{array}$ \\
\hline 10 & 2.25 & 0.038 & 0.352 \\
\hline 2.25 & 0.825 & 0.091 & 1.62 \\
\hline 0.825 & 0.30 & 0.356 & 4.13 \\
\hline 0.30 & 0.11 & 0.705 . & 2.73 \\
\hline 0.11 & 0.025 & 0.993 & 0.89 \\
\hline 0.025 & 0.009 & 0.998 & 0.192 \\
\hline
\end{tabular}

All the activities calculated are saturated activities, those that would obtain after steadystate operation for a period of time that is long compared to the pertinent half lives. The mercury was assumed to be in the reactor and in a constant flux zone for the entire period of irradiation. Since this obviously will not be the case, corrections can be made by multiplying the average power density by the ratio of the time spent by the mercury in the reactor to the total cycle time. This ratio is approximately 0.005 for the $100-\mathrm{mw}(\mathrm{e})$ reference MCBR core.

\section{5. $\quad$ Shielding}

The shield design is guided by two distinct criteria, the energy degradation and absorption of the fast neutrons leaking from the blanket and the attenuation of the gamma radiation produced in the core and blanket as well as that produced by the thermalization and capture of the leakage neutrons. The detailed analysis of the shielding requirements that will permit an optimum shield is a complicated and tedious procedure which was not considered necessary for this conceptual design. Instead, a simple analysis was made which overestimates the amount of shielding required but gives results adequate for a reasonable estimate of the shield cost.

\section{a. Primary Neutron and Gamma Shielding}

The radial and top biological shield for the reactor proper consists of five feet of sand saturated with water plus boron in the form of sodium pentaborate to remove neutrons and seven feet of ordinary concrete to absorb gamma radiation. This amount of shielding limits the dose rate at the surface of the shield to $0.75 \mathrm{mrem} / \mathrm{hr}$. The bottom biological shield consists of five feet of sand and water plus boron and one foot of ordinary concrete to limit the dose rate in the control rod room to $5 \mathrm{r} / \mathrm{hr}$ during full-power operation. 


\section{MERCURY COOLED BREEDER REACTOR}

A mixture of sand and water saturated with sodium pentaborate and possibly stabilized with silica gel to prevent water leakage is used to slow down the fast neutrons, thereby allowing their capture in the boron. The mixture of sand and water has gamma ray shielding properties that are nearly as good as ordinary concrete, thus allowing a reduction in the thickness of the concrete portion of the shield. (See Dwg. F-185 for configuration of shield.)

In calculating thicknesses of shielding; five sources of radiation are considered:

1) Leakage neutrons from the blanket.

2) Fission and fission product gammas.

3) Core structure activation gammas.

4) Blanket structure activation gammas.

5) Mercury activation gammas.

For the case of the radial and bottom shield, the controlling source is mercury activation; in the case of the top shield, all sources except the core structural gammas are significant. The magnitudes of these radiation sources expressed as neutron or gamma energy currents at the blanket surfaces are indicated schematically in Figure 32.

\section{b. Mercury Pipe Shielding}

The thickness of steel or concrete required to shield pipes containing the activated - liquid mercury and mercury vapor to dose rates of $5 \mathrm{mr} / \mathrm{hr}$ was determined by assuming a line source for both the small liquid mercury lines and the larger lines filled with mercury vapor. Self shielding by the mercury was accounted for; depths. of liquid mercury of about 1 inch are equivalent to nearly. infinite depths because of the low energy of the decay gamma photons and the high density of liquid mercury. The values determined are presented in Table XXII.

\section{TABLE XXII}

Mercury Pipe Shielding Thickness for Surface Dose Rate of $5 \mathrm{mr} / \mathrm{hr}$

\begin{tabular}{|c|c|c|c|}
\hline \multicolumn{2}{|c|}{$\begin{array}{l}\text { Mercury Pipe Shielding Thickness for } \\
\text { Surface Dose Rate of } 5 \mathrm{mr} / \mathrm{hr} \\
\end{array}$} & \multirow{2}{*}{\multicolumn{2}{|c|}{$\begin{array}{l}\text { Shielding Thickness } \\
\text { (in.) }\end{array}$}} \\
\hline & $\cdot$ & & \\
\hline & & Steel & Concrete \\
\hline$\supset^{\prime}$ Liquid Mercury, 8-in. Sch. 30 Pipe & & 7 & 23 \\
\hline Mercury Vapor, 30-in. Sch. 10 Pipe & & 6 & 19.5 \\
\hline
\end{tabular}




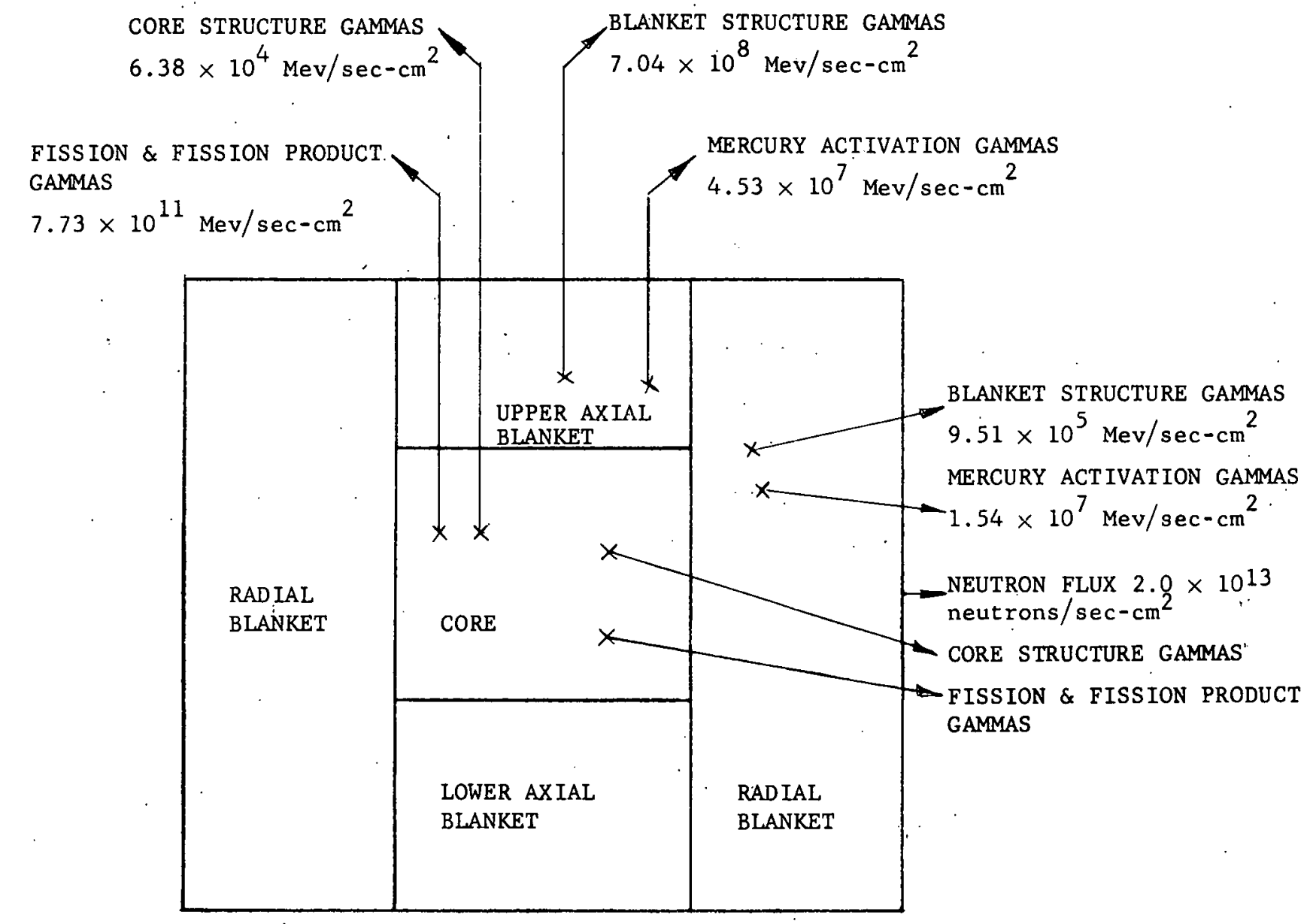

SOURCES OF RADIATION LEAVING OUTER BLANKET SURFACE

FIGURE 32 


\section{MERCURY COOLED BREEDER REACTOR}

\section{c. Shutdown Shielding}

For the purpose of determining the gamma ray source strengths during refueling operations, the reactor was assumed to have been shut down for $2 \frac{1}{2}$ hours and the reactor vessel head removed. The source strengths at the outside surface of the top axial blanket for the four gamma ray groups under consideration were then calculated, using simple exponential attenuation techniques including buildup factors and slab geometry. It was evident from the resulting dose rates that a top shield plug would be necessary to limit to a permissible level the dose rate received by personnel changing fuel elements.

A plot of dose rate at the surface of the shield plug for various thicknesses of steel as a function of depth of mercury over the upper axial blanket is shown in Figure 33. For a dose rate of $5 \mathrm{mrem} / \mathrm{hr}, 6.5$ inches of mercury and 12 inches of steel are required; 6.5 inches of mercury over the blanket is the minimum required to insure that the active portions of the fuel elements will be immersed in mercury, even when all but one of them have been removed from the reactor. Total immersion is necessary to insure cooling without vaporization.

It is interesting to note that for a given thickness of steel, the dose rate at the surface of the steel will not decrease indefinitely with increased mercury depth. This is true because the gammas from the core and blanket regions are effectively shielded by the mercury and the activated mercury itself dominates the contribution to the dose rate above the shield indexing plug.

\section{d. Thermal Shielding}

The purpose of the thermal shield is to protect the reactor pressure vessel from the heat generated by the following four sources:

1) Neutrons captured by the steel.

2) Gamma ray heating from the core region.

3) Thermalization of fast neutrons.

4) Mercury activation heating decay.

In addition, this shield protects the vessel against thermal shocks caused by thermal transients in the mercury coolant. Lamination allows mercury coolant to pass through the shield to remove the heat generated by the radiation absorption.

The controlling source is the thermalization of fast neutrons and their subsequent capture.

The attenuation of the neutron current through the successive thermal shield laminations was estimated, and a volume heat source proportional to the rate of neutron removal was assumed. 


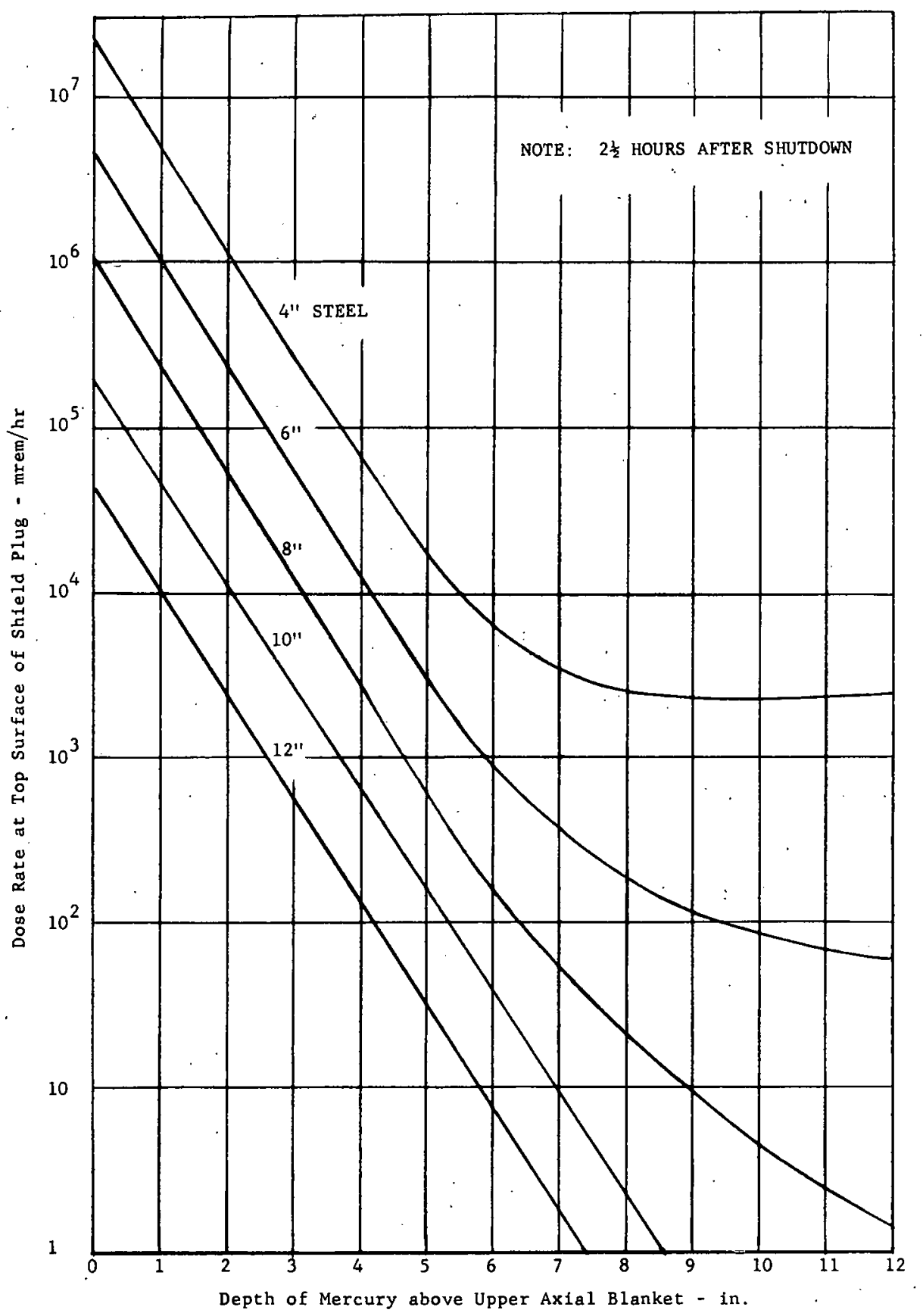

DOSE RATE FOR VARIOUS DEPTHS OF MERCURY ABOVE BLANKET

FIGURE 33 
These values were then used to determine the thickness of the respective laminations for an allowable thermal stress of 7300 psi.

The thicknesses of the laminations, rounded off to the next lower, standard thickness of

plate, are, beginning with the innermost shield: $3 / 8 \mathrm{inch}, 5 / 8 \mathrm{inch}, 5 / 8 \mathrm{inch}, 3 / 4 \mathrm{inch}$ and 1 inch for a total thermal shield thickness of 3-3/8 inch. The shields are separated from each other by an annular mercury coolant passage $\frac{1}{2}$ inch thick.

\section{B. REACTOR PLANT DESCRIPTION}

The design and performance characteristics of the $100-\mathrm{mw}(\mathrm{e})$ power plant and reference MCBR are summarized in Table XXIII. Note that all dimensions given represent hot operating conditions of the various components.

The plant consists of the reactor and auxiliaries, condenser-boilers for condensing mercury vapor and generating superheated steam, primary and auxiliary mercury systems, utilities systems, a safety system, and a fuel-handling system.

It is estimated that the total mercury holdup in the reactor plant required to meet all operating and emergency situations will be about 360,000 pounds (4750 flasks). This amounts to 3. 6 pounds of mercury per kilowatt of power produced, which is roughly one-half the quantity of mercury required for conventional mercury power plants. A discussion of mercury availability is presented in Appendix J.

Dwg. D-180 is a schematic flow and heat balance diagram.for the primary reactor system. It is seen that the primary system consists of a stream of saturated liquid mercury at $920^{\circ} \mathrm{F}$, which is pumped into the reactor core and blanket. The mercury boils as it flows through the core and blanket assemblies, and liquid mercury droplets suspended in saturated mercury vapor emerge from the upper end of the core and blanket. The two phases are separated at the reactor vessel outlet. The saturated liquid flows downward through the thermal shield and is combined with the mercury condensate at the pump inlet. The saturated mercury vapor is condensed at $920^{\circ} \mathrm{F}$ in the condenserboilers, generating $1800-$ psig steam at $900^{\circ} \mathrm{F}$. The steam flows directly to the turbine. Feedwater at a constant temperature of $450^{\circ} \mathrm{F}$ is pumped to the condenser-boilers from the power-generation plant. Details of the reactor plant system are shown on Dwg. R-181. Design data on reactor plant equipment are summarized in Appendix K. 
TABLE XXIII

ح PLANT AND REACTOR

DESIGN AND PERFORMANCE CHARACTERISTICS

Plant Performance Data

Net electric power (mw)

94.5

Net plant efficiency (\%)

33.4

Reactor thermal power ( $\mathrm{mw}$ )

283

Core

255

Blanket

28

Steam conditions:

Pressure (psia)

1815

Temperature ( $\left.{ }^{\circ} \mathrm{F}\right)$

900

Flow $(\mathrm{lb} / \mathrm{hr})$

$1,020,000$

Mercury vapor conditions:

Pressure (psia)

110

Temperature $\left({ }^{\circ} \mathrm{F}\right)$

920

Flow (lb/hr)

Plant load factor

$7,700,000$

Total mercury holdup (lb)

0.80

360,000

\section{Reactor Performance Data}

Over-all reactor dimensions

Total fuel alloy loading ( $\mathrm{kg}$ fuel alloy)

Total blanket loading (kg depleted U)

Initial fuel enrichment ( $w / o$ )

Final fuel enrichment (w/o)

Core volume (liters)

Core average heat flux (Btu/hr- $\mathrm{ft}^{2}$ )

Maximum heat flux (Btu/hr- $\mathrm{ft}^{2}$ )

Average power density (kw/liter)

Core average specific power (kw/ kg U)

Discharged fuel average burnup $(\mathrm{mwd} / \mathrm{t})$

Discharged blanket average burnup $(\mathrm{mwd} / \mathrm{t})$

Heat transfer surface $\left(\mathrm{ft}^{2}\right)$

Core

$10^{\prime}$ OD $\times 20^{\prime} 8^{\prime \prime}$ length

9700

100,570

26.5

25.6

2642

119,000

446,000

96.5

29. 2

10,000

1,000

Upper axial blanket

7310

Lower axial blanket

645

Radial blanket

1511

24,800

Pressure drop (psi) .

Core

50.0

Axial blanket

10.2

Radial blanket

14.0 
TABLE XXIII

(Continued)

\section{Maximum-to-Average Heat Flux Ratios}

Fuel rod

1.37

Fuel-pin-diameter tolerance

1.05

Pin-cladding eccentricity

1.14

Cladding-thickness tolerance

1. 13

Uranium density

1.01

Fuel assembly

Flux distribution

1.05

Channeling

1.06

Burnup

1.00

Reactor

Radial flux distribution

1.42

Longitudinal flux distribution

1.52

Power excursion

1.15

Over-all

\section{Reactor Physics Data}

Critical mass U 235(kg)

Core conversion ratio

Blanket conversion ratio

Total conversion ratio

Average core neutron energy (Mev)

Average core flux (neutrons $/ \mathrm{cm}^{2}-\mathrm{sec}$ )

Maximum/average core power

$$
\text { Axial }
$$

Radial

1.51

1.42

0.4

$0.89 \times 10^{14}$

2.14

Average generation time (sec)

Delayed neutron fraction

Mean delay time of delayed neutrons (sec)

Prompt neutron lifetime (sec)

Temperature coefficient of reactivity $\left(\Delta \mathrm{k} / \mathrm{k}{ }^{\circ} \mathrm{C}\right)$ Size and fuel expansion

Doppler effect

Blanket

Mercury density coefficient of reactivity $\left(\Delta \mathrm{k} / \mathrm{kgm} / \mathrm{cm}^{3}\right)$

$-13.55 \times 10^{-6}$

$-3.0 \times 10^{-6}$

$-1.22 \times 10^{-6}$
0.09

0.0075

12.0

$2 \times 10^{-7}$

$-17.75 \times 10^{-6}$

$-0.015$ 
TABLE XXIII

(Concluded)

Core and Blanket Data

Equivalent circle diameter (in.)

Length (in.)

Number of element assemblies

Assembly spacing (in.)

Mass of uranium $(\mathrm{kg})$

Composition (vol. \%)

Coolant

Fuel

Steel

Sodium

Structure-fuel alloy volume ratio

Fuel and Blanket Element Data

Materials

cladding

Thermal bond

Uranium

Cladding OD (in.)

Cladding thickness (in.)

Uranium OD (in.)

Thermal bond thickness (in.)

Over-all length (in.)

Core and Blanket Element Assembly Data

Configuration

Structural materials

Element pitch

Pitch/diameter ratio

Number of elements per assembly

Element-to-housing spacing

Outer dimension (across flats) (in.)

Over-all length (in.)

Housing thickness (in.) $\underline{\text { Core }}$

Blanket

\begin{tabular}{lll}
\hline Upper & $\begin{array}{l}\text { Lower } \\
\text { Axial }\end{array}$ & Axial \\
\hline
\end{tabular}

61.3

55.70

258

0.03

8730

61. 3

61.3

100.9

19.68

258

19.68

258

95.00

0.03

0.03

462

2520

5750

0.03

92,300

62.3

71.7

47. 1

16.2

22.2

13. 10

15. 2

33.4

67.2

2.4

13.5

16.0

11. 7

3. 3

3.5

4.9

69.5

86.8

58.0

\begin{tabular}{|c|c|c|c|}
\hline $\begin{array}{l}90 \mathrm{w} / \circ \mathrm{U} \\
10 \mathrm{w} / \mathrm{\circ} \mathrm{Mo}\end{array}$ & $\leftarrow$ & d Uran & - \\
\hline 0.18 & 0.424 & 0.424 & 0.424 \\
\hline 0.008 & 0.01 & 0.01 & 0.01 \\
\hline 0.156 & 0.390 & 0.390 & 0.390 \\
\hline 0.004 & 0.007 & 0.007 & 0.007 \\
\hline 60.1 & 17.8 & 20.0 & 103.1 \\
\hline
\end{tabular}

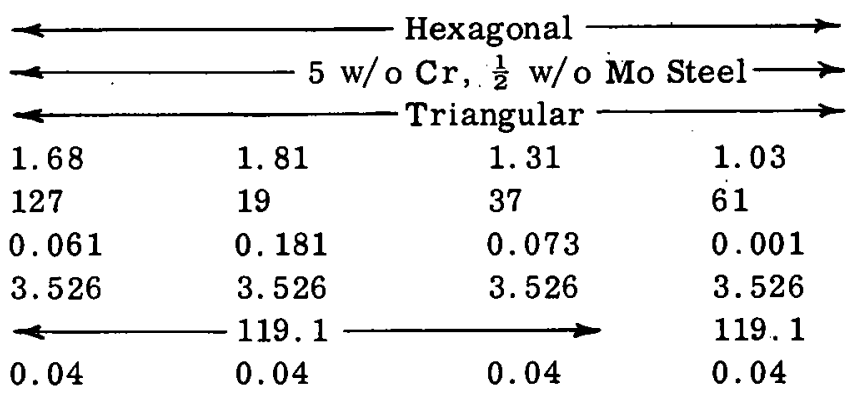




\section{MERCURY COOLED BREEDER REACTOR}

\section{1. $\underline{\text { Reactor }}$}

The reactor, R-1 (see Dwg. R-181), is a cylindrical pressure vessel 10 feet in diameter by 20 feet 8 inches in length, and is located centrally within the containment vessel. The reactor is divided into five main operating zones: core, axial blanket (upper and lower), radial blanket, vapor plenum, and liquid inlet iplenums. The reactor vessel and all internals are fabricated of $5 \mathrm{w} / \mathrm{o} \mathrm{Cr}$, $\frac{1}{2}$ w/o Mo steel. Details of the reactor pressure vessel and internals are shown on Dwg. F-182.

The reactor internals consist of fuel-element assemblies, radial blanket-element assemblies, control-rod assemblies, assembly support and alignment plates, core and radial blanket inlet plenums, vapor plenums, core holddown assembly, mercury spray ring, liquid mercury disentrainers, thermal shield, and a region for containing the remains of the core in the event of a meltdown. Data on the core, the axial and radial blankets, and the core and blanket elements and assemblies are summarized in Table XXIII.

\section{a. Core and Blanket Element Assemblies}

The core and radial blanket elements are assembled in identical hexagonal housings 3.50 inches across the flats and 118. 28 inches long to facilitate handling and transfer. The housing dimension was fixed by the fuel assembly size, which was selected on the basis of the nuclear characteristics of the core as well as over-all size and reactivity considerations during handling. There are 258 core assemblies and 462 radial blanket assemblies, resulting in an equivalent circle diameter 61.3 inches (hot) for the core and 100.9 inches (hot) for the outside of the radial blankets. Details of the assemblies, individual elements, and fittings are shown on Dwgs. F-183 and D-184. It should be noted that dimensions on the drawings are for a cold condition, whereas the dimensions in Table XXIII are for hot operating conditions.

The upper end of each assembly terminates in an adapter having a tapered head to facilitate handling and, in the case of the core assemblies, holddown. The core assemblies must be held against drag of the coolant flow and the buoyant effect of the mercury. The weight of the radial blanket assemblies is sufficiently greater and coolant flow through them lower, so that mechanical holddown of these assemblies is unnecessary. The adapters are spring mounted to permit axial expansion.

Each assembly has a 10.5-inch-long adapter at the lower end which fits into machined holes in the two support plates. The assemblies are supported by the upper plate and aligned by the lower plate. A tapered shoulder at the upper end of this adapter engages a seat in the upper support plate to form a seal. Tolerances and clearances between the plate and the adapter must be carefully 
maintained to insure a misalignment of no more than 0.05 inch at the upper handling head. Small pads are welded to each side of the housings to maintain a nominal clearance of 0.03 inch between assemblies. Adjacent assemblies are in contact only at the pads, permitting easy removal of an assembly when the pads are out of alignment. The pads are located at the point where maximum deflection of the assembly due to differential temperature would occur.

Heat is removed from the assemblies by mercury flowing up from the inlet plenums. The coolant enters the core assemblies through the open end of the lower adapter and enters the radial blanket assemblies through orifice holes in the side of the adapter. Pressure at the inlet to the core assemblies will be $173 \mathrm{psig}$, which is sufficient to overcome static head and pressure drop through the assembly. Pressure at the inlet to the radial blanket assemblies will be automatically controlled at about 120 psig to insure that these assemblies are not lifted out of the support plates. Reactor coolant flow is discussed in more detail in the section on the primary mercury coolant system.

Each core assembly comprises three active sections: upper blanket, core, and lower blanket. The three groups of elements are assembled axially in one hexagonal housing to facilitate handling. The core section contains 127 fuel elements of $0.179 \mathrm{OD}$, arranged on a triangular pitch of 0.302 inch: The individual fuel elements are fastened into the hexagonal housing at the lower end by attachment to parallel grid strips as shown on Dwg. F-183. The upper ends are unrestrained to permit free axial expansion. Spacing between the fuel elements is maintained by alloy steel ribs wrapped helically around the cans on 10-inch pitch and welded to the element end fittings.

The upper and lower axial blanket sections are similarly constructed. The lower blanket consists of 37 elements on 0.555 inch triangular pitch, the upper blanket of 19 elements on 0.767 inch triangular pitch. All elements are 0.420 inch OD and contain pins of unalloyed depleted uranium. The axial blanket elements are fastened to the housing at each end by parallel grid strips that permit axial expansion, the upper grid strips being notched to position the elements. Spacing was determined by pressure drop limitations.

The radial blanket assemblies contain 61 elements on 0.436 inch triangular pitch and are also 0.420 inch $O D$. The radial blanket elements are fastened at each end by parallel grid strips and are spaced closely so that notches or spacer wires are unnecessary. The size and number of the radial blanket elements were fixed by assembly size, element fabrication, and heat transfer considerations. The axial and radial blanket elements were made identical except for length, so as to reduce fabrication costs. 


\section{MERCURY COOLED BREEDER REACTOR}

A detailed discussion of the materials and fabrication considerations on which selection of element construction was based is presented in Appendix F. The core and blanket elements are of the "canned slug" type. Precision cast pins of enriched uranium alloy or depleted uranium are fitted into thin-walled alloy steel tubes and the annulus filled with static sodium to provide a thermal bond. End fittings or plugs are welded in place under inert gas atmosphere to seal each element. The fuel elements consist of 0.153 -inch OD pins of $26.5 \%$ enriched uranium alloyed with $10 \%$ molybdenum in 0.179 -inch $O D \times 0.008$-inch long wall tubes. Sodium fills the 0.005-inch annulus and extends 0.65 inch above the pin. A 4.50-inch inert gas space accommodates expansion of the sodium and fuel. The 0.382-inch OD blanket pins of depleted uranium are fitted in 0.420 -inch $O D$ tubes with 0.01 inch walls. Sodium fills the 0.009 -inch annulus and extends 1.0 inch above the radial and 0.61 inch above the axial blanket pins. An inert gas space of 1.28 inches for the upper axial, 1.20 inches for the lower axial, and 6.43 inches for the radial blanket provides for expansion. The methods employed in fabricating and assembling the elements are in accordance with technologies developed for the EBR-II and Enrico Fermi plants.

\section{b. Control and Safety Rods}

Detailed design of control and safety rods and drive mechanisms has not been attempted. However, the approximate number, type, and location of the rods has been estimated. The rods and assemblies are similar to those employed in the EBR-II, except that power level will be maintained both by controlled removal of fuel and by insertion of poison. The rods are driven from the bottom and penetrate the lower head of the reactor vessel. Drive mechanisms and penetrations are visualized as being similar to those developed for EBWR. The location of control assemblies is shown on Dwg. F-182.

Six identical control rods, uniformly spaced within the reactor core, provide operational control for the reactor. Each control assembly consists of a control rod moving in a hexagonal guide tube. The guide tube is identical to the housing of the stationary core assemblies. The control rod is a modified core assembly containing 91 fuel elements and is encased in a housing 3.00 inches across the flats. The control-rod assembly is smaller than a core assembly by one row of fuel pins. Above the fuel section of the control rod is a blanket section containing 19 upper axial blanket elements and a poison section containing boron carbide cylinders. Below the fuel section is a section containing 37 lower axial blanket elements.

When the control rod is inserted, the fuel section will be positioned in the core and the poison section will extend above the upper blanket. No holddown rod is provided in the holddown 


\section{MERCURY COOLED BREEDER REACTOR}

assembly for the 13 control and safety rods. When the control rod is withdrawn, the poison section will be centered in the core. The control rods terminate at the upper end in a standard adapter so that they may be removed in the same manner as the core assemblies after disengagement from the drive mechanism. The guide tubes are locked in position but may be withdrawn after adjacent core assemblies have been removed.

The lower portion of the control rod is a cylindrical tube with guide bearings which bear on the guide tube. Coolant enters the control assembly through the end of the guide tube and flows into the control rod through orifice holes in the lower tube and hexagonal housing. The orifices are graduated to match flow to the rod position.

The seven safety-rod assemblies are similar to the control-rod assemblies except for the lower end of the rods and the drive mechanism. The safety rods are not used for normal operational control but provide additional negative reactivity for shutdowns or emergencies. Coolant flow through the safety rods is similar to that through the control rods except that no provision is made for variable flow.

\section{c. Meltdown Section}

The lower reactor vessel has been designed to provide safe containment for molten fuel in the unlikely event of a core meltdown. The meltdown section is designed to disperse total molten fuel, sodium, and structure from the core across the lower head of the vessel. A total of 375 twoinch-diameter $2 \%$ boron steel rods are welded to the head to poison and spread out the molten fuel and thereby insure subcriticality. The rods also fill the meltdown section so as to minimize mercury holdup while providing sufficient space for the molten fuel.

In the event of a meltdown, molten fuel will flow down through the lower core assemblies and into the meltdown section. Contained mercury will cool the molten material, and the solid uranium will be spread out around the poison rods.

\section{d. Thermal Shield}

A laminated thermal shield lines the reactor vessel wall to attenuate gammas and highenergy neutrons and thereby reduce radiation damage and thermal stresses in the vessel wall. Thermocouples indicate vessel wall temperature at key points. The shield is composed of five alloy steel cylinders mounted concentrically with the vessel, the cylinders being separated by spacers to provide coolant channels. Liquid mercury disentrained from the liquid-vapor mixture flows downward between the layers to remove heat generated by radiation absorption. The shield extends from 


\section{MERCURY COOLED BREEDER REACTOR}

the upper support plate to a point about 6 inches above the upper blanket. The design basis for the thermal shield is discussed in section A. 5.

e. Core Holddown Assembly

A holddown assembly is provided for the core assemblies to prevent them from being lifted out of the support plates due to coolant flow and the buoyant effect of the mercury. The handling head at the top of each core assembly engages the female knob of the holddown rod. With the holddown mechanism in place, a spring in the upper adapter section of each core assembly is compressed, holding the assembly firmly in place and allowing for thermal expansion.

A three-arm spider supports and positions the assembly within very close tolerances. The spider is supported on lugs attached to the vessel wall at its extremities. Tapered aligning pins are provided to facilitate positioning of the spider. The assembly is held in place by six retaining nuts. The nuts may be removed or installed only when the index plate is in place. This procedure is discussed in the fuel handling system section.

\section{f. Pressure Vessel}

The cylindrical pressure vessel has an outside diameter of 10 feet and an over-all height (excluding control-rod thimbles) of 20 feet 8 inches. The vessel is designed to withstand a pressure of $210 \mathrm{psig}$ at a maximum temperature of $1000^{\circ} \mathrm{F}$ in accordance with the ASME Boiler and Pressure Vessel Code, Section VIII, for Unfired Pressure Vessels (1959 Edition and Case Interpretations $1270 \mathrm{~N}$ and $1273 \mathrm{~N}$ for Nuclear Installations). The design pressure was set for the bottom head and is based on a relief valve setting of 125 psig, a maximum pressure drop of 60 psi, and a static pressure of 25 psig. Overpressure of the vessel is prevented by six relief valves designed with sufficient total capacity to insure that the design pressure of the vessel is not exceeded by more than $10 \%$. The relief valves are located in the vessel vapor lines upstream of any valves in accordance with the Code and Case Interpretation 1271N, Special Ruling on Safety Devices for Nuclear Vessels.

The vessel shell, heads, and attached internals are fabricated of $5 \mathrm{w} / \mathrm{o} \mathrm{Cr}, 1 / 2 \mathrm{w} / \mathrm{o}$ Mo steel conforming to ASME Specification SA-357. The total thickness of the vessel shell is 2 inches, and the head thickness is 1.88 inch minimum. The bottom head is welded to the vessel and contains 375 two-inch-diameter $2 \%$ boron steel poison rods and 13 external control-rod thimbles. The cover is secured to the vessel by a bolted flange arrangement and is sealed by a double-ring-type joint. Tapered alignment pins are provided to facilitate setting the cover 
in place. All vessel welded joints are of the double-welded butt type and are fully radiographed, and the vessel is stress relieved.

The vessel shell is penetrated by nozzles, instrument taps, and the control-rod thimbles. All penetrations are reinforced in accordance with the ASME Code. The following internals, as shown on Divg. F-182, are considered an integral part of the vessel: disentrainers, spray ring, thermal shield, support plates, and poison elements. The estimated weight of the vessel, cover, and the above internals is 157,000 pounds.

The support plate assembly is designed to support and align the fuel and blanket assemblies, with the reactor filled to a maximum level with mercury. The two $3 \frac{1}{2}$-inch-thick plates are welded together and spaced at the periphery. The 3-inch space between plates forms the radialblanket inlet plenum. The size of the plenums has been minimized to reduce mercury holdup. Clearances between the plates and the 733 assembly adapters, as well as all tolerances, must be small to limit misalignment of the handling head at the top of the assemblies. The plates must therefore be accurately machined in the shop and carefully aligned in the field.

\section{Primary Mercury Coolant System}

Heat generated in the reactor core and blanket sections is removed by boiling mercury flowing upward through the Reactor $(\mathrm{R}-1$, Dwg. $\mathrm{R}-181)$. The mercury vapor is condensed on the shell side of the three vertical Condenser-Boilers ( $E-1 \mathrm{~A}, \mathrm{E}-1 \mathrm{~B}$, and E-1C), transferring the latent heat to water and steam. The condensed mercury combines with the liquid recycle stream from the thermal shield and is pumped by the Mercury Recirculating Pumps $(\mathrm{P}-1 \mathrm{~A}, \mathrm{P}-1 \mathrm{~B}$, and $\mathrm{P}-1 \mathrm{C})$ back to the reactor. The reactor and all primary system piping, equipment, and instruments are insulated, and parts in contact with mercury are fabricated of $5 \mathrm{w} / \mathrm{o} \mathrm{Cr}, \frac{1}{2} \mathrm{w} / \mathrm{o}$ Mo steel. The entire piping system is welded except at the pumps.

The reactor vapor outlet plenum is maintained at $95 \mathrm{psig}$, which corresponds to a saturation temperature of $920^{\circ} \mathrm{F}$. This is the maximum temperature that can be tolerated without exceeding the maximum allowable fuel-element-cladding temperature of $1000^{\circ} \mathrm{F}$. The liquid-vapor mixture of mercury at $920^{\circ} \mathrm{F}$ enters the vapor plenum at a vapor quality of $30 \%$. The liquid component is required to insure wetting of the heat transfer surfaces.

Pressure and temperature of the vapor are recorded, and alarms warn of high and low pressure and high temperature. Relief valves protect the reactor from overpressure. High pressure or popping of the relief valves will initiate a reactor scram. Reactor pressure is maintained 


\section{MERCURY COOLED BREEDER REACTOR}

manually by the operator by adjustment of control-rod position. The liquid-vapor mixture passes through baffled disentrainers located over the vapor outlet nozzles. The disentrained liquid flows down through coolant passages in the thermal shield, removing the heat generated there by radiation absorption. A liquid-level controller maintains a mercury level 6 inches above the shielding plates by throttling the 12-inch mercury recycle line. This insures cooling of the shield and provides a seal for the dip-leg from the disentrainers.

The liquid-free saturated vapor passes through three 30 -inch lines to the condenser-boilers. The lines are sloped so that any liquid will drain back into the reactor. Remote-controlled valves are provided in the inlet and outlet lines of each condenser-boiler unit. In the event of a tube leak, or at low power levels, the operator in the control room can isolate an individual condenser-boiler unit. Although the inlet-line valves are 24-inch, with high-pressure pneumatic actuators, closing times of a few seconds are possible. At design power, 7,700,000 lb/hr of mercury vapor is generated. As discussed earlier, subcooling due to pressure drop in the vapor system increases nonboiling length in the core and adversely affects core performance. The vapor system has therefore been designed for a maximum pressure drop of 3 psi to minimize subcooling of the condensed mercury. The mercury vapor is completely condensed in the condenser-boilers. The over-all duty of the units is $955,000,000 \mathrm{Btu} / \mathrm{hr}$. With a constant feedwater temperature of $450^{\circ} \mathrm{F}, 1,020,000 \mathrm{lb} / \mathrm{hr}$ of 1800 -psig steam at $900^{\circ} \mathrm{F}$ is generated. Design considerations for the condenser-boilers are discussed in more detail in the next section.

The condensed mercury flows to the Mercury Level Drum (D-6), where it combines with the liquid mercury recycle stream. Since the mercury level in the reactor adjusts itself according to power level, primary system mercury level is indicated in D-6. Mercury makeup or pumpout is initiated manually by the operator to maintain the minimum mercury level required for proper pump suction conditions. Alarms are provided to warn of high or low level.

Two recirculating pumps and a duplicate spare are provided to pump 25,500,000 1b/hr of liquid mercury back to the reactor. The pumps are designed for a differential head of 28 feet (150 psi at operating temperature) to overcome static head and pressure drop across the reactor, inlet lines, and the flow-control valve. Remote motor starters and pump discharge pressure indicators are provided in the control room, and spare pump valves are normally open. In the event of pump trouble, the spare pump can be started immediately from the control room to insure continuity of coolant flow. 
Mercury condensate from the condenser-boilers and total flow to the reactor are recorded. The exit vapor quality from the reactor is critical and must be controlled. This is accomplished by instruments that calculate the ratio of the condensed vapor rate to the total liquid rate and record and control total liquid rate to maintain a constant quality. Alarms are provided to warn of low coolant flow or high quality. High reactor quality will scram the reactor. In the event of reactor scram due to power failure or high quality, a remote-operated valve in the pump bypass line opens, insuring continuous coolant flow by natural circulation. It is estimated that liquid level will be maintained about 3 inches above the bottom of the core at design power. A calibrated differential-pressure instrument indicates reactor liquid level.

Since approximately $90 \%$ of the reactor heat is generated in the core, coolant requirements for the core and blanket are radically different. Two coolant inlet plenums are therefore provided. The flow split is automatically controlled by a ratio flow controller. Coolant enters the core and control-rod assemblies at $173 \mathrm{psig}$, which is sufficient to overcome liquid head and pressure drop through the axial blankets and core. Radial blanket inlet pressure is automatically maintained at about 120 psig to insure that these assemblies are not lifted out of the support plates by pressure surges. Alarms are provided to warn of high pressure and low flow to the blanket plenum. The individual assemblies are orificed to match flow to the distributed heat-generation rate.

\section{Condenser-Boilers}

Process, control, and fabrication requirements of the condenser-boiler units were investigated in conjunction with the Industrial Division of American-Standard and a reasonable over-all design established for estimating purposes. Some development to resolve construction and process problems may be required prior to final design and fabrication of the units.

For the conceptual design, three vertical once-through-type units have been selected. rather than the multiple-unit, natural-circulation type, because control of steam conditions is simplified at low power levels when excess heat transfer surface is available. Double-walled tubes and fixed double-tube sheets are required to minimize the possibility of steam entering the reactor in the event of a tube rupture or weld leak. The units have high-pressure steam on the tube side and noncorrosive mercury on the shell side. The annulus between the double tubes and tube sheets contains mercury, which acts as a thermal bond and facilitates detection of tube leaks.

Both top and bottom heads are removable so that the shell and fixed tube bundle can, after draining, be pulled to the operating floor for maintenance. The heads are seal-welded, and the seal welds and piping must be cut when a unit is to be removed. Each condenser-boiler unit is isolated in 


\section{MERCURY COOLED BREEDER REACTOR}

a shielded compartment to permit removal of the heads and cutting of the connecting piping with the plant in operation. A spare shell unit is stored within the containment vessel so that a bundle can be replaced with the reactor in operation at partial power. The condenser-boiler shells are protected by the vapor-line relief valves. Thermal relief valves are provided on the tube annulus and steam side of each unit to prevent over-pressure due to thermal expansion when the units are blocked-in. Mechanical and process data on the condenser-boiler units are summarized in Appendix K.

The mercury in the tube annuli is continuously recirculated through a leak-detection system. This system consists of a surge drum, recirculating pump, and necessary instrumentation. A leak in the inner tube will cause a pressure rise in the system and actuate an alarm. A leak in the outer tube will be indicated as a differential mercury flow between the inlet and return lines. Fresh mercury will be supplied to the system from the outlet of the Mercury Cleanup Drum (D-1). The system is periodically flushed to the Mercury Sump (D-2) for oxide-sludge removal. The tube annuli can be blown out with inert gas when maintenance is necessary. Details of the leak-detection system are not shown on Dwg. R-181.

\section{Steam and Feedwater Systems}

Although the power-generation system has not been designed in detail, flow and control of feedwater and steam at the condenser-boilers has been established. With the once-through-type condenser-boiler, evaporator blowdown will not be possible. Selection of this type is therefore based on the premise that new techniques in treatment of feedwater to "ultra-purity"levels would obviate the need for evaporator blowdown.

The condenser-boilers are supplied with $1,020,000 \mathrm{lb} / \mathrm{hr}$ of the "ultra-purity" feedwater at a constant feedwater temperature of $450^{\circ} \mathrm{F}$. Feedwater flow is recorded continuously, and an alarm is provided to warn of low flow, which will also scram the reactor. The feedwater is preheated, evaporated, and the steam superheated to $900^{\circ} \mathrm{F}$ at $1800 \mathrm{psig}\left(278^{\circ} \mathrm{F}\right.$ superheat). The feedwater rate is controlled automatically to maintain a constant steam pressure to the turbine. Steam superheat is held constant by controlled attemperation of the steam with feedwater. Steam flow from and water flow to the attemperator are recorded. Thus, even at low reactor power levels when excess heat transfer surface is available, steam conditions at the turbine will be constant. Operation in this manner permits operation of the reactor at constant pressure independent of power demand.

In the event of cooling water failure, the reactor will automatically scram. Provision is made for automatically relieving system pressure to the atmosphere so that feedwater stored in the elevated deaerator storage tank can flow by gravity through the condenser-boilers to remove heat 
until the shutdown cooling system can take over. The steam and high-pressure feedwater piping systems are welded and are fabricated entirely of $2 \frac{1}{4}$ w/o $\mathrm{Cr}, 1$ w/o Mo steel.

\section{Auxiliary Mercury Systems}

a. Cleanup and Additive Injection System

Experience with mercury in conventional power plants has verified that magnesium and titanium must be added in small amounts to mercury to eliminate mass transfer and insure good wetting of heat transfer surfaces. In addition, the oxides formed must be removed to prevent plugging of coolant passages and localized dewetting. Experience has shown that the oxide removal can be easily accomplished by reducing liquid velocity to a point where the low-density oxides can float to the surface of the mercury and accumulate.

A system has been provided to permit continuous cleanup of a portion of the mercury coolant stream and periodic injection of magnesium and titanium. About $1 \%$ of the primary mercury stream is drawn off the mercury recirculating pump discharge and pumped by the Auxiliary Mercury Pump (P-3) to the Mercury Cleanup Drum (D-1). One operating and one spare pump are provided. $D-1$ is a $2.5^{\prime}$ OD $\times 9^{\prime}$ horizontal pressure vessel with a $1^{\prime} \mathrm{OD} \times 2^{\prime}$ pot on the top. The drum is designed to provide a settling time of 10 minutes and reduce mercury velocity to less than $0.02 \mathrm{ft} / \mathrm{sec}$. The oxides float to the top in this zone of low velocity and collect in the pot. The mercury level in the pot is recorded. When sufficient oxides have accumulated, the low mercury level will sound an alarm and the oxide sludge can be manually blown down to the mercury recovery system, which is discussed later. The clean mercury flows to the top of the reactor and is sprayed over the element assemblies. Flow through the system is recorded and controlled automatically. To clean static mercury prior to a startup of the plant, all mercury in the reactor system can be recirculated through the cleanup system. All mercury, whether makeup or returned, must enter the primary or the auxiliary mercury system through the cleanup drum.

The cleanup drum also provides emergency surge for flooding the reactor. It is sufficiently elevated that mercury will flow to the reactor spray ring by gravity in the event of pump failure. This provides some emergency cooling and insures liquid wetting of the fuel pins, even during major upsets such as power failure. A $10-\mathrm{kw}$ immersion heater $(\mathrm{H}-3)$ is provided in $\mathrm{D}-1$ to make up heat losses from the cleanup system if necessary, or to heat the mercury to reactor system temperature if the drum has been isolated. A thermal relief valve is provided on the drum to prevent overpressure. 


\section{MERCURY COOLED BREEDER REACTOR}

Magnesium and titanium are added by periodically routing a stream of mercury through the filled Injection Chambers (D-3 and D-4). The chambers are small pots with removable top covers and are normally isolated from the system. Routine samples of the circulating mercury are taken at the outlet of D-1 and analyzed for additive and sludge concentration. When necessary, one chamber is filled with magnesium in the form of small ingots of pure metal and the other with titanium hydride powder. A stream of hot mercury is routed through the chambers, dissolving the additive material. Experience indicates that the additive concentration must be maintained at 50 to $70 \mathrm{ppm}$ of magnesium and $0.35 \mathrm{ppm}$ of titanium. It is estimated conservatively that the annual consumption for the plant will be $300 \mathrm{lb}$ of magnesium and $50 \mathrm{lb}$ of titanium.

\section{b. Startup System}

Two heaters are provided in the cleanup-system return line to the reactor for heating the reactor and primary system during initial startup. The heaters are 60-kw circulation-type units with alloy-steel-sheathed hairpin elements. They are designed to heat the primary system at a rate of 50 degrees per hour. A thermostat is provided for adjusting the heat-up rate. Two units are provided to permit removal of one for maintenance. During normal operation, the heaters are turned off and the mercury circulates through the shells. The cleanup drum can be bypassed during startup if desired.

\section{c. Shutdown Cooling System}

A shutdown cooling system is provided to condense small quantities of mercury vapor during shutdown and to remove decay heat from the recirculating liquid mercury when the reactor is flooded. This system does not provide emergency cooling, which is handled by the condenser-boilers.

The system includes an air cooler and a recirculating pump. Prior to normal shutdown, the system will be gradually heated by bleeding mercury vapor through it. During shutdown, the Mercury Shutdown Cooler (E-2) will condense a small percentage of the vapor. As power level is gradually reduced, the cooler smooths out operation as the large condenser-boilers are cut out stepwise. Once the reactor is flooded with liquid to a point 6.5 inches above the upper blanket, the Mercury Shutdown Pump (P-2) starts and the liquid mercury recirculates through the cooler to remove decay heat and to cool the liquid if desired.

The cooler is located outside the containment vessel and is designed for a duty of $12,000,000 \mathrm{Btu} / \mathrm{hr}$, permitting the reactor system to be cooled at an average rate of about 65 degrees per hour while removing decay heat at an average rate of $1 \%$ of maximum reactor heat rate. The cooler is a standard air-fin type, provided with adjustable louvers and two-speed fan to manually 
control cooling rate. The pump is a centrifugal type with special high-temperature seal, and is designed to pump total primary system mercury through the cooler in one hour. Flow through the system is recorded and cooler outlet temperature indicated.

\section{d. Sump System}

A Mercury Sump (D-2) is provided to collect miscellaneous mercury streams. The sump is located at the low point of the reactor containment building to receive drips and drains from equipment and lines. It also acts as a receiver for surplus mercury leaving the primary system, condensed relief valve blowdown, makeup mercury, and contaminated mercury from the condenserboiler leak-detection system.

The sump is a $6^{\prime}$ OD $\times 18^{\prime}$ pressure vessel designed to hold the total mercury in the reactor systems. A $10-\mathrm{kw}$ immersion heater $(\mathrm{H}-4)$ is provided in the $2^{\prime} \mathrm{OD} \times 3^{\prime}$ pot on the bottom of the sump to heat stored mercury to system temperature or to vaporize water if necessary. Mercury is pumped from the sump by a long-shaft sump pump $(\mathrm{P}-4)$ provided with high-temperature seal. The pump is designed for a differential head of 90 feet, which is sufficient to pump mercury from the sump at atmospheric pressure to the elevated Mercury Cleanup Drum (D-1) at 110 psia. Merçury from the sump can be returned to the reactor system only through the cleanup drum. Remote operating pump discharge and bypass valves and remote pump starting are provided to facilitate normal or emergency makeup of mercury to the system. Sump pressure, temperature, and level are indicated in the control room. Flow rate to and from the sump is recorded and may be controlled manually from the control room.

\section{e. Mercury Recovery System}

Conventional mercury plant experience indicates that the oxide sludge collected in the cleanup drum will contain about $90 \%$ free mercury. A simple system is provided to recover as much of the mercury as possible and return it to the sump.

The collected sludge is periodically blown to the Mercury Recovery Furnace (H-2), which is an electrically heated retort with a conical bottom. The sludge is heated by electric coils to vaporize the mercury; the vapor is condensed in the small water-cooled Mercury Recovery Condenser (E-5) and then drained into the sump. A similar system has worked satisfactorily in conventional plants. Mercury losses in the sludge and losses due to sampling and adherence to fuel assemblies and equipment are conservatively estimated at 1500 pounds per year.

The sludge will be radioactive and thus. cannot be removed manually as is done in conventional plants. A method of sludge disposal has been devised which involves the use of nitrogen to 


\section{MERCURY COOLED BREEDER REACTOR}

blow sludge from the retort into a concrete disposal cask. The cask has a recessed steel top with a valved stub. When the cask is full, the top and valve can be covered with concrete and the entire cask disposed of. Test work will be required to determine the nature of the sludge and to verify the feasibility of this method of disposal.

\section{f. Water-Removal System}

The only possible source of contamination of the mercury with water will result from a condenser-boiler tube leak or rupture. Water leakage is isolated and detected in the leak-detection system. The leaking unit can be isolated, and the reactor scrammed if necessary, before flushing out the contaminated mercury to the sump.

A system is provided to permit removal of the water from the sump. The sump is allowed to cool to about $250^{\circ} \mathrm{F}$ and is then held at this temperature by the sump heater. The water vapor present is vented from the sump and condensed in the small water-cooled Water Recovery Condenser $(E-6)$. The water can then be collected in a disposal cask similar to the oxide disposal cask or transported to the Waste Disposal Building in steel drums.

\section{Relief-Valve Blowdown System}

The large mercury relief valves and the thermal-expansion relief valves on the E-1 leakdetection.system and in the Mercury Cleanup Drum (D-1), which may release mercury vapor, discharge into a closed blowdown system. The system consists of a blowdown manifold and a coil-inbox cooler to condense the vapor. The Relief Condenser $(E-4)$ is designed with sufficient surface to completely condense the maximum mercury vapor rate. The condenser consists of a coil of finned tube sections.closely spaced in a concrete box. The box contains sufficient water to condense the total vapor rate for a period of one minute without vaporizing appreciable water. The relief condenser is located adjacent to the reactor containment vessel, and any steam formed is vented to the atmosphere. An alarm is provided to warn of low water level.

The thermal-expansion relief valves on the steam side of the condenser-boilers release to the atmosphere.

\section{Reactor Evacuation System}

Prior to each startup of the reactor, the system will be evacuated with the Reactor Evacuation Pump (P-6). After shutdown, the vacuum is broken with nitrogen. This simple system is adequate for removing oxygen to a level at which magnesium and titanium oxidation will be normal. During subsequent heatup of the system, all high points will be vented to a closed vent system to remove non-condensable gases. The gases, which will be slightly radioactive, will be diluted with 
large quantities of air and discharged up the stack. No inert gas blanketing system is required with mercury.

\section{Shield Cooling System}

Heat generated in the reactor biological shields is removed by a closed water cooling system consisting of Shield Coolant Pumps (P-5A and P-5B), Coolers (E-3A and E-3B), Drum (D-5), and, cooling coils imbedded in the stabilized sand-water shield and the concrete outer shield surrounding the reactor. The system is designed to remove $0.075 \%$ of the reactor heat generation rate at full power or $720,000 \mathrm{Btu} / \mathrm{hr}$. Two rows of cooling coils spaced on 2 -foot centers are imbedded in the sand-water shield and one row in the concrete shield. The coils are fabricated of $2 \frac{1}{2}$ inch, schedule 40, carbon steel pipe. Treated demineralized water is circulated at $50 \mathrm{gpm}$ through the coils by a centrifugal pump, and the heat is removed in a water-cooled tube-in-shell cooler. A spare pump and cooler are provided to insure continuity of operation. The system.is designed for a maximum coolant temperature of $180^{\circ} \mathrm{F}$ to prevent water loss and internal stresses in the shield that would reduce the shielding efficiency. The coolant drum is designed to contain the total water in the system. Coolant flow and temperature are indicated in the control room, and alarms are provided to warn of low flow, low coolant drum level, and high temperature.

\section{Instrumentation and Controls Systems}

System design for the MCBR reactor plant is similar to that for conventional plants. The primary aim of the instrumentation and controls systems is to provide for safe and efficient operation of the plant. The number of controls included is the minimum required for satisfactory operation. Wherever possible, normal operating, startup, and shutdown procedures are automatic. Essential controls may be either automatically or manually operated to permit servicing of automatic equipment. Control, regulation, monitoring, and adjustment of operating variables is centralized in a control room located in the turbine-generator building. It is estimated that an operator and one assistant in the control room and a roving operator can routinely control the plant operation.

Reactor safety systems have been designed to provide for rapid scram when required, but an effort has been made to minimize reactor shutdowns for minor upsets or failures. All control valves will fail in a safe position. Failure of important devices or excessive deviation of important operating variables will be annunciated. Failure of critical devices will automatically scram the reactor. The following unacceptable conditions initiate scram: 


\section{MERCURY COOLED BREEDER REACTOR}

1) High turbine condenser pressure.

2) Low feedwater flow.

3) High reactor exit vapor quality.

4) Control rods fully withdrawn.

5) High reactor vapor-plenum pressure.

6) Popping of reactor relief valves.

7) Short reactor period.

8) High reactor power level.

a. Process Instrumentation

Process control points and instrumentation for the reactor plant have been outlined under discussions of the individual systems. Over-all operating, startup, and shutdown control procedures will be discussed later. Process instrumentation and controls are shown on Dwg. R-181.

b. Nuclear Instrumentation

The nuclear instrumentation system, as shown on Dwg. C-188, is patterned after the EBR II system. There are eight nuclear channels divided into the following groups:

1) Two startup channels that indicate reactor period and record log count rate during startup and fuel-transfer operations.

2) Two intermediate log power channels that indicate period and record log count rate.

3) One linear power channel that provides a linear flux signal.

4) Three safety channels that shut down the reactor under abnormally high flux conditions.

The channels in each group have a common $\log N$ flux recorder. Necessary switches are provided to permit switching channels and bypassing startup channel trips. Fission counters are used to measure neutron flux during startup. Compensated ionization chambers are provided for the power channels to discriminate against fission gamma background, particularly at low power levels.

Short reactor period or high power level will actuate trips and automatically scram the reactor.

10. Fuel-Handling System

Over-all fuel-transfer procedures and preliminary design features of fuel-handling mechanisms have been established. Since mercury can be exposed to air at low temperatures without danger or excessive oxidation, the fuel-transfer operation can take place with the reactor cover removed. This greatly simplifies the procedures and equipment employed as compared to that 
required for sodium-cooled reactors. The primary restrictions are a) mercury temperature must be reduced to about $200^{\circ} \mathrm{F}$ to minimize vaporization, and b) personnel must be shielded from the radioactive mercury during the transfer operation. A stepwise fuel-transfer procedure is presented in section F, "Plant Operating Procedures."

The fuel-transfer system devised consists of an indexing plate, a fuel-transfer cask with grappling mechanism, a fuel-decay storage tank, and the main reactor containment building crane. The cask and indexing plate are used only during the transfer operation and are normally stored on the operating floor. Prior to transfer of fuel, the core holddown assembly must be removed from the reactor and stored in the shielded storage room provided on the first subgrade level of the containment building. The indexing plate is lowered into the reactor to shield personnel while they are removing the holddown assembly retaining nuts. The assembly is then connected to the indexing plate; and both plate and assembly are transferred to the assembly storage room. Location of the fuel-transfer equipment is shown on Dwgs. F-185 and F-186.

\section{a. Indexing Plate}

The indexing plate is a $9.5^{\prime}$ OD $\times 12^{\prime \prime}$ thick plate similar to that designed for the EBWR. The plate consists of a support ring and two eccentrically disposed rotating discs. The two geared discs are rotated manually so as to align a plugged, stepped hole over a given assembly in the core or blanket. Attached to the plug is an offset rod that is used to push out and reset the plug. The plate also serves to shield personnel working over the reactor during the entire transfer operation and also when connecting and disconnecting the core holddown assembly from the plate. A disciussion of the shield design basis is given in the Shield Design section. The plate is supported and aligned in the upper part of the reactor vessel by the same lugs that support and align the core holddown assembly: These lugs are shown on Dwg. F-182.

\section{b. Fuel-Transfer Cask}

Fuel and blanket assemblies are transferred to and from the reactor in a $4^{\prime}$ OD $\times 12^{\prime}$ water-cooled transfer cask similar to that used on the EBWR. The cask is a steel cylinder with 22-inch-thick walls designed to provide biological shielding for the most radioactive fuel assemblies. The top of the cask is plugged and the lower end is closed by a sliding door. Decay heat generated in the assemblies will be removed in the cask by a water cooling coil wrapped around the assembly space.

The grappling mechanism for retrieving the assemblies is contained within the cask and consists of a tool and actuating mechanism for grappling the handling head on the assembly, a tubular 


\section{MERCURY COOLED BREEDER REACTOR}

shaft, which telescopes to reduce head room requirements, and necessary safety latches to prevent accidental release of the assembly during:transfer. The tool is inserted and retracted manually, and the latch is actuated manually. Gear ratios are such that fuel cannot be inserted into the core at excessive rates. A cylindrical skirt is provided at the base of the cask to minimize dose rate at this point. Two casks are provided to speed the fuel-transfer operation.

\section{c. Fuel-Decay Storage Tank}

Fuel assemblies will be allowed to decay for 90 days before being removed from the containment building. A concrete-shielded Fuel Decay Storage Tank $(\mathrm{K}-1)$ is provided in which to -store and cool the assemblies. This tank is located on the first subgrade level of the reactor containment building, with access to individual storage pots through plugs in the operating floor. Because of the large fuel mass $(9.32 \mathrm{~kg} \mathrm{U} \mathrm{235)}$ in each core assembly, safe storage in a water pool to remove decay heat is questionable. The assemblies are therefore stored in individual mercury-filled finned pots and cooled by air.

The fuel-decay storage tank is a 4-foot-thick concrete box with concrete shield cover. The individual pots are fabricated of 4 -inch, schedule $30,5 \mathrm{w} / \mathrm{o} \mathrm{Cr}, \frac{1}{2} \mathrm{w} / \mathrm{o}$ Mo steel finned pipe and are suspended in a rack. A blower pulls in air through the containment building air intake and blows it across the pots and out the main stack. The tank is designed to hold 130 core and control-rod assemblies and 40 blanket assemblies at one time. This storage space is based on removal of $50 \%$ of the core assemblies and $9 \%$ of the blanket assemblies after six months of operation at full power. The blower is designed to remove maximum decay heat ( $1 \%$ of maximum power) from this number of assemblies. The mercury in the pots insures subcriticality of the stored assemblies and thereby permits close spacing. Removable stepped plugs in the cover provide access to the storage pots.

11. Reactor Containment Vessel (Dwgs. F-185, F-186, F-187)

The reactor containment vessel is a $75^{\prime}$ OD $\times 115^{\prime}$ over-all length, cylindrical, steel pressure vessel with $\frac{1}{2}$-inch-thick shell, 5/16-inch-thick hemispherical top head, and $\frac{1}{2}$-inch-thick flanged and dished elliptical bottom head with 7/8-inch-thick knuckle. The vessel is designed in accordance with the ASME Boiler and Pressure Vessel Code, Section VIII, for Unfired Pressure Vessels (1959 Edition and Case Interpretations for Nuclear Installations). The shell and heads are to be fabricated of ASME Specification SA-201, Grade B steel, conforming to ASME Specification SA-300. All joints are to be double butt welded, radiographed, and fully inspected and leak tested. The lower portion of the vessel, which contains no penetrations, would be erected, then inspected and encased in concrete, in accordance with the code. The top portion of the vessel would be 
erected after installation of the internals and the complete vessel pressure-tested. The upper vessel shell is penetrated by a large bolted equipment door, a personnel air lock, an emergency air lock, and necessary piping and electrical conduit penetrations. Chicago Bridge \& Iron Co. assisted with the design of the containment vessel.

The vessel is designed to contain all radioactive mercury and fission products released from the reactor in the event of a major accident. The worst credible accident is assumed to be rupture of the reactor vessel or primary piping due to simultaneous loss of coolant flow and failure of control rods. A maximum internal pressure of 15 psig has been used in design of the vessel. This pressure is based on the consequences resulting from meltdown of one-third of the reactor core. Energy sources from the core meltdown plus thermal energy stored in the mercury in the reactor and primary lines were considered. Chemical reaction between mercury and materials present is not a factor. In the event of a rupture in the system, the coolant would be flashed into the containment vessel, where it would give up some of its energy to the contained air and produce a rapid increase in pressure. The maximum equilibrium pressure in the free volume of the vessel selected was calculated at $15 \mathrm{psig}$. Air contained in the vessel was assumed to be at $80^{\circ} \mathrm{F}$. It was conservatively assumed that no condensation of mercury vapor would occur during the emergency period.

C. POWER-GENERATION PLANT DESCRIPTION

A detailed design of the power-generation plant is beyond the scope of this contract, but the overall characteristics of the plant have been established to permit estimating total plant cost based on reliable costs for plants of similar size. The plant will be a standard power-generation plant consisting of a turbine-generator set, condenser, regenerative feedwater heaters, deaerating heater and storage tank, condensate and feedwater pumps, condensate storage tank, and extensive watertreatment facilities.

The power-generation plant will supply "ultra-purity" feedwater at a constant temperature of $450^{\circ} \mathrm{F}$ to the condenser-boilers. The $1,020,000 \mathrm{lb} / \mathrm{hr}$ of 1800 -psig steam produced at a constant temperature of $900^{\circ} \mathrm{F}$ will be routed to a standard, tandem-compound, double-flow, condensing turbine with reheater and five extraction openings. Steam flow to the turbine will be regulated by a turbine governor control, and surplus steam will be desuperheated and dumped to the condenser, which will operate at $1.5 \mathrm{in} . \mathrm{Hg}$ absolute. Condensate from the main condenser is pumped through two regenerative feedwater heaters to an elevated deaerator heater and storage tank. Sufficient storage is provided in the deaerator storage tank to supply emergency cooling water by gravity flow to the condenser-boilers for five minutes in the event of feedwater pump failure. Feedwater from the 


\section{MERCURY COOLED: BREEDER REACTOR}

deaerator storage tank is pumped through a reheater-drains cooler and two regenerative feedwater heaters to the condenser-boilers. Extraction steam rate to the last heater is automatically controlled to maintain feedwater temperature at $450^{\circ} \mathrm{F}$. Flow through the power-generation plant is shown schematically on Dwg. D-180.

Makeup water to the plant will pass through water-treatment, filtration, and demineralization facilities located in the water-treatment building. "Ultra-purity" of the feedwater will be maintained by routing a portion of the condensate through a bypass filtration and demineralization system and back to the condenser. The low-pressure feedwater heater drains, which may contain appreciable corrosion products, will be returned directly to the condenser so that they are demineralized immediately in the bypass system. A storage tank will handle condensate surge.

\section{PLANT SITE}

For the conceptual design and for estimating purposes, the plant site was arbitrarily selected on level ground adjacent to a reliable water source and convenient to roads, railway transportation, sewers, and other utilities. The plant will be a "grass roots" installation in a reasonably isolated location near a center of population. Moderate weather conditions, grade, and soil conditions are assumed for the site. Six acres of land are required for the plant as laid out. For estimating purposes, it is assumed that the plant site will be graded, paved, .and fenced. Elaborate architecture or extensive landscaping have not been provided for.

\section{E. PLANT LAYOUT}

The 100-mw(e) nuclear power plant consists of a boiling-mercury fast breeder reactor, condenser-boilers, a standard steam turbine-generator plant complete with auxiliaries and substation, waste disposal and maintenance shop facilities, and necessary control rooms, laboratories, and offices. The major components of the power plant are grouped in six buildings: reactor containment, turbine-generator, water treatment, maintenance shop, waste disposal, and office. The general arrangement is designed to provide adequate staging areas and to effect economy and continuity of construction, operations, and maintenance. Road access is provided to all buildings, and railway spurs service the reactor, turbine-generator, shop, and waste-disposal buildings.

Over-all plant layout is shown on Dwg. D-189 and also on the plant illustrations included as a frontispiece to this report.

\section{Reactor Containment Building}

Essentially all facilities comprising the nuclear reactor portion of the plant are housed in a conventional containment vessel. A cutaway illustration of the containment building is included on the 
frontispiece to the report. Plans and sections of the containment building are shown on Dwgs. F-185, F-186, F-187. The design basis for the containment vessel is discussed in an earlier section.

Layout of the reactor building and contained equipment has been predicated on the following basic principles:

1) The reactor vessel and all equipment normally containing mercury coolant must be located within the containment vessel.

2) The reactor vessel and mercury systems must be biologically shielded to permit personnel access to the containment building levels during operation.

3) Plugs and remote valving must be provided to permit access to individual pieces of equipment after draining.

4) Relative elevations of equipment must satisfy pump suction, natural circulation, drainage, venting, and piping-expansion requirements.

5) Equipment must be arranged so as to minimize mercury holdup and building size and to simplify piping.

Consistent with these principles, a $75^{\prime} \mathrm{OD} \times 115^{\prime}$ steel containment building with a shielded operating floor at grade and four operating levels below grade has been selected. The reactor and essentially all auxiliary equipment are located on the four subgrade levels. The concrete coil-in-box type Relief Condenser (E-4, Dwg. R-181) and the Mercury Shutdown Cooler (E-2) are located outside and immediately adjacent to the containment building at grade. A shielded stairway and equipment hoist provide normal access to the three subgrade levels containing equipment. A brief description of the equipment at each level is presented below.

a. Operating Floor (Plan I, Dwg. F-186)

The operating level is biologically shielded from the reactor and auxiliaries below. Removable shielding plugs provide access to the reactor vessel, condenser-boilers, fuel-decay storage tank, and core holddown assembly storage room. A 50-ton traveling-bridge two-hook crane handles the shield plugs, reactor cover and holddown assembly, and fuel-transfer cask and indexing plate. The condenser-boiler plugs, covers, and bundles are removed by a stationary hoist. A railway track facilitates transfer of equipment and fuel-assembly casks through the equipment door. Space is provided for storage of the fuel-transfer equipment and for a spare condenser-boiler shell unit. Entry to the stairway and equipment hoist is from this level. 


\section{MERCURY COOLED BREEDER REACTOR}

b. First Basement (Plan II, Dwg. F-186)

The first subgrade floor contains the fuel-decay storage tank, condenser-boilers, the core holddown assembly storage room, reactor evacuation pump, and building air conditioning equipment. Access to the tank, condenser-boiler, storage room, and vapor line valves and instrumentation is from the operating floor. Individual condenser-boilers are enclosed in shielded compartments to permit maintenance during operation after complete draining. A stairway provides access to the evacuation pump and air conditioning equipment.

c. Second Basement (Plan III, Dwg. F-186)

The second subgrade level contains the magnesium and titanium injection chambers, mercury recovery system, mercury cleanup drum, mercury startup heaters, and shield cooling system drum, pumps and coolers. Access to this level is provided by the stairway and hoist. The mercury equipment is separated in individual shielded compartments to permit access for operational and maintenance reasons without shutting down the plant.

d. Third Basement (Plan IV, Dwg. F-187)

Space is provided on the third subgrade level for piping runs and for the mercury-level drum. Normally, there will be no access to this level.

. e. Fourth Basement (Plan V, Dwg. F-187)

This level contains the mercury recirculating pumps, auxiliary mercury pumps, mercury shutdown pump, mercury sump and sump pump, and water-removal system. Individual pumps are contained in shielded compartments. Remote-operated and extension valves are provided to permit rapid switching and draining of pumps. The sump is at the lowest point in the system so that all equipment and lines can be drained into it.

2. Turbine-Generator Building .

For design and estimating purposes, a standard turbine-generator plant complete with feedwater heaters and pumps, condenser, reheater, deaerator, condensate pumps and bypass demineralizer, electrical switchgear, instrument air compressors, and attendent equipment has been selected. These facilities are contained in a $100^{\prime} \times 150^{\prime}$ building located adjacent to the reactor containment building. The turbine-generator building also houses a control room and laboratory for the entire power plant.

3. Water-Treatment Building

The water-treatment building houses cooling water pumping, straining, and treatment facilities and makeup feedwater filtering, demineralization, and treatment facilities. A condensate storage tank is located adjacent to the turbine-generator building. 


\section{Office Building}

A one-story office building with $2500 \mathrm{sq}$. $\mathrm{ft}$. of floor space provides offices for general administrative, engineering, health physics, and accounting personnel.

\section{Maintenance Shop}

The shop houses equipment, spare parts, and materials required for performing normal maintenance operations on a conventional power plant.

\section{Waste-Disposal Building}

A separate $30^{\prime} \times 40^{\prime}$ building houses the nominal waste-disposal facilities. The building contains a shielded hot cell and remote manipulator, large and small autoclave for removing radioactive mercury from equipment prior to maintenance, and radioactive water decay tanks and demineralizer. Space is provided for storing disposal casks, new fuel elements, mercury flasks, and a stock of magnesium and titanium. An overhead monorail hoist is provided to facilitate handling of equipment and materials.

\section{F. PLANT OPERATING PROCEDURES}

Operating control points and the functions of equipment and controls during startup, normal operation, and shutdown have been discussed in detail with the individual systems and in the Instrumentation and Controls Systems section. The latter summarizes the stepwise operating procedures for the plant as a whole. The Piping \& Instrument Diagram, Dwg. R-181, should be referred to for equipment numbers and to follow flow and instrumentation for the reactor plant.

\section{Startup Procedure}

Normal startup presumes that the reactor has been opened for fuel transfer. Startup procedures may be initiated when all equipment has been closed and pressure-tested, the fuel and blanket assemblies are in place, all control rods are withdrawn, and auxiliary mercury systems are full of mercury. If the reactor system has been shut down for some time, all mercury should be circulated through the cleanup system prior to sta'rtup, and magnesium and titanium added if necessary. During normal shutdiown, mercury will be continuously recirculated through the shutdown cooling system, and this flow will be maintained during startup. The shield cooling system will operate at all times. The plant may then start up in the following sequence:

(1) Start pump P-6 and evacuate R-1 and primary system lines and equipment to remove nitrogen and air.

(2) Start pump P-3, recirculating mercury through D-1 and spraying cold mercury over the core and blanket assemblies. 


\section{MERCURY COOLED BREEDER REACTOR}

(3) Shut down pump P-2 and open the vapor line to condenser E-2.

(4) Start heaters $\mathrm{H}-1 \mathrm{~A}$ and $\mathrm{H}-1 \mathrm{~B}$ and heat mercury at about 50 degrees per hour.

(5) As the mercury temperature rises, open valves to permit the primary system downstream of E-1A, B, and C to fill with mercury. Liquid level will be maintained well up in the core by pumping mercury into D-1 from sump D-2 with pump.P-4. Liquid . spraying from above will insure heat transfer from the exposed fuel-pin surfaces above the liquid level.

(6) When mercury temperature reaches $600^{\circ} \mathrm{F}$, drain sufficient mercury to sump D-2 to maintain low-power operating level in the core. Vent all high points to remove noncondensable gases.

(7) Gradually insert operating control rods and bring mercury to its saturation temperature, $675^{\circ} \mathrm{F}$.

(8) Condense initial vapor formed in shutdown condenser E-2 and control recycle liquid rate to maintain level above thermal shield.

(9) Start flow of ultra-purity feedwater through feedwater system and start E-1 leakdetection system.

(10) When feedwater flow is established, bleed small amounts of vapor through the condenser-boilers to gradually heat these units and establish natural circulation through the primary system. Steam generated will be dumped to the main condenser, bypassing the turbine.

(11) Raise reactor power level at a prescribed rate and increase vapor flow through E-1A. Block off condenser $\mathrm{E}-2$.

(12) When $20 \%$ of full power is reached, start pump P-1A and manually control pumping rate to maintain reactor vapor quality at $30 \%$. Drain sufficient mercury to sump D-2 to maintain level in D-6 at 12 to 15 feet above pump suction.

(13) Adjust ratio of flows to core and blanket inlet plenums.

(14) Gradually increase reactor pressure by manual adjustment of feedwater rate until 95 psig and $920^{\circ} \mathrm{F}$.are reached.

(15) Continue to increase power level, cutting in E-1B and E-1C and pump P-1B when required.

(16) Route steam to turbine at desired power level and adjust condensate and feedwater systems. 


\section{Normal Operation}

The reactor will operate as a base load unit, and power level will be adjusted manually to correspond to anticipated power demand. Operating variables in the steam, feedwater, condensate, and reactor systems are, in general, controlled automatically. Details of these controls have been discussed earlier. Mercury and feedwater must be sampled routinely to maintain purity. Magnesium and titanium concentration of the mercury must be watched closely. About $1 \%$ of total mercury flow will be routed through the cleanup system under normal operating circumstances.

\section{Shutdown Procedure}

For anticipated shutdowns, e.g., fuel transfer, the following procedure will be followed;

(1) Prior to shutdown, bleed vapor through shutdown condenser E-2 to heat the system.

(2) Gradually reduce power level at a predetermined rate.

(3) Begin dumping steam generated to the main condenser, bypassing the turbine.

(4) Place steam, feedwater, and mercury systems on hand control and gradually reduce reactor pressure.

(5) Continue to reduce power level; bypass E-1B and C and pump P-1B when vapor rate is sufficiently reduced.

(6) Increase mercury level in reactor by pumping down level in D-6 and primary system lines as far as possible.

(7) Block off D-1 but continue to recirculate through spray ring with pump P-3 to insure fuel-element cooling.

(8) Withdraw control and safety rods and shut down last condenser-boiler and recirculating pump. The vapor generated will be condensed in $\mathrm{E}-2$.

(9) Raise level in reactor to 6.5 inches above blanket by pumping mercury out of sump D-2..

(10) Start shutdown pump P-2 and cool liquid to $200^{\circ} \mathrm{F}$.

(11) Stop pump P-3 but continue to recirculate through E-2 with pump P-2 during entire shutdown period to remove decay heat.

(12) Break vacuum with nitrogen and proceed with fuel-transfer procedure.

4. Fuel-Transfer Procedure

The following stepwise procedure will accomplish unloading and loading of the core and blanket assemblies:

(1) Reduce reactor power to zero by withdrawing all control rods.

(2) Raise mercury level in reactor to 6.5 inches above blanket. 
(3) Begin recirculating mercury through shutdown cooler E-2 with shutdown pump P-2. Cool mercury to $200^{\circ} \mathrm{F}$.

(4) Relocate new core and blanket assemblies from storage to fuel-decay storage tank, leaving one open space.

(5) Remove the four reactor top shield plugs with crane and store on the operating floor.

(6) Remove reactor vessel cover holddown nuts manually.

(7) Remove core holddown assembly storage room cover with crane.

(8) Attach one crane hook to reactor vessel cover and the other hook to the indexing plate.

(9) Evacuate all personnel from building; remove cover and insert indexing plate in the reactor remotely.

(10) Manually remove core holddown assembly retaining nuts and attach holddown assembly to plate. Attach second crane hook to holddown storage room cover.

(11) Evacuate personnel, and transfer plate and holddown assembly into holddown assembly storage room remotely. Disconnect plate from holddown manually.

(12) Return indexing plate to position in reactor remotely.

(13) Replace holddown storage space cover remotely.

(14) Manually rotate indexing discs until hole is positioned over assembly to be removed.

(15) Position transfer cask over index hole and push plug out of way.

(16) Open cask bottom door and lower tool over assembly handling head and engage latch.

(17) Withdraw assembly, close cask bottom door, and reset plug.

(18) Transfer the cask to fuel-decay storage tank.

(19) Start blower, push out plug, and position cask.

(20) Open cask door and lower assembly into storage pot.

(21) Reset plug and close cask door.

(22) Position cask over fresh assembly and pull assembly into cask, using reverse procedure.

(23) Lower fresh assembly into reactor and repeat procedure, using two casks until all fresh assemblies are in reactor.

(24) Store the casks and attach the crane hooks to indexing plate and the holddown storage room cover.

(25) Evacuate personnel and remove holddown storage room cover remotely.

(26) Lower indexing plate onto holddown assembly and make connection manually. Evacuate personnel. 
(27) Lower holddown assembly into reactor remotely.

(28) Manually install holddown assembly retaining nuts and disconnect indexing plate.

(29) Replace holddown assembly storage room cover and attach second crane hook to reactor vessel cover.

(30) Evacuate personnel, remotely remove indexing plate, and position reactor vessel cover.

(31) Manually install reactor vessel cover retaining nuts. Replace shield plugs.

(32) Initiate normal startup procedure. 
THIS PAGE

WAS INTENTIONALLY

LEFT BLANK 


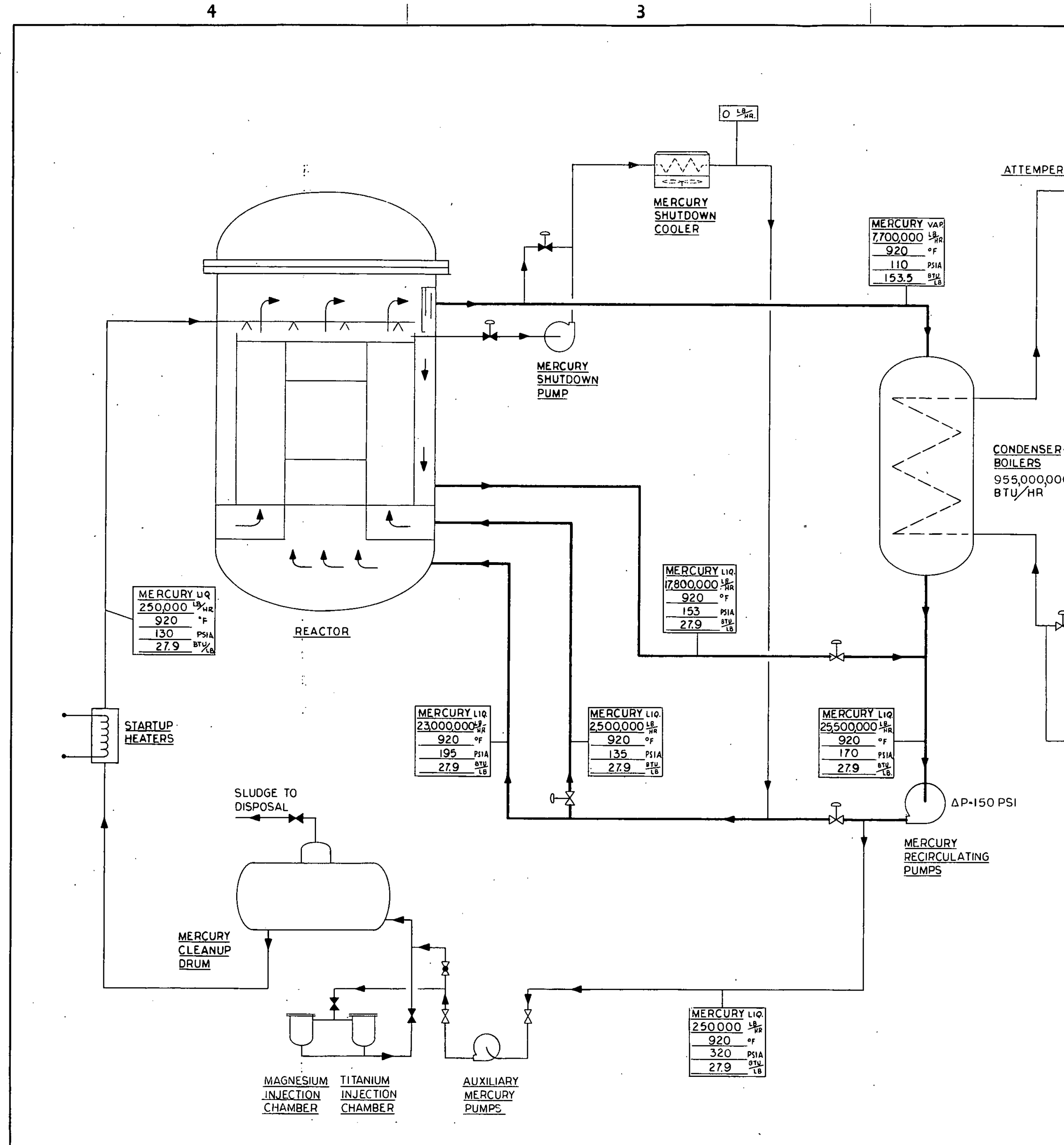

2

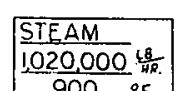

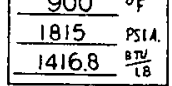

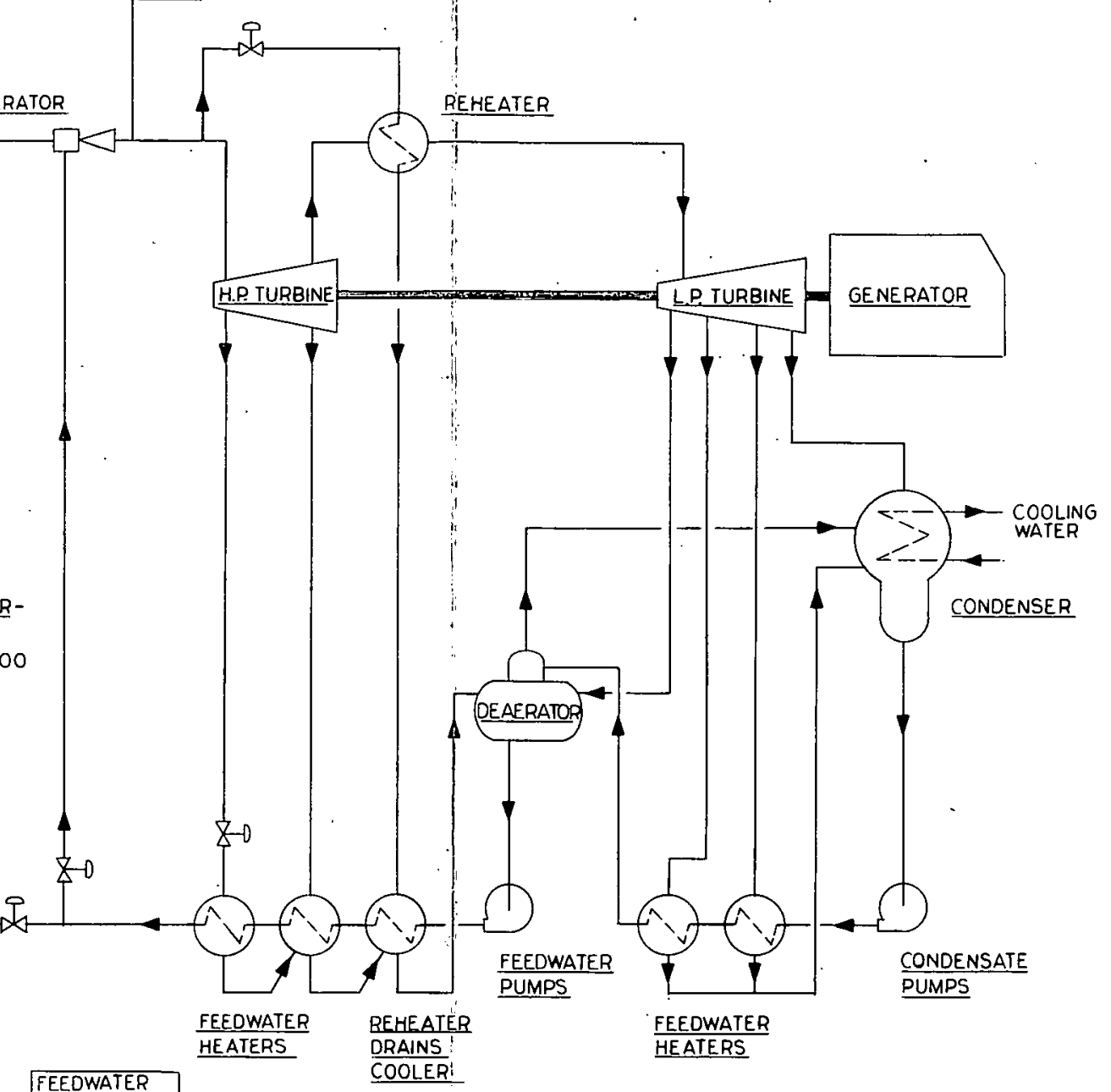

$\frac{\text { EEOWWALR }}{.020 .000}$

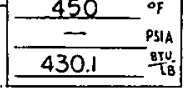

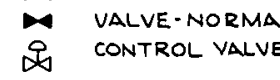

-REFERENCE DRAWINGS-

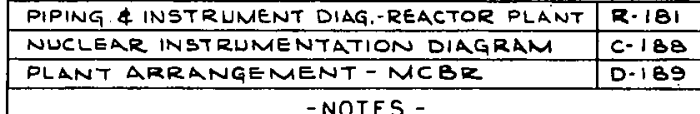
FOR COMPLETE LIST OF REERENCE
ORRWINGS SEE PLANT ARRANGE MENT
DWG. D. IG9.

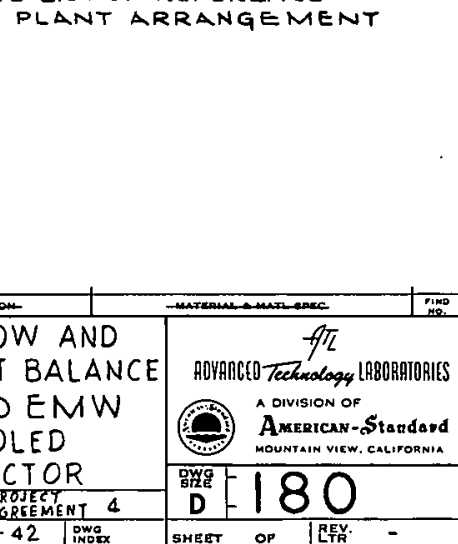


THIS PAGE

INTENTIONALLY LEFT BLANK 


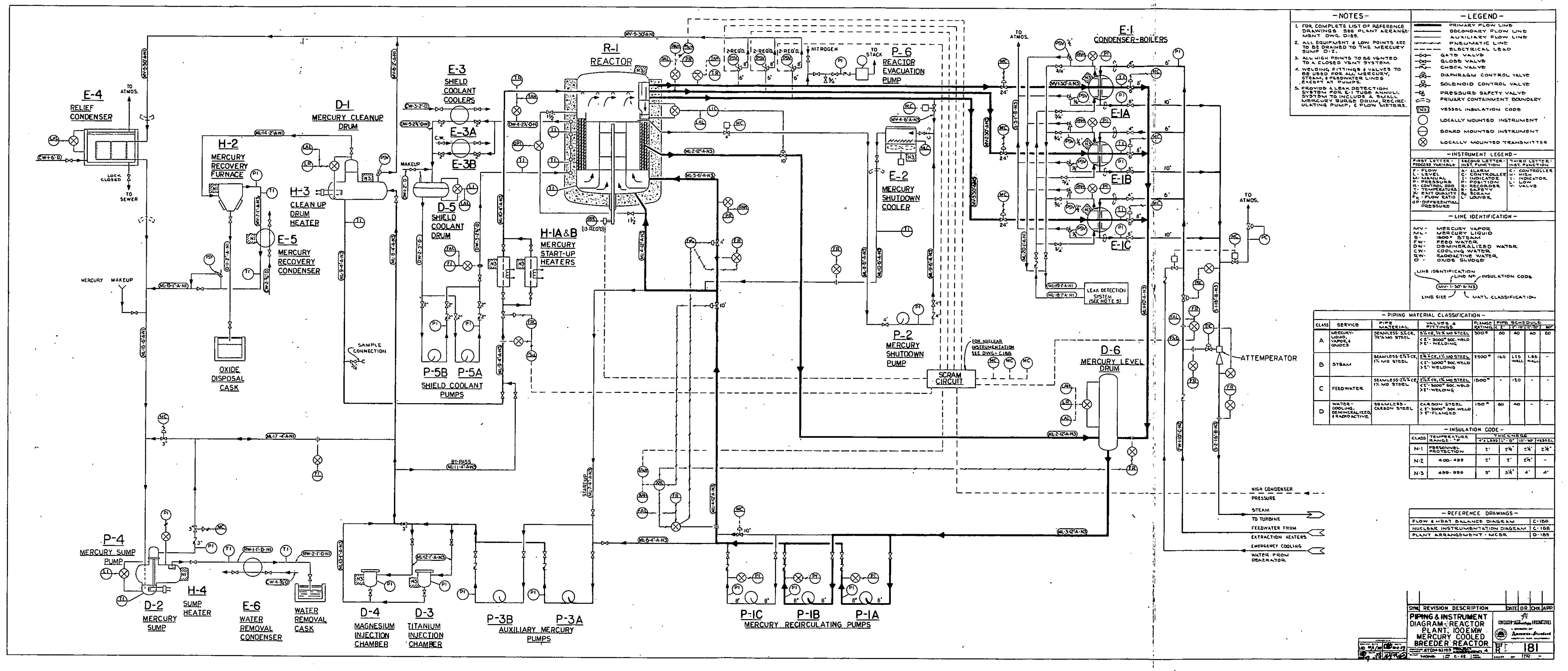




$$
\text { THIS PAGE }
$$

WAS INTENTIONALLY LEFT BLANK 


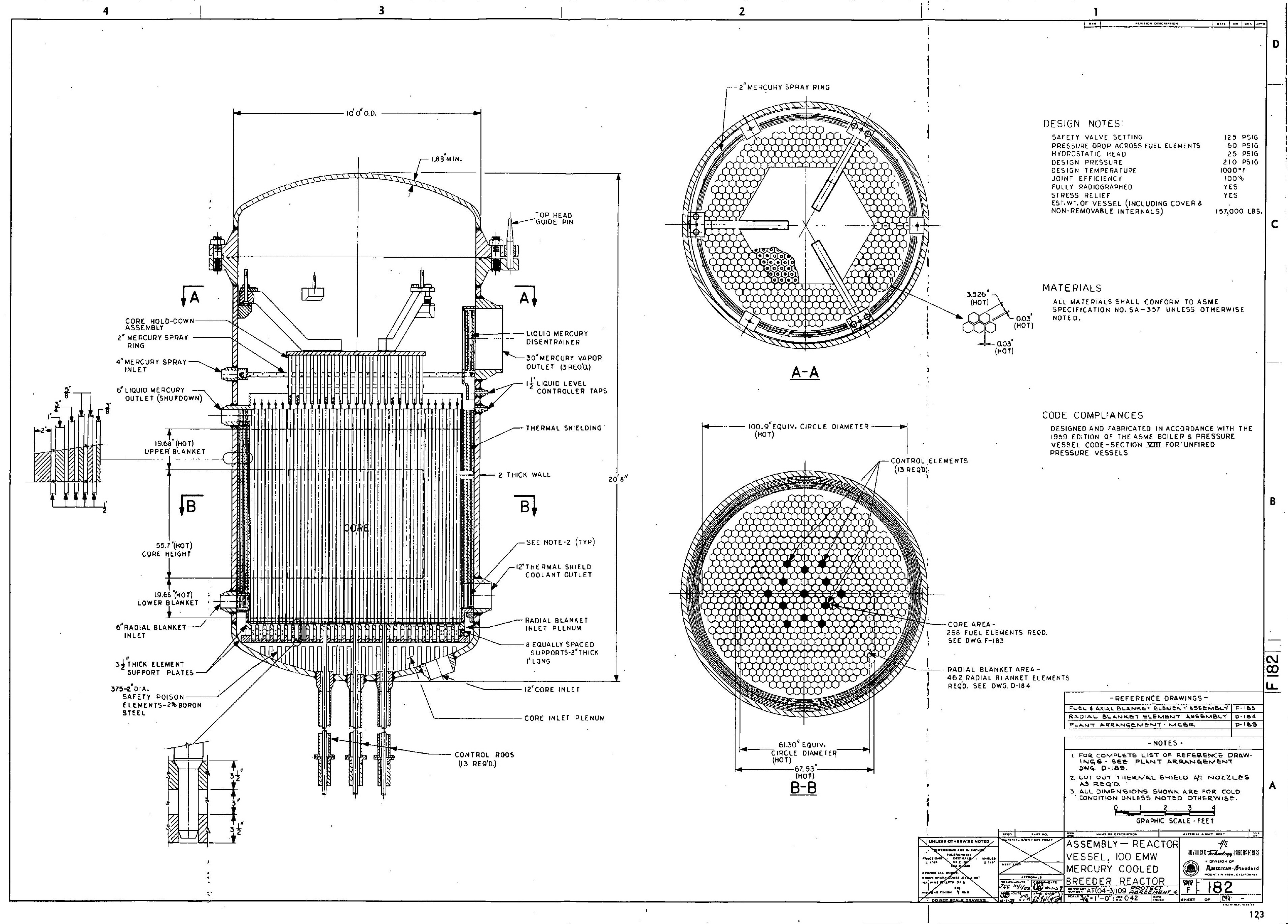


THIS PAGE

WAS INTENTIONATIY

LEFT BLANK 


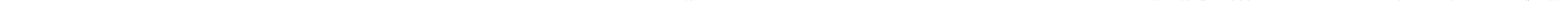


TH.IS PAGE.

WAS INTENTIONAITY LEFT BLANK 
$93.10^{\prime \prime}$

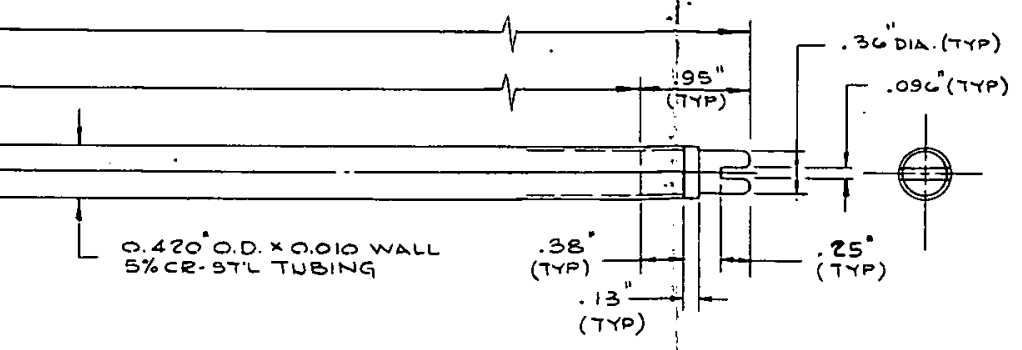

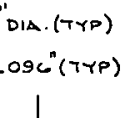

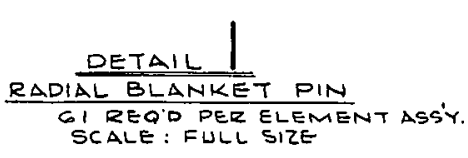

$118.28^{11}$ $-1$ $0.75^{\prime \prime}$
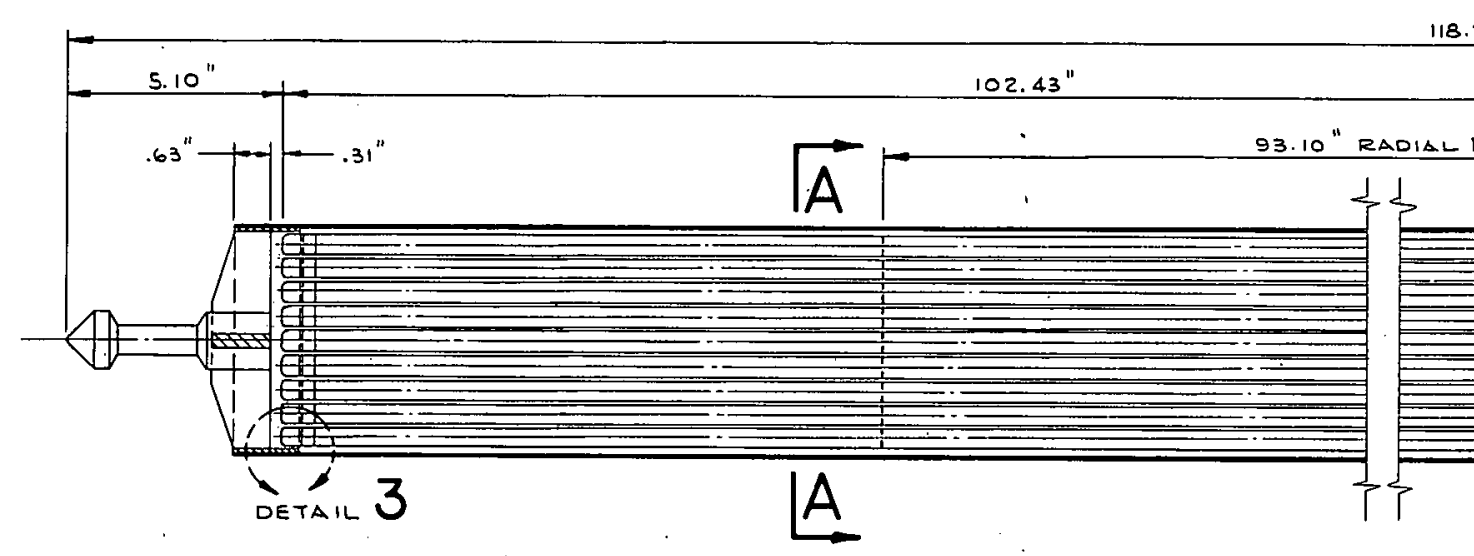

RADIAL BLAM DETAIL 2

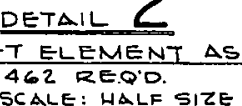

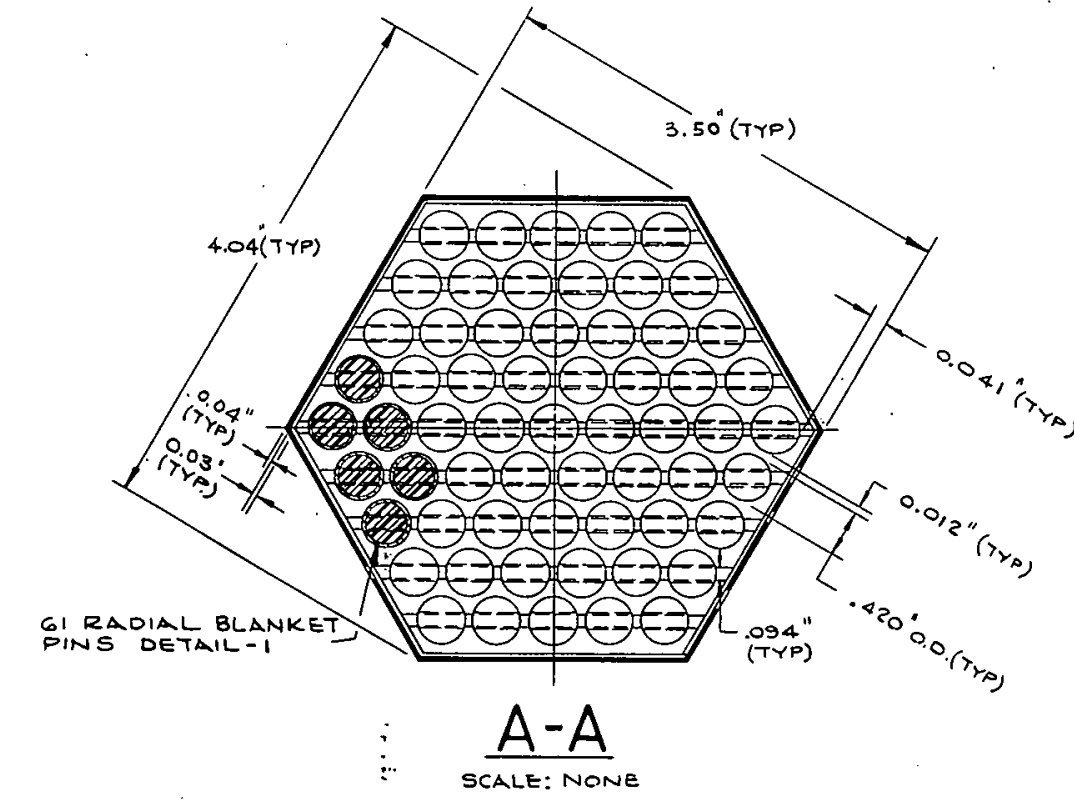

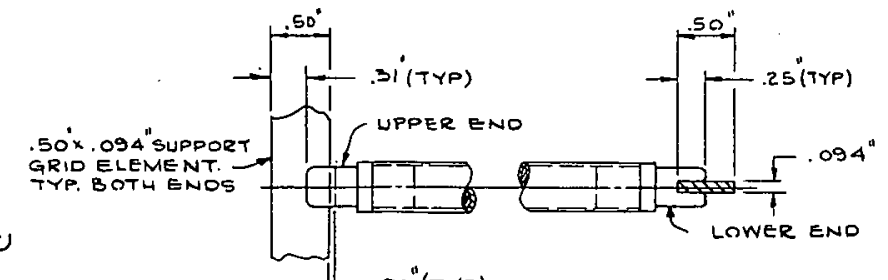

$-00(7+1)$

DetaIL 3

$\frac{A-A}{\text { scalt: Nowe }}$
SEALE : FuLL șize

\begin{tabular}{|l|l|}
\hline \multicolumn{2}{|c|}{ - REFERENCE DRAWINGS - } \\
\hline ASSEMBLY REACTOR VESSEL \\
\hline RSEA
\end{tabular}

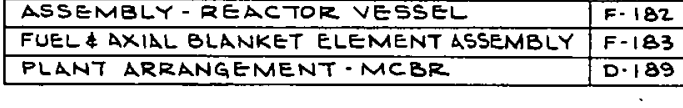
PLANT ARRANGEMENT MCDO

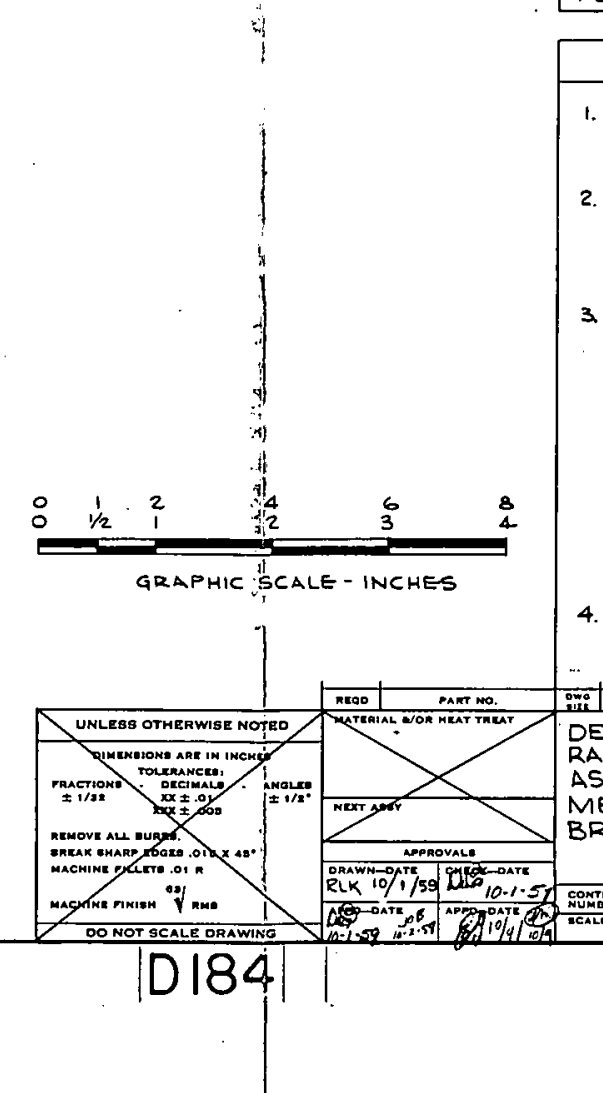

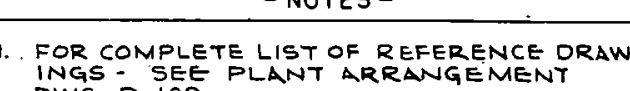
DESIGN CONDITIONS:

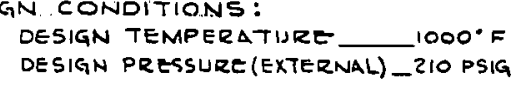

3. MATERIALS:

BLANKET FUEL CLADDING\& BALANCE OF STRUCTURE Thorh, composition: $4.6 \% \mathrm{CR}$,
$.5 \% \mathrm{SI}$,
$.5 \%$ Mo,

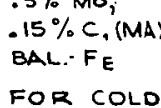
4. ALL DIMENSIONS SHOWN ARE FOR COLO
CONDITION UNLESS OTHERWISE NOTED.

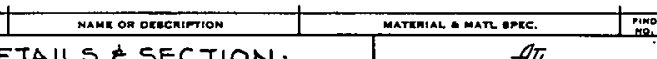
ADOALBLANCTION MERCURY, COOLED
BREEDER REACTOR 
THIS PAGE

WAS INTENTIONALIY LEFT. BLANK 


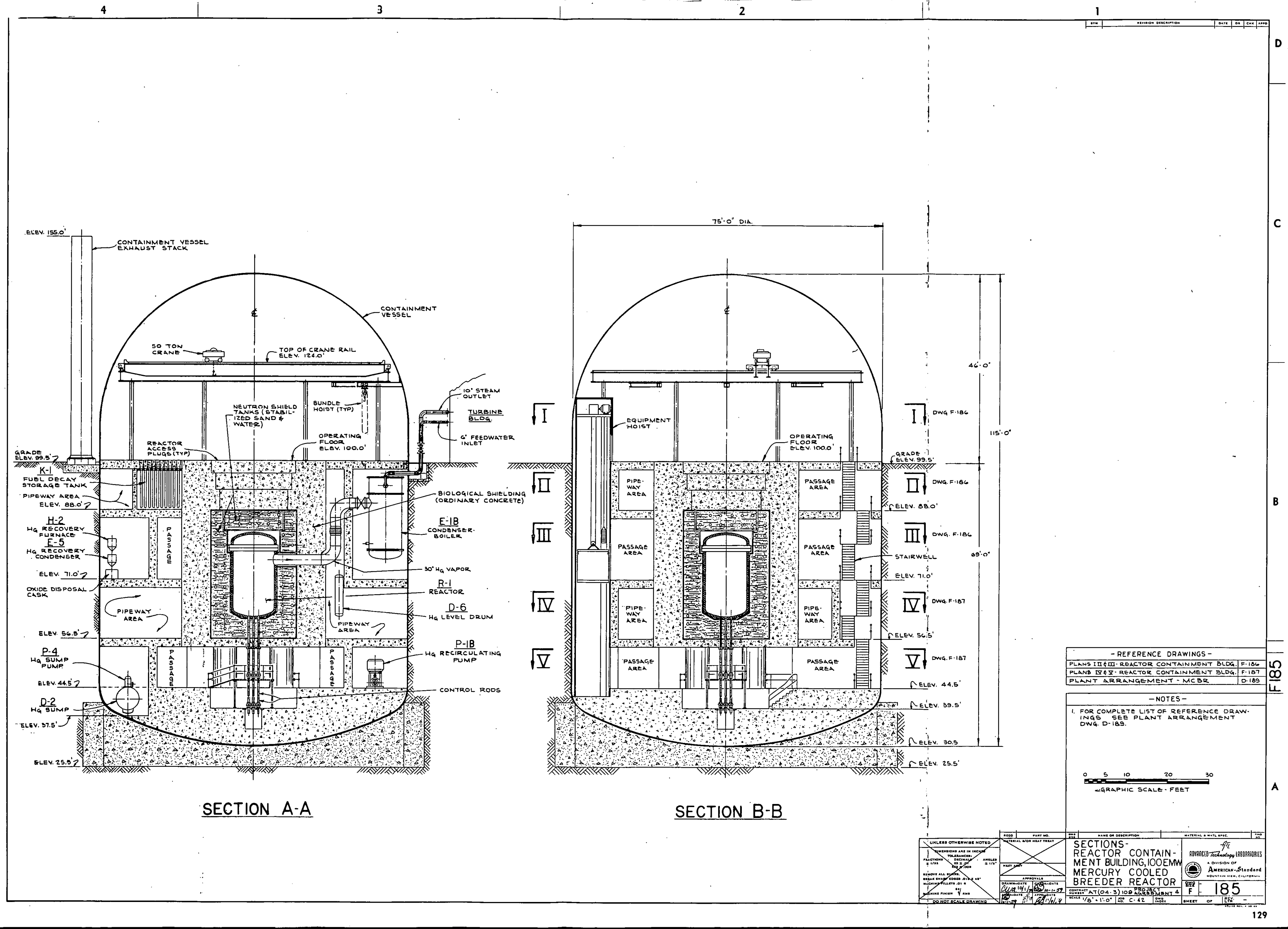


THIS PAGE

WAS INTENTIONALLY LEET BLANK 


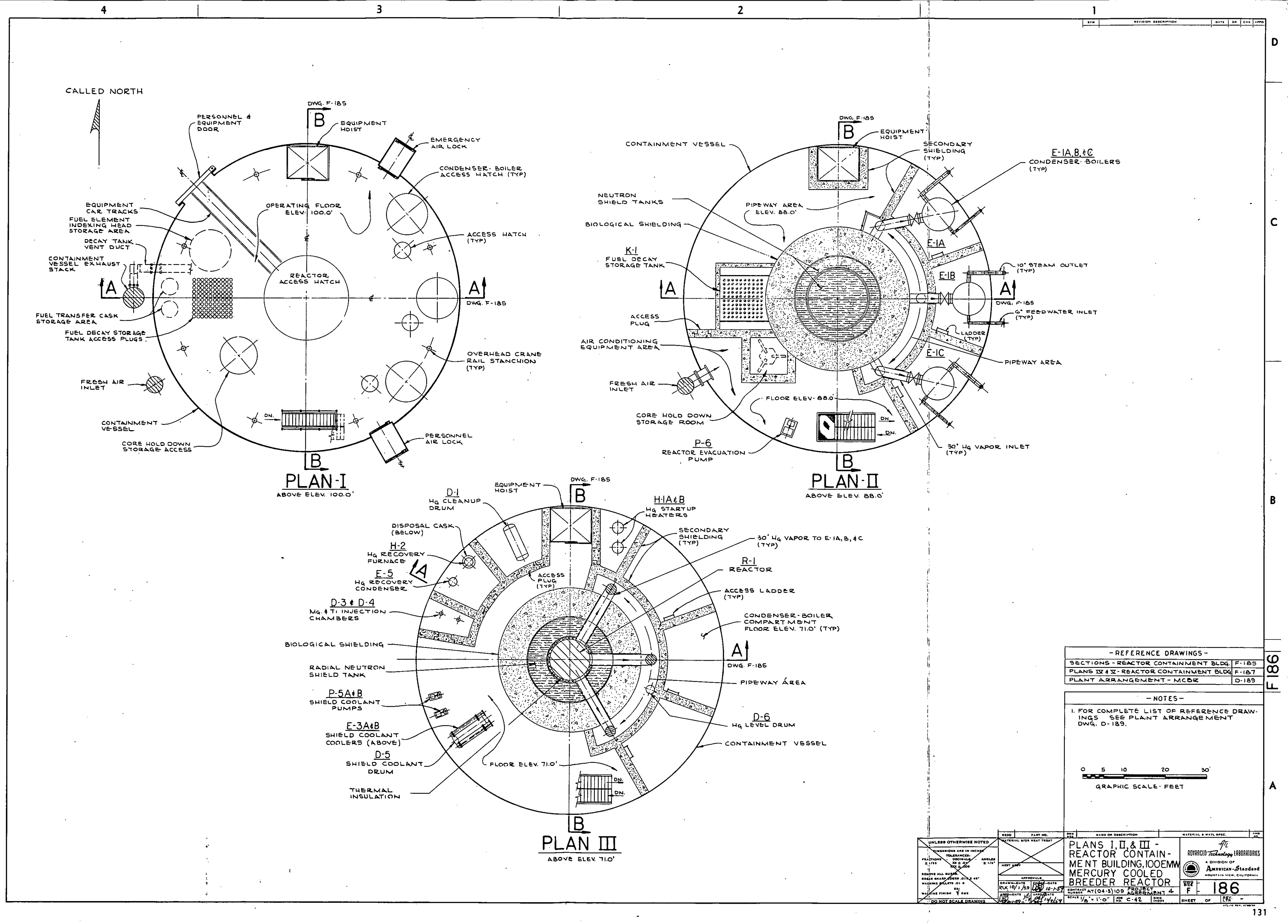


THIS PAGE

WAS INTENTIONALLY LEFT BLANK 


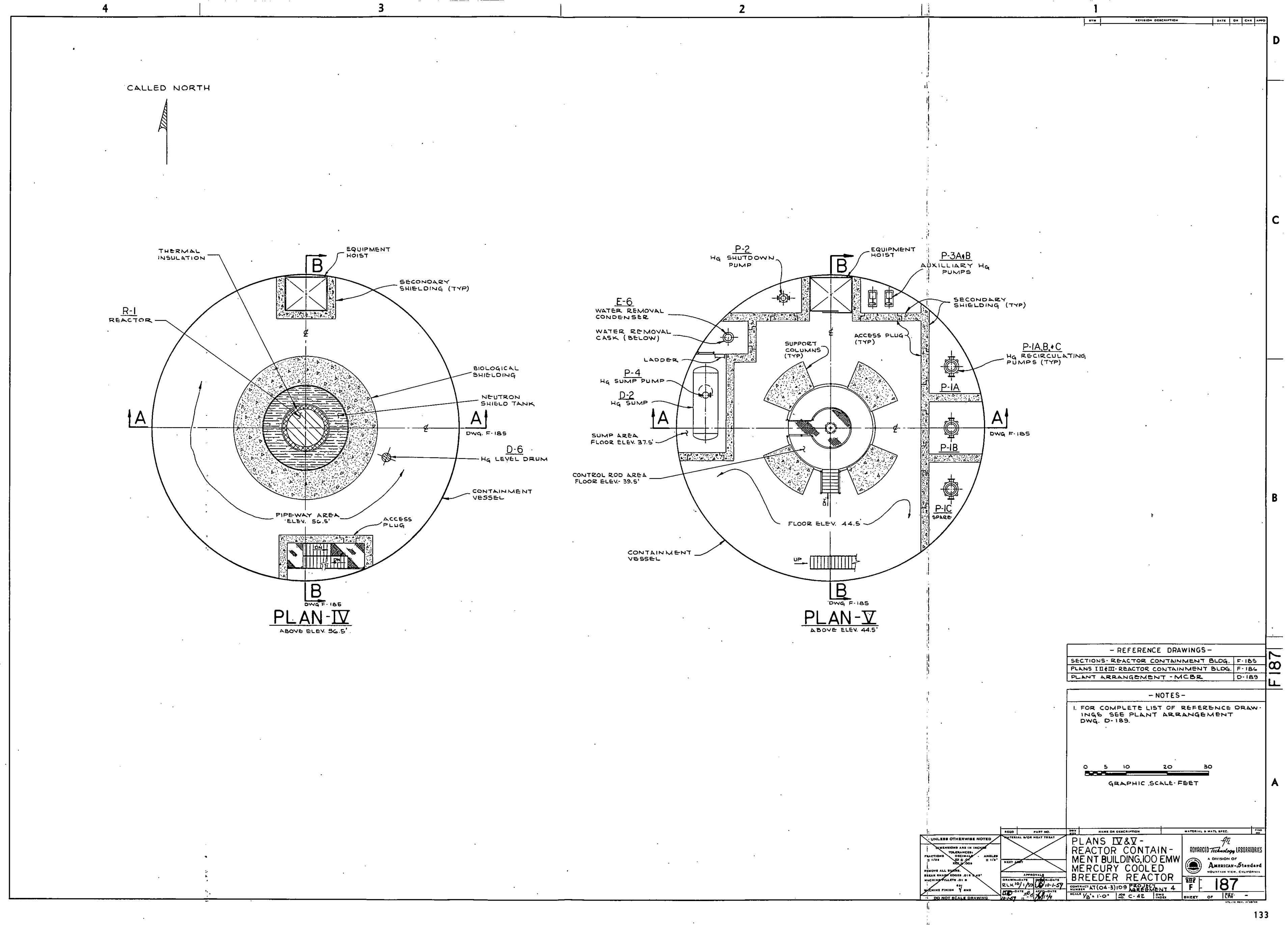


THIS PAGE

WAS INTENTIONA LEET BLANK 


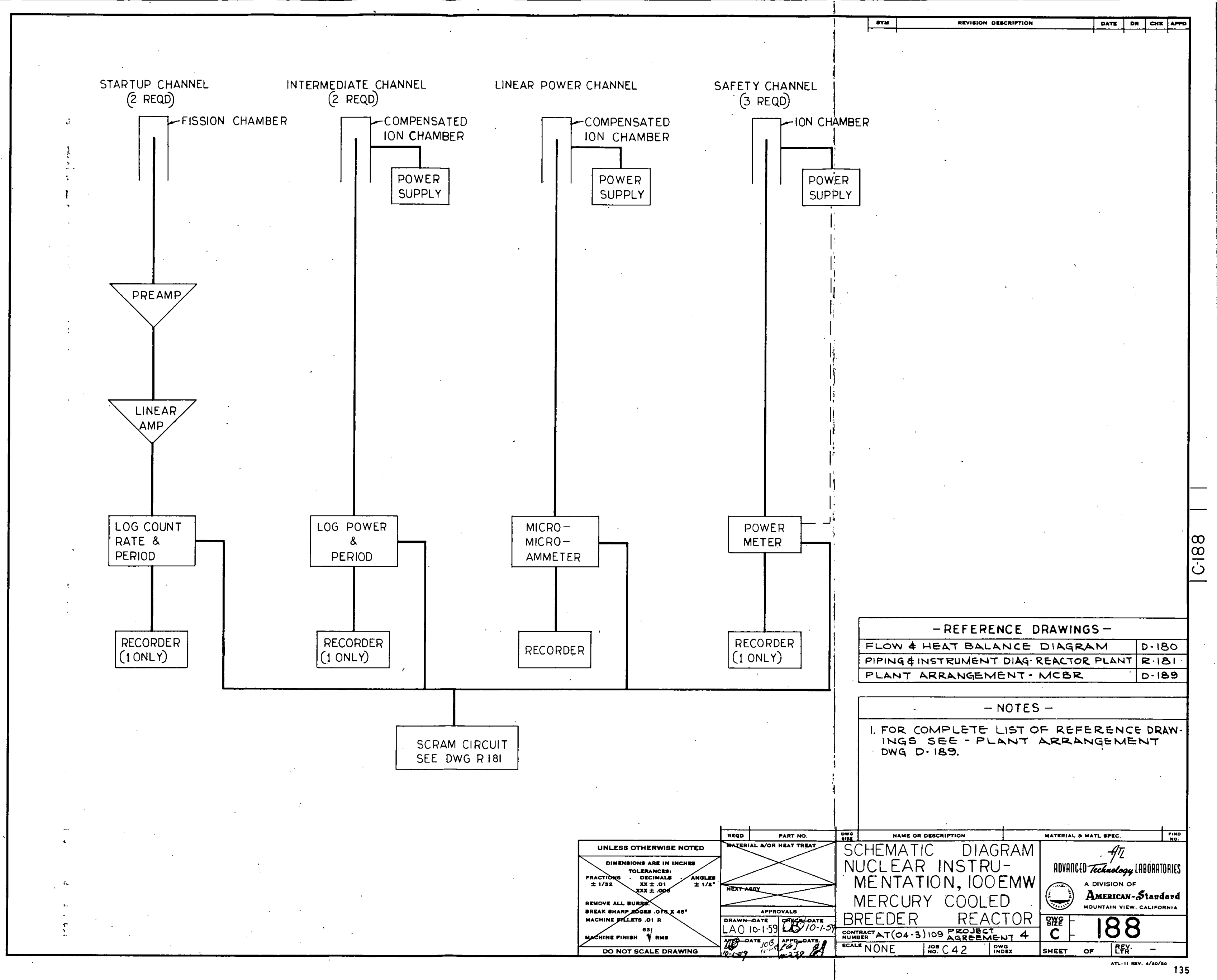


THIS PAGE

WAS INTENTIONALIY LEFT BLANK 


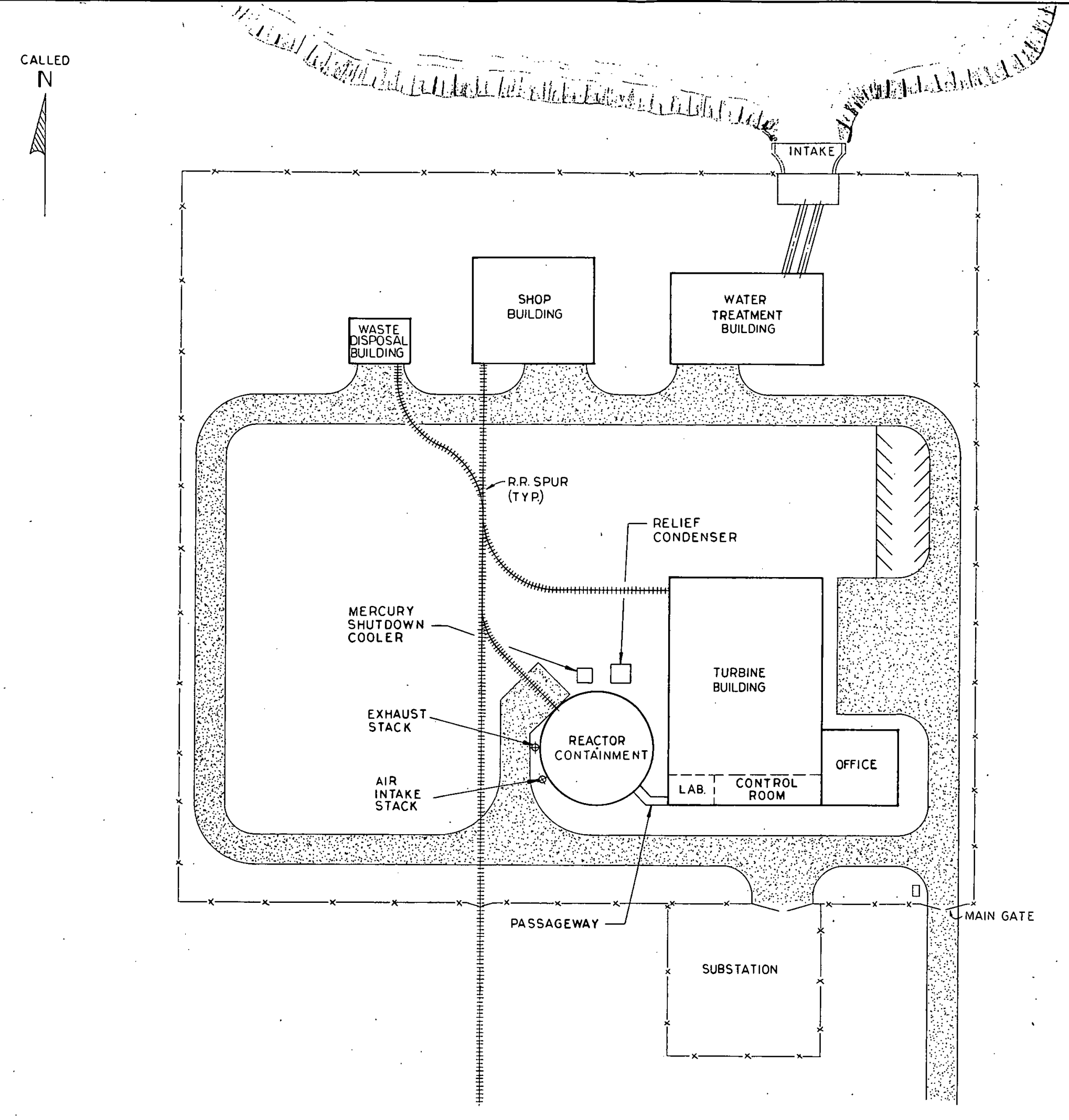


THIS : PAGE

WAS INTENTIONALLY LEFT BLANK 


\section{MERCURY COOLED BREEDER REACTOR}

\section{RECOMMENDED RESEARCH AND DEVELOPMENT}

Technical feasibility of the Mercury Cooled Breeder Reactor concept has been established with reasonable confidence, and its economic characteristics are sufficiently attractive to warrant a review of the program required to construct and operate an MCBR power plant prototype.

The foregoing sections of this report have been primarily concerned with calculations on the first MCBR concept selected for evaluation. This concept utilizes uranium metal as the fuel and an indirect steam cycle employing a mercury condenser-water boiler unit, rather than a direct-cycle mercury turbine followed by a condenser-boiler and steam plant.

The next phase of the MCBR development is the preparation of a preliminary design in more detail than was possible in this initial evaluation study. By this procedure, a more realistic and quantitative evaluation of the economic advantages of the MCBR system can be made, and the stability and control characteristics can be examined in detail. A program of design comparison is also recommended for several attractive modifications of the basic system first studied. If a modification appears particularly promising, it should be incorporated into the preliminary design. The following areas are worthy of such consideration:

1) The kinetic behavior of the MCBR core following changes in load, pressure, and reactivity. Improvement in cycle efficiency by utilizing a direct cycle with a mercury turbine.

2) Utilization of oxide fuel elements, possibly of flat-plate geometry, to achieve higher temperatures, better neutron economy, and lower fuel-cycle costs than with uranium alloy elements:

3) An increase in the allowable heat flux by using a spherical core.

In conjunction with the continuing design studies, an experimental program is recommended to provide the physics and engineering data needed to permit construction of an MCBR plant. Since. mercury as a coolant has been used successfully in conventional power-generating stations, considerable basic data and experience are available for its application as a reactor coolant and working fluid. The extension of knowledge required for design of a nuclear plant is thus minimal compared with other possible coolants.

A major materials or fuel development program is not anticipated, since no significant materials problem appears to exist for a reactor fueled with metallic uranium elements and cooled with mercury at a temperature no higher than $1000^{\circ} \mathrm{F}$, both requirements being consistent with the performance needed for a power-extraction system of high efficiency. The technologies of fuel fabricating and reprocessing and the associated costs are sufficiently well known to eliminate the need for additional. research, although some minor development may be required to permit large-scale 


\section{MERCURY COOLED BREEDER REACTOR}

production of fuel elements at minimum cost. Eventually, the improved performance possible at higher temperatures and/or higher exposure level will create the need for better fuel alloys and containment materials. Such a need will then justify materials research and development.

After completion of the preliminary design and test programs, which can proceed simultaneously, it is recommended that a reactor test be designed, constructed, and operated, followed by preparation of a final design for an MCBR power plant. The program proposed herein is designed to produce an optimum design for a power-producing MCBR system.

Figure 34 presents an estimate of the time schedule and cost of each of these four phases. Note that no specific materials program is shown.

\section{PHASE I - PRELIMINARY DESIGN OF MCBR POWER-PRODUCING SYSTEM}

This phase covers the preparation of a preliminary design for the MCBR power plant, using a cylindrical-core geometry. The system design will be carried out in detail to provide a more definite evaluation of the costs and operability, including kinetics and control, of the MCBR from a total power plant standpoint. The design will be based on known technology and will utilize, where possible, the work performed in other Commission-sponsored projects, as well as commercial practice with mercury. Improvements that have the potential for reducing fuel-cycle costs will be evaluated and, where appropriate, incorporated into the preliminary design. The tasks of Phạse I are outlined below.

Task 1 - Preliminary Design of a MCBR Power-Producing System with a Cylindrical Core

a. Reactor. A preliminary design will be prepared for the reactor vessel, fuel elements, and control devices. Core calculations will be refined for optimum cycle costs and cost trends determined.

b. Kinetics. The dynamic response of the pressure, vapor fraction, and power level in the core to perturbations in reactivity, power demand, and pressure will be examined by analyses of representative cores.

c. Shielding. The plant shielding requirements and the optimum shielding design will be determined.

d. System Design. A flow diagram and piping and instrument diagrams will be prepared for the reactor and power-producing system. The plant will be optimized for power production at minimum cost, and a direct cycle with a mercury turbine will be considered.

e. Materials Analysis. A materials selection analysis will be prepared for all equipment in the plant. 


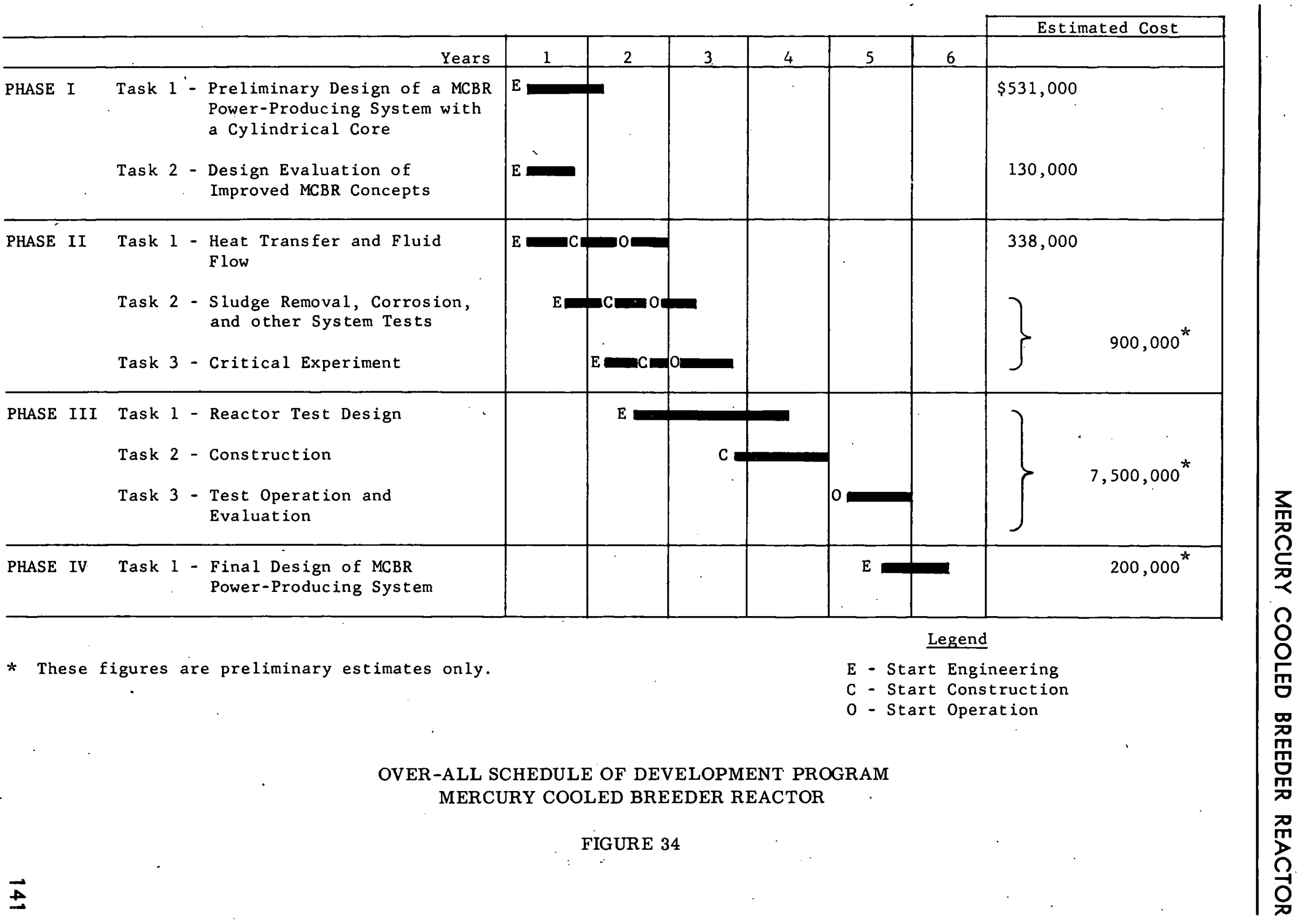




\section{MERCURY COOLED BREEDER REACTOR}

f. Fuel-Handling System. Preliminary designs will be prepared for the required fuelhandling system.

g. Equipment Specifications. Preliminary specifications will be prepared for the major equipment items in the plant. Piping standards will be prepared for the mercury and high-pressure steam system. If required, suppliers will be retained to perform a preliminary design on special components.

h. Plant Layout. A preliminary plant and equipment layout will be prepared, including containment, waste disposal, fuel storage, and major items of equipment, such as reactor and auxiliaries, and turbine-generator and related equipment.

i. Safety Evaluation. A preliminary safety evaluation will be prepared for the system.

j. Power and Plant Costs. Detailed cost estimates will be prepared for the plant capital costs, operating costs, and fuel-cycle costs.

k. Schedules. Schedules will be prepared for design and construction of the plant.

$\underline{\text { Task } 2}$ - Design Evaluation of Improved MCBR Concepts

a. Spherical Core. Because of pressure-drop limitations in a cylindrical core at large power outputs, it is possible to realize a significant increase in the allowable heat flux and specific power in the core by using a spherical-core geometry with the mercury flowing out from the center. A design of this type has the potential of reducing fuel-cycle costs 2 to $3 \mathrm{mils} / \mathrm{kwh}$ over a cylindricalcore configuration. It is recognized that mechanical complexity is introduced by a core of this type. Therefore, the following work is recommended to evaluate the feasibility of the concept.

1) Prepare a preliminary core analysis for a spherical-core geometry.

2) Prepare conceptual designs for the reactor vessel, fuel elements, and fuelhandling equipment.

3) Estimate fuel-cycle and capital-equipment costs for the reactor and compare to the costs with a cylindrical-core geometry.

4) Prepare the scope of any required development work, and estimate cost.

5) Make recommendations on feasibility of the concept and advisability of further work.

b. Fuel-Element Design Evaluation. It is possible to reduce the fuel-cycle costs for the MCBR by improvements in materials of construction and configuration of the fuel elements. It appears that use of an oxide element would permit an increase in power density and fuel-pin diameter. Also, a flat-plate element may offer the potential for increasing the specific power. The following work is recommended to permit evaluation of improved fuel-element designs. 
1) Prepare a core analysis for an oxide-type element and flat-plate or other promising fuel-element configurations.

2) Prepare conceptual designs for the reactor and fuel elements for the concepts considered.

3) Estimate fuel-cycle and capital-equipment costs for the fuel-element concepts considered.

4) Prepare the scope of any required development work and estimate costs.

5) Evaluate the concepts and recommend on advisability of further work.

\section{PHASE II - PRECONSTRUCTION TEST PROGRAM}

This phase covers the performance of tests to provide the data required before a MCBR can be constructed and operated. Since the problems confronting the designers of conventional power plants differ from those present in a nuclear reactor, some extension of current knowledge is necessary for application of mercury to a nuclear reactor. The following information is needed to permit construction of a high-performance nuclear plant using mercury as the coolant: a) burnout heat flux for mercury at high vapor qualities, b) slip ratios or average mercury densities in boiling mercury channels, c) two-phase pressure drops for boiling mercury, d) fast neutron cross section data for mercury. It is recommended that this experimental phase of the program be started concurrently with the preliminary design of the MCBR power-producing system, Phase I above. The tasks of Phase II are detailed below.

\section{Task 1 - Heat Transfer and Fluid Flow}

This task will include experimental effort to determine burnout heat flux, two-phase mixture densities, and two-phase flow resistance for ranges of variables required for design of the MCBR. Existing information on mercury boiling heat transfer, two-phase flow losses, and two-phase mixture density is sufficient for the design of conventional power plants. To exploit fully the potential of mercury for nuclear applications, however, a heat transfer and fluid flow test program should be undertaken. This program will investigate higher heat fluxes and mixture densities (which are of greatly increased importance in nuclear plants), and the resistance to flow of boiling mercury. This program will obviate the necessity of extrapolating the variable ranges covered by existing data to cover the range of interest for reactor application. Extrapolation of existing data places a limit on the confidence that can be placed in attainment of design objectives.

Variation of experimental parameters will be within the following limits. 


\section{MERCURY COOLED BREEDER REACTOR}

Exit quality of two-phase mixture - 0 to $35 \%$

Entrance velocity of liquid mercury - up to $5 \mathrm{ft} / \mathrm{sec}$

Entrance subcooling - up to $200^{\circ} \mathrm{F}$

Pressure level - atmospheric to 200 psia

Internal diameter of test section -0.1 to 0.5 in.

The various test equipment required for performance of this task is described below.

\section{a. Heat Transfer Loop}

The experimental work will be conducted with flow of mercury inside a heated tube. The tube will be heated by axial conduction of electric current. To limit the fraction of heat generated in the mercury, the electrical resistance of the tube wall must be low relative to that of the mercury column. By using a copper-jacketed carbon steel test section, the heat generated in the mercury can be kept at less than $5 \%$ of the total. The high thermal conductivity of copper also will assist in maintaining a low temperature drop through the test section wall. The external surface of the copper will be chrome plated to prevent oxidation.

Flow passages in the MCBR conceptual design have a hydraulic diameter of about 0.14 inch. Selection of an internal diameter in the range of 0.1 to 0.5 inch for the test section will cover the range of interest for hydraulic diameters. Heat fluxes of up to $1,000,000 \mathrm{Btu} / \mathrm{hr}-\mathrm{ft}{ }^{2}$ will be investigated. This work will require a power supply capable of at least $320 \mathrm{kw}$ for a 3 -foot test section.

\section{b. Instrumentation}

Density distribution of the two-phase fluid mixtures in the test section will be measured by radiation attenuation techniques. No basic difficulty in adapting these techniques to mercury appears to exist, although some care in the choice of source and detecting equipment is required. Sources of gamma radiation having photon energies of 1 to $2 \mathrm{Mev}$ are acceptable for this purpose and are readily available. Cobalt 60 will fulfill the requirements of this experiment.

Gamma-detecting equipment of high sensitivity is required to minimize the strength of

the source. A scintillating crystal and photomultiplier tube, similar to that on hand at ATL, should perform satisfactorily.

Pressure measurements along the test section will be obtained by pressure taps connected to single-leg mercury manometers. The upper ends of the manometers will be connected in common to the vapor space above the test section.

Volumetric flow rates of liquid mercury and mercury vapor will be measured at several points in the system. The flowing streams to be metered are indicated on Preliminary Flow 
Diagram, Dwg. B-179. Standard orifice flanges and orifice plates machined to the specifications of the ASME Standards will yield flow measurements with satisfactory accuracy for this experiment.

Surface temperatures in this test section will be measured with chromel-alumel thermocouples imbedded in the test section wall. The output of these thermocouples will be led to a multipoint temperature recorder and automatically recorded.

Heat flux through the inside surface of the test section will be determined in two ways.

Electrical input to the test section will be measured with a current transformer and a wattmeter.

Voltage taps will be located on the test section so as to insure an accurate measurement of heat input over a known length of the test section. As a check, the heat input will be calculated from a heat balance taken between the test section inlet and the two outlets (liquid and vapor) of the vapor separator.

\section{c. Auxiliary Equipment}

A preliminary piping and instrument diagram of the heat transfer apparatus is shown on Dwg. B-179. The major auxiliary equipment consists of the following items:

Vapor separator. 'The liquid-vapor mixture leaving the test section flows to the separator, which separates the two phases and permits flow-rate measurements for each phase.

Condenser. After metering, the two phases are mixed and delivered to an air-cooled condenser. Air cooling is used because the high temperature of the mercury makes water cooling difficult. The temperature of the liquid mercury delivered to the surge tank and thence to the pump is controlled by a water cooler and a bypass line around the condenser.

Sludge removal drum and injection chambers. Experience in mercury power plants shows that oxide removal is easily accomplished in regions where the liquid velocity is low enough to enable the oxides to accumulate on the free surface. The sludge drum and injection chambers provide these regions and permit purification of the mercury and addition of additives to the mercury during operation. Their inclusion in the experimental equipment will also permit experience in their operation, which will be of value in the design of a MCBR system.

Preheater. The preheater permits control of the entrance subcooling to the test section.

\section{$\underline{\text { Task } 2}$ - Sludge Removal, Corrosion, and Other System Tests}

This task will verify the expected low-corrosion properties of mercury for low-alloy carbon steels in the presence of radiation, and modify and test conventional sludge removal and other plant systems for nuclear plant operation. Although experience with existing mercury systems indicates that there are no problems with corrosion or from oxide sludge formation, confirmatory test work in these areas is recommended. 


\section{MERCURY COOLED BREEDER REACTOR}

Development of a system to remove and prepare for disposal of the magnesium oxide sludge, to add magnesium and titanium, and to sample and analyze the flowing radioactive mercury will be important before a detailed design is complete. Much of the required information will be developed in the course of the heat transfer loop experimentation, and little or no additional equipment is required.

Experimental determination of the kinds and amounts of radioactivity resulting from the exposure of mercury to a fast neutron flux is needed. The absorption and diffusion characteristics of these neutron-produced isotopes are unknown and should be evaluated. The program might include measurement of the mercury cross sections, although such measurements are believed to be part of the National laboratories' present programs.

The effect, if any, of radiation on the corrosion and mass transport characteristics of Croloy and stainless steel are unknown and should be examined with an in-pile experiment. Activation data might be obtained with the same apparatus.

$\underline{\text { Task } 3}$ - Critical Experiment

This task includes the necessary critical experiment to verify the physics calculations. Calculational techniques for this reactor are well developed, and no difficulty is expected in performing this task.

PHASE III - REACTOR TEST

This phase will involve design, construction, and operation of a reactor test, using the data from Phases I and II to check out performance data for the MCBR. Based upon the results of the MCBR program, the reactor test would include the core design that shows the greatest potential for production of economic power. This phase consists of the following tasks:

$\underline{\text { Task } 1}$ - Reactor Test Design.

Task 2 - Construction.

Task 3 - Test Operation and Evaluation.

PHASE IV - FINAL DESIGN OF MCBR POWER-PRODUCING SYSTEM

This phase covers the preparation of a final design for an MCBR power plant, optimized to produce power at minimum cost. The results of efforts in the preceding phases will be used to alter, where necessary, the preliminary design performed in Task 1 of Phase I. The final design produced in this phase will thus be based on experimentally verified data. 


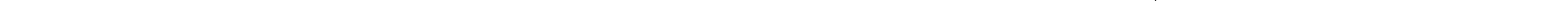


THIS PAGE:

AS INTENTIONALLY

LEFT BLANK 


\section{BOILING MERCURY HEAT TRANSFER EXPERIMENT}

A preliminary low-cost experiment on heat transfer to mercury liquid-vapor mixtures was conducted, with the limited objective of measuring very high heat fluxes, thereby verifying that the thermal design conditions selected for the MCBR were attainable. The design condition of $446,000 \mathrm{Btu} / \mathrm{hr}-\mathrm{ft}^{2}$ maximum flux in the MCBR core was exceeded; a flux of $600,000 \mathrm{Btu} / \mathrm{hr}-\mathrm{ft}{ }^{2}$ to mercury having a calculated density of about $20 \mathrm{lb} / \mathrm{ft}^{3}$ was measured. Equipment limitations prevented attainment of higher fluxes.

As noted in Appendix $\mathrm{C}$, the maximum heat flux that has been attained in previous boilingmercury heat transfer experiments is about $200,000 \mathrm{Btu} / \mathrm{hr}-\mathrm{ft}^{2}$, although theory leads to the prediction of a maximum nucleate boiling flux of approximately $10^{6} \mathrm{Btu} / \mathrm{hr}-\mathrm{ft}^{2}$. The experimentally determined values obatined here, as well as those reported previously (see Appendix C), were measured with nucleate boiling of mercury to which had been added magnesium and titanium; in none of these experiments was there an indication that the maximum nucleate heat flux had been attained. Attainment of higher heat fluxes was prevented by limitations in either experimental equipment or the objectives of the experiment. In the present experiment, these equipment. limitations were partially lifted, permitting heat fluxes more closely approaching, but not yet verifying, the theoretical limit.

\section{A. EXPERIMENTAL APPARATUS}

The apparatus, shown schematically in Figure 35 and in detail in drawing F-53, was designed for simplicity in operation, instrumentation, and fabrication. Measurement of the flow rate of the naturally circulating mercury is afforded by a thermal flow meter in which the temperature change of the flowing mercury and the electrically supplied heat input to the meter are measured variables. The flow rate of the liquid mercury is related to these two variables by a simple heat balance made across the electric heater. The primary measurement of mercury pressure (under conditions of net boiling) is afforded by measuring the (saturation) temperature of the mercury leaving the test section. A Bourdon pressure gage is provided to permit rapid visual notification of possible pressure abnormalities during operation. Temperature measurements are made with shielded chromel-alumel thermocouples welded to the external surfaces of the loop. A hand potentiometer is used to measure thermocouple voltages.

The test section proper consists of a $7 / 16$-inch OD steel tube with a 0.109 -inch wall. Heat is generated in the test section wall by conduction of electric current through the tube wall. The heated length of the tube is 4 inches. The remainder of the flow conduit is $7 / 16$-inch OD with an 


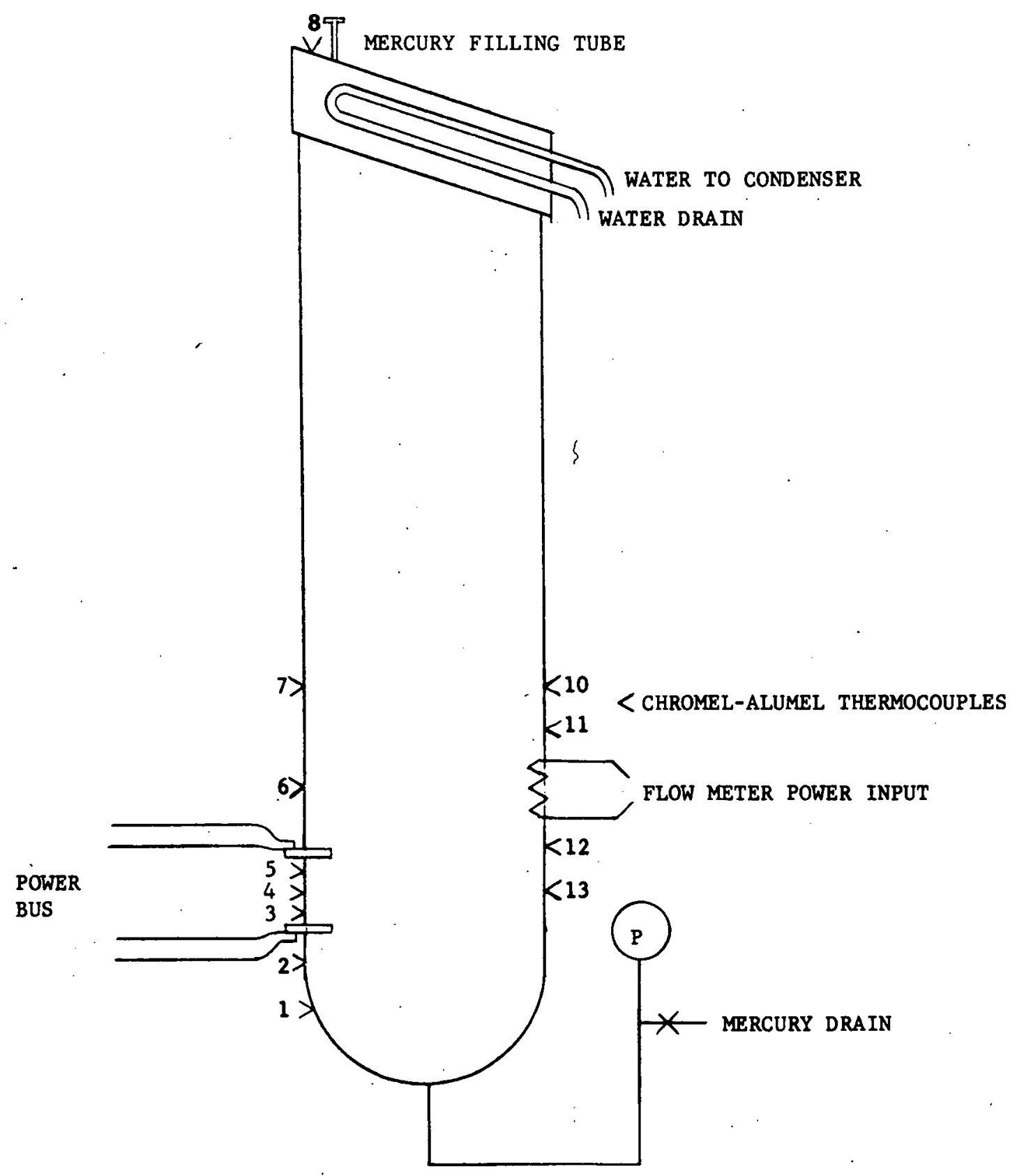

SCHEMATIC OF BOILING MERCURY TEST LOOP

FIGURE 35 
THIS PAGE

WAS INTENTIONALLY

LEFT. BLANK 
0.05-inch wall. Two steels were used in successive versions of the loop. The first version used 4130 steel for the loop and test section; the second used 304 stainless steel for the loop and 1018 steel for the test section.

Since the liquid mercury is a reasonably good conductor of electricity, a fraction of the total heat generated will be generated directly in the mercury. If the mercury in the test section is liquid, then the ratio, $S_{h}$, of the heat generated in the wall to the total heat generated is given simply as

$$
S_{h}=\frac{\mathrm{R}_{H g} / R_{w}}{1+\frac{R_{H g}}{R_{w}}},
$$

in which $\mathrm{R}_{\mathrm{Hg}}$ and $\mathrm{R}_{\mathrm{w}}$ are the electrical resistances of the mercury core and the tube wall, respectively. In order to make the fraction of heat generated in the wall large, it is necessary to make the rcsistance of the wall small relative to the resistance of the liquid mercury contained by the wall. A limit on the reduction of the wall resistance is imposed by the resultant excessively large current required to heat the test section. The design compromise used corresponds to the generation of $89 \%$ of the heat in the tube wall and requires a power input of $2.38 \mathrm{kw}$ at a current of 2000. amperes for the production of a heat flux at the wall of $500,000 \mathrm{Btu} / \mathrm{hr}-\mathrm{ft}^{2}$. During boiling, the area of the mercury conduction path is diminished and the fraction of heat generated in the wall is, of course, higher than the above value.

Power for the test section is supplied by a special welder power supply having a continuous rating of about 5000 amperes at 4.4 volts. The capability of the power source is thus more than sufficient for the application. Power input to the test section is determined by measuring the voltage drop between two voltage taps connected to the test section wall. The electrical resistance of the test section is computed from the resistivity of the steel evaluated at the measured wall temperature. An RF (thermocouple) ammeter was selected to measure the voltage drop in the test section, since the voltage waveform differs markedly from a simple sine wave.

The mercury vapor is condensed at the top of the loop by contact with a stainless steel watercooled tube. Prior to operation, the system is completely filled with liquid mercury to the top of the tube above the condenser (see Dwg. F-53). The tube is then capped, and liquid mercury is drained to the desired operating level by means of the drain tube connected to the bottom of the loop. During operation, no gas other than mercury vapor and dislodged occluded gases is present 


\section{MERCURY COOLED BREEDER REACTOR}

in the system. Titanium hydride and magnesium powder are added to the loop in desired quantities before filling with mercury.

Since the objective of the experiment is to demonstrate attainment of high boiling heat fluxes, it is apparent that containment for the released mercury vapor following a burnout must be anticipated. The containment system, shown on Dwg. F-53, utilizes a water seal for this purpose.

\section{B. RESULTS}

In full-scale mercury-vapor power plants, titanium and magnesium are added in small amounts to the mercury to produce wettable surfaces on the furnace tubes. During initial startup, these plants occasionally encounter difficulties in the wetting because of improperly cleaned tubes containing oxide scale; hence, it could be anticipated that tube wetting would be a problem in the smallscale apparatus.

Initial operation of the loop revealed that the 4130 steel test section wall first used was not wet by the mercury. This condition was manifested during boiling by the excessive wall temperature characteristic of film boiling. Supplementary experiments conducted in the laboratory failed to uncover a pickling method that would clean the tube sufficiently to permit wetting by mercurymagnesium amalgams. In the mercury power plants, wetting is achieved by exposure of the system to the mercury and additions for a few hours at operating temperature, but at low power. It was found possible to attain wetting, even at room temperature, by mechanically cleaning the surface and then depositing a thin copper layer by dipping the specimen in a copper sulfate solution. Following this treatment, the mercury readily wet the surface.

Preliminary operation of the apparatus disclosed that oxide scale was a problem in the condenser and other sections of the loop. Also, if care was not exercised in adding the magnesium, it tended to accumulate as a solid plug in the lower portion of the loop. Hence, the loop and the condenser were rebuilt of type 304 stainless steel, and the test section proper was made of 1018 steel, which has similar wetting characteristics to the alloy steel contemplated for fuel cladding in the MCBR.

Access for cleaning the loop was afforded by providing a flange with O-ring seal on one end of the condenser and by using Imperial "Hi-Seal" stainless fittings in place of the flanges previously usèd in the legs of the loop. The loop was carefully cleaned, vacuum tested for leaks, and given a thin internal copper wash. Magnesium and titanium hydride (8 $\mathrm{gm}$ of $\mathrm{Mg}$ and $0.5 \mathrm{gm}$ of $\mathrm{TiH}$ ) were

* It was subsequently found that a similar technique has been developed at the Brookhaven National Laboratory by O. E. Dwyer and co-workers. 


\section{MERCURY COOLED BREEDER REACTOR}

added after the loop was partially filled with clean mercury to a level within the condenser. More mercury was then added to bring the level to the top of the seal plug. After the loop was sealed, 65 of the 85 pounds of mercury in the loop were drained in order to bring the free surface of the mercury to a level just covering the loop leg openings to the condenser. Subsequent operation of the loop proved highly successful.

Experimental results are presented in Table XXIV. Inspection of these data shows that the maximum heat flux achieved was $600,000 \mathrm{Btu} / \mathrm{hr}-\mathrm{ft}^{2}$, with a calculated exit quality of about $5 \%$. Assuming a slip ratio of 2.0 , the average mixture density and void fraction are computed for the two high-flux runs; these results are presented in Table XXV. For comparison, the values of these performance parameters for the reference $100 \mathrm{mw}(\mathrm{e}) \mathrm{MCBR}$ core are also shown in Table XXV.

It should be noted that the flux in the experiment test section is approximately uniform over its length, while the flux in the reactor core is maximum near the center. Since in both cases the coolant density continuously decreases as it flows through the channel, the average density in the reactor is appreciably greater at the point of maximum flux than at the exit where the density is computed. The heat flux and the void fraction achieved thus exceed the design conditions selected for the MCBR.

During the course of the experiment, hydrodynamic oscillations of the mercury flow were occasionally indicated by the Bourdon pressure gage. In all cases, these oscillations could be made to vanish by increasing the heat input or by increasing the system pressure. Increasing the heat input was effective at the lower heat flux level at which boiling in the test section was beginning. At the higher heat fluxes, an increase in system pressure was required to stop the oscillations. System pressure was increased by decreasing the water rate to the mercury condenser. ${ }^{*}$ Lack of an effective means of metering the low water rates required for stability at the high heat fluxes and also concern over the safety afforded by the water seal in the event of a system rupture at the higher pressures required for high heat fluxes led to termination of the experimental work at a flux of $600,000 \mathrm{Btu} / \mathrm{hr}^{-\mathrm{ft}^{2}}{ }^{2}$. It is to be emphasized that the observed thermal and hydrodynamic performance of the loop gave every indication that higher fluxes could be achieved before reaching the burnout heat flux.

* The fact that this was found to be an effective means of varying system pressure indicates, contrary to the findings reported in references 15 and 33 , that the difference between the saturation temperature of condensing mercury and the temperature of the condensing surface is an important variable in determining the rate of condensation. 


\section{TABLE XXIV \\ Results of Mercury Experiment}

\begin{tabular}{|c|c|c|c|c|c|c|c|c|c|}
\hline Run & $\begin{array}{c}\left(\mathrm{Btu} / \mathrm{hr}-\mathrm{ft}^{2}\right. \\
\left.\times 10^{-3}\right) \\
\end{array}$ & $\begin{array}{c}\text { Test } \\
\text { Section } \\
\text { Pressure }\end{array}$ & $\begin{array}{c}\text { Flow } \\
\text { Velocity } \\
\text { at Inlet } \\
\text { to Test } \\
\text { Section } \\
\\
(\mathrm{ft} / \mathrm{sec})\end{array}$ & $\begin{array}{l}\text { Inlet } \\
\text { Temp. }\end{array}$ & $\begin{array}{c}\text { Temp. } \\
\text { Increase } \\
\text { Through } \\
\text { Test } \\
\text { Section } \\
. \\
\left({ }^{\circ} \mathrm{F}\right) \\
\end{array}$ & $\begin{array}{c}\text { Inside } \\
\text { Wall } \\
\text { Temp. } \\
\text { at T. C. } 5 \\
\\
\text { (॰ F) }\end{array}$ & $\begin{array}{c}\text { Inside } \\
\text { Wall } \\
\text { Temp. } \\
\text { Less } \\
\text { Saturation } \\
\text { Temp. } \\
\\
\left.{ }^{\circ} \mathrm{F}\right) \\
\end{array}$ & $\frac{\text { Heat Out }}{\text { Heat In }}$ & $\begin{array}{c}\text { Exit } \\
\text { Quality }\end{array}$ \\
\hline 1 & - & - & - & - & - & - & - & - & - \\
\hline 2 & 24 & - & 2.9 & 66 & 137 & 647 & - & 2. 16 & - \\
\hline 3 & 92 & - & 0.67 & 282 & 169 & 468 & - & 1.65 & - \\
\hline 4 & 150 & - & 1.0 & 256 & 217 & $50 \dot{4}$ & - & 2.0 & - \\
\hline 5 & 190 & - & $1 . .1$ & 293 & 227 & 562 & - & 1.78 & - \\
\hline 6 & 230 & - & 1.9 & 320 & 221 & 587 & - & 2. 50 & $L$ \\
\hline 7 & 260 & - & 1.5 & 355 & 221 & 629 & - & 1. 66 & - \\
\hline 8 & 400 & - & 1.3 & 386 & 240 & 701 & - & 1. 0 & - \\
\hline 9 & .460 & 10 & 1.1 & 392 & 249 & 741 & 100 & - & 0.015 \\
\hline 10 & 67 & - & - & 247 & 214 & 453 & - & - & - \\
\hline 11 & - & - & - & - & - & - & - & - & - \\
\hline 12 & 210 & - & 1.3 & 480 & 135 & 674 & - & 1.03 & - \\
\hline 13 & 280 & 10 & 1.4 & 488 & 153 & 710 & 69 & - & 0.001 \\
\hline 14 & 340 & 14 & 1.1 & 506 & 122 & 759 & 88 & - & 0.032 \\
\hline 15 & 470 & 17 & 0.89 & 524 & 168 & 776 & 84 & - & 0.061 \\
\hline 16 & 550 & 19 & 0.74 & 536 & 165 & 776 & 75 & - & 0.10 \\
\hline 17 & 600 & 33 & 1.5 & 649 & 112 & 825 & 64 & - & 0.049 \\
\hline
\end{tabular}

TABLE XXV

\section{Performance Characteristics}

\begin{tabular}{|c|c|c|c|}
\hline & $\underline{\text { Run } 16}$ & Run 17 & MCBR Core \\
\hline Maximum heat flux (Btu/hr-ft ${ }^{2}$ ) & 550,000 & 600,000 & 446,000 \\
\hline Saturation pressure (psia) & 19 & 33 & 110 \\
\hline Saturation temperature $\left({ }^{\circ} \mathrm{F}\right)$ & 701 & 761 & 920 \\
\hline Exit quality (\%) & 10 & 4.9 & 30 \\
\hline Exit void fraction (\%) & 0.993 & 0.978 & 0.992 \\
\hline Exit coolant density $\left(\mathrm{lb} / \mathrm{ft}^{3}\right)$ & 5.5 & 17.9 & 7.3 \\
\hline
\end{tabular}




\section{DISCUSSION}

The heat flux in the test section is calculated on the basis of measurements of the voltage drop across the central 3 inches: The equation used is

$$
\mathrm{q} / \mathrm{A}=22.6 \times 10^{6} \frac{\mathrm{E}^{2}}{\rho}
$$

in which $\mathrm{E}$ (volts) = measured voltagè drop and $\rho(\mu \mathrm{ohm}-\mathrm{cm})=$ electrical resistivity of 1018 steel evaluated at the temperature indicated below. The electrical resistivity and thermal conductivity of 1018 steel were estimated by interpolation between the values given as a function of temperature in the 1948 edition of the Metals Handbook for the 1008 and 1023 steels. A first estimate of the temperature drop from the outside to the inside of the test section wall was given by the equation

$$
\mathrm{T}_{\mathrm{o}}-\mathrm{T}_{\mathrm{i}}=0.00386 \frac{\mathrm{g} / \mathrm{A}}{\mathrm{k}}
$$

in which the thermal conductivity, $\mathrm{k}\left(\mathrm{Btu} / \mathrm{hr}-\mathrm{ft}{ }^{2}{ }^{\circ} \mathrm{F} / \mathrm{ft}\right)$ and the electrical resistivity, $\rho$, used in calculating $\mathrm{q} / \mathrm{A}$ were evaluated at a temperature $\left(\mathrm{T}_{5}\right)$ indicated by T. C. 5 (see Figure 35 ). The mean temperature of the wall, $\mathrm{T}_{5}-1 / 2\left(\mathrm{~T}_{0}-\mathrm{T}_{\mathrm{i}}\right)$, was then used to evaluate the values of $\rho$ and $\mathrm{k}$ in the above equations to give the heat flux and inside wall temperature for Table XXIV.

Accuracy of the voltage measurements is estimated to be $\pm 5 \%$. If accuracy of the electrical resistivity is taken to be $10 \%$, then the accuracy of the heat fluxes presented in the Tables is probably within $\pm 20 \%$, an accuracy range consistent with the limited funds and objectives of the experimental work. Accuracy of the total heat input to the mercury (the denominator of the entries in the next to the last column of Table XXIV) is considerably poorer, since the rate of heat conduction to or from the test section via the electrodes is unknown. The heat input was taken to be the product of the heat flux and the inside surface area of the 4-inch free length of the test section. The heat output is calculated as the product of the mass rate and the enthalpy change of the mercury. The enthalpy change is determined by the temperature change of the mercury, $\mathrm{T}_{6}-\mathrm{T}_{2}$. No entry for heat out is given in Table XXIV for the runs with net vapor generation, because $T_{6}$ is then not a measure of the enthalpy of the mercury leaving the test section.

The test section pressure recorded in Table XXIV is the saturation pressure corresponding to the temperature indicated by T. C. 6 (Figure 35). A pressure entry is given only for those runs in which net boiling occurred (e.g., those runs for which an exit quality is indicated in the Table).

The exit quality of the mercury liquid-vapor mixture is calculated, on the basis of a heat balance, by using the equation 


\section{MERCURY COOLED BREEDER REACTOR}

$$
\chi_{e}=\frac{1}{\Delta h} \frac{(\text { Heat In })}{\text { (Mass Rate) }}-\mathrm{C}_{\mathrm{p}}\left(\mathrm{T}_{\text {sat }}-\mathrm{T}_{2}\right) \text {, }
$$

in which $\mathrm{T}_{2}$ is the inlet temperature to the section. It may be noted that, had "Heat Out" been used rather than "Heat In" in the above equation, the exit quality entry in the Table would be larger than that shown.

No calibration of the thermal flow meter was made. Errors in flow measurements can be expected due, primarily, to heat losses from the metering section. These errors would tend to make the computed mass rate (inlet velocity in Table XXIV) higher than the true value. If the mass rate used is, in fact, higher than that which actually occurred then, with the actual values, the heat balance would be improved and the exit quality would be higher than that given in the Table. There is reason, therefore, to believe that the density of the liquid-vapor mixture was even lower than is implied by the data presented in Table XXrV.

The objectives of the experiment, to produce and measure very high heat fluxes to boiling mercury, was accomplished with the achievement of heat flux values up to $600,000 \mathrm{Btu} / \mathrm{hr}-\mathrm{ft}{ }^{2}$. Since the saturation temperature and pressure at which the experiment was conducted (33 psia) is substantially less than that of any reasonable reactor core design, and since the burnout heat flux characteristically increases with increased pressure, it is concluded that design heat fluxes to liquid-vapor mercury mixtures at least up to $600,000 \mathrm{Btu} / \mathrm{hr}-\mathrm{ft}^{2}$ are entirely feasible. 
MERCURY COOLED BREEDER REACTOR

APPENDIX

159 


\section{APPENDIX A}

\section{SCOPE OF CONTRACT}

This technical and economic evaluation of boiling mercury as a coolant for fast breeder reactors was performed by American-Standard under Contract No. AT(04-3)-109, Project Agreement No. 4, with the United States Atomic Energy Commission. The scope of the contract directive is quoted below.

"1. Scope of Work - The work under this project shall consist of a mercury cooled fast breeder reactor feasibility study generally in accordance with the Contractor's proposal to the Commission, P-471 dated August 29, 1958 and shall include the following:

a. Physics' calculations as necessary to determine breeding gain, critical mass, neutron flux and power distribution.

b. A literature review on boiling mercury heat transfer to determine realistically achievable heat transfer coefficients and maximum heat fluxes. An effort will be made during the study to obtain and use the latest data available on burnout heat flux and heat transfer coefficients.

c. An analysis of the kind and amount of mercury activation, and calculations of the shielding necessary for the mercury:loop.

d. Calculation of the temperature and mercury density reactivity coefficients.

e. Heat transfer and fluid flow calculations to determine the thermal and fluid dynamic characteristics of the reactor.

f. Mechanical design studies and a conceptual design based on metallic uranium fuel and using indirect cycle steam generation. This conceptual design should include preliminary discussion and design of the mechanism used to produce the mercury fog, including a summary of commercial experience with this device.

g. An analysis of possible corrosion and erosion problems.

h. An estimate of capital and fuel cycle costs based on the conceptual design, along with preliminary estimate of possible savings in future designs. Fuel cycle costs will be based on Pu buy-back prices of $\$ 12$ and $\$ 30$ per gram regardless of isotopic concentration. Capital costs will include a calculation of mercury inventory costs.

i. A description and analysis of the recommended research and development program necessary to develop a successful commercial reactor. This program should include an outline, time schedule, and cost estimate of the recommended program." 


\section{APPENDIX B}

\section{PHYSICAL PROPERTIES OF MERCURY}

Mercury physical properties of primary interest for heat transfer calculations are tabulated in the Liquid Metals Handbook ${ }^{11}$ for temperatures up to $600^{\circ} \mathrm{F}$. Thermodynamic properties are exhaustively treated in National. Bureau of Standards Report NBS-2204 ${ }^{12}$ for temperatures up to $932^{\circ} \mathrm{F}$. Since this upper temperature limit is too low for the requirements of many applications, extrapolation to higher temperatures is necessary. Because the methods of extrapolation are not well established, the extrapolated values used in the MCBR evaluation are preserved in this appendix.

Thermal properties, measured and extrapolated, are summarized in the following graphs for temperatures up to $1200^{\circ} \mathrm{F}$, the sources of data and methods of extrapolation being indicated on each. The accuracy of the extrapolations is believed adequate for most application purposes.

Since publication of the Liquid Metals Handbook, new data on the thermal conductivity of liquid mercury have been presented by Ewing, et al, ${ }^{13}$ and corroborated recently by Russian work. ${ }^{14}$ Ewing's values are therefore recommended in place of the LMH tabulation. Ewing's conductivity value at $600^{\circ} \mathrm{F}$ is about $15 \%$ less than the LMH value, but his data extrapolate to the LMH value at $32^{\circ} \mathrm{F}$.

Most United States correlations of heat transfer to liquid mercury have been based on LMH . conductivity values. However, errors introduced by using one set of property values to correlate heat transfer data and another set to apply the correlations should be small, inasmuch as most liquid mercury heat transfer data were obtained at low temperatures, where the two sets of properties do not differ greatly.

Table B-I presents conversion values, for convenience. Properties of mercury not presented on Figures B-1 through B-11 are listed in Table B-II. 


\section{MERCURY COOLED BREEDER REACTOR}

TABLE B-I

CONVERSION TABLE

To Convert From

psia

psia

psia

$\mathrm{lb} / \mathrm{ft}^{3}$

$\mathrm{lb} / \mathrm{ft}^{3}$

$\mathrm{Btu} / \mathrm{hr}-\mathrm{ft}^{2}\left({ }^{\circ} \mathrm{F} / \mathrm{ft}\right)$

$\mathrm{Btu} / \mathrm{hr}-\mathrm{ft}^{2}\left({ }^{\circ} \mathrm{F} / \mathrm{ft}\right)$

micro-ohm-ft

micro-ohm-ft

$\mathrm{lb} / \mathrm{hr}-\mathrm{ft}$

$\mathrm{lb} / \mathrm{ft}$

Btu/lb

Btu $/ \mathrm{lb}-{ }^{\circ} \mathrm{F}$
To

atmosphere

in. $\mathrm{Hg}$

$\mathrm{mm} \mathrm{Hg}$

$\mathrm{gm} / \mathrm{cm}^{3}$

lb/in. 3

$\frac{\text { calorie }}{\mathrm{sec}-\mathrm{cm}^{2}-{ }^{\circ} \mathrm{C} / \mathrm{cm}}$

$\frac{\text { watt }}{\mathrm{cm}^{2}-{ }^{\circ} \mathrm{C} / \mathrm{cm}}$

micro-ohm-in.

micro-ohm-cm

centipoise

dyne $/ \mathrm{cm}$

calorie/gm

calorie/gm $-{ }^{\circ} \mathrm{C}$
Multiply by

0.06805

2. 03

51. 71

0.016018

0.0005787

0.0041338

0.017304

12

30.48

0.413

14620

0. 5555

1. 0 
Index

Mercury Physical Property Data

Figure No.

Property

B-1

Saturation Pressure

B-2

Heat of Vaporization

B-3

Surface Tension

B-4

Thermal Conductivity of Liquid

B-5

Electrical Resistivity of Liquid

B-6

Density of Liquid

B-7

Density of Vapor

B-8

Heat Capacity of Liquid

B-9

Heat Capacity of Vapor

B-10

Viscosity of Liquid

B-11

Viscosity of Vapor 


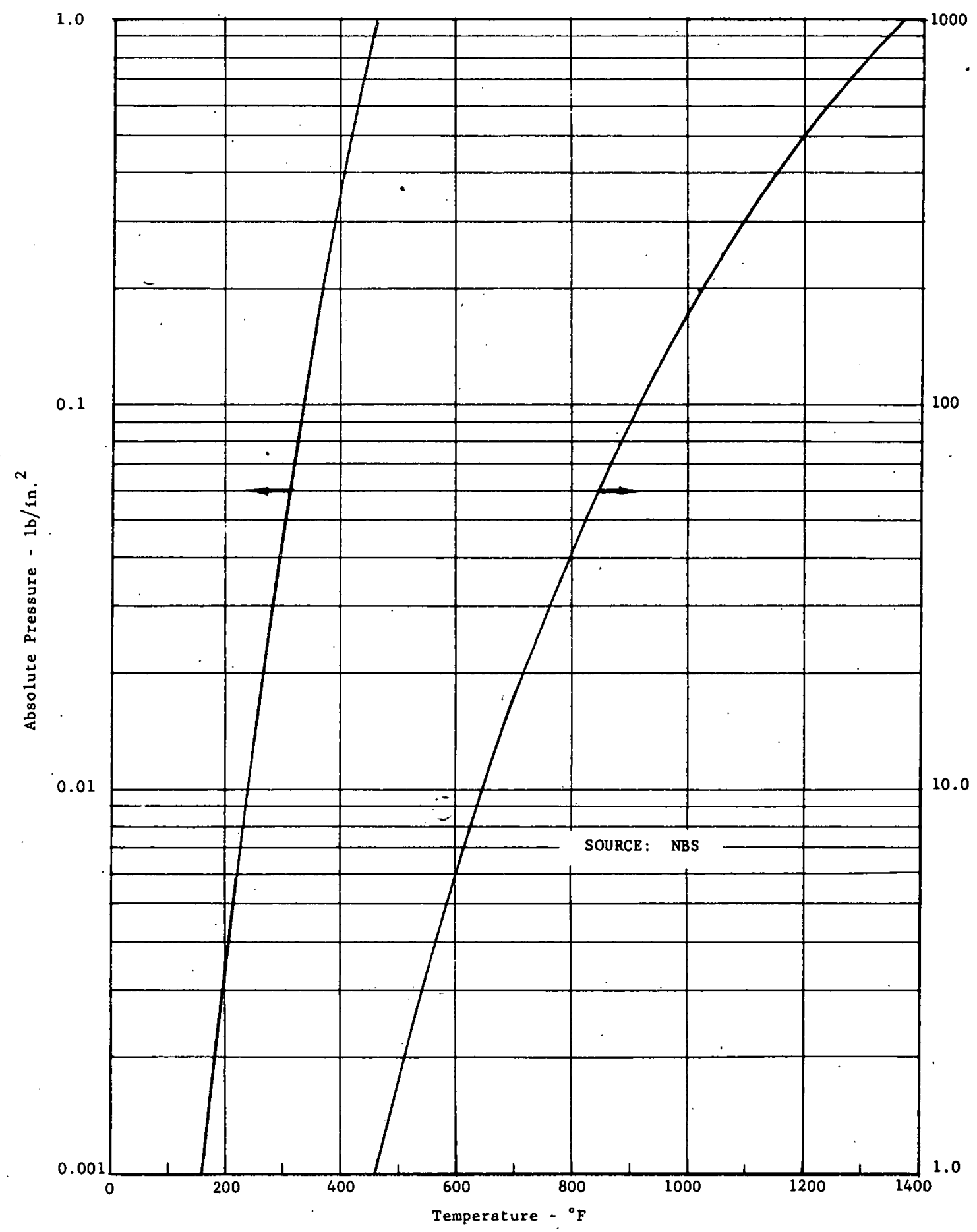

MERCURY SATURATION PRESSURE

FIGURE B-1 
).

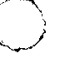

$\circ$

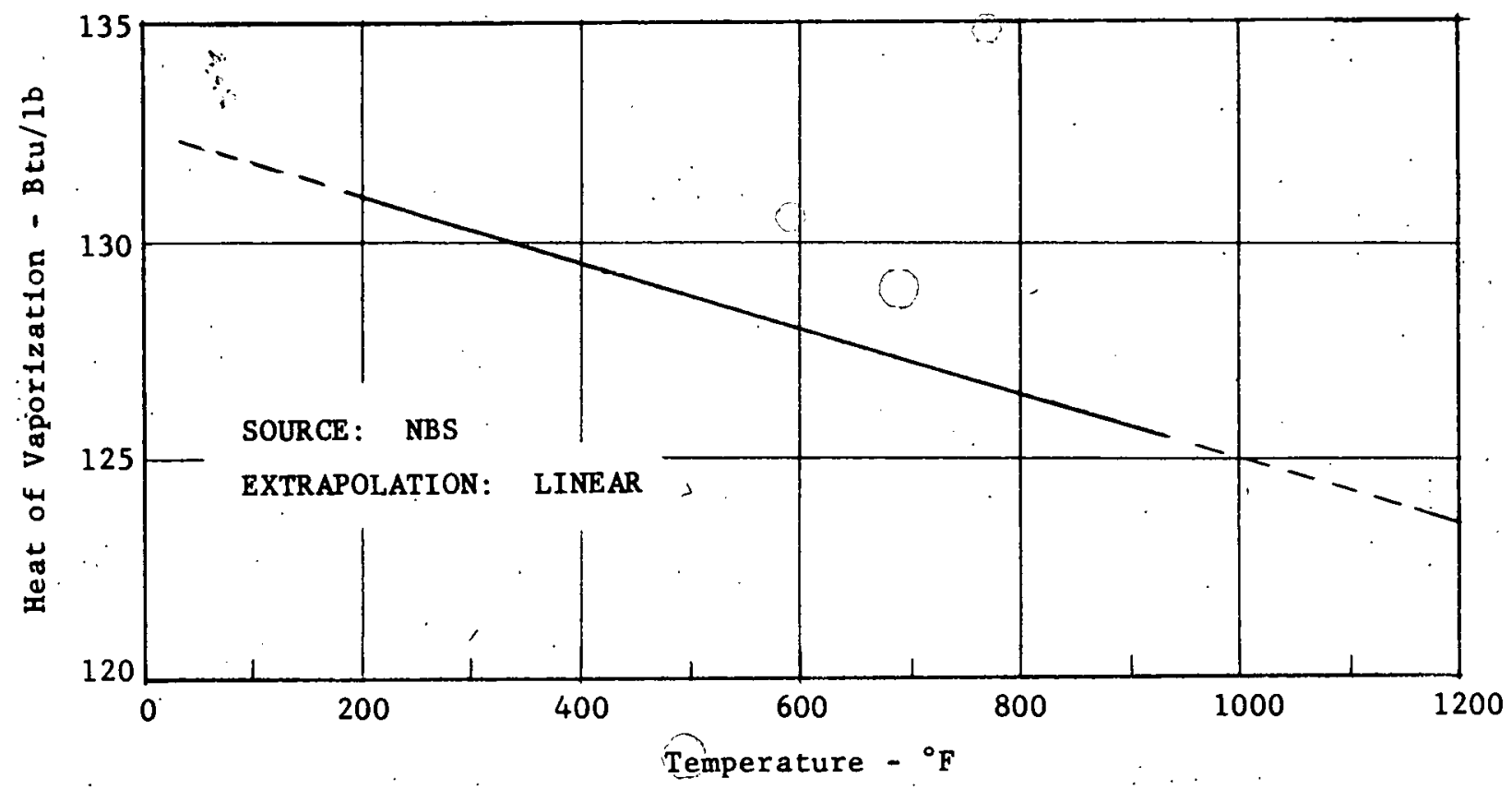

MERCURY HEAT OF VAPORIZATION

FIGURE B-2 


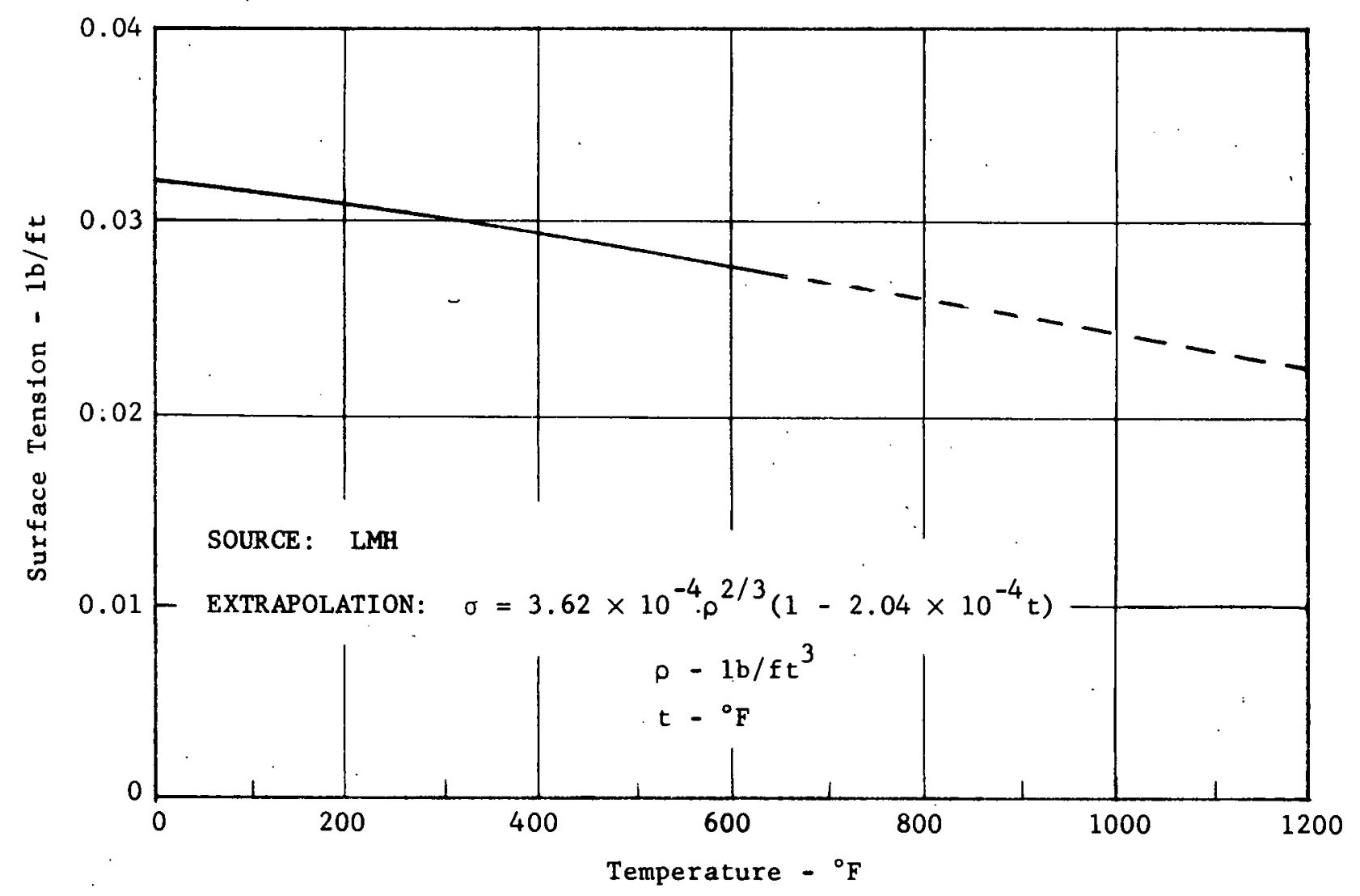

SURFACE TENSION OF MERCURY

FIGURE B-3 


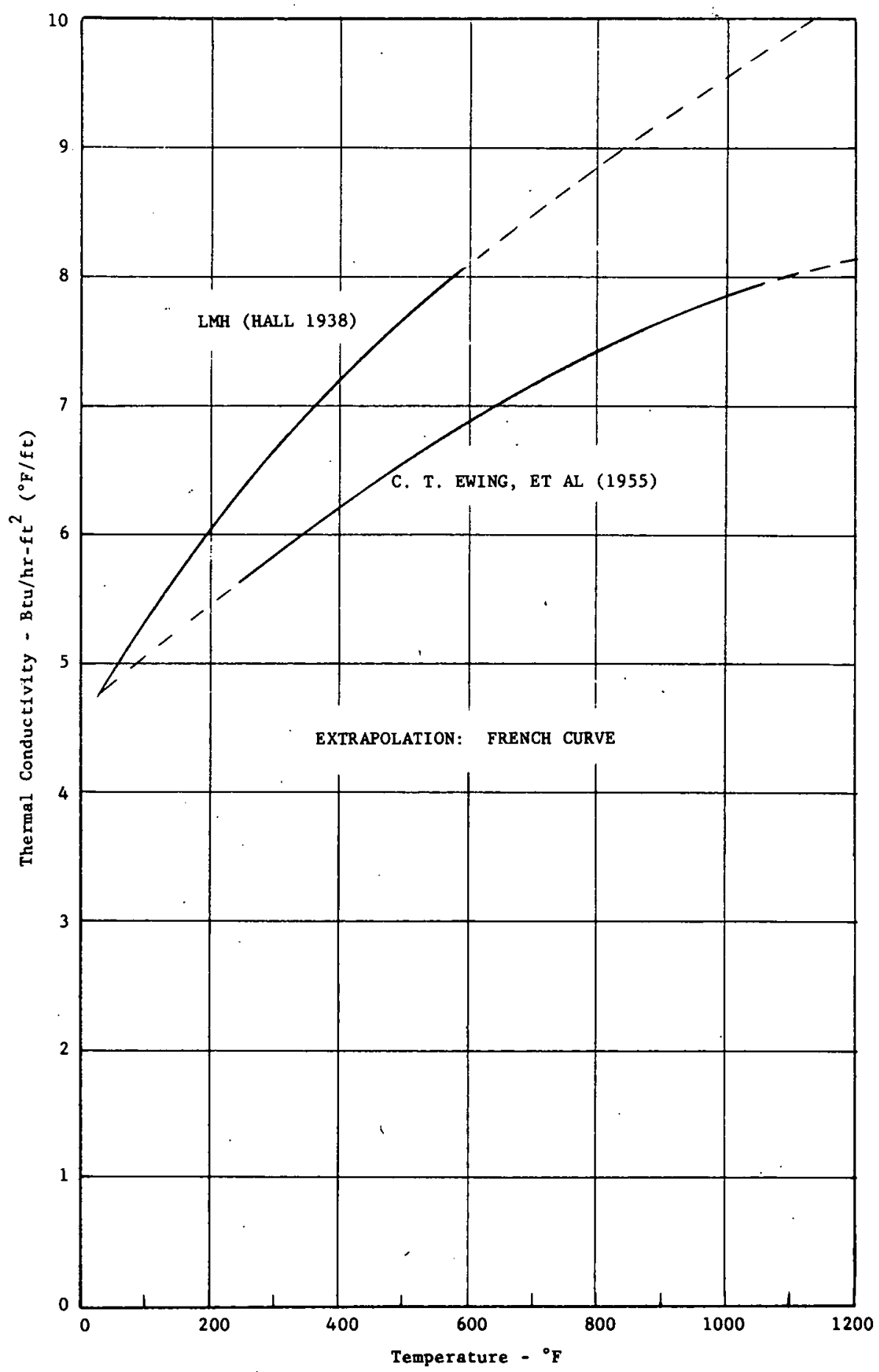

THERMAL CONDUCTIVITY OF LIQUID MERCURY

FIGURE B-4 


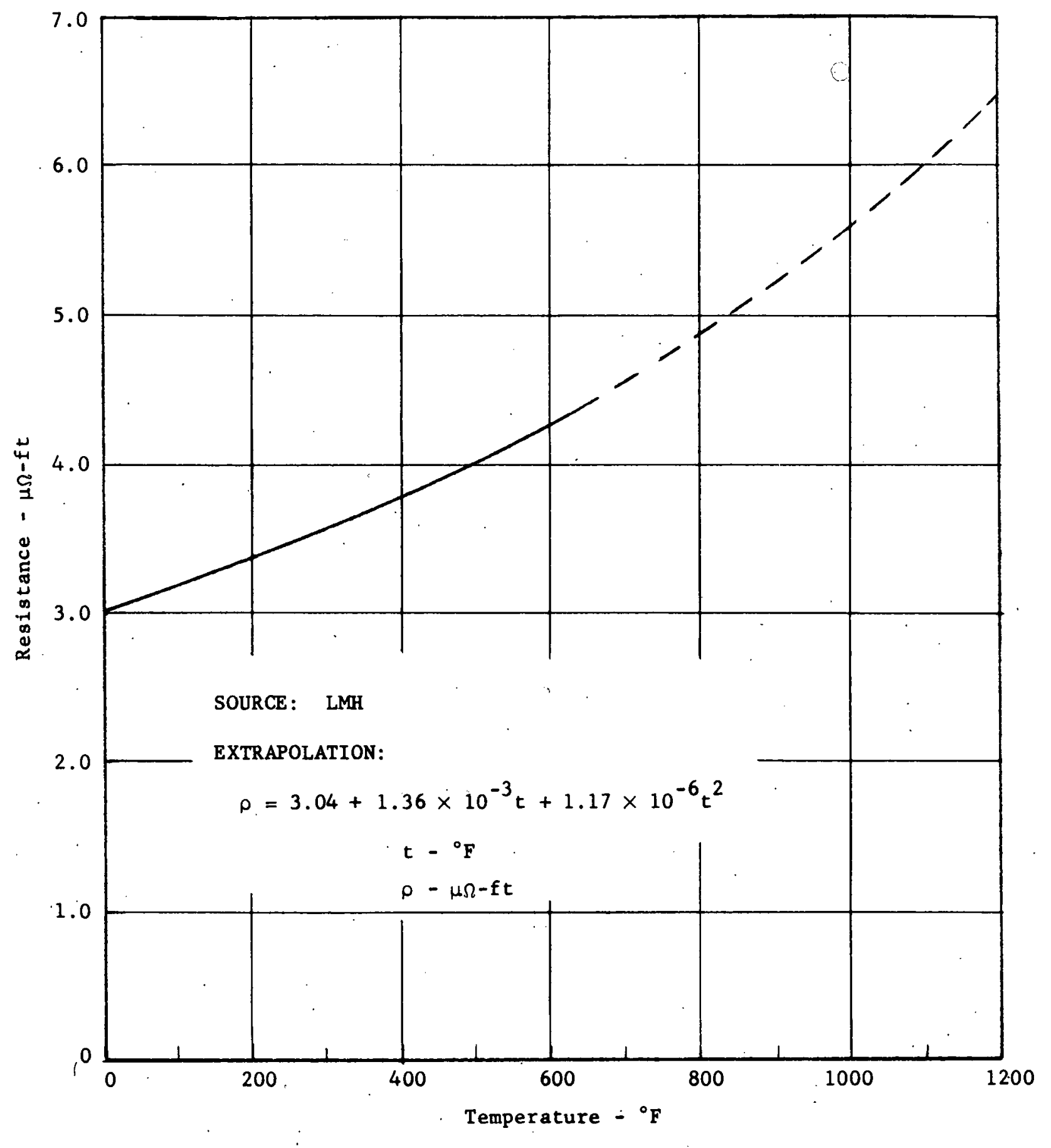

ELECTRICAL RESISTIVITY OF LIQUID MERCURY

FIGURE B-5 


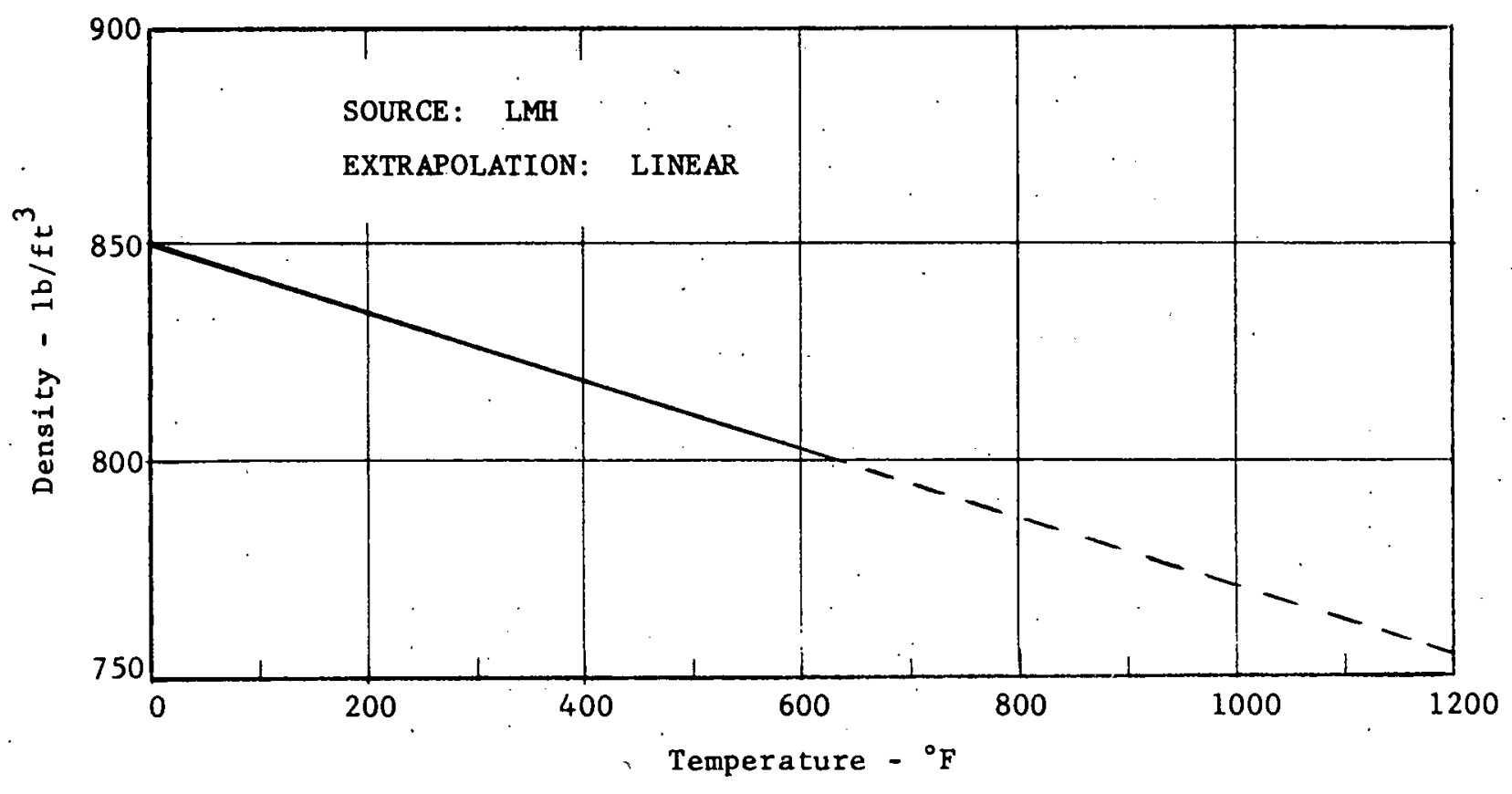

DENSITY OF LIQUID MERCURY

FIGURE B-6 


\section{MERCURY COOLED BREEDER REACTOR}

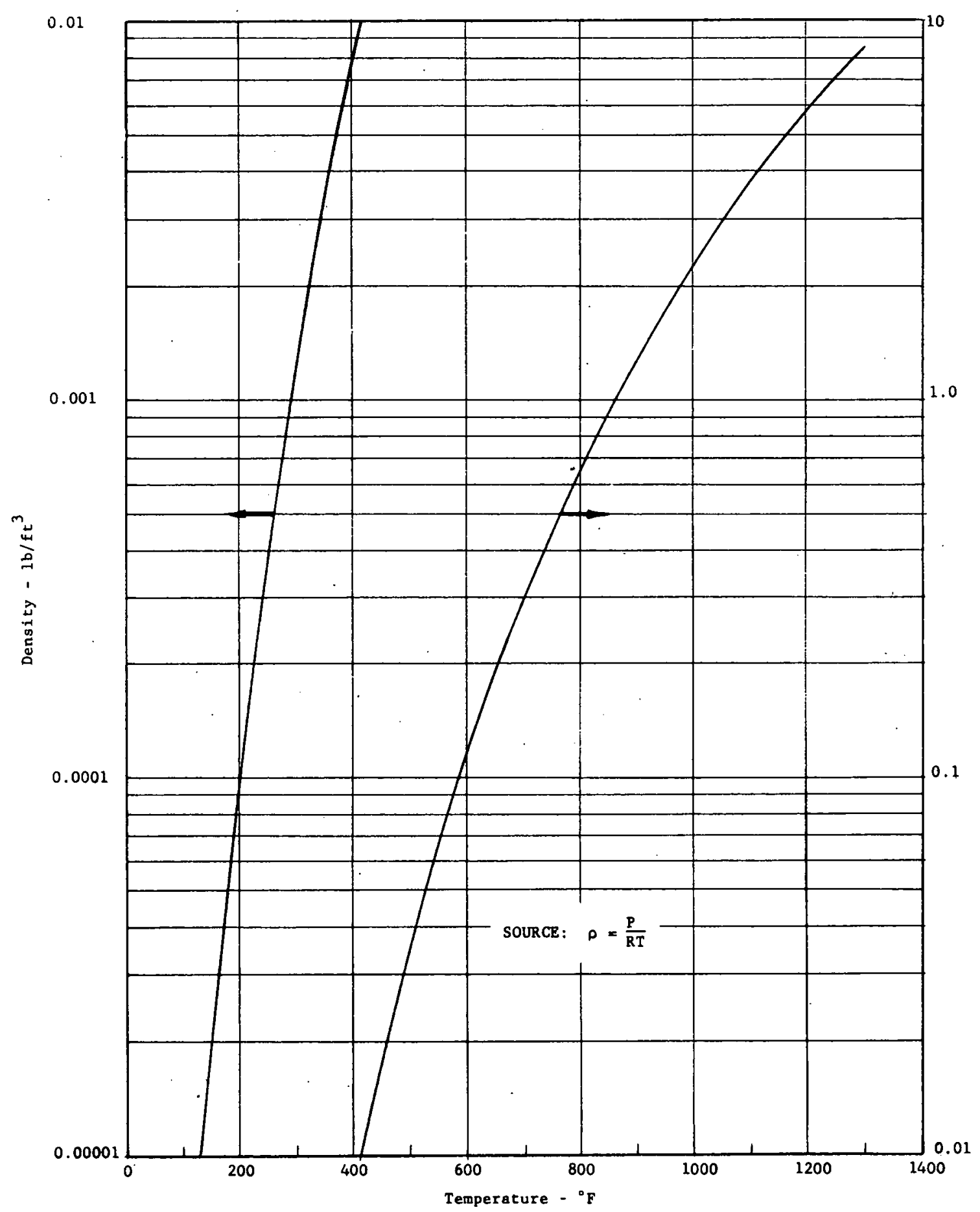

MERCURY VAPOR DENSITY AT SATURATION CONDITIONS

FIGURE B-7 


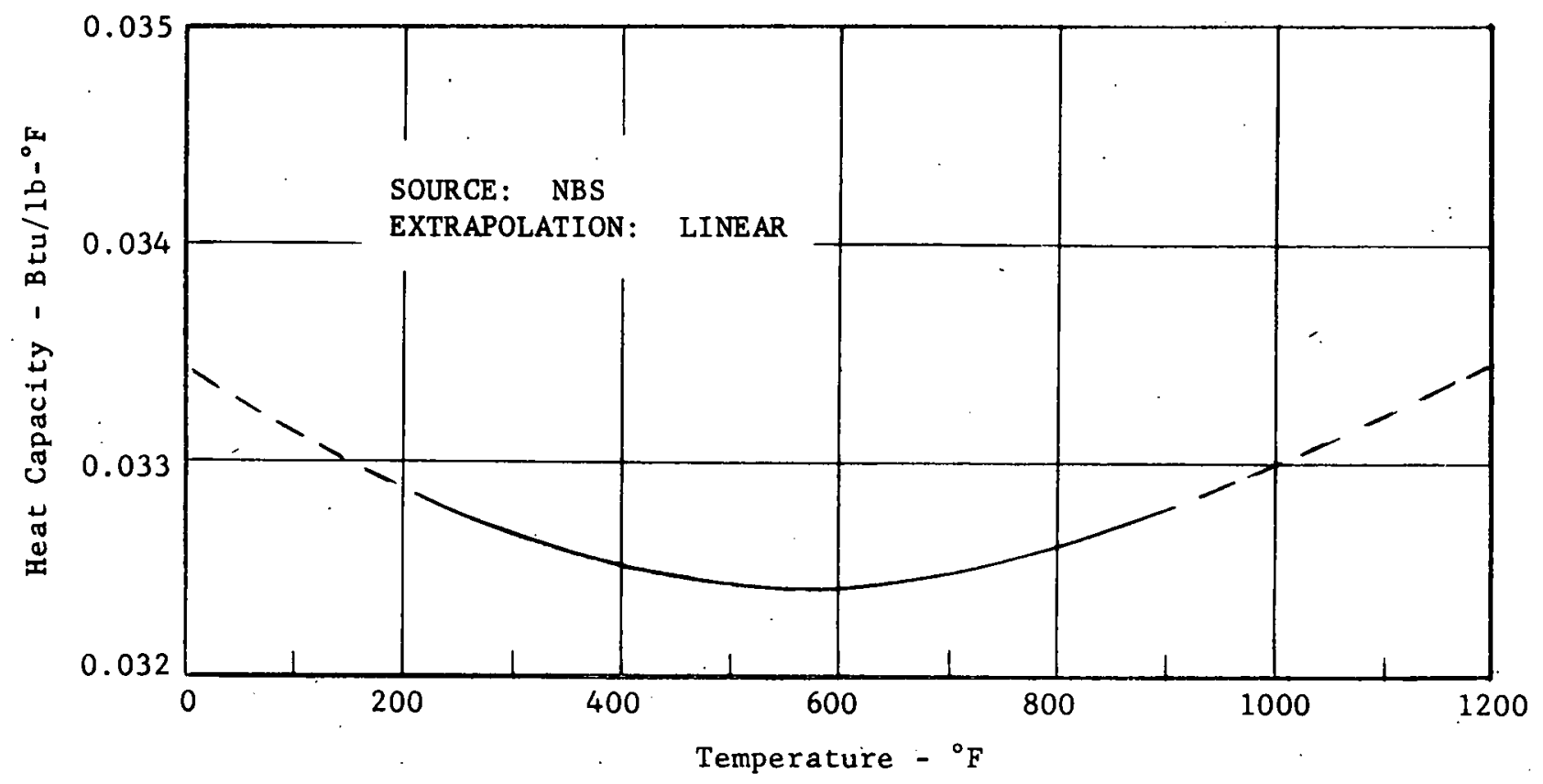

HEAT CAPACITY OF LIQUID MERCURY

FIGURE B-8 


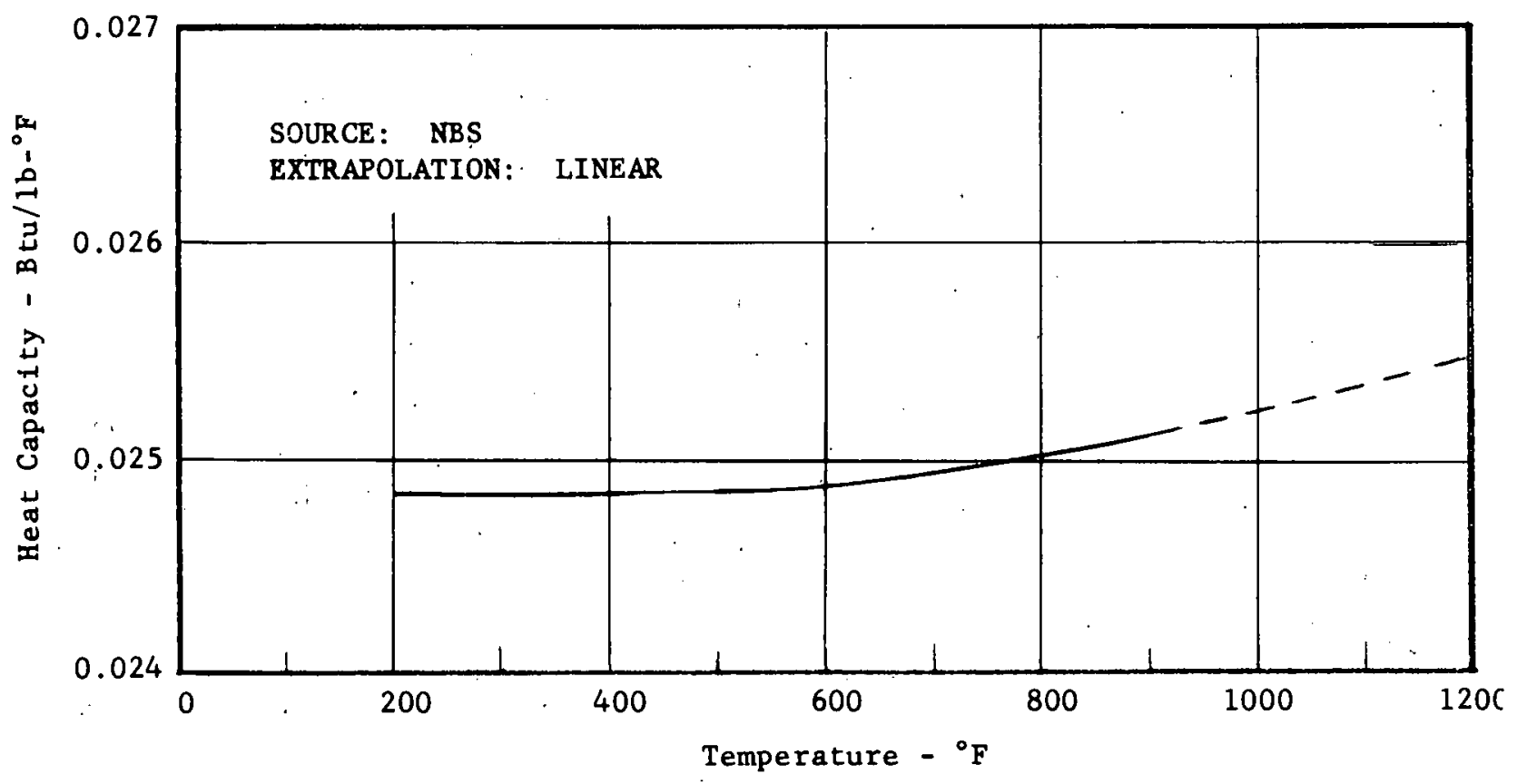

HEAT CAPACITY OF MERCURY VAPOR

FIGURE B-9 


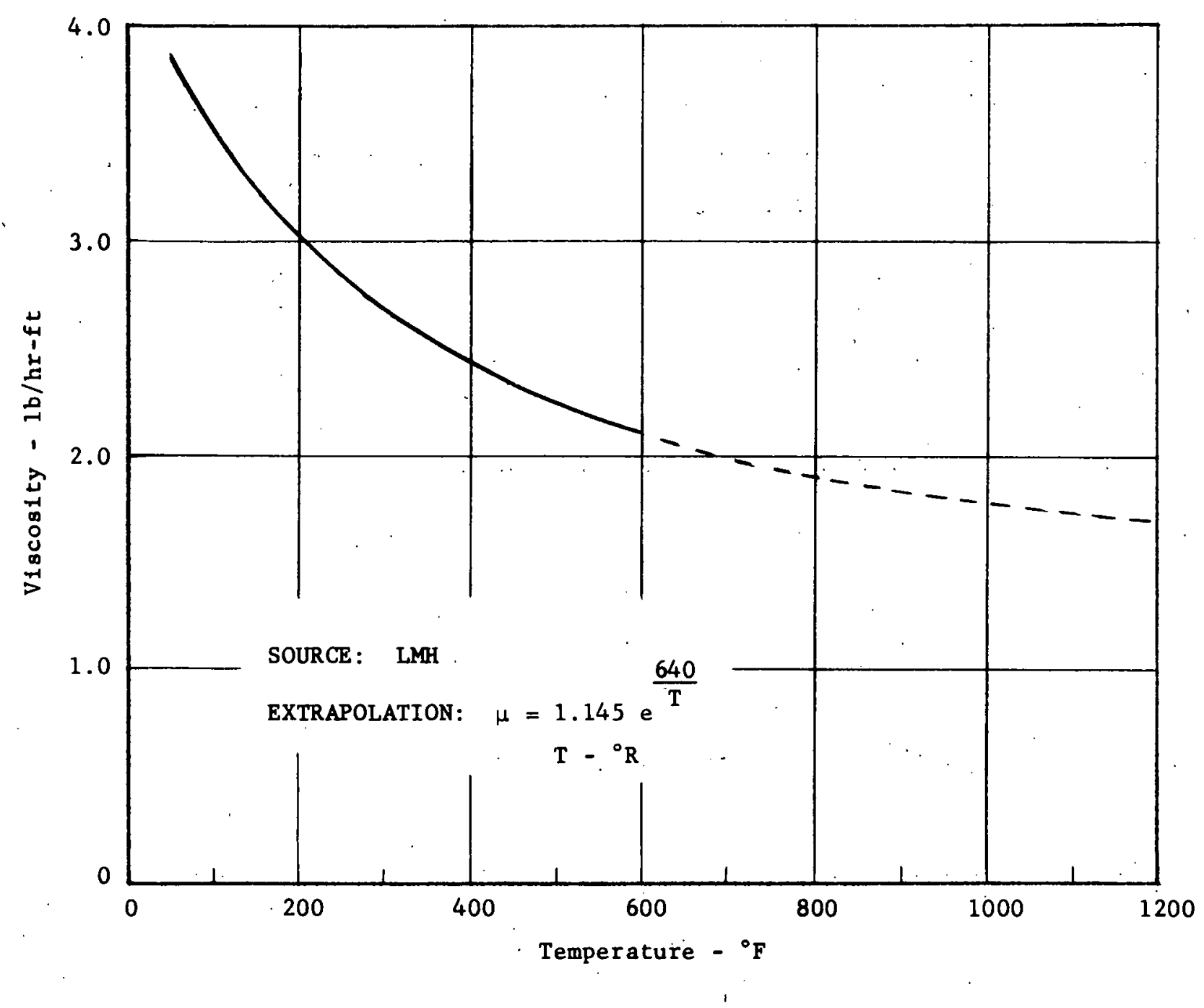

VISCOSITY OF LIQUID MERCURY

FIGURE B-10 


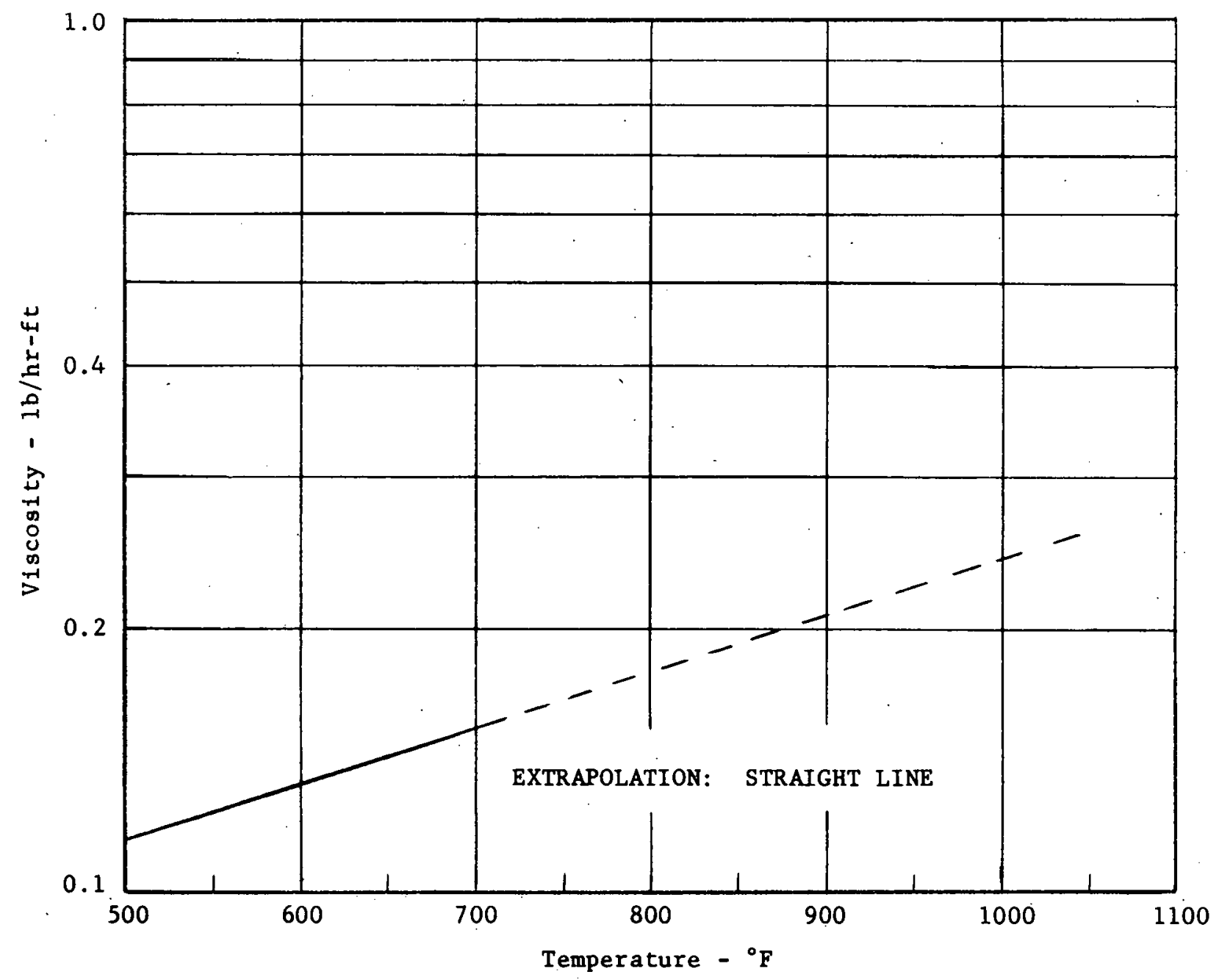

VISCOSITY OF MERCURY VAPOR

FIGURE B-11 
TABLE B-II

OTHER PROPERTIES OF MERCURY

$$
\text { Property }
$$

Thermal

conductivity

Gas constant .

Volume increase on fusion

Heat of fusion

Fusion temperature

Critical constants:

Pressure

Temperature

Density

Atomic weight

\begin{abstract}
State
$\overline{\text { Vapor }}$
\end{abstract}

.

$\left({ }^{\circ} \mathrm{F}\right)$

392
Value
$\overline{0.0197 \mathrm{Btu} / \mathrm{hr}-\mathrm{ft}^{2}\left({ }^{\circ} \mathrm{F} / \mathrm{ft}\right)}$
$0.0537 \frac{\mathrm{psia}}{{ }^{\circ} \mathrm{R} . \mathrm{lb} / \mathrm{ft}^{3}}$

Source

$3.6 \%$

$5.04 \mathrm{Btu} / \mathrm{lb}$

$-38$

$2800-3000$

$14,700-51,000$ psia

$250-310 \mathrm{lb} / \mathrm{ft}^{3}$

200.61

LMH -52

LMH-52

IC T-1929

LMH -52

ICT-1929

LMH -52 


\section{MERCURY COOLED BREEDER REACTOR}

\section{APPENDIX C \\ MERCURY HEAT TRANSFER AND FLUID FLOW}

(A Review of the Literature)

Data and correlations that permit prediction of the performance characteristics of mercury as a heat transfer medium are available from published sources. The portions of these published accounts that are applicable to the evaluation and design of mercury cooled reactors have been excised and are recorded here, with interpretation.

1. Use of Mercury in Power Plants

The technology of mercury for use as a thermodynamic medium and heat transfer fluid was initiated in the United States in $1913,{ }^{16}$ when Dr. W. le Roy Emmet of the General Electric Company described the mercury-steam binary cycle. The first industrial application of this cycle occurred at Dutch Point power station in 1923. ${ }^{16}$ Since that time, experience has been gained through the development of several power plants, of which three are presently operating: the Pittsfield Plant of the General Electric Company in Massachusetts, the South Meadow Generating Station of the Hartford Electrical Light Company in Connecticut, and the Schiller Station of Public Service of New Hampshire. Mercury vapor has also found use as a heat transfer medium for fractionating columns used in petroleum refining at the Marcus Hook plant of the Sun Oil Company.

It is of interest to note that mercury technology has been actively pursued in Russia. The level reached, relative to other liquid metals, led to the selection of mercury as coolant in the initial stages of their fast breeder program, even though other liquid metals were recognized to have superior nuclear and heat transfer properties for their purposes. 17

The early history of the mercury binary-cycle system was beset with the difficulties normal to new developments. The major problem was caused by the mass transfer of iron, which built up flow-restricting deposits in the circulation system. This problem was solved by adding small amounts of magnesium and titanium to the mercury and by making the mercury system airtight. The air in-leakage rate at the Kearny plant, in which mercury flow to the turbine is $2,200,000$ $\mathrm{lb} / \mathrm{hr}$, is reported ${ }^{19}$ to be about $0.5 \mathrm{cu} \mathrm{ft} / \mathrm{hr}$. These advances, together with the use of fog sections in the boiler (described later), have permitted a reduction in mercury inventory to a level of about

* Much additional information on boiling and two-phase flow of mercury became available too late to be included in this review. The information is contained in "Liquid Metal Heat Transfer Media," a translation from the Russian (Ref. 15). 
$4-3 / 4 \mathrm{lb} / \mathrm{kw}$ in the Schiller station and $5-1 / 2 \mathrm{lb} / \mathrm{kw}$ in the Hartford station (based on electrical output of both mercury and steam turbines). It has been estimated ${ }^{16}$ that $2 \mathrm{lb} / \mathrm{kw}$ is attainable with additional development.

Even though mercury equipment has received much less developmental effort than has steam equipment, progress has been such that the later binary plants have operated with exceptionally high availability. The Hartford plant is reported ${ }^{18}$ to have operated as a base load plant with an availability of $96 \%$ for the past four years. It is thus apparent that mercury technology is sufficiently advanced to permit the design of highly dependable boilers, turbines, condensers, and associated equipment operating with mercury turbine inlet conditions of $975^{\circ} \mathrm{F}$ and 145 psia.

Mercury power plants have not experienced the acceptance anticipated at the beginning of their development, primarily because of economic and technical advances in steam plants. Initially, the heat rate of the mercury binary system station was enough smaller than that of the then-conventional steam station that the binary system, even though of higher capital cost, promised to produce cheaper power in high-fuel-cost areas. With the development of higher pressure and temperature steam conditions and the reheat cycle, the advantages of the binary system diminished. As a result, the last binary system, the Schiller station, was placed into operation in 1950 .

The increasing cost of mercury has also contributed to early loss of the potential advantage of the binary system. In 1930 , the cost of mercury is reported ${ }^{16}$ to have been about $\$ 0.75$ per pound, or $\$ 5.7$ per flask (a flask is 76 pounds of mercury). This unit price has increased erratically and attained a maximum price, in 1954 , of $\$ 325$ per flask. The present price is about $\$ 225$ per flask. With a requirement of about $5 \mathrm{lb} / \mathrm{kw}$, the mercury inventory alone accounts for about $\$ 15$ to $\$ 20$ per kilowatt of the plant costs. In view of the excellent availability record noted for the Hartford plant, it is to be concluded that economic rather than technological factors have led to the demise of the mercury binary-cycle power plant.

\section{Corrosion-Inhibiting Additives}

Perhaps the major advance in the development of mercury power plants was the discovery 19 that titanium and magnesium, when added in small amounts to the mercury, effectively eliminated mass transfer and corrosion of steel container materials and insured good wetting of the heat transfer surfaces. Mass transfer of iron from the container walls was so diminished that it has been stated ${ }^{18}$ that no corrosion allowance is required for mercury at $1000^{\circ} \mathrm{F}$ saturation temperature in steel containers. 


\section{MERCURY COOLED BREEDER REACTOR}

Prior to the discovery of these additives, difficulty was experienced in attaining consistent heat transfer fluxes in mercury boiler tubes. Addition of both additives produces complete wetting of the surface and permits consistent high heat fluxes. Addition of magnesium alone is sufficient to produce wetting, but existing evidence strongly indicates that both additives are required for attainment of high heat fluxes. In an experiment ${ }^{18}$ at the Schiller station, the magnesium concentration was maintained at normal levels, but titanium additions were stopped. When the titanium level dropped below the saturation concentration, hot tubes began to appear in an erratic fashion. Upon addition of titanium, the hot tube condition was eliminated in a few minutes.

Further evidence that both additives are required for attainment of high heat fluxes is found in some experimental work on heat transfer to mercury, ${ }^{20}$ in which the magnesium concentrations were varied from zero to $0.05 \%$. No titanium was added. The experiments were conducted at 1 and 10 atmospheres pressure, with a $22-\mathrm{mm}-\mathrm{OD}$, electrically heated, horizontal tube in a pool of mercury. The maximum transitional heat flux (the maximum nucleate boiling flux) was 138,000 $\mathrm{Btu} / \mathrm{hr}-\mathrm{ft}^{2}$ and occurred at 1 atmosphere pressure and a magnesium concentration of $0.05 \%$. In contrast, experiments using both additives indicate that the transitional flux should be much higher than this value. Experiments reported by Bonilla, et al, ${ }^{21}$ for pool boiling from a flat horizontal surface were conducted with heat fluxes up to $200,000 \mathrm{Btu} / \mathrm{hr}-\mathrm{ft}^{2}$. It is also reported that experimental work at the General Electric Company was conducted, ${ }^{18}$ using mercury flowing upward in a tube. In this work, boiling heat fluxes in excess of $200,000 \mathrm{Btu} / \mathrm{hr}-\mathrm{ft}^{2}$ were attained. In neither of the latter experiments was there any indication that the transitional flux was approached. The maximum reported fluxes were limited by apparatus limitations or by lack of interest in the attainment of higher fluxes, rather than by the boiling phenomena.

The detailed mechanism by which the magnesium and titanium inhibit mass transfer and insure good wetting at the mercury-wall interface is not definitely known. Titanium is found in a thin surface layer on the wall, and it can be presumed that the improved wetting observed with titanium added to the mercury is associated with a change in the surface-free energy of the mercury-titanium component at the interface. Whether the titanium layer exists as an intermetallic compound or in some other form is not firmly established. It appears that the magnesium acts as an oxygen scavenger, in which function it removes the oxide layer from the metal wall, permitting intimate contact between the mercury and the wall. With titanium additions, the magnesium undoubtedly also protects the titanium from rapid oxidation. Sodium has been used in place of magnesium, with 
'fair success. Magnesium is preferred, however, because it is easily handled and its reaction products form an unobjectionable powder which is easily separated from the mercury. ${ }^{19}$

Required concentrations of the additions are low. Practice at the Hartford plant ${ }^{18}$ calls for maintenance of $0.35 \mathrm{ppm}$ of titanium and 50 to $70 \mathrm{ppm}$ of magnesium. These levels are maintained in the 185,000-lb mercury inventory with a yearly make-up rate of about $50 \mathrm{lb}$ of magnesium and $9 \mathrm{lb}$ of titanium. The titanium is added as titanium hydride.

\section{Heat Transfer to Boiling Mercury}

Heat transfer to boiling mercury at the saturation temperature has been measured by several investigators. R. E. Lyon, et al, ${ }^{22}$ describe experiments that utilized a horizontal, 3/4-inch-OD, 316 stainless steel tube as the heat transfer surface. They present boiling data at atmospheric pressure for pure mercury, mercury with $0.10 \% \mathrm{Na}$, mercury with $0.02 \% \mathrm{Mg}$ and $0.0001 \% \mathrm{Ti}$, sodium, sodium-potassium alloy (56 to $59 \%$ potassium), and cadmium. Data with pure mercury suggest that the heating surface was unwetted by the mercury. The trend is similar to that which would be expected for film boiling. For example, at a flux of $30,000 \mathrm{Btu} / \mathrm{hr}-\mathrm{ft}^{2}$, the difference between surface and saturation temperatures is about $1000^{\circ} \mathrm{F}$. The data for mercury with sodium added indicate a maximum nucleate boiling heat flux of about $60,000 \mathrm{Btu} / \mathrm{hr}-\mathrm{ft}^{2}$, and that film boiling occurs for higher fluxes. Data for mercury with magnesium and titanium additions are presented for heat fluxes up to about $100,000 \mathrm{Btu} / \mathrm{hr}-\mathrm{ft}^{2}$, at which flux the difference between tube and mercury saturation temperatures is about $12^{\circ} \mathrm{F}$. There is no indication of an approach to a . transition in the boiling mechanism. Collection of data at higher fluxes was prevented by the limited capacity of the mercury condenser.

Similar experiments have been reported by Korneev, ${ }^{20}$ who used a horizontal, 22-mm-OD, carbon steel tube for the heating surface. Experiments at 1 and 10 atmospheres pressure were conducted, with magnesium added to the mercury in concentrations ranging up to $0.05 \%$. Figure $\mathrm{C}-1$ shows the measured heat flux as a function of the difference between surface and saturation temperatures for 1 and 10 atmospheres pressure and a magnesium concentration of $0.03 \%$. Variation of the peak nucleate heat flux with changing magnesium concentration is shown in Figure C-2. The maximum nucleate boiling flux of $138,000 \mathrm{Btu} / \mathrm{hr}-\mathrm{ft}^{2}$ was observed with $0.05 \%$ magnesium and 1 atmosphere pressure. This low maximum flux is undoubtedly due to incomplete wetting, since the addition of magnesium without titanium does not insure complete wetting of the heat transfer surface. 


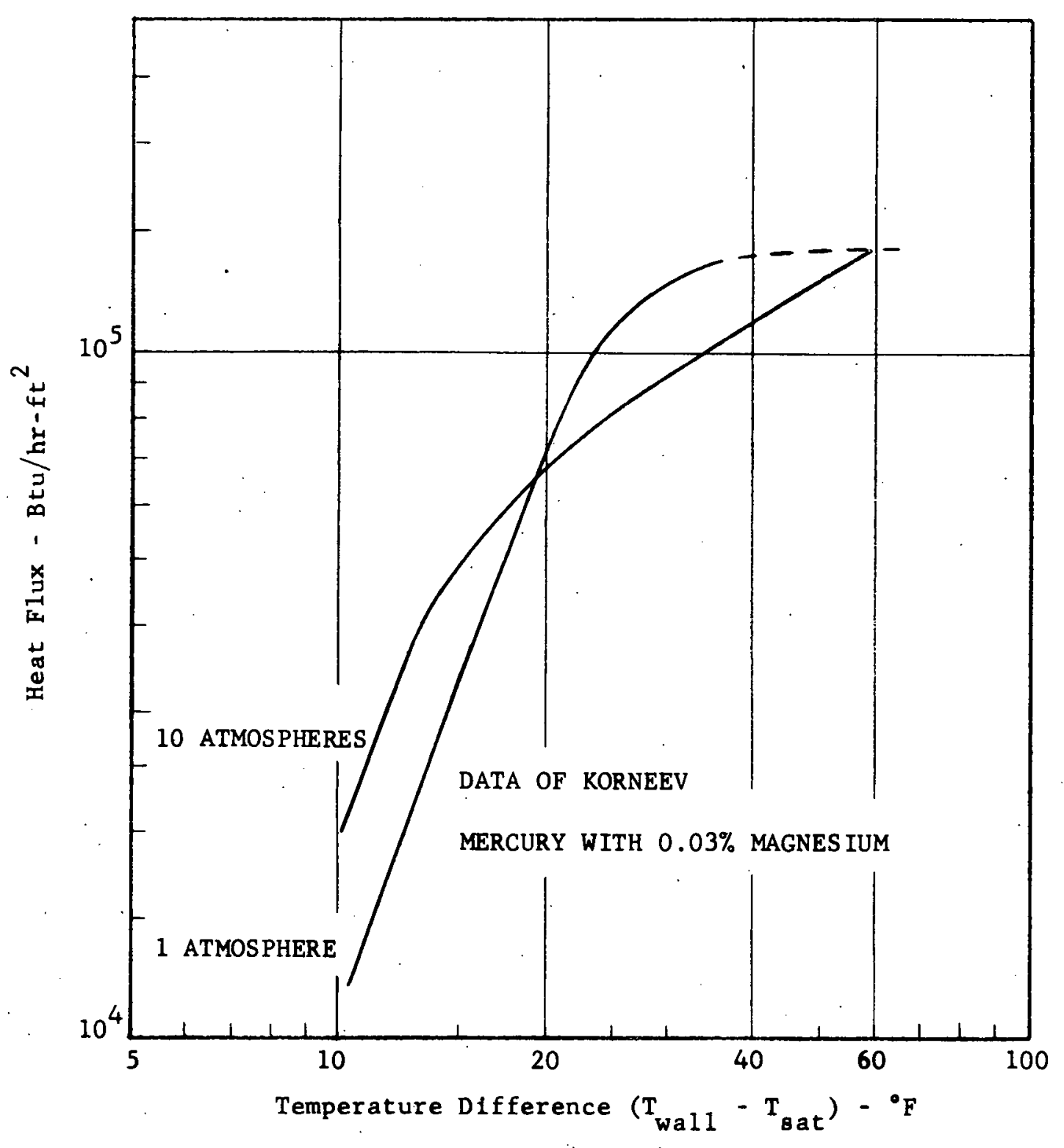

BOILING HEAT FLUX.AS A FUNCTION

OF TEMPERATURE DIFFERENCE

FIGURE C-1 


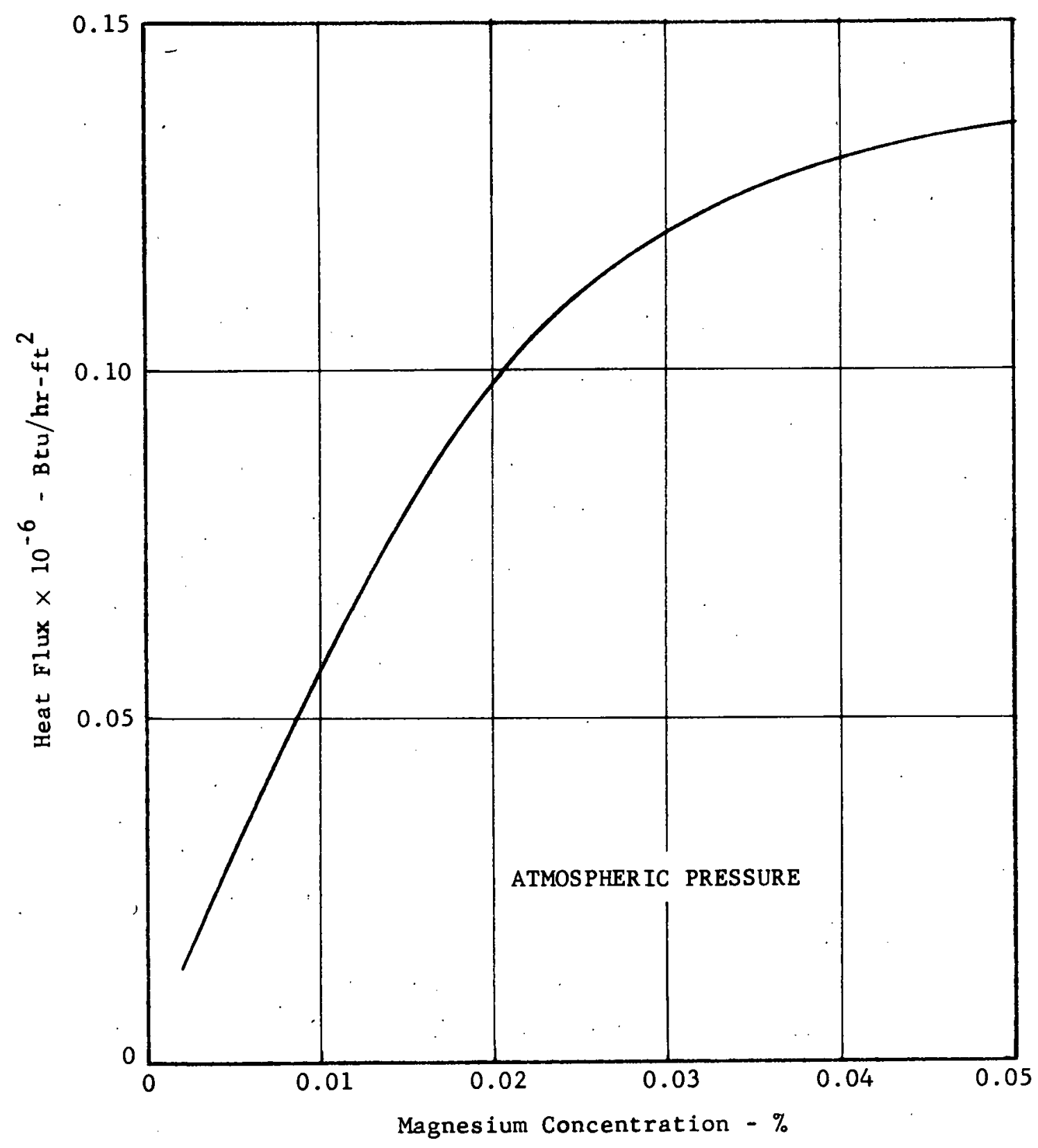

PEAK NUCLEATE BOILING HEAT FLUX FOR MERCURY-MAGNESIUM MIXTURES

FIGURE C-2 


\section{MERCURY COOLED BREEDER REACTOR}

The apparent fact that a higher peak flux was observed at 1 rather than 10 atmospheres pressure is at variance with both theory and experimental data on other fluids. For low reduced pressures, less than about 0.3 , theory indicates and experiments with other liquids show that the peak nucleate flux should increase with increasing pressure. The critical pressure for mercury is unknown, but estimates give values of 1000 to 3500 atmospheres; therefore, the reduced pressures of Korneev's experiments were of the order of 0.001 , very much below the range in which the reversal might be expected to occur.

Experiments reported by Bonilla, et al, ${ }^{21}$ employed a horizontal, low-carbon-steel plate as the heat transfer surface. Data are given both for pure mercury and for mercury with $0.02 \%$ magnesium and $0.0001 \%$ titanium additions. Boiling data with pure mercury exhibit the pure mercury behavior noted by Lyon, et al. ${ }^{22}$ With the additives, the Bonilla data at 1 atmosphere pressure are also similar to Lyon's data with additives, but the maximum flux is extended to $200,000 \mathrm{Btu} / \mathrm{hr}-\mathrm{ft}^{2}$, without evidence of transition from the nucleate boiling mechanism. Again, collection of data at higher fluxes was prevented by equipment limitations rather than by the boiling phenomena. Data are presented for three pressures: 83,287 , and $800 \mathrm{~mm} \mathrm{Hg}$. Using these data to establish pressure dependence, equation $\mathrm{C}-1$ represents the difference between heating surface and mercury saturation temperatures as a function of heat flux and pressure. The equation is restricted to the nucleate boiling regime.

$$
\Delta \mathrm{T}=0.22 \frac{(\mathrm{g} / \mathrm{A})^{0.435}}{\mathrm{p}^{0.29}},
$$

where $\Delta \mathrm{T}$ is in ${ }^{\circ} \mathrm{F}, \mathrm{q} / \mathrm{A}$ in $\mathrm{Btu} / \mathrm{hr}^{-\mathrm{ft}^{2}}{ }^{2}$, and $\mathrm{p}$ in psia. The equation is graphically represented in Figure C-3. Saturation temperature rather than pressure is shown on the curves.

W. S. Farmer ${ }^{23}$ is reported to have studied pool boiling of pure mercury. Horizontal surfaces of copper and chrome plate were used in his experiments, which were conducted at a pressure of $6.3 \mathrm{~mm} \mathrm{Hg}$. The chrome-plated surfaces exhibited higher temperatures than the copper surfaces, which, in contrast to the chrome plate, can be presumed to have been well wetted by the mercury. The maximum flux measured with the copper surface appears to have been slightly in excess of $120,000 \mathrm{Btu} / \mathrm{hr}-\mathrm{ft}^{2}$, with no indication of a departure from the nucleate boiling phenomena. The data obtained with the copper surface correspond reasonably well with predictions afforded by equation $\mathrm{C}-1$. 


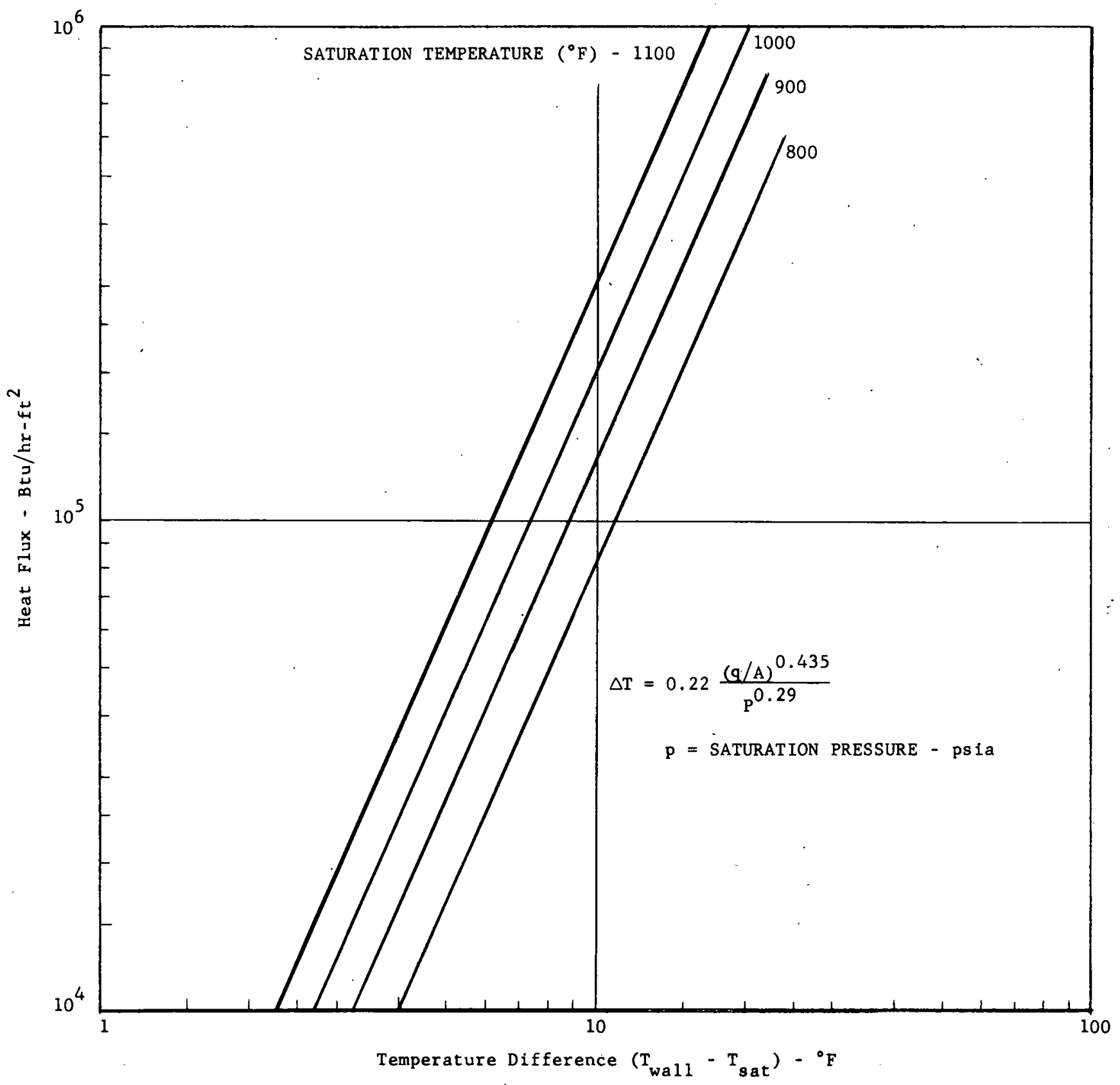

NUCLEATE BOILING HEAT FLUX FOR

MERCURY WITH MAGNESIUM AND TITANIUM ADDED

FIGURE C -3 


\section{MERCURY COOLED BREEDER REACTOR}

In the process of developing the mercury binary cycle, General Electric Company conducted several experiments with heat transfer to mercury flowing upward in a tube. The results of this work have not been published and are not generally available. It is reported, however, that heat fluxes in excess of $200,000 \mathrm{Btu} / \mathrm{hr}^{-\mathrm{ft}}{ }^{2}$ were attained in a tube in which, progressing from inlet to exit, the mercury was successively in the liquid state, boiling, and a mixture of vapor and liquid termed a mercury fog. Fluxes higher than about $200,000 \mathrm{Btu} / \mathrm{hr}-\mathrm{ft}^{2}$ were not imposed in the experimental apparatus, because the flux range of interest for contemplated applications was many times less than that value. Both titanium and magnesium additives were used in the experimental work.

Establishment of the fact that high heat fluxes could be sustained by the two-phase mixture was one of the developments that permitted a large reduction in the mercury inventory required for the binary cycle. Mixture densities as low as $13 \mathrm{lb} / \mathrm{ft}^{3}$ are stated to be realized in mercury boilers, and a density of $2.5 \mathrm{lb} / \mathrm{ft}^{3}$ is claimed to be possible without a reduction in the heat-absorbing ability of the boilers as designed. 1

Some Russian work on heat transfer to mercury liquid-vapor mixtures flowing in a horizontal pipe is reported by Korneev and Puganov. ${ }^{24}$ Stratification of the liquid phase was observed to occur when the liquid velocity was less than a limiting value, this value being given by the empirical relation

$$
\mathrm{v}_{\ell}=0.085(\mathrm{q} / \mathrm{A})^{0.42} \mathrm{D}_{\mathrm{i}}^{0.76} \text {. }
$$

where $\mathrm{V}_{\ell}=$ liquid velocity $(\mathrm{ft} / \mathrm{sec})$.

$$
\begin{aligned}
& \mathrm{q} / \mathrm{A}=\text { heat flux }\left(\mathrm{Btu} / \mathrm{hr}-\mathrm{ft}^{2}\right), \\
& D_{i}=\text { internal diameter of the pipe (ft). }
\end{aligned}
$$

Equation $\mathrm{C}-2$ is based on data taken over the following ranges:

$$
1800<(\mathrm{q} / \mathrm{A})<26,000 \mathrm{Btu} / \mathrm{hr}-\mathrm{ft}^{2} \text {. }
$$

0.51 in. $<\mathrm{D}_{\mathrm{i}}<1.56$ in.

Korneev states that variation of pressure within the range of 1 to 12 atmospheres has practically no effect on heat transfer, and while velocity of the vapor phase does affect the stratification phenomenon, equation $\mathrm{C}-2$ insures non-stratified flow for the calculated (or higher) liquid velocities, regardless of the vapor velocity. 
With non-stratified flow, the unit thermal conductance, $h$, is given by the relation

$$
h=0.258 \frac{(q / A)^{0.67} v_{v}^{0.3}}{D_{i}^{0.45}}
$$

where $\mathrm{V}_{\mathrm{v}}=$ velocity of the vapor phase in $\mathrm{ft} / \mathrm{sec}, \mathrm{h}$ is in $\mathrm{Btu} / \mathrm{hr}-\mathrm{ft}^{2}-{ }^{\circ} \mathrm{F}, \mathrm{q} / \mathrm{A}$ is in $\mathrm{Btu} / \mathrm{hr}-\mathrm{ft}^{2}$, and $D_{i}$ is in $\mathrm{ft}$. Although the velocity of the liquid and vapor phases is not defined in the original reference, ${ }^{24}$ it is presumably the velocity the phase would exhibit if the other phase were absent. Equation $\mathrm{C}-3$ is based on data taken over the following ranges:

$1840<\mathrm{q} / \mathrm{A}<35,800 \mathrm{Btu} / \mathrm{hr}^{-\mathrm{ft}^{2}}$.

$3.28<\mathrm{V}_{\mathrm{v}}<62 \mathrm{ft} / \mathrm{sec}$.

$0.0432 \mathrm{ft}(0.52$ in. $)<\mathrm{D}_{i}<0.131 \mathrm{ft}(1.57 \mathrm{in.})$.

The equation is presented graphically in Figure $\mathrm{C}-4$, without regard to the variable ranges noted above. The maximum nucleate boiling flux is not.knuwn and the refore not shown on the graph.

A theory ${ }^{25}$ leading to the prediction of the peak nucleate heat flux (burnout flux) for pool boiling from a horizontal surface has recently met with good success, both in representing the detailed structure of the peak boiling phenomena as photographically observed and in predicting the magnitude of the burnout flux. The theory differs from previous attempts in that it is based on a hydrodynamic stability analysis of the vapor-liquid interface at the heat transfer surface and is independent, in its formulation and application, of empirically determined coefficients. While no data for liquid metals exist against which the theory can be tested for low Prandtl number liquids, the nature of the theory suggests that boiling liquid metals should not differ from water and similar liquids with respect to the boiling phenomena considered in the theory. The equation for predicting the maximum nucleate flux, $\mathrm{q} / \mathrm{A}$, in boiling is

$$
\mathrm{q} / \mathrm{A}=\frac{\pi}{24} \lambda_{\cdot \mathrm{v}}\left[\frac{\gamma \operatorname{gg}_{\mathrm{c}}\left(\rho_{\ell}-\rho_{\mathrm{v}}\right.}{\rho_{\mathrm{v}}}\right]^{1 / 4}\left[\frac{\rho_{\ell}}{\rho_{\ell}+\rho_{\mathrm{v}}}\right]^{1 / 2} \cdot,
$$

where $\lambda=$ heat of vaporization,

$\rho_{\mathrm{v}}, \rho_{\ell}=$ densities of liquid and vapor, respectively,

$\gamma=$ surface tension of the liquid,

$\mathrm{g}=$ acceleration due to gravity (i.e., , body force per unit mass),

$\mathrm{g}_{\mathrm{c}}=$ gravitational conversion constant. 


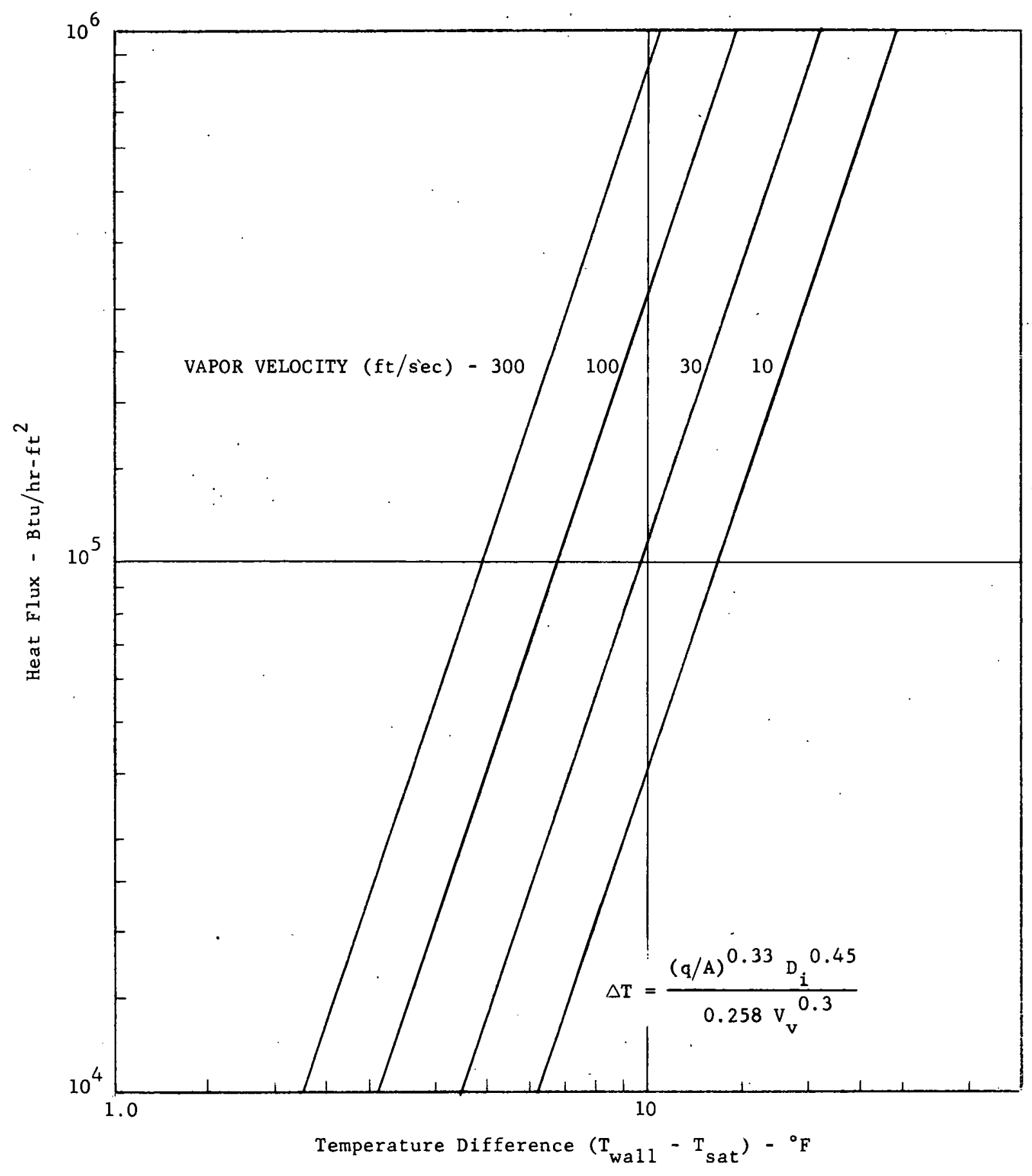

HEAT TRANSFER TO MERCURY LIQUID-VAPOR MXXTRES FLOWING IN A PIPE $\left(D_{i}=0.20-I N C H\right.$ DIAMETER)

FIGUR E C -4 
Figure $\mathrm{C}-5$ shows the maximum nucleate boiling heat flux predicted by this equation for mercury at different saturation temperatures. Inspection of the curves shows that the maximum flux increases rapidly with pressure (or saturation temperature), as is typical of other liquids at low reduced pressure. At $1000^{\circ} \mathrm{F}$ saturation temperature, the predicted maximum flux is slightly greater than $1,000,000 \mathrm{Btu} / \mathrm{hr}-\mathrm{ft}^{2}$.

Other equations intended for the prediction of the maximum nucleate heat flux in pool boiling have been derived on the basis of data correlations guided by various assumed boiling mechanisms. However, since these equations are based on data obtained using water and some simple organic fluids, their applicability to liquid metals is to be regarded with caution. Table C-I lists some of these equations and presents the maximum nucleate heat flux predicted by each for mercury at a saturation temperature of $1000^{\circ} \mathrm{F}$.

\section{TABLE C-I}

Predictions of Maximum Nucleate Heat Flux in Pool Boiling of Mercury at $1000^{\circ} \mathrm{F}$ Saturation Temperature

\begin{tabular}{|c|c|c|}
\hline Author & Equation & $\begin{array}{r}\text { Max. Flux } \\
\left(\mathrm{Btu} / \mathrm{hr}-\mathrm{ft}^{2}\right) \\
\end{array}$ \\
\hline Addoms ${ }^{26}$ & $\mathrm{q} / \mathrm{A}=2.2 \lambda \rho_{\mathrm{v}}\left(\frac{\mathrm{k}}{\rho \mathrm{c}_{\mathrm{p}}}\right)_{\ell}^{1 / 3}\left(\frac{\rho_{\ell}}{\rho_{\mathrm{v}}}-1\right)^{1 / 2}$ & $6,500,000$ \\
\hline $\begin{array}{l}\text { Rohsenow } \\
\text { and Griffith }\end{array}$ & $\mathrm{q} / \mathrm{A}=143 \lambda \rho_{\mathrm{v}}\left(\frac{\rho_{\ell}}{\rho_{\mathrm{v}}}-1\right)^{0.6}$ & $1,390,000$ \\
\hline Kutaleladze $e^{26}$ & $\mathrm{q} / \mathrm{A}=0.16 \lambda\left[\operatorname{ggg}_{\mathrm{c}} \rho_{\mathrm{v}}^{2} \cdot\left(\rho_{\ell}-\rho_{\mathrm{v}}\right)\right]^{1 / 4}$ & $1,340,000$ \\
\hline Zuber and Tribus 25 & $\mathrm{q} / \mathrm{A}=\frac{\pi}{24} \lambda \rho_{\mathrm{v}}\left[\frac{\gamma_{\mathrm{gg}}{ }_{\mathrm{c}}\left(\rho_{\mathrm{l}}-\rho_{\mathrm{v}}\right)}{\rho_{\mathrm{v}}^{2}}\right]^{1 / 4}\left[\frac{\rho_{\ell}}{\rho_{\ell}+\rho_{\mathrm{v}}}\right]^{1 / 2}$ & $1,100,000$ \\
\hline Griffith $^{28}$ & $\frac{41.5(\mathrm{~g} / \mathrm{A})}{\rho_{\mathrm{v}} \lambda\left[\frac{\left(\rho_{\ell}-\rho_{\mathrm{v}}\right) \mathrm{g}}{\mu_{\ell}}\left(\frac{\mathrm{k}}{\rho \mathrm{c}}\right)_{\mathrm{p}}^{2}\right]^{1 / 3}}=\mathrm{f} \frac{\mathrm{p}}{\mathrm{p}_{\mathrm{c}}}=\begin{array}{l}2300 \text { for } \\
1000^{\circ} \mathrm{F} \text { sat. } \\
\text { temp. }\end{array}$ & $51,000,000$ \\
\hline
\end{tabular}




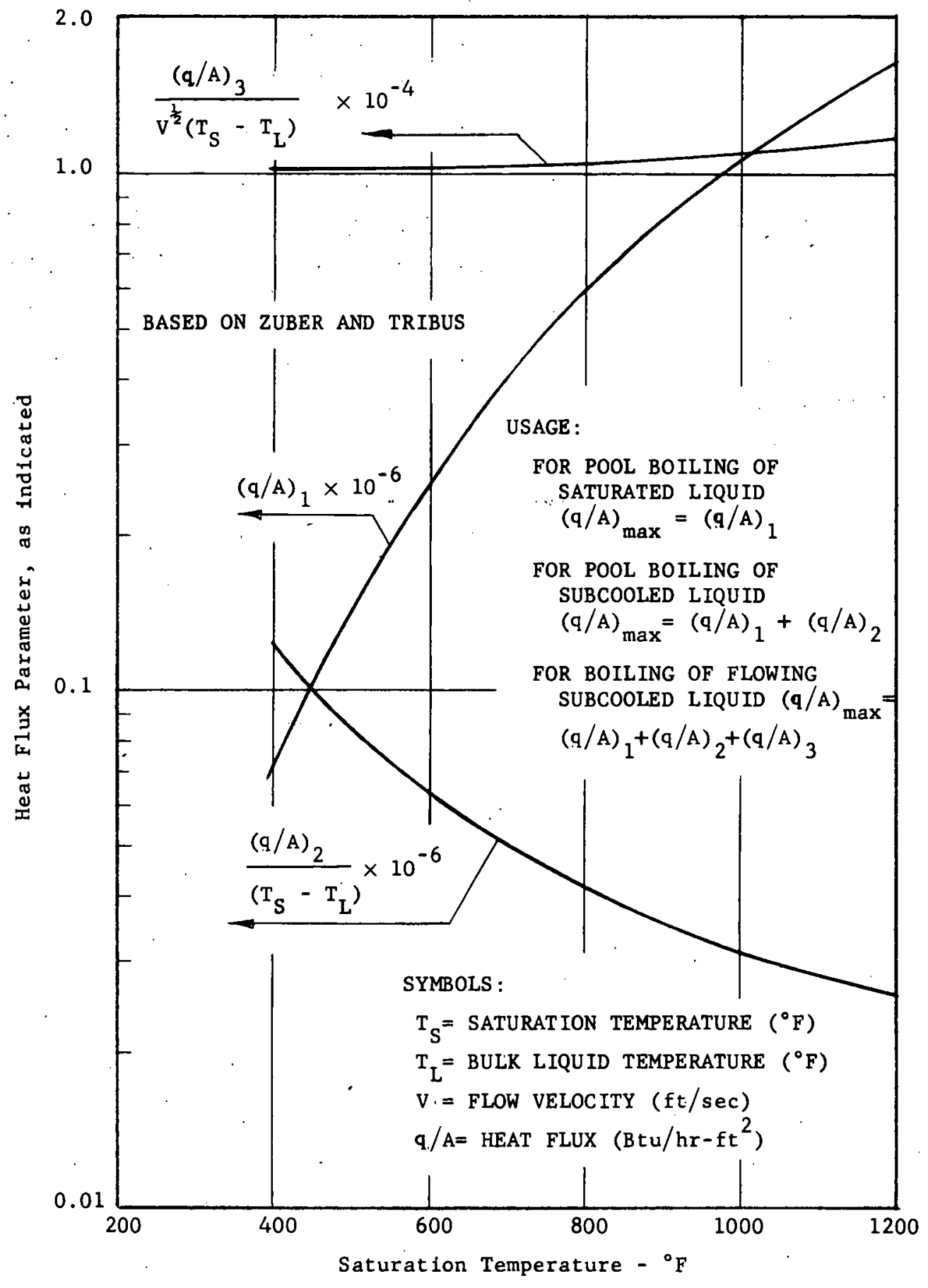

- MAXIMUM NUCLEATE BOILING HEAT FLUX FOR MERCURY AT OR BELOW SATURATION TEMPERATURE

FIGURE C-5 
Zuber and Tribus have extended their analysis of pool boiling of saturated liquids to include prediction of the maximum nucleate boiling heat flux for pool and forced-flow boiling of subcooled liquids. Their analysis is applied to mercury in Figure $\mathrm{C}-5$, on which is shown the usage of the various terms presented. Figure C-6 applies the information presented in Figure $\mathrm{C}-5$ to the prediction of the maximum nucleate boiling flux for subcooled liquid mercury at a saturation pressure of 180 psia (corresponding to a saturation temperature of $1000^{\circ} \mathrm{F}$ ). It may be noted that the theory predicts a very large increase in maximum nucleate heat flux with subcooled liquid and that the effect of flow velocity is relatively small.

Theories for predicting the maximum flux with flowing liquid-vapor mixtures are not available in the literature. Griffith ${ }^{28}$ has presented an empirical correlation of burnout heat fluxes that is recommended for boiling with subcooled, saturated, or flowing liquid-vapor mixtures. The correlation is a generalization of data obtained using water and several simple organics. The pool boiling maximum flux prediction presented in Table C-I is the form Griffith's correlation takes for the special case of pool boiling of saturated liquids. The predicted value shown for mercury appears unreasonably high, and applicability of the more general form of the correlation to mercury does not appear reasonable.

4. Heat Transfer to Liquid (Non-Boiling) Mercury

Heat transfer to liquid metals has received a large amount of attention over the last few years, and extensive reviews of this work are available. Perhaps the most thorough review of the experimental data for flow through tubes has been presented by Lubarsky and Kaufman. ${ }^{29}$ Their recommended equation for predicting the Nusselt modulus for fully developed hydrodynamic and thermal profiles with flow in a round tube with uniform heat addition is

$$
\mathrm{Nu}=0.625 \mathrm{Pe}^{0.4} \quad(100<\mathrm{Pe}<20,000) .
$$

Properties of the liquid metals are specified to be those given in the Liquid Metals Handbook. ${ }^{11}$

A Russian review article ${ }^{30}$ recommends, for the same flow conditions,

$$
\mathrm{Nu}=3.3+0.014 \mathrm{Pe}^{0.8} \quad(300<\mathrm{Pe}<20,000)
$$

and $\mathrm{Nu}=0.7 \mathrm{Pe}^{0.33} \quad(80<\mathrm{Pe}<300)$.

These two equations are stated to be applicable to non-purified liquid metals flowing in technical (commercial-quality) tubes and are considered as giving the lower liquid-metal heat transfer limit. Physical properties utilized in establishing and using the two equations are not given in the review article but are referenced. 


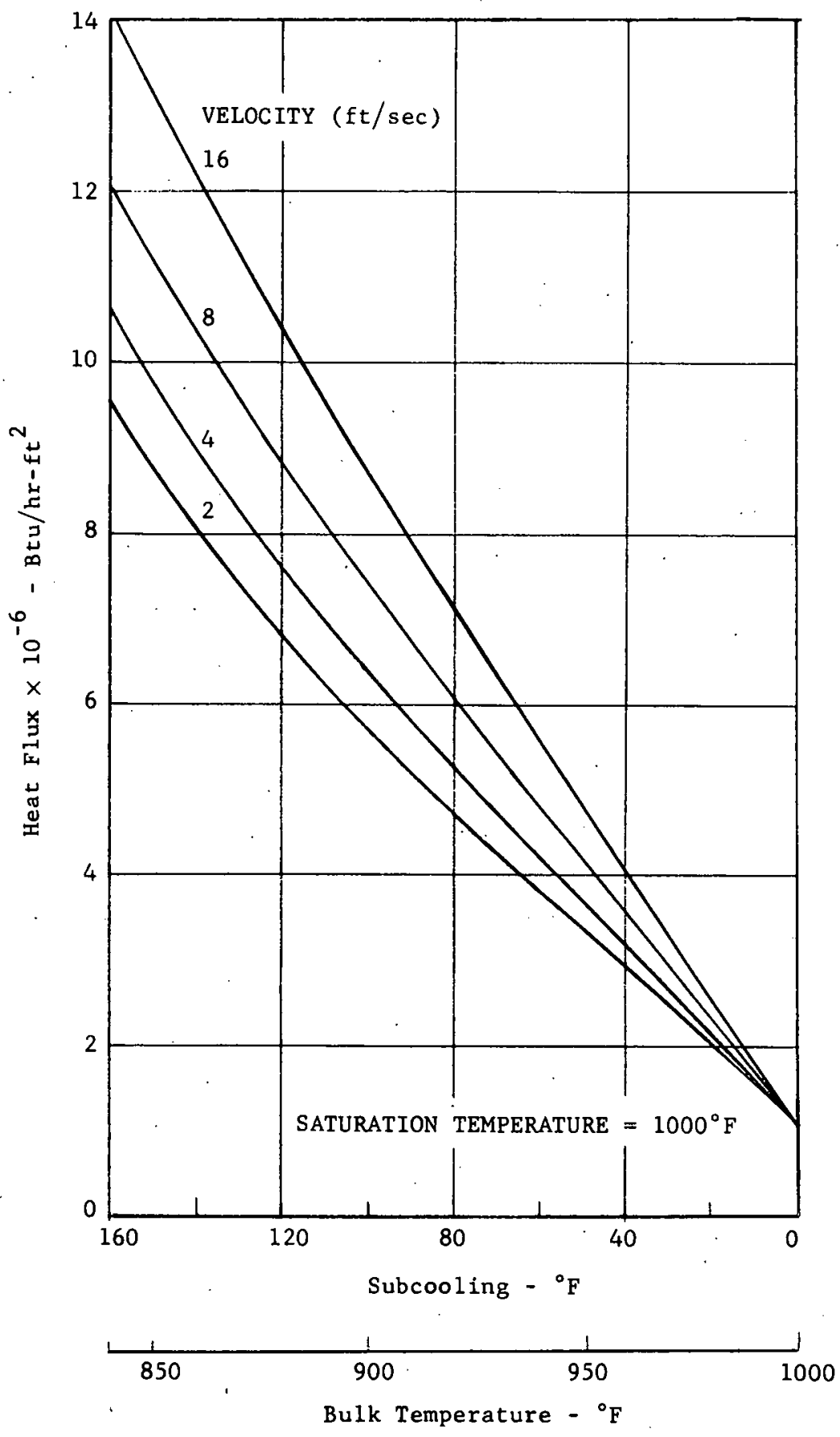

MAXIMUM NUCLEATE BOILING HEAT FLUX FOR

FLOWING SUBCOOLED MERCURY

(ACCORDING TO ZUBER AND TRIBUS)

FIGURE $\mathrm{C}-6$ 
Figure $\mathrm{C}-7$ presents the Nusselt modulus as given by equations $\mathrm{C}-5, \mathrm{C}-6$, and $\mathrm{C}-7$. Equation C-5 is recommended for use, both because of its simplicity and because it is based on properties data readily available in the Liquid Metals Handbook.

Heat transfer to mercury flowing over tubes has been studied experimentally in a staggeredtube array with 1.375 tube diameters spacing between adjacent tube centers. ${ }^{31}$ The equation that correlated the data is given as

$$
\mathrm{Nu}=4.03+0.228 \mathrm{Pe}^{0.67}
$$

in which the characteristic dimension is the tube outer diameter, and the velocity (in the Peclet modulus) corresponds to that occurring in the minimum flow area. Properties data given in the Liquid Metals Handbook were used in reducing the experimental data. Over the range of Pe covered in the experimental work, the data are equally well represented by a simpler equation, which is recommended for ease of computation.

$$
\mathrm{Nu}=0.55 \mathrm{Pe}^{0.55} \quad(500<\mathrm{Pe}<4000) .
$$

\section{Condensation of Mercury}

Condensation of mercury on copper, nickel, and stainless steel tubes has been studied by Misra and Bonilla. ${ }^{32}$ The condensation was observed in the form of drops on stainless steel, as a film on copper, and as a film on nickel, when meticulous care was observed in cleaning the surfaces. Titanium and magnesium were added to the mercury, but no effect on condensation phenomena was observed. With stainless steel as the condensing surface, unit conductances from about 4000 . $\mathrm{Btu} / \mathrm{hr}-\mathrm{ft}^{2}{ }^{\circ} \mathrm{F}$ at atmospheric pressure to 50,000 at lower pressures were reported. The range of heat fluxes covered in the work extended up to $750,000 \mathrm{Btu} / \mathrm{hr}-\mathrm{ft}^{2}$.

Russian work by Gel'man ${ }^{15,33}$ on the condensation of mercury vapor on steel tubes indicates that orientation of the tube does not affect the heat transfer and that the condensation is in the form of drops. Gel'man's experimental results are summarized by the empirical equation

$$
\mathrm{q} / \mathrm{A}=1.8 \times 10^{4} \mathrm{p}^{1 / 3}\left[1+1.7\left(\rho_{\mathrm{v}} \mathrm{v}_{\mathrm{v}}\right)^{1 / 3}\right],
$$

where $\mathrm{q} / \mathrm{A}$ is in $\mathrm{Btu} / \mathrm{hr}-\mathrm{ft}^{2}, \mathrm{p}=$ pressure in psia, $\rho_{\mathrm{v}}=$ vapor density in $\mathrm{lb} / \mathrm{ft}^{3}$, and $\mathrm{v}_{\mathrm{v}}=$ vapor velocity in $\mathrm{ft} / \mathrm{sec}$. The variable ranges covered in the experimental work are:

$$
\begin{aligned}
& 1.5<\mathrm{p}<18 \text { psia. } \\
& 2<\Delta \mathrm{T}<160^{\circ} \mathrm{F} . \\
& 0.6<\mathrm{V}_{\mathrm{v}} \rho_{\mathrm{v}}<13.5 \mathrm{lb} / \mathrm{sec}-\mathrm{ft}^{2}
\end{aligned}
$$




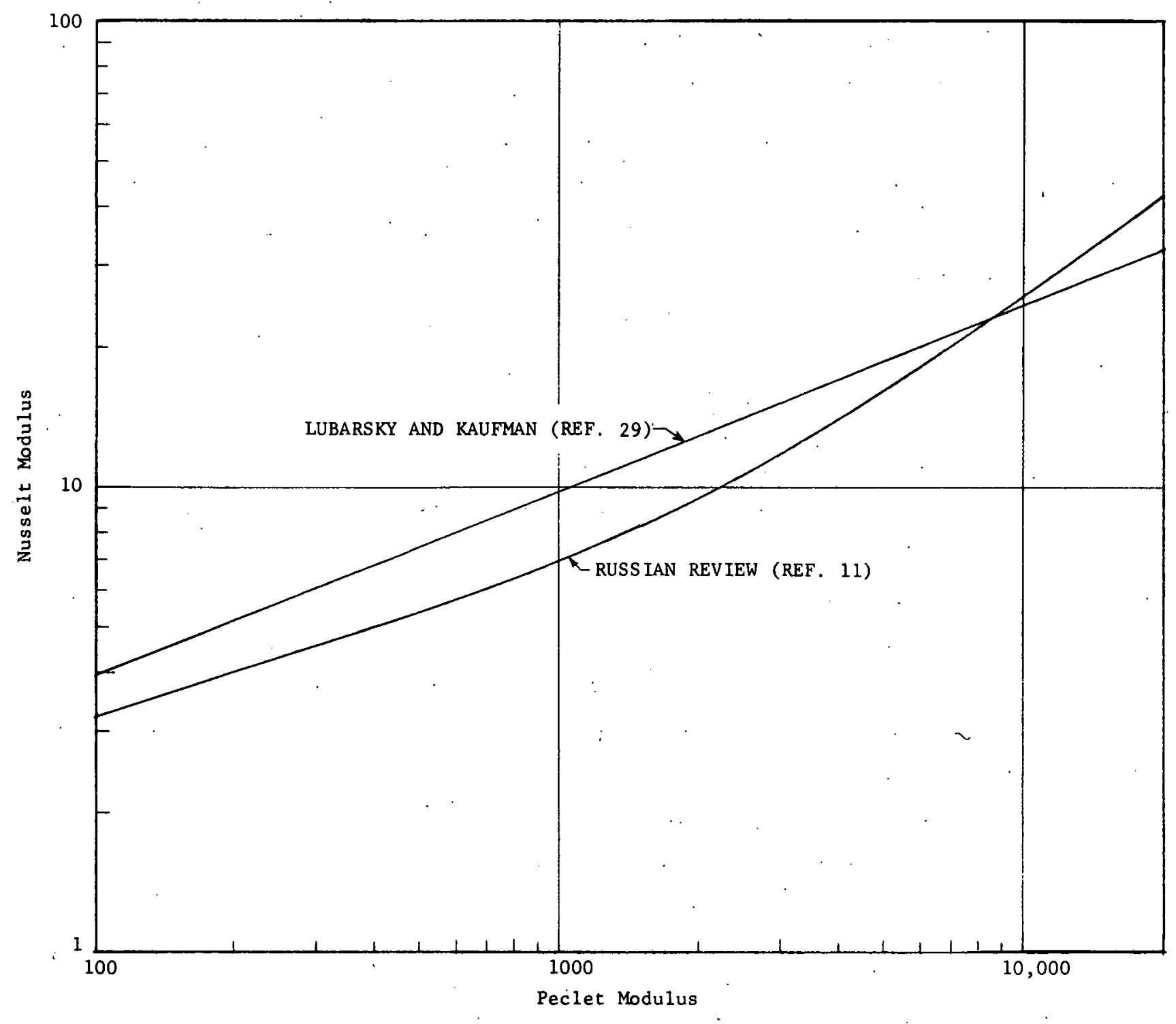

NUSSELT MODULUS FOR LIQUID METALS - UNIFORM HEAT INPUT

FIGURE C-7 
It is of interest to note that the temperature difference, $\Delta \mathrm{T}$, between the saturation temperature and the wall surface temperature is not represented in the above equation. This omission reveals that the heat flux is substantially independent of the temperature difference between the mercury vapor and the wall.

With $\mathrm{K}$ percent air in the mercury vapor, the heat flux is stated to be given by the equation

$$
\mathrm{q} / \mathrm{A}=\frac{1.8 \times 10^{4} \mathrm{p}^{1 / 3}}{\mathrm{~K}^{0.2}}\left[1+1.7\left(\rho_{\mathrm{m}} \mathrm{V}\right)^{1 / 3}\right]
$$

in which $\mathrm{m}$ refers to the air-mercury mixture. The concentration, $\mathrm{K}$, was varied from 2 to $12 \%$.

\section{Flow Friction}

Experiments on pressure losses with flowing, liquid-vapor mixtures of mercury are not reported in the literature. However, prediction methods developed with other liquid-vapor mixtures may be presumed applicable to mercury and thus will be compared.

Flow friction losses with two-phase flow are conveniently summarized in terms of a two-phase friction multiplier, $R$, defined by the equation

$$
-\frac{d p}{d z}=R \frac{f}{D} \frac{G^{2}}{2 g_{c} \rho_{\ell}}
$$

where $\mathrm{p}=$ pressure,

$\mathrm{z}=$ distance in direction of flow,

$\mathrm{f}=$ friction factor,

$\mathrm{D}=$ channel diameter,

$\mathrm{G}=\operatorname{mass}$ flux

$\mathrm{g}_{\mathrm{c}}=$ gravitational conversion constant.

$\rho_{\ell}=$ liquid density.

The terms for which $\mathrm{R}$ is a factor in the above equation represent the friction pressure gradient that would obtain if the flow were entirely liquid.

Methods for estimating $\mathrm{R}$ have been given by Martinelli and Nelson, ${ }^{34}$ Lockhart and Martinelli, ${ }^{26}$ Lottes, et al, ${ }^{35}$ Bonilla, ${ }^{26}$ and others. The multipliers suggested by these investigators can be compared by reference to Figure $\mathrm{C}-8$, which shows the multipliers as a function of mixture quality for mercury liquid-vapor mixtures at $1000^{\circ} \mathrm{F}$. The slip ratio, $\sigma, a$ parameter on some of the curves, is the ratio of the vapor-phase velocity to the liquid-phase 


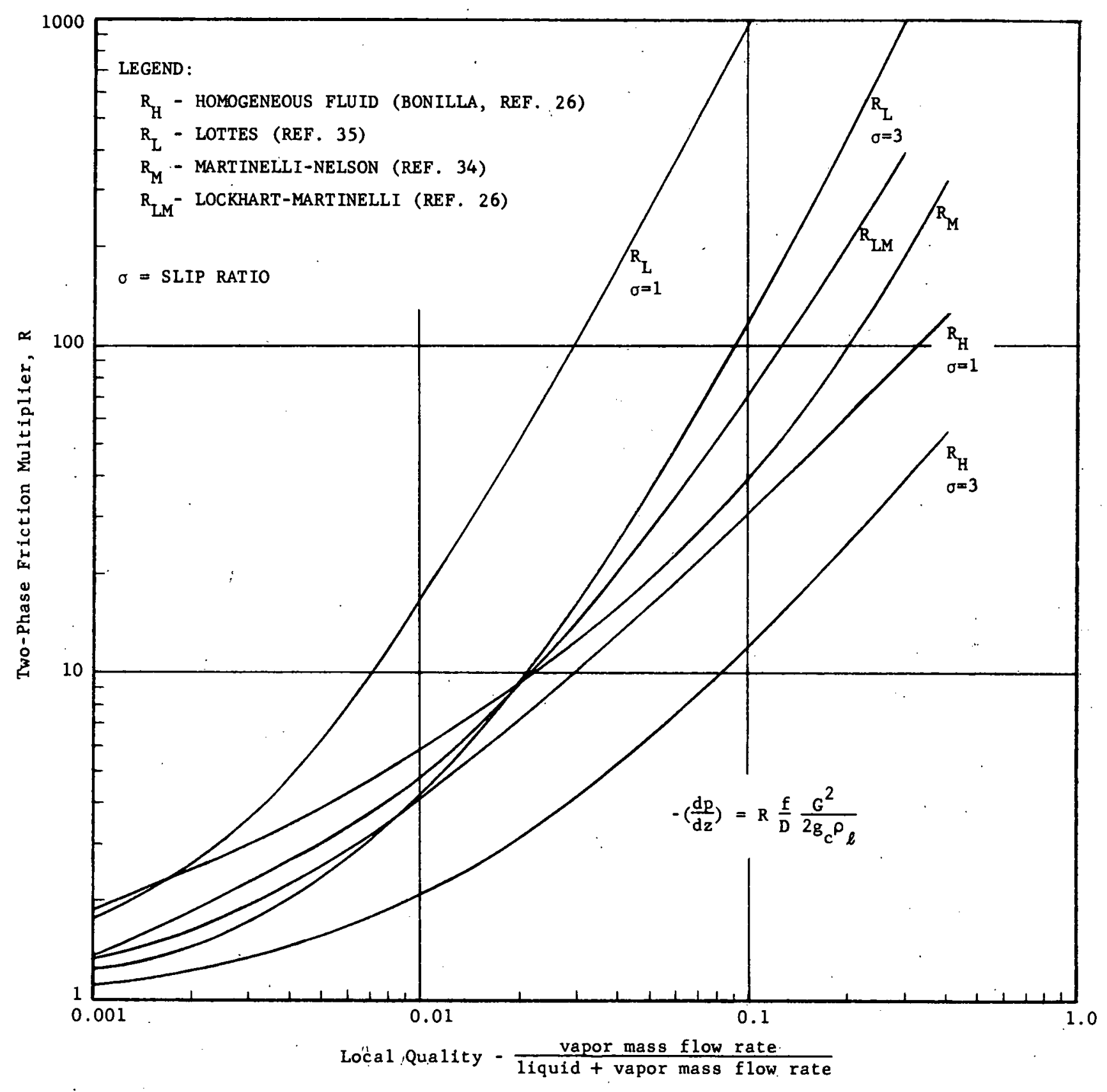

TWO-PHASE FRICTION MULTIPLIERS FOR MERCURY AT $1000^{\circ} \mathrm{F}$ SATURATION TEMPERATURE

FIGURE C-8 
velocity. The slip ratio is usually determined by density measurements of the flowing two-phase mixture. The relation between slip and density is derived from continuity requirements and has the form

$$
\bar{\rho}=\rho_{\mathrm{v}}\left(\frac{\sigma+\frac{\chi}{1-\chi}}{\sigma \frac{\rho_{\mathrm{v}}}{\rho_{\ell}}+\frac{\chi}{1-\chi}}\right),
$$

where $\bar{\rho}=$ average liquid-vapor density,

$$
\sigma=\text { slip ratio, }
$$

$\chi=$ mixture quality, defined as the ratio of the mass flow rate of vapor to the total mass flow rate of coolant.

For the homogeneous fluid model, it is considered that the liquid-vapor mixture is a homogeneous fluid; thus, the friction multiplier is

$$
\mathrm{R}_{\mathrm{H}}=\frac{\rho_{\ell}}{\bar{\rho}}=\frac{\rho_{\ell}}{\rho_{\mathrm{v}}}\left(\frac{\sigma \frac{\rho_{\mathrm{v}}}{\rho_{\ell}}+\frac{\chi}{1-\chi}}{\sigma+\frac{\chi}{1-\chi}}\right)
$$

in which $\bar{\rho}$ denotes the density of the mixture. For a slip ratio of unity, the multiplier has its maximum value. Bonilla ${ }^{26}$ reports a modified multiplier

$$
\mathrm{R}_{\mathrm{B}}=\frac{\rho_{\ell} \mathrm{f}}{\bar{\rho} \mathrm{f}_{\mathrm{o}}},
$$

where $\bar{\rho}=$ homogeneous mixture density with unity slip ratio,

$\mathrm{f}_{\mathrm{o}}=$ friction factor for single-phase flow (all liquid),

$\mathrm{f}=\mathrm{a}$ friction factor evaluated as a function of a modified Reynolds modulus:

$$
\mathrm{Re}=\mathrm{GD} \frac{1-\chi}{\mu_{\ell}}+\frac{\chi}{\mu_{\mathrm{v}}} .
$$

The usual friction factor-Reynolds modulus relation applicable for single-phase flow is used. For mercury at $1000^{\circ} \mathrm{F}$ saturation temperature, the ratio $\mathrm{f} / \mathrm{f}_{\mathrm{o}}$ does not depart appreciably from unity relative to the ratio of the various multipliers shown in Figure C-8; therefore, the additional complication introduced by use of the friction factor ratio does not appear warranted. 


\section{MERCURY COOLED BREEDER REACTOR}

Lottes, et al, ${ }^{35}$ suggest a friction multiplier of the form

$$
\mathrm{R}_{\mathrm{L}}=\left[1+\chi\left(\frac{\rho_{\ell}}{\sigma \rho_{\mathrm{v}}}-1\right)\right]
$$

This multiplier is stated to give reasonable agreement with experimental.data on flow of lowquality water-steam mixtures.

Martinelli and Nelson ${ }^{34}$ correlated a large number of data on two-phase flow friction losses and have presented their correlation in a generalized form that can be applied to liquid-vapor mercury mixtures flowing in a horizontal tube. The Martinelli-Nelson friction multiplier for flow of mercury at a saturation pressure of $1000^{\circ} \mathrm{F}$ is shown in Figure C-8.

Lockhart and Martinelli 26 present flow friction data for upward flow of liquid vapor mixtures. Their friction multiplier is also shown in Figure C-8. Because the Lockhart-Martinelli multiplier is based on a correlation of extensive data on upward flow of two-phase mixtures, it is reasonable to assume, in the absence of mercury data, that it best predicts the two-phase friction multiplier for upward flow of mercury. For this reason, the Lockhart-Martinelli multiplier was selected for use in the MCBR feasibility calculations.

\section{Flow Acceleration}

When heat is added to a two-phase single-component fluid flowing in a conduit, the average flow velocity will increase with distance along the conduit. This increase in velocity requires a pressure gradient that is independent of the friction characteristics of the flow and that can be determined from the momentum equation. The integrated form giving the pressure difference from a region where the flow is all liquid to a cross section of the conduit whe re the quality is $\chi$, is

$$
\Delta \mathrm{P}_{\text {acc }}=\frac{\mathrm{G}^{2}}{2 \mathrm{~g}_{\mathrm{c} \ell} \rho_{\ell}} 2 \chi\left[\chi\left(\frac{\rho_{\ell}}{\rho_{\mathrm{v}}}-1\right)+(1-\chi)\left(\sigma+\frac{\rho_{\ell}}{\sigma \rho_{\mathrm{v}}}-2\right)\right] .
$$




\section{APPENDIX D \\ DERIVATION OF PRESSURE DROP EQUATIONS}

Pressure drop across the core and blanket of a cylindrical fuel element is obtained by summing expressions for each of the individual head losses associated with flow through a heated channel. The flow area is assumed to be uniform in each region and is characterized by an equivalent diameter, $D_{h}$, defined as four times the ratio of coolant flow area to wetted perimeter.

1. Hydrostatic Head Difference

The hydrostatic head is determined by the length-average mixture density, $\bar{\rho}$ :

$$
\Delta \mathrm{h}_{\text {hyd }}=\frac{\bar{\rho}}{\rho_{\ell}} \mathrm{L},
$$

where $\rho_{\ell}=$ liquid density and $L=$ height of the channel. At any cross section of the flow, the ratio of mixture density to liquid density is given as

$$
\frac{\bar{\rho}}{\rho_{\ell}}=\frac{\sigma+\frac{\chi}{1-\chi}}{\sigma+\frac{\chi}{1-\chi} \frac{\rho_{\ell}}{\rho_{\mathbf{v}}}}
$$

where $\sigma=$ slip ratio, $x^{\prime}=$ mixture quality, and $\rho_{\mathrm{v}}=$ vapor density. The length-average mixture density is shown in Figure D-1 as a function of exit quality for the case of unity slip ratio (no slip), zero inlet subcooling, and sinusoidal heat input along the channel. Figure D-2 shows the same information but for uniform heat input. With slip ratios greater than unity, the length-average density would be higher than shown. This fact is illustrated in Figure D-3, which shows the variation of local mixture density along the flow channel for various assumed slip ratios.

Neutron absorption by the mercury in the core makes it desirable to minimize the average density of the liquid vapor mixture, thus making the exit quality of the mixture large. Large exit qualities are also desirable, as will be shown, in order to reduce the pressure drop between the top and bottom of the core. However, as the exit quality is increased, it is to be expected, on the basis of experience with other liquids, that the heat transfer capabilities of the mercury will diminish. In particular, the burnout heat flux can be expected to decrease with increasing quality. Although no data on mercury exist for use in evaluating the burnout flux with different mixture qualities, an exit quality of the order of 0.20 to 0.30 is considered reasonable, and these values have been used in this feasibility investigation. It may be noted by reference to Figures $\mathrm{D}-1$ and 


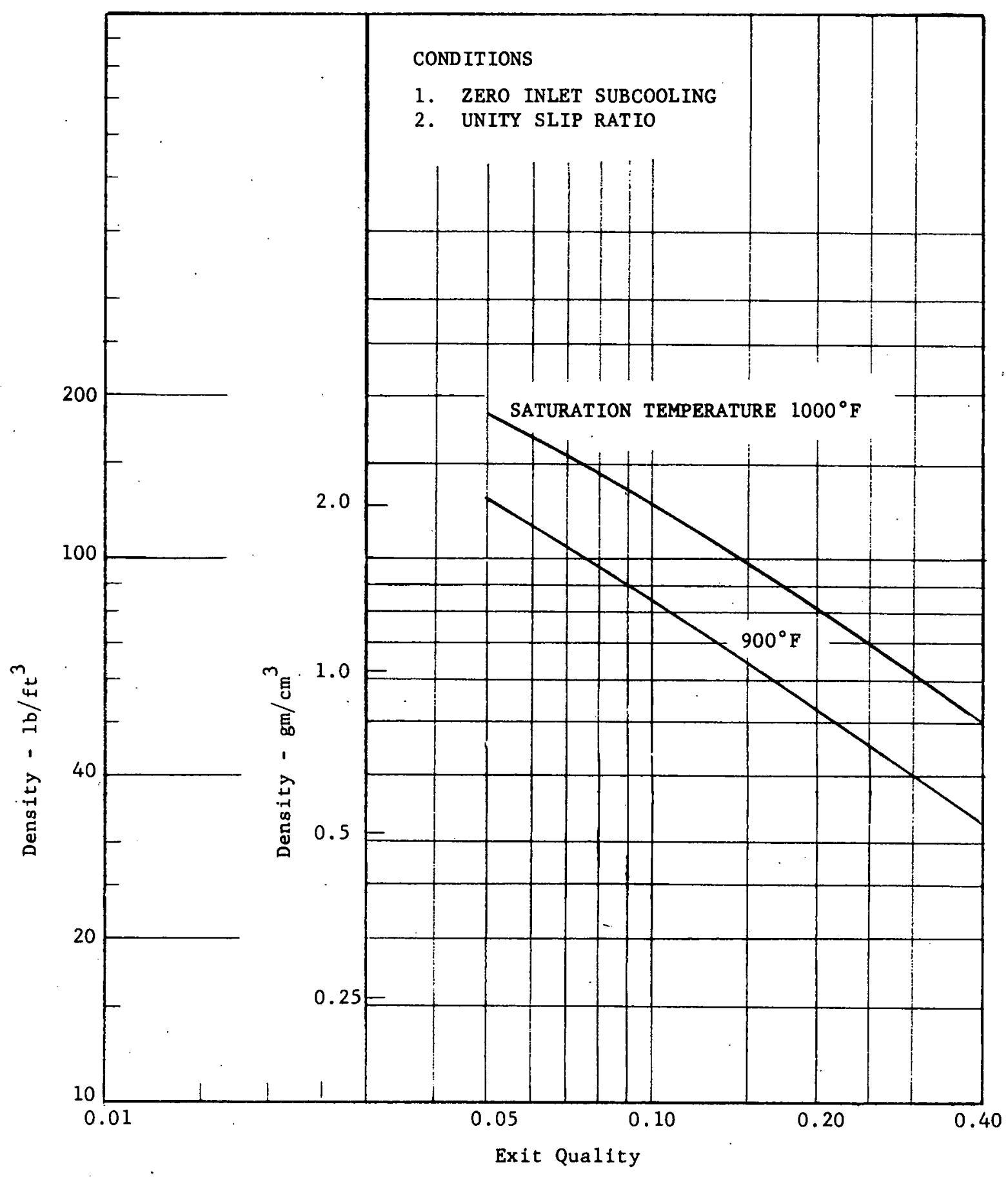

LENGTH-AVERAGE MIXTURE DENSITY OF LIQUID-VAPOR MERCURY FOR SINUSOIDAL HEAT INPUT

FIGURE D-1 


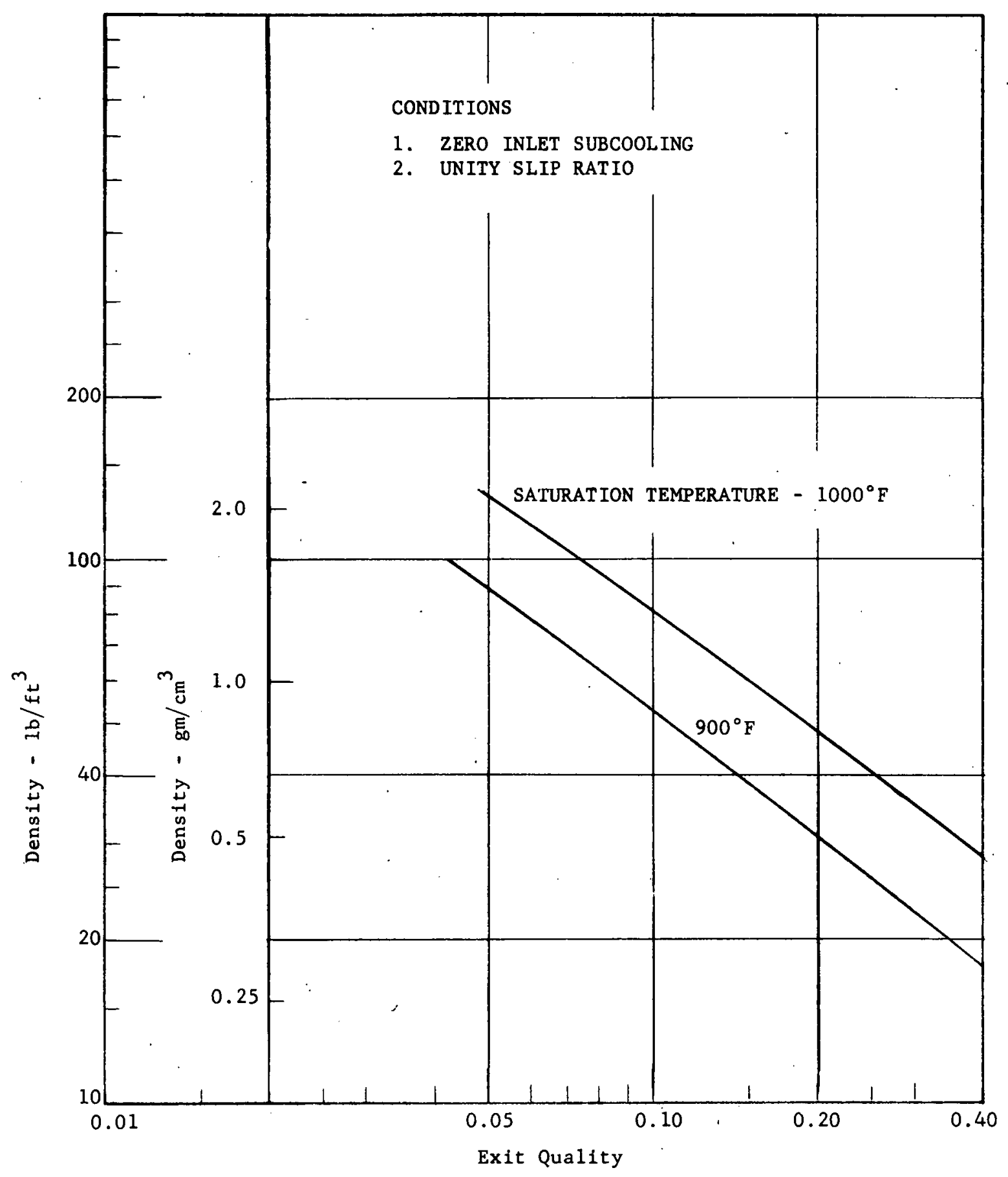

LENGTH-AVERAGE MIXTURE DENSITY OF LIQUID-VAPOR MERCURY FOR UNIFORM HEAT INPUT

FIGURE D-2 


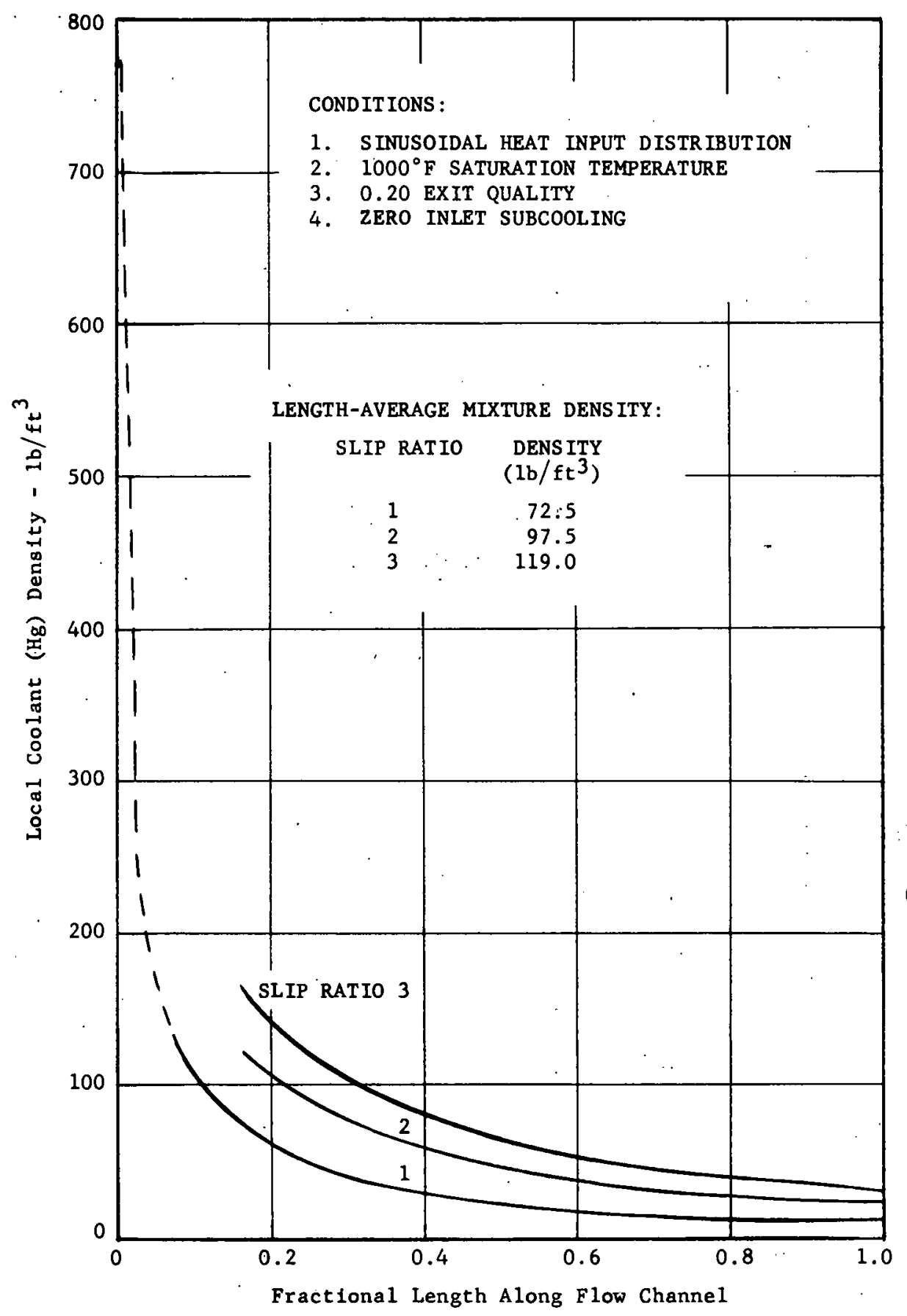

DENSITY DISTRIBUTION OF LIQUID-VAPOR MERCURY MIXTURE FOR VARIOUS SLIP RATIOS

FIGURE D-3 
D-2 that an exit quality of 0.20 gives a ratio of length-average mixture density to liquid density of 0.10 or less. Thus, the hydrostatic head difference in a fuel channel is a small fraction of the channel height. The important head differences are those attributable to flow friction and acceleration head differences.

2. Flow Friction Head Loss

The flow friction head loss is given by the equation

$$
\Delta \mathrm{h}_{\mathrm{f}}=\frac{\mathrm{fL}}{\mathrm{D}_{\mathrm{h}}} \frac{\mathrm{G}^{2}}{2 \mathrm{~g} \rho_{\ell}{ }^{2}}\left[\frac{1}{\mathrm{~L}} \int_{0}^{\mathrm{L}} \mathrm{R} \mathrm{dz}\right]
$$

where $D_{h}=$ equivalent diameter of the flow channel, $G=$ mass flux, and $R$. local two-phase friction multiplier. The term multiplying the bracketed quantity is the head loss that would exist if the flow were in the liquid phase, and the bracketed quantity is the length-average two-phase friction multiplier. At any given mercury pressure, the friction multiplicr, $R$, is a function of local mixture quality, according to the evaluation methods summarized in Appendix C. Thus, determination of the mixture quality along the flow channel permits evaluation of the length-average friction multiplier. The quality is given from a heat balance as

$$
\frac{x}{x_{e}}=\int_{0}^{z} \cdot \frac{q^{\prime} d z}{q}
$$

in which $\chi_{e}=$ quality at exit from the channel, $q=$ rate of heat transfer to the mercury flowing in the boiling length of the channel, $q^{\prime}=$ heat transfer rate per unit length, and $z=$ distance along channel measured from the point at which net boiling begins.

By using the Lockhart-Martinelli friction multiplier with the foregoing equations, and the assumption of zero inlet subcooling, the following length-average multiplier is obtained for mercury at $1000^{\circ} \mathrm{F}$ saturation temperature.

$$
\overline{\mathrm{R}}=950 \chi_{\mathrm{e}}^{1.5} \quad\left(0.1<\chi_{\mathrm{e}}<0.35\right),
$$

and, for $900^{\circ} \mathrm{F}$ saturation temperature,

$$
\overline{\mathrm{R}}=1500 \chi_{\mathrm{e}}^{1.5} \quad\left(0.1<\chi_{\mathrm{e}}<0.35\right) .
$$

Equations D-5 and D-6 are applicable to both uniform and sinusoidal heat input along the channel and, by deduction, to any heat input distribution symmetrical about the reactor mid-plane. The friction head loss for $1000^{\circ} \mathrm{F}$ saturation temperature is thus expressible as 


$$
\Delta \mathrm{h}_{\mathrm{f}}=\frac{\mathrm{G}^{2}}{2 \mathrm{~g} \rho_{\ell}^{2}}\left[950 \chi_{\mathrm{e}}^{\left.1.5 \frac{\mathrm{fL}}{\mathrm{D}_{\mathrm{h}}}\right]}\right.
$$

\section{Accelèration Head Difference}

Application of the momentum equation to flow of a two-phase mixture in a channel of uniform cross section gives the following acceleration head difference between a station at which the flow is all liquid and a station of which the quality is $\chi$ and the slip ratio $\sigma$ :

$$
\Delta \mathrm{h}_{\mathrm{acc}}=\frac{\mathrm{G}^{2}}{2 \mathrm{~g} \rho_{\ell}^{2}} 2 \chi\left[\chi\left(\frac{\rho_{\ell}}{\rho_{\mathrm{v}}}-1\right)+(1-\chi)\left(\sigma+\frac{\rho_{\ell}}{\rho_{\mathrm{v}} \sigma}-2\right)\right] .
$$

The slip ratio can be expected to be greater than unity, but the largest head difference corresponds to unity, the value selected for use. The effect of the value of the slip ratio on the acceleration head difference can be seen in Figure D-4. For a slip ratio of unity, the acceleration head difference is

$$
\Delta \mathrm{h}_{\mathrm{acc}}=\frac{\mathrm{G}^{2}}{2 \mathrm{~g} \rho_{\ell}^{2}} 2 \times\left(\frac{\rho_{\ell}}{\rho_{\mathrm{v}}}-1\right)
$$

\section{Combined Head Losses}

The sum of the friction and acceleration head differences for mercury at a saturation temperature of $1000^{\circ} \mathrm{F}$ is thus

$$
\Delta \mathrm{h}=\frac{\mathrm{G}^{2}}{2 \mathrm{~g} \rho_{\ell}^{2}} \cdot\left[950 \times \chi^{1.5 \frac{\mathrm{fL}}{\mathrm{D}_{\mathrm{h}}}}+2 \chi\left(\frac{\rho_{\ell}}{\rho_{\mathrm{v}}}-1\right)\right] .
$$

For a saturation temperature of $900^{\circ} \mathrm{F}$, the same equation applies, with 1500 replacing the 950 factor.

Retaining the simplifying assumption that the inlet subcooling is zero, equation $D-10$ can be put into a form more easily applied to the feasibility calculations. For this purpose, the mass flow flux $(G)$ is replaced by the following equation, which represents a heat balance on the boiling portion of a flow channel:

$$
\mathrm{G}=\frac{(\mathrm{q} / \mathrm{A})}{\chi_{\mathrm{e}} \lambda} \frac{4 \mathrm{~L}_{\mathrm{c}}}{\mathrm{D}_{\mathrm{h}}},
$$

where $\lambda=$ heat of vaporization. Substitution of D-11 into D-10 gives, for the summation of flow friction and acceleration head differences: 


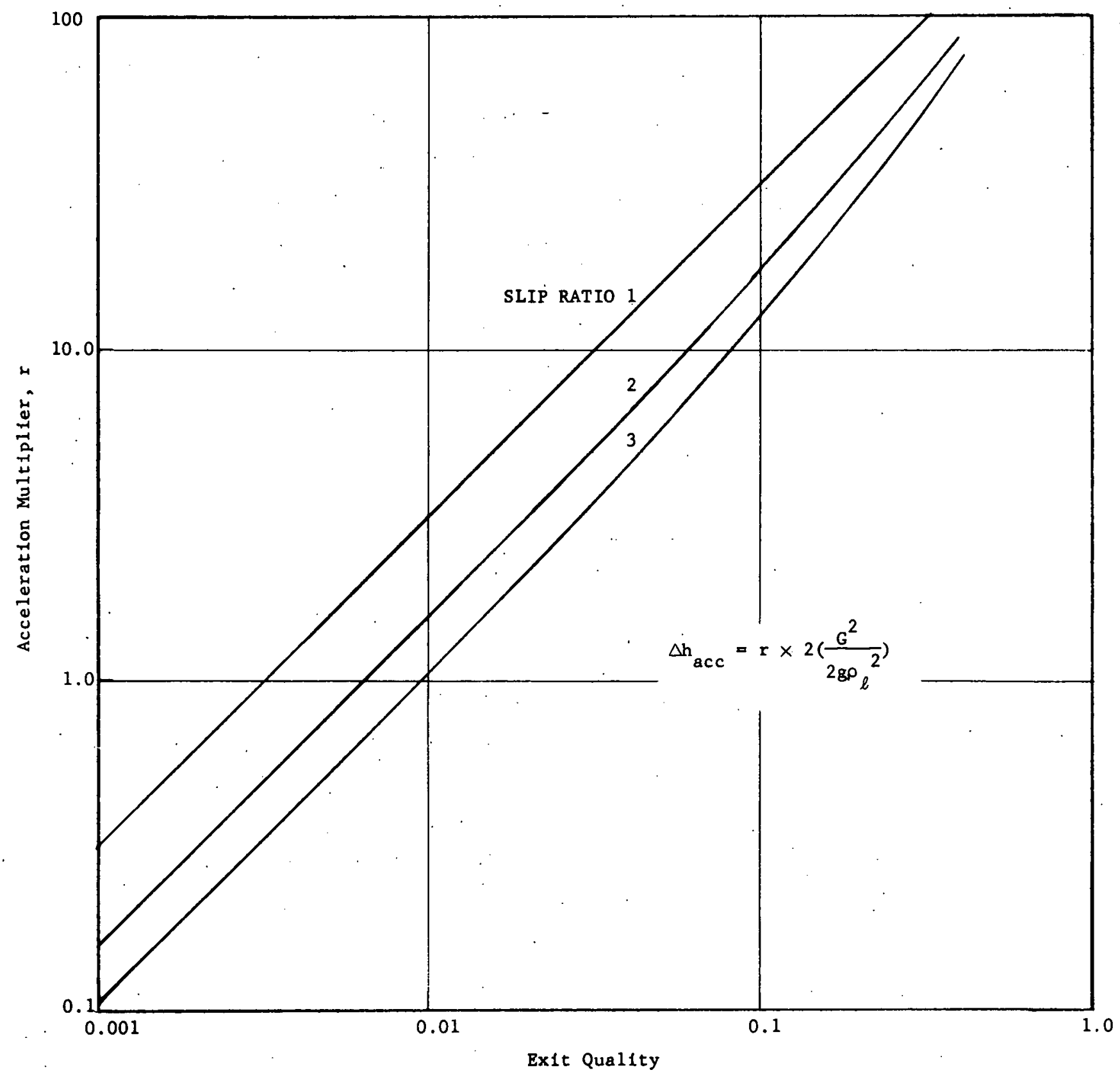

ACCELERATION PRESSURE DROP MULTIPLIER FOR MERCURY AT $1000^{\circ} \mathrm{F}$ SATURATION TEMPERATURE

FIGURE D-4 


\section{MERCURY COOLED BREEDER REACTOR}

$$
\Delta \mathrm{h}=\frac{(\mathrm{q} / \mathrm{A})^{2} \operatorname{avg}^{16\left(\mathrm{~L}_{\mathrm{c}} / \mathrm{D}_{\mathrm{h}}\right)^{2}}}{\chi_{\mathrm{e}} \lambda^{2} \rho_{\ell} \rho_{\mathrm{v}} 2 \mathrm{~g}}\left[2.76 x_{\mathrm{e}}^{\frac{1}{2}} \frac{\mathrm{fL}_{\mathrm{c}}}{\mathrm{D}_{\mathrm{h}}}+2\right]
$$

where $L_{c}=$ boiling length of fuel portion of an element. (In this equation, the factors 950 and 1500 for saturation temperatures of 1000 and $900^{\circ} \mathrm{F}$, respectively, have been replaced by the nearly equivalent term $2.76 \rho_{\ell} / \rho_{\mathrm{v}}$.) Calculations show that the two terms in the bracket, which are proportional to the flow friction and acceleration head difference, are of the same order of magnitude.

Equation D-12 describes the head difference across the core proper. To this difference must be added the head difference incurred by flow of the liquid through the lower blanket and the nonboiling length of the core and of the two-phase mixture through the upper blanket. Head difference across the lower blanket is simply a friction term and is given by

$$
\Delta \mathrm{h}_{\mathrm{bl}}=\frac{\mathrm{G}^{2}}{2 \mathrm{~g} \rho_{\ell}^{2}} \frac{\mathrm{fL}}{\mathrm{D}_{\mathrm{bl}}}
$$

Substituting $G$ from equation $D-11$ and factoring the coefficient of $D-12$ gives

$$
\Delta \mathrm{h}_{\mathrm{bl}}=\frac{(\mathrm{q} / \mathrm{A})^{2} \operatorname{avg}^{16\left(\mathrm{~L}_{\mathrm{c}} / \mathrm{D}_{\mathrm{h}}\right)^{2}}}{\chi_{\mathrm{e}} \lambda^{2} \rho_{\ell} \rho_{\mathrm{v}} 2 \mathrm{~g}}\left[\frac{\rho_{\mathrm{v}}}{\chi_{\mathrm{e}} \rho_{l}} \frac{\mathrm{fL}_{\mathrm{bl}}}{\mathrm{D}_{\mathrm{h}_{\mathrm{bl}}}}\right]
$$

The order of magnitude of the bracketed term is no greater than 0.01 , which is smaller than the corresponding two-phase friction term and the acceleration term by a factor of several hundred. Therefore, the head loss across the lower blanket and, by an analogous argument, the head loss across the non-boiling length of the core, are negligibly small.

For the upper blanket, the quality of the mixture will be sensibly uniform, since the heat added is small relative to heat addition in the core. The head difference across the upper blanket is thus purely a friction loss and is given by the equation

$$
\Delta \mathrm{h}=\frac{\mathrm{G}^{2}}{2 \mathrm{~g} \rho_{\ell}^{2}} \frac{\mathrm{fL}_{\mathrm{b}}}{\mathrm{D}_{\mathrm{h}_{\mathrm{b}}}} \mathrm{R}
$$

where $L_{b}=$ thickness of upper blanket, and $R$ is the friction multiplier given by the equation

$$
\mathrm{R}=6.52 \frac{\rho_{\ell}}{\rho_{\mathrm{v}}} \chi_{\mathrm{e}}^{1.5}
$$


which is derived by fitting a straight line to the Lockhart-Martinelli curve presented in Figure C-8 (Appendix C) for qualities greater than 0. 1.

Fuel elements in the Enrico Fermi reactor contain a central region of enriched fuel and, on either end, depleted uranium extensions which form the blanket directly above and below the core proper. Assuming the same type of fuel element for the MCBR gives, for the friction and acceleration head differences between the bottom and top of the combination elements:

$$
\Delta \mathrm{h}=\frac{(\mathrm{q} / \mathrm{A})^{2} \operatorname{avg} 16\left(\mathrm{~L}_{\mathrm{c}} / \mathrm{D}_{\mathrm{h}}\right)^{2}}{\chi_{\mathrm{e}} \lambda^{2} \rho_{\ell} \rho_{\mathrm{v}} 2 \mathrm{~g}} \quad\left\{\left[2.76 \frac{\mathrm{fL}_{\mathrm{c}}}{\mathrm{D}_{\mathrm{h}}}+6.52 \frac{\mathrm{fL}_{\mathrm{b}}}{\mathrm{D}_{\mathrm{h}_{\mathrm{b}}}}\right] \chi_{\mathrm{e}}^{\frac{1}{2}}+2\right\} .
$$

In this equation, $\left(\mathrm{q} / \mathrm{A}_{\mathrm{avg}}\right)$ is, as before, the length-average heat flux along boiling length of the enriched fuel portion of an element, and $L_{c}$ and $L_{b}$ are, respectively, the boiling length of the fuel portion of an element and the thickness of the upper blanket. 


\section{MERCURY COOLED BREEDER REACTOR}

\section{APPENDIX E}

\section{MC̣R PHYSICS CALCULATIONS AND DATA}

\section{Prediction of Criticality and Breeding Ratio}

The analysis of any chain reacting system, including one with a fast neutron spectrum, must be based on a solution to the Boltzmann equation. Many approximate methods of solution have been studied, each subject to special çonditions; however, only a few have been used extensively in the actual analysis of the performance of fașt reactor systems.

At present, the most widely used approximation to the transport equation is the $\mathrm{S}_{\mathrm{N}}$ method discussed by Carlson, ${ }^{36}$ which is extremely useful in multiregion spherical geometry. The transport equation is very difficult to separate, even in the simplest geometry; consequently, calculations involving reflected cylinders and slabs usually are evaluated by the $S_{N}$ method as if they were infinite in the transverse direction.

A more frequently used method of analysis is based on simple diffusion theory. It has been demonstrated by Okrent, et al, ${ }^{37}$ and Avery ${ }^{38}$ that this method is adequate to describe the nuclear characteristics of the large dilute fast power breeders. Since the diffusion equation is separable in simple geometry, reflected cylinders and slabs with finite unreflected transverse dimensions, as well as multiregion spheres, can be treated rigorously.

Since there are computational advantages to be gained by using diffusion theory for routine reactor analysis, it is necessary to determine the conditions under which such a simplified treatment is adequate.

A very complete study of this kind was made by Loewenstein and Okrent, ${ }^{39}$ who show comparisons of diffusion theory and $\mathrm{S}_{\mathrm{N}}$ methods for several sets of evaluations. In one set, the basis for comparison was the calculation of the multiplication constants for fixed compositions and geometries. Spherical representations of some ZPR-III systems were evaluated, and the variations in multiplication were found to be approximately $2.0 \%$. Loewenstein and Okrent ${ }^{39}$ also concluded that the deviations between the diffusion theory calculations and the $\mathrm{S}_{\mathrm{N}}$ calculations depend on reflector effectiveness as well as core size, because the diffusion theory leakage prescription becomes poorer as neutron flux becomes more anisotropic.

Similar studies have been made for large cores. ${ }^{39}$ These comparisons were based on calculation of the critical radius by the diffusion theory and the $S_{N}$ methods. The variation in critical 


\section{MERCURY COOLED BREEDER REACTOR}

radius between the two methods was found to be approximately $1.5 \%$. Again the deviation is found to increase as leakage from the core becomes more important.

From studies conducted on the ZPR- $\Pi 1$, it has been determined that normalized one-dimensional diffusion-theory calculations predict criticality fairly well for cores that are uniformly reflected with a high-density-uranium blanket. Only when the reflector density is decreased or its uniformity destroyed do such one-dimensional diffusion-theory calculations tend to yield misleading results.

The above considerations appear to justify the use of diffusion theory in initial evaluations of the comparatively large mercury cooled breeder reactor; therefore, the multigroup diffusion code PROD-II and a more convenient modification of PROD, VAL PROD, were used for neutron physics calculations performed in these evaluations. A full description of the theory and the machine program are given by Habetler ${ }^{40}$ and Walbran. ${ }^{41}$

\section{Multigroup Constants}

The analysis of a fast system is very dependent on the choice of the basic microscopic nuclear. parameters used and the methods of introducing them into the analysis. A multigroup approach is necessary if the range of the fast neutron spectrum is large or if detailed information concerning the spatial variation of the neutron spectrum throughout a single system is desired.

The multigroup constants used in this study are those suggested by Loewenstein and Okrent, ${ }^{39}$ defined below. All cross sections are given in barns.

$$
\begin{aligned}
j & =\text { energy group } \\
\chi & =\text { fission spectrum (fraction of fission neutrons born into each group) } \\
E_{L} & =\text { lower boundary of energy group (Mev) } \\
\Delta U & =\text { group lethargy interval } \\
\nu & =\text { number of neutrons emitted per fission } \\
\sigma_{\mathrm{tr}}= & \text { transport cross section } \\
\sigma_{\mathrm{f}}= & \text { fission cross section } \\
\sigma_{\mathrm{c}}= & \text { parasitic neutron absorption cross section } \\
\sigma_{\text {in }}= & \text { cross section for neutrons removed from energy group by inelastic scattering } \\
\sigma_{\text {in }}(\mathrm{j} \rightarrow \mathrm{j}+\mathrm{k})= & \text { transfer cross section for inelastic scattering from group } \mathrm{j} \text { to group } \mathrm{j}+\mathrm{k} \\
& \sum_{\mathrm{k}} \neq \sigma_{\text {in }}(\mathrm{j} \rightarrow \mathrm{j}+\mathrm{k})=\sigma_{\text {in }}
\end{aligned}
$$


Values of these constants are given in Table E-I.

TABLE E-I

Neutron Energy Grouping

\begin{tabular}{rlll}
\hline Group $j$ & $\chi$ & $E_{L}$ & $\Delta U$ \\
\hline 1 & 0.338 & 2.25 & 1.5 \\
2 & 0.236 & 1.35 & 0.5 \\
3 & 0.178 & 0.825 & 0.5 \\
4 & 0.116 & 0.5 & 0.5 \\
5 & 0.066 & 0.3 & 0.5 \\
6 & 0.033 & 0.18 & 0.5 \\
7 & 0.017 & 0.11 & 0.5 \\
8 & 0.008 & 0.067 & 0.5 \\
9 & 0.006 & 0.025 & 1.0 \\
10 & 0.002 & 0.0091 & 1.0 \\
11 & 0 & 0.0035 & 1.0 \\
\hline
\end{tabular}

The choice of whether to use a large number of groups, each with a small energy interval, or a smaller number with a large energy interval for each group is somewhat arbitrary. Threshold reactions, such as fission of $\mathrm{U} 238$, make it convenient to specify some group boundaries by the neutron energies at which the reactions become important. To account for large amounts of iron or sodium, the choice would tend to a large number of groups to take into account the pronounced resonance structure between $25 \mathrm{kev}$ and $3 \mathrm{Mev}$. For systems containing large quantities of fissile and fertile material, the neutron spectrum is extremely dependent upon the inelastic scattering properties of the heavy isotopes; however, information on the inelastic scattering cross sections and the energy distribution of the emergent neutrons is limited. For such cases, a fairly small number of groups appears sufficient to make use of the existing reliable information. In small highly enriched assemblies, several groups at high energies are adequate: For large dilute systems, the important parasitic capture effects in the kilovolt region must be taken into account by adding groups in this region.

The total number of groups used here is eleven, which is a reasonable compromise of the conflicting considerations mentioned. This number, give or take a few groups, appears to have found rather wide acceptance by a number of investigators. ${ }^{37,38,39}$ The group structures used are by no means unique; they are influenced by the objectives of the calculations. 


\section{Cross Section Data}

The sets of microscopic cross section data shown in Tables E-II through E-VII are generally based on the data of Hughes and Schwarz, ${ }^{42}$ but are adjusted using the transport approximation to account for anisotropic scattering. Fission cross sections also are based on the data of Hughes and Schwarz.

Neutron yields per fission were suggested by Loewenstein and Okrent, ${ }^{39}$ whose values were used in this investigation. This yield is lower than that measured by Diven, et al, ${ }^{43}$ and calculated by Leachman; ${ }^{44}$ therefore, the results of the calculations of critical mass and breeding ratio will tend to be conservative.

Parasitic capture cross sections of the non-fissionable and fertile materials are those reported by Hughes and Schwar $\mathrm{z}^{42}$ and Diven, ${ }^{45}$ by inference from relevant material replacement experiments of Long. ${ }^{46}$

Inelastic cross sections for the lighter elements are generally based on neutron removal measurements and the known excitation energy levels of such materials. Where possible, inelastic cross sections at high energies were supplemented by sphere measurements, using the well known fission thresholds of $U 238$ and Np 237.47

While some information on the inelastic spectrum of $U 235$ may be inferred from the Los Alamos sphere experiments, the statistical nucleus model was used for U 235 at all energies. These parameters will reflect uncertainties because of the gaps in available data. However, the arbitrary adjustment of these parameters to permit agreement with experimental criticality of any given system probably would give misleading results on a different system, especially if the proposed system has a neutron energy spectrum markedly different from that used to adjust the parameters.

The sets of microscopic data shown in the Tables E-II.through E-VII were the basis for many of the analyses discussed by Loewenstein and Okrent, ${ }^{39}$ whose calculations were used to predict critical masses, fission distributions, and activation ratios for material replacement experiments performed at the ZPR-III facility and at Los Alamos Scientific Laboratory. The successful use of these data for the various investigations described above gives reasonable confidence in their suitability for the neutron physics investigations of the Mercury Cooled Breeder Reactor study. 


\section{MERCURY COOLED BREEDER REACTOR}

TABLE E-II

Uranium-235

\begin{tabular}{rlllll}
\hline $\mathrm{j}$ & $\sigma_{\mathrm{tr}}$ & $\nu$ & $\sigma_{\mathrm{f}}$ & $\sigma_{\mathrm{c}}$ & $\sigma_{\text {in }}$ \\
\hline & & & & & \\
1 & 4.5 & 2.77 & 1.3 & 0.1001 & 2.3 \\
2 & 4.5 & 2.65 & 1.28 & 0.0998 & 1.85 \\
3 & 4.8 & 2.58 & 1.25 & 0.100 & 1.15 \\
4 & 5.1 & 2.53 & 1.20 & 0.144 & 1.2 \\
5 & 6.3 & 2.51 & 1.28 & 0.192 & 0.7 \\
6 & 7.9 & 2.49 & 1.42 & 0.2556 & 0.4 \\
7 & 9.65 & 2.48 & 1.6 & 0.32 & 0 \\
8 & 10.9 & 2.47 & 1.9 & 0.475 & 0 \\
9 & 12.25 & 2.47 & 2.3 & 0.69 & 0 \\
10 & 13.5 & 2.47 & 3.4 & 1.19 & 0 \\
11 & 14.3 & 2.47 & 6.0 & 2.52 & 0 \\
\hline
\end{tabular}

Inelastic Matrices

Uranium-235 $\sigma_{\text {in }}(j \rightarrow j+k)$

\begin{tabular}{cllllllll}
\hline $\mathrm{j}$ & 1 & 2 & 3 & 4 & 5 & 6 & 7 & 8 \\
\hline $\mathrm{j}+\mathrm{k}$ & & & & & & & & \\
1 & 0 & 0 & 0 & 0 & 0 & 0 & 0 & 0 \\
2 & 0.881 & 0 & 0 & 0 & 0 & 0 & 0 & 0 \\
3 & 0.66 & 0.845 & 0 & 0 & 0 & 0 & 0 & 0 \\
4 & 0.382 & 0.488 & 0.544 & 0 & 0 & 0 & 0 & 0 \\
5 & 0.207 & 0.265 & 0.294 & 0.576 & 0 & 0 & 0 & 0 \\
6 & 0.115 & 0.144 & 0.161 & 0.314 & 0.351 & 0 & 0 & 0 \\
7 & 0.0552 & 0.0712 & 0.0805 & 0.157 & 0.175 & 0.2 & 0 & 0 \\
8 & 0 & 0.0361 & 0.07 & 0.14 & 0.17 & 0.19 & 0 & 0 \\
\hline
\end{tabular}


TABLE E-III

Uranium-238

\begin{tabular}{rlllll}
\hline$j$ & $\sigma_{\operatorname{tr}}$ & $\nu$ & $\sigma_{\mathrm{f}}$ & $\sigma_{\mathrm{c}}$ & $\sigma_{\text {in }}$ \\
\hline 1 & 4.7 & 2.65 & 0.59 & 0.015 & 2.87 \\
2 & 4.5 & 2.55 & 0.45 & 0.062 & 2.44 \\
3 & 5.0 & 2.47 & 0.003 & 0.13 & 1.2 \\
4 & 5.5 & 0 & 0 & 0.143 & 0.44 \\
5 & 6.7 & 0 & 0 & 0.13 & 0.47 \\
6 & 8.25 & 0 & 0 & 0.15 & 0.55 \\
7 & 9.65 & 0 & 0 & 0.20 & 0.55 \\
8 & 10.9 & 0 & 0 & 0.30 & 0.40 \\
9 & 12.25 & 0 & 0 & 0.40 & 0.05 \\
10 & 13.5 & 0 & 0 & 0.61 & 0 \\
11 & 14.3 & 0 & 0 & 0.80 & 0 \\
\hline
\end{tabular}

\section{Inelastic Matrices}

Uranium-238 $\sigma_{\text {in }}(j-j+k)$

\begin{tabular}{clllllllll}
\hline $\mathbf{j}$ & 1 & 2 & 3 & $\mathbf{4}$ & $\mathbf{5}$ & $\mathbf{6}$ & $\mathbf{7}$ & 8 \\
\hline $\mathrm{j}+\mathrm{k}$ & & & 0 & & 0 & & & & \\
1 & 0 & 0 & 0 & 0 & 0 & 0 & 0 & 0 \\
2 & 1.06 & 0 & 0 & 0 & 0 & 0 & 0 & 0 \\
3 & 0.46 & 0.62 & 0 & 0 & 0 & 0 & 0 & 0 \\
4 & 0.66 & 0.89 & 0.52 & 0 & 0 & 0 & 0 & 0 \\
5 & 0.39 & 0.52 & 0.35 & 0.44 & 0 & 0 & 0 & 0 \\
6 & 0.12 & 0.16 & 0.22 & 0 & 0.47 & 0 & 0 & 0 \\
7 & 0.18 & 0.1 & 0.11 & 0 & 0 & 0.5 & 0 & 0 \\
8 & 0 & 0.15 & 0 & 0 & 0 & 0.05 & 0.55 & 0 \\
\hline
\end{tabular}


TABLE E-IV

Plutonium-239

\begin{tabular}{rlllll}
\hline $\mathrm{j}$ & $\sigma_{\mathrm{tr}}$ & $\nu$ & $\sigma_{\mathrm{f}}$ & $\sigma_{\mathrm{c}}$ & $\sigma_{\text {in }}$ \\
\hline 1 & 4.6 & 3.18 & 2.0 & 0.04 & 1.35 \\
2 & 4.6 & 3.09 & 1.95 & 0.078 & 1.0 \\
3 & 5.26 & 3.02 & 1.86 & 0.093 & 0.7 \\
4 & 5.9 & 2.97 & 1.75 & 0.123 & 0.7 \\
5 & 7.1 & 2.95 & 1.70 & 0.17 & 0.4 \\
6 & 8.5 & 2.93 & 1.68 & 0.27 & 0.23 \\
7 & 9.5 & 2.92 & 1.73 & 0.48 & 0 \\
8 & 10.8 & 2.91 & 1.80 & 0.54 & 0 \\
9 & 12.3 & 2.91 & 2.0 & 0.74 & 0 \\
10 & 16.4 & 2.91 & 2.25 & 1.06 & 0 \\
11 & 16.8 & 2.91 & 3.5 & 2.1 & 0 \\
\hline
\end{tabular}

Inelastic Matrix

Plutonium-239 $\sigma_{\text {in }}(\mathrm{j} \rightarrow \mathrm{j}+\mathrm{k})$

\begin{tabular}{lllllllll}
\hline$j$ & $1 \quad$ & 2 & 3 & 4 & 5 & 6 & 7 & 8 \\
\hline$j+k$ & & & & & & & & \\
1 & 0 & 0 & 0 & 0 & 0 & 0 & 0 & 0 \\
2 & 0.513 & 0 & 0 & 0 & 0 & 0 & 0 & 0 \\
3 & 0.382 & 0.457 & 0 & 0 & 0 & 0 & 0 & 0 \\
4 & 0.221 & 0.264 & 0.331 & 0 & 0 & 0 & 0 & 0 \\
5 & 0.120 & 0.143 & 0.179 & 0.336 & 0 & 0 & 0 & 0 \\
6 & 0.0648 & 0.078 & 0.0980 & 0.183 & 0.2 & 0 & 0 & 0 \\
7 & 0.0486 & 0.0385 & 0.0490 & 0.0917 & 0.1 & 0.115 & 0 & 0 \\
8 & 0 & 0.0195 & 0.0327 & 0.087 & 0.099 & 0.115 & 0 & 0 \\
\hline
\end{tabular}


TABLE E-V

Molybdenum

\begin{tabular}{rlll}
\hline$j$ & $\sigma_{\text {tr }}$ & $\sigma_{\mathrm{c}}$ & $\sigma_{\text {in }}$ \\
\hline 1 & 2.5 & 0.01 & 1.4 \\
2 & 3.2 & 0.017 & 0.84 \\
3 & 4.0 & 0.024 & 0.4 \\
4 & 5.3 & 0.034 & 0 \\
5 & 6.4 & 0.04 & 0 \\
6 & 7.2 & 0.046 & 0 \\
7 & 7.8 & 0.057 & 0 \\
8 & 7.9 & 0.066 & 0 \\
9 & 7.4 & 0.09 & 0 \\
10 & 7.1 & 0.12 & 0 \\
11 & 7.2 & 0.2 & 0 \\
\hline
\end{tabular}

$\underline{\text { Inelastic Matrices }}$

Molybdenum $\sigma_{\text {in }}(j \rightarrow j+k)$

\begin{tabular}{lllllllll}
\hline $\mathrm{j}$ & $\mathbf{1}$ & 2 & 3 & 4 & 5 & 6 & 7 & 8 \\
\hline $\mathrm{j}+\mathbf{k}$ & & & & & & & & \\
1 & 0 & 0 & 0 & 0 & 0 & 0 & 0 & 0 \\
2 & 0.35 & 0 & 0 & 0 & 0 & 0 & 0 & 0 \\
3 & 0.40 & 0.411 & 0 & 0 & 0 & 0 & 0 & 0 \\
4 & 0.30 & 0.33 & 0 & 0 & 0 & 0 & 0 & 0 \\
5 & 0.15 & 0.09 & 0.108 & 0 & 0 & 0 & 0 & 0 \\
6 & 0.1 & 0 & 0.117 & 0 & 0 & 0 & 0 & 0 \\
7 & 0.1 & 0 & 0.068 & 0 & 0 & 0 & 0 & 0 \\
8 & 0 & 0 & 0.127 & 0 & 0 & 0 & 0 & 0 \\
\hline
\end{tabular}




\section{MERCURY COOLED BREEDER REACTOR}

TABLE.E-VI

Iron

\begin{tabular}{rlll}
\hline $\mathrm{j}$ & $\sigma_{\mathrm{tr}}$ & $\sigma_{\mathrm{c}}$ & $\sigma_{\text {in }}$ \\
\hline 1 & 2.05 & 0.005 & 1.18 \\
2 & 2.0 & 0.005 & 0.65 \\
3 & 1.9 & 0.005 & 0.4 \\
4 & 2.2 & 0.005 & 0 \\
5 & 3.0 & .0 .006 & 0 \\
6 & 3.5 & 0.007 & 0 \\
7 & 4.3 & 0.008 & 0 \\
8 & 5.3 & 0.008 & 0 \\
9 & 6.8 & 0.025 & 0 \\
10 & 4.0 & 0.012 & 0 \\
11 & 5.0 & 0.014 & 0 \\
& & & \\
\hline
\end{tabular}

$\underline{\text { Inelastic Matrices }}$

Iron $\sigma_{\text {in }}(j \rightarrow j+k)$

\begin{tabular}{cllllllll}
\hline $\mathrm{j}$ & 1 & 2 & 3 & 4 & 5 & 6 & 7 & 8 \\
\hline $\mathrm{j}+\mathrm{k}$ & & & & & & & & \\
1 & 0 & 0 & 0 & 0 & 0 & 0 & 0 & 0 \\
2 & 0.45 & 0 & 0 & 0 & 0 & 0 & 0 & 0 \\
3 & 0.206 & 0.39 & 0 & 0 & 0 & 0 & 0 & 0 \\
4 & 0.196 & 0.26 & 0 & 0 & 0 & 0 & 0 & 0 \\
5 & 0.122 & 0 & 0.17 & 0 & 0 & 0 & 0 & 0 \\
6 & 0.0802 & 0 & 0.104 & 0 & 0 & 0 & 0 & 0 \\
7 & 0.0448 & 0 & 0.0592 & 0 & 0 & 0 & 0 & 0 \\
8 & 0.0814 & 0 & 0.0664 & 0 & 0 & 0 & 0 & 0 \\
\hline
\end{tabular}


TABLE E-VII

Mercury

\begin{tabular}{rrrr}
\hline$j$ & \multicolumn{1}{c}{$\sigma_{\mathrm{tr}}$} & \multicolumn{1}{c}{$\sigma_{\mathrm{c}}$} & $\sigma_{\text {in }}$ \\
\hline 1 & 5.254 & 0.013 & 2.4 \\
2 & 4.761 & 0.017 & 1.4 \\
3 & 4.357 & 0.025 & 0.9 \\
4 & 5.338 & 0.05 & 0.5 \\
5 & 6.427 & 0.075 & 0.3 \\
6 & 8.422 & 0.115 & 0.19 \\
7 & 9.369 & 0.125 & \\
8 & 10.256 & 0.137 & \\
9 & 11.346 & 0.17 & \\
10 & 12.982 & 0.22 & \\
11 & 14.986 & 0.8 & \\
\hline
\end{tabular}

Inelastic Matrices

Mercury $\sigma_{\text {in }}(j \rightarrow j+k)$

\begin{tabular}{cllllllll}
\hline $\mathrm{j}$ & 1 & 2 & 3 & 4 & 5 & 6 & 7 & 8 \\
\hline $\mathrm{j}+\mathrm{k}$ & & & & & & & & \\
1 & 0 & 0 & 0 & 0 & 0 & 0 & 0 & 0 \\
2 & 0.91 & 0 & 0 & 0 & 0 & 0 & 0 & 0 \\
3 & 0.61 & 0.6 & 0 & 0 & 0 & 0 & 0 & 0 \\
4 & 0.41 & 0.4 & 0.43 & 0 & 0 & 0 & 0 & 0 \\
5 & 0.24 & 0.2 & 0.23 & 0.3 & 0 & 0 & 0 & 0 \\
6 & 0.14 & 0.11 & 0.1 & 0.1 & 0.18 & 0 & 0 & 0 \\
7 & 0.04 & 0.06 & 0.09 & 0.06 & 0.07 & 0.08 & 0 & 0 \\
8 & 0.04 & 0.03 & 0.05 & 0.04 & 0.05 & 0.09 & 0 & 0 \\
\hline
\end{tabular}




\section{MERCURY COOLED BREEDER REACTOR}

\section{Neutron Balance}

In the course of this investigation, a code was written to perform a complete neutron balance on the core and blanket, thus making it convenient to obtain the total number of captures and fissions in the system. The neutron-balance calculations permit evaluation of the over-all effect on neutron distribution of any material variations in the system.

The balance code evaluates the following quantities:

$\mathrm{N}_{\mathrm{C}}(235)=$ total number of captures in $\mathrm{U} 235$ in core and blanket.

$\mathrm{N}_{\mathrm{f}}(235)=$ total number of fissions in $\mathrm{U} 235$ in core and blanket.

$\mathrm{N}_{\mathrm{c}} \cdot(238)=$ total number of captures in $\mathrm{U} 238$ in core and blanket.

$\mathrm{N}_{\mathrm{f}}(238)=$ total number of fissions in $\mathrm{U} 238$ in core and blanket.

$\mathrm{N}_{\mathrm{c}}(\mathrm{Mo})=$ total number of captures in molybdenum in core and blanket.

$\mathrm{N}_{\mathrm{c}}(\mathrm{Fe})=$ total number of captures in iron in core and blanket.

$\mathrm{N}_{\mathrm{c}}(\mathrm{Hg})=$ total number of captures in mercury in core and blanket

$\nu \mathrm{N}_{\mathrm{f}}(235)=$ total number of neutrons produced by fissions in $\mathrm{U} 235$ in core and blanket.

$\nu \mathrm{N}_{\mathrm{f}}(238)=$ total number of neutrons produced by fissions in $\mathrm{U} 238$ in core and blanket.

The results are normalized to one source neutron. From these data, the following ratios are evaluated:

$$
\begin{aligned}
\alpha_{235} & =\frac{N_{c}(235)}{N_{f}(235)} \\
\alpha_{M o} & =\frac{N_{c}(M o)}{N_{f}(235)} \\
\alpha_{F e} & =\frac{N_{c}(F e)}{N_{f}(235)} \\
\alpha_{H g} & =\frac{N_{c}(F e)}{N_{f}(235)} \\
\bar{\nu}(235) & =a v e r a g e \text { number of neutrons per fission in U } 235 . \\
& =\frac{\nu N_{f}(235)}{N_{f}(235)}
\end{aligned}
$$


$\bar{\nu}(238)=$ average number of neutrons per fission in U 238

$=\frac{\mathrm{NN}_{\mathrm{f}}(238)}{\mathrm{N}_{\mathrm{f}}(238)}$.

$\Delta \nu^{\prime} \quad=$ number of neutrons per $\mathrm{U} 235$ fission contributed by $\mathrm{U} 238$ fission

$=[\bar{\nu}(238)-1] \frac{\mathrm{N}_{\mathrm{f}}(238)}{\mathrm{N}_{\mathrm{f}}(235)}$.

BRII = theoretical maximum breeding ratio

$=\frac{1}{1+\alpha_{235}}\left[\bar{\nu}(235)-1-\alpha_{235}-\alpha_{\text {Mo }}-\alpha_{\mathrm{Fe}}-\alpha_{\mathrm{Hg}}+\Delta \nu^{\prime}\right]$.

$\mathrm{k} \quad=$ multiplication

$=\frac{\bar{\nu}(235)+\Delta \nu^{\prime}+\frac{\Delta \nu^{\prime}}{\bar{\nu}(238)-1}}{1+\alpha_{235}+\frac{\Delta \nu^{\prime}}{\bar{\nu}(238)-1}+\operatorname{BRII}\left(1+\alpha_{235}+\alpha_{\mathrm{Mo}}+\alpha_{\mathrm{Fe}}+\alpha_{\mathrm{Hg}}\right)}$

$\mathrm{L}_{\mathrm{nc}}=$ leakage from core

$=\left(\sum \nu N_{f}\right)$ core $-\left(\sum N_{c}\right)_{\text {core }}-\left(\sum N_{f}\right)$ core

$\mathrm{BRI}=$ breeding ratio

$=\frac{\mathrm{N}_{\mathrm{c}}(238)}{\mathrm{N}_{\mathrm{a}}(235)} \cdot \cdots$

The theoretical maximum breeding ratio, BRII, assumes an infinite blanket, consequently no loss of neutrons from the system. The breeding ratio, BRI, is reduced from the theoretical maximum by the blanket leakage, as well as by the neutrons scattered from the lowest energy group. Since most of these suffer resonance capture in the U 238, they actually contribute to the breeding gain of the system. BRI is therefore a slight underestimate of the actual breeding ratio of the system.

Table E-X presents the results of the neutron-balance analyses for the three uranium enrichments in the core and for the standard blanket described in the body of this report. The case numbers refer to specified values of the core parameters as given in Table E-ViII. 
TABLE E-VIII

\section{MCBR Core Parameters}

\begin{tabular}{|c|c|c|c|}
\hline $\begin{array}{l}\text { Case } \\
\text { Number }\end{array}$ & $\begin{array}{l}\text { Coolant } \\
\text { Volume } \\
\text { Fraction }\end{array}$ & $\begin{array}{c}\text { Average } \\
\text { Coolant (Hg) } \\
\text { Density } \\
\left(\mathrm{gm} / \mathrm{cm}^{3}\right) \\
\end{array}$ & $\begin{array}{c}\text { Structure- } \\
\text { Fuel Alloy } \\
\text { Volume Ratio }\end{array}$ \\
\hline--01 & 0.1 & 2.0 & 0.2 \\
\hline-02 & 0.3 & 2.0 & 0.2 \\
\hline--03 & 0.5 & 2.0 & 0.2 \\
\hline--04 & 0.3 & 2.0 & 0.1 \\
\hline--05 & 0.3 & 2.0 & 0.2 \\
\hline--06 & 0.3 & 2.0 & 0.3 \\
\hline--07 & 0.3 & 0.5 & 0.2 \\
\hline--08 & 0.3 & 2.0 & 0.2 \\
\hline--09 & 0.3 & 4.0 & 0.2 \\
\hline--10 & 0.3 & 13. 6 & 0.2 \\
\hline
\end{tabular}

Table E-XI gives a similar neutron balance for the Enrico Fermi Reactor, while Table E-XII presents additional neutron balances for MCBR cores of $20 \%$ enrichment, but with various blanket compositions as indicated in Table E-IX.

TABLE E-IX

\section{MCBR Blanket Parameters}

\begin{tabular}{ccccc} 
Case & $\begin{array}{c}\text { Coolant } \\
\text { Volume } \\
\text { Fraction }\end{array}$ & $\begin{array}{c}\text { Average } \\
\text { Coolant (Hg) } \\
\text { Density } \\
\left(\mathrm{gm} / \mathrm{cm}^{3}\right)\end{array}$ & $\begin{array}{c}\text { Structure- } \\
\text { Fuel Alloy } \\
\text { Volume Ratio }\end{array}$ \\
\hline 2011 & 0.1 & & 2.0 & 0.2 \\
2002 & 0.2 & 2.0 & \\
2012 & 0.3 & 2.0 & 0.2 \\
2013 & 0.2 & 2.0 & 0.2 \\
2002 & 0.2 & & 2.0 & 0.1 \\
2014 & 0.2 & 2.0 & 0.2 \\
2015 & 0.2 & 0 & 0.3 \\
2002 & 0.2 & 2.0 & 0.2 \\
2016 & 0.2 & 4.0 & 0.2 \\
& 0.2 & 0.2
\end{tabular}


TABLE E-X

\section{MCBR NEUTRON-BALANCE ANALYSIS}

15\% ENRICHMENT IN CORE

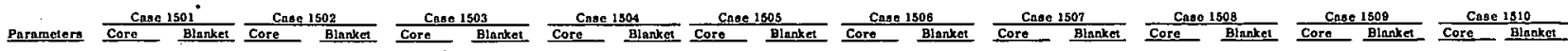

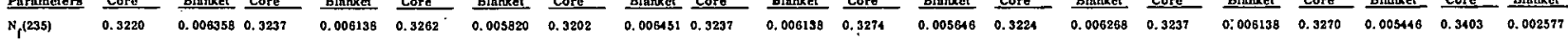

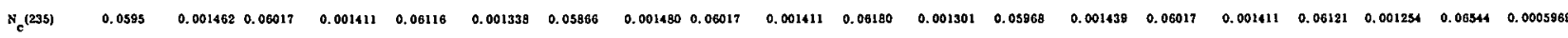

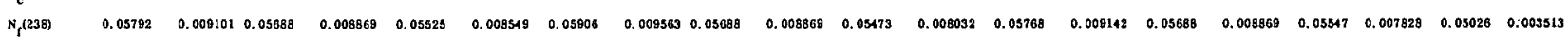

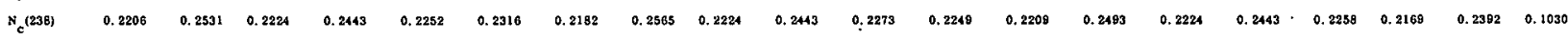

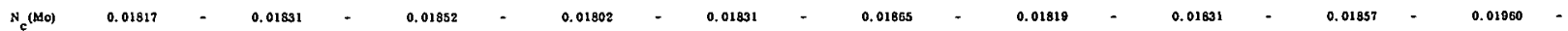

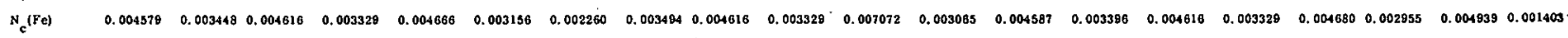

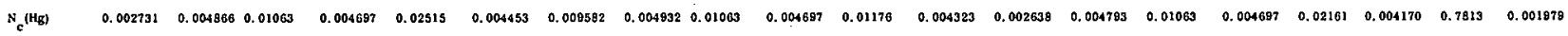

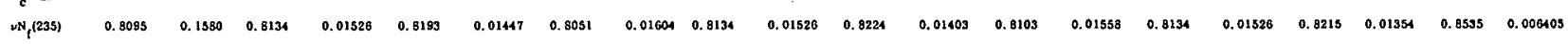

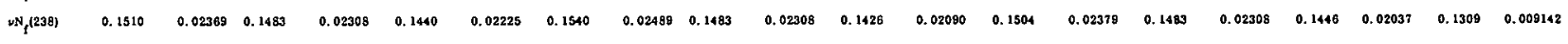

\begin{tabular}{|c|c|c|c|c|c|c|c|c|c|c|}
\hline$a_{235}$ & 0.1953 & 0.1867 & 0.1882 & 0.1341 & 0.1867 & 0.1894 & 0.1860 & 0.1867 & 0.1879 & 0.1920 \\
\hline$a_{\mathrm{MO}}$ & 0.05533 & 0.05551 & 0.05578 & 0.05517 & 0.05551 & 0.05600 & 0.05336 & 0.05351 & $0.05 \dot{3} 85$ & 0.05718 \\
\hline $\mathrm{a}_{\mathrm{Fa}}$ & 0.02444 & 0.02408 & 0.02356 & 0.01701 & 0.02408 & 0.03043 & 0.02429 & 0,02409 & 0.02296 & 0.01850 \\
\hline$a_{\text {Mg }}$ & 0.02353 & 0.04648 & 0.08918 & 0.04443 & $0.046+18$ & 0.04829 & 0.02261 & 0.04649 & 0.07755 & 0.2337 \\
\hline $\bar{v}$ (235) & 2. 3132 & 2.5125 & 2.5115 & 2.5139 & 2. 5125 & 2.5112 & 2. 5130 & 2. 5125 & 2.5110 & 2.5081 \\
\hline $\bar{\nabla}(239)$ & 2. 6062 & 2. 6060 & 2. $\cos 7$ & 2. 6064 & 2.6060 & 2.6056 & 2. 6062 & 2.6060 & 2. 6057 & 2.6047 \\
\hline$\Delta \nu^{\prime}$ & 0.3278 & 0.3202 & 0.3080 & 0.3375 & 0.3202 & 0.3025 & 0.3266 & 0.3202 & 0.3057 & 0.2517 \\
\hline BR11 & 1. 3091 & 1.2807 & 1. 2314 & 1.3090 & 1. 2907 & 1. 2524 & 1.3081 & 1. 2907 & 1. 2401 & 1.05471 \\
\hline k. & 1.0000 & 1.0000 & 1.0000 & 1.0000 & 1.0000 & 1.0000 & 1.0000 & 1.0000 & 1.0000 & 1.0000 \\
\hline$L_{n c}$ & 0.2749 & 0.2649 & $0.2+72$ & 0.2731 & 0.2049 & 0.2563 & 0.2748 & 0.2649 & 0.2517 & 0.1866 \\
\hline BRI & 1. 2165 & I. 1924 & 1. 1579 & 1,2274 & 1. 1924 & 1. 1413 & $1.20 \mathrm{GH}$ & 1. 1924 & 1. 1209 & 0. 837 \\
\hline
\end{tabular}

208 ENHICHMENT IN CORE

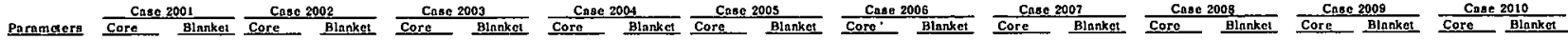

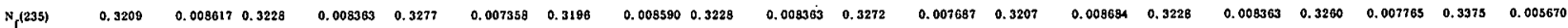

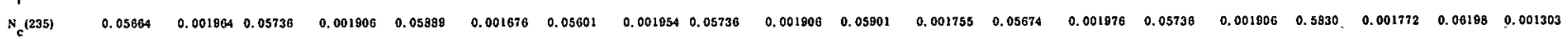

$\begin{array}{lllllllllllllllllllll}\mathrm{N}_{1}(238) & 0.05101 & 0.01414 & 0.05000 & 0.01362 & 0.04807 & 0.01201 & 0.05188 & 0.01441 & 0.05000 & 0.01362 & 0.04801 & 0.01224 & 0.05030 & 0.01443 & 0.05000 & 0.01362 & 0.04483 & 0.01239 & 0.04429 & 0.008374\end{array}$

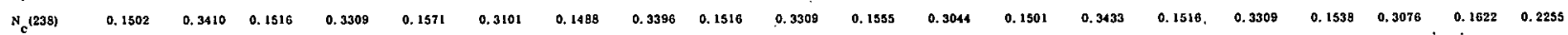

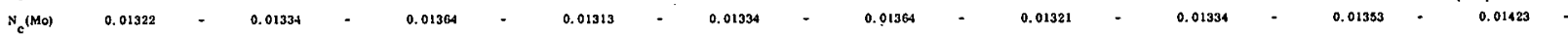

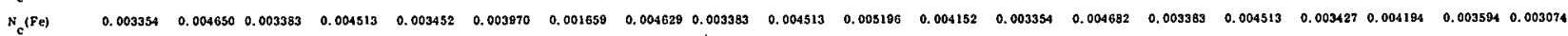

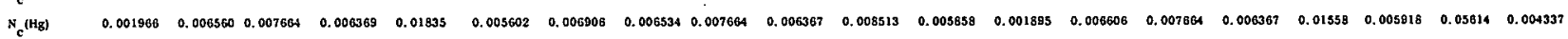

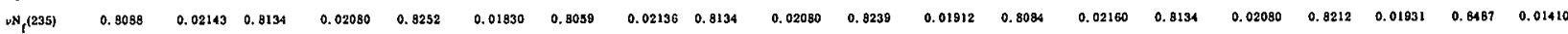

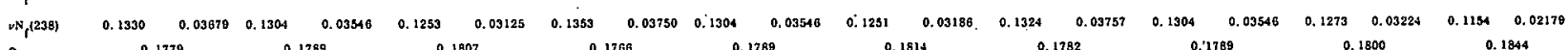

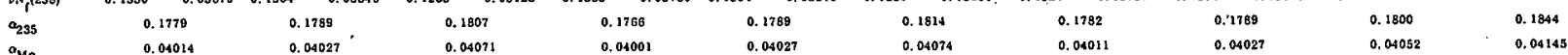

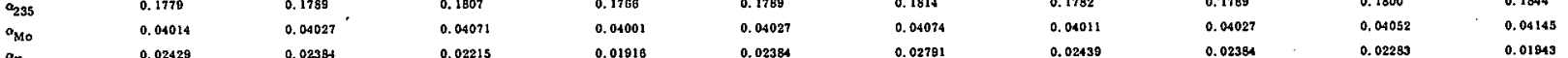

$0.02394 \quad 0.02791 \quad 0.024390 .02394$

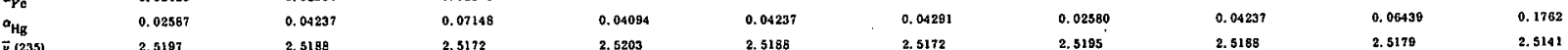

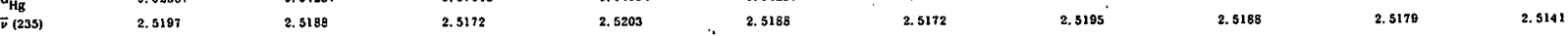

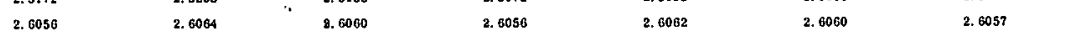

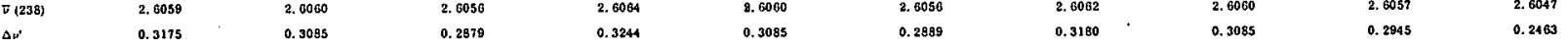

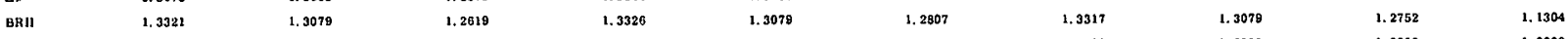

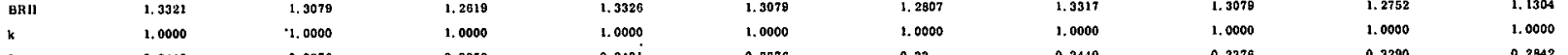

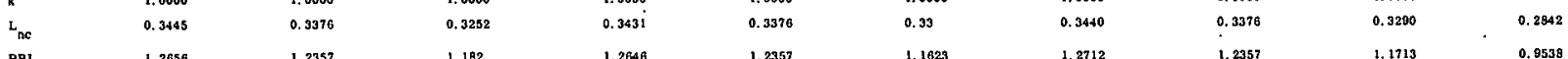

30 E ENACHMENT IN CORE

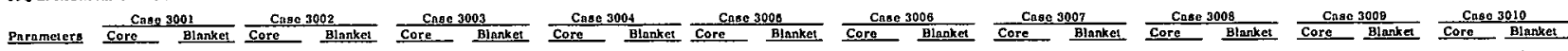

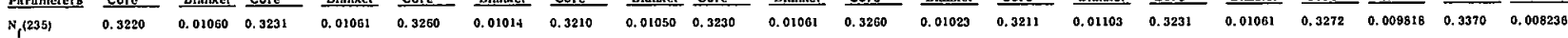

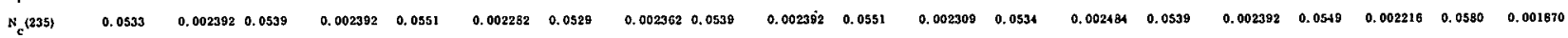

$\begin{array}{lllllllllllllllllllll}\mathrm{N}_{\mathrm{f}}(238) & 0.04015 & 0.02045 & 0.03023 & 0.02055 & 0.03769 & 0.01932 & 0.01197 & 0.02076 & 0.03823 & 0.02055 & 0.03782 & 0.01933 & 0.03909 & 0.02173 & 0.03923 & 0.02053 & 0.03829 & 0.01859 & 0.03486 & 0.01428\end{array}$

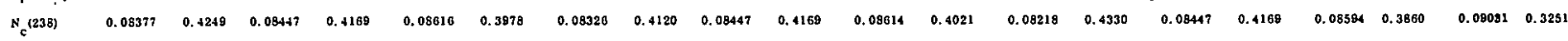

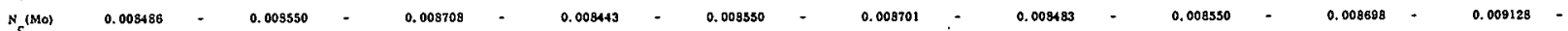

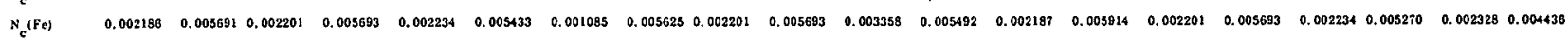

$\begin{array}{lllllllllllllllllllll}N_{c} \text { (Hg) } & 0.001238 & 0.008017 & 0.004826 & 0.008022 & 0.01152 & 0.007859 & 0.004359 & 0.007827 & 0.004826 & 0.008022 & 0.005333 & 0.007739 & 0.001195 & 0.008332 & 0.004826 & 0.008022 & 0.008344 & 0.007428 & 0.03544 & 0.006258\end{array}$

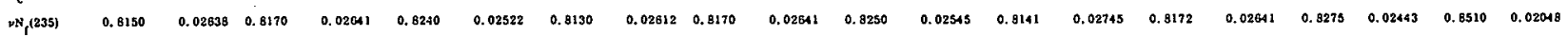

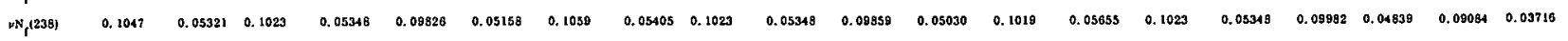

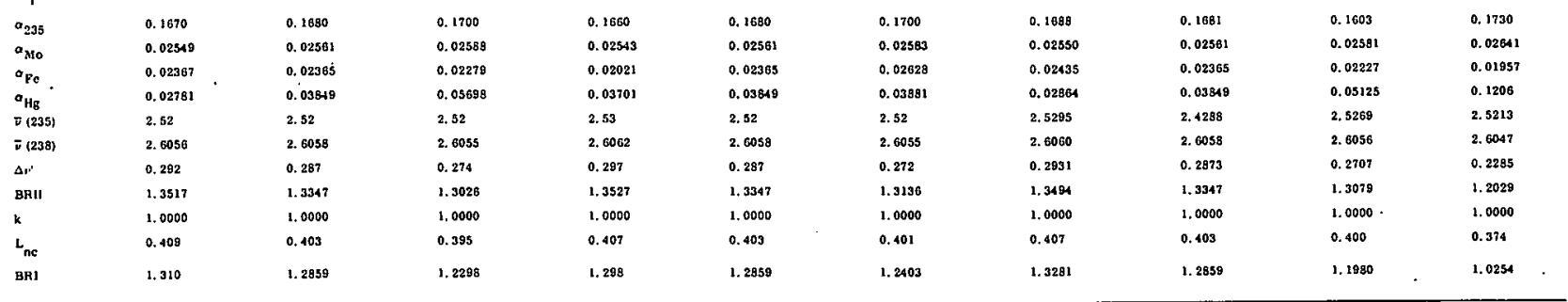

- The first two digts of the case number Indicate the percent enrtehment of the urantus In the corc. 
TABLE E-XI

ENRICO FERMI REACTOR

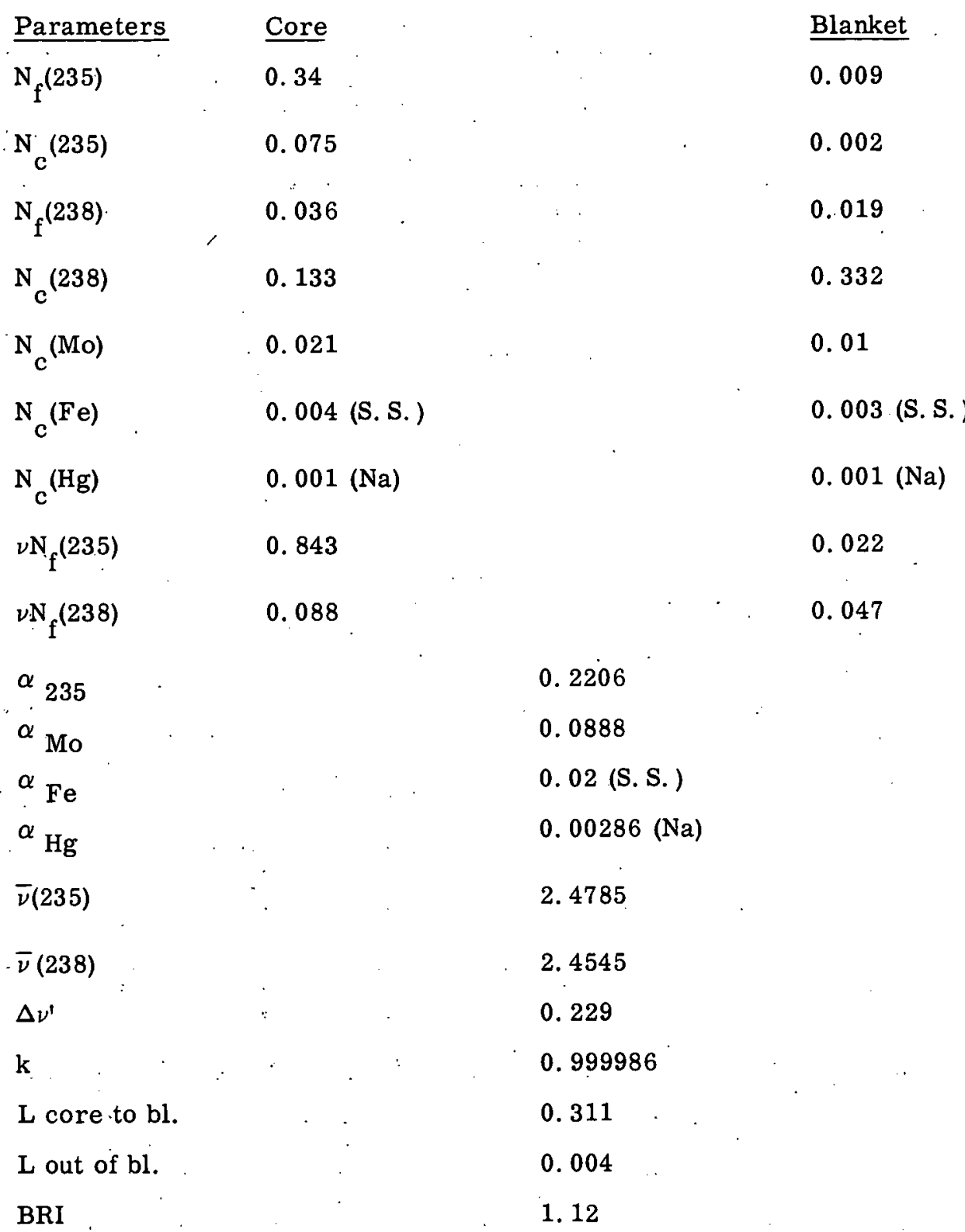


TABLE E-XII

MCBR NEUTRON-BALANCE ANALYSIS

\section{VARIATIONS IN BLANKET COMPOSITION}

\begin{tabular}{|c|c|c|c|c|c|c|c|c|c|c|c|c|c|c|c|c|c|c|}
\hline \multirow{3}{*}{$\frac{\text { Parameters }}{N_{f}(235)}$} & \multicolumn{2}{|c|}{ Case $2011^{\circ}$} & \multicolumn{2}{|c|}{ Case 2002} & \multicolumn{2}{|c|}{ Case 2012} & \multicolumn{2}{|c|}{ Case 2013} & \multicolumn{2}{|c|}{ Ca8e 2002} & \multicolumn{2}{|c|}{ Case 2014} & \multicolumn{2}{|c|}{ Case 2015} & \multicolumn{2}{|c|}{ Cage 2002} & \multicolumn{2}{|c|}{ Case 2016 } \\
\hline & Core & Blanket & Core & Blanket & Core. & Blanket & Core & Blanket & Core & Blanket & Core & Blanket & $\begin{array}{l}\text { Core } \\
\end{array}$ & Blanket & Core & Blanket & Core & Blanket \\
\hline & 0.3231 & 0.008172 & 0. 3228 & 0.008363 & 0.3225 & 0.008572 & 0.3217 & 0.008852 & 0.3228 & 0.008363 & 0.3239 & 0.007832 & 0.3222 & 0.008648 & 0.3228 & 0.008363 & 0.3234 & 0.008095 \\
\hline$N_{c}(235)$ & 0.05748 & 0.001862 & 0.05736 & 0.001906 & 0.05722 & 0.001853 & 0.05714 & 0.001993 & 0.05736 & 0.001906 & 0.05758 & 0.001806 & 0.05723 & 0.001971 & 0.05736 & 0.001906 & 0.05748 & 0.001845 \\
\hline$N_{f}(\mathbf{2 3 B})$ & 0.04978 & 0.01381 & 0.05000 & 0.01362 & 0.05026 & 0.01341 & 0.04972 & .0 .01456 & 0.05000 & 0.01362 & 0.05026 & 0.01278 & 0.04996 & 0.01402 & 0.05000 & 0.01362 & 0.05004 & 0.01325 \\
\hline$N_{c}(238)$ & 0,1518 & 0.3335 & $0.1516^{\circ}$ & 0.3308 & 0.1513 & 0.3264 & 0.1511 & 0.3492 & 0.1516 & 0.3309 & 0.1521 & 0.3156 & 0.1512 & 0.3423 & 0.1516 & 0.3309 & 0. 1519 & 0.3203 \\
\hline $\mathrm{N}_{c}$ (Mo) & 0.01336 & - & 0.01334 & - & 0.1331 & - & 0.01329 & - & 0.01334 . & - & 0.01338 & - & 0.01331 & - & 0.1334 & - & 0.01337 & - \\
\hline$N_{c}(\mathrm{Fe})$ & 0.003387 & 0.004546 & 0.003383 & 0,004513 & 0.003378 & 0.004456 & 0.003369 & 0.002367 & 0.003383 & 0.004513 & 0.003396 & 0.006470 & 0.003376 & 0.004664 & 0.003383 & 0.004513 & 0.003390 & 0.004370 \\
\hline $\mathrm{N}_{\mathrm{c}}(\mathrm{Hg})$ & 0.007678 & 0.002851 & 0.007664 & 0.006367 & 0.007648 & 0.01077 & 0.007639 & 0.006163 & 0.007664 & 0.006367 & 0.007689 & 0.006580 & 0.007646 & - & 0.007664 & 0.006367 & 0.007681 & 0.01233 \\
\hline$\nu \mathrm{N}_{\mathrm{f}}(\mathbf{2 3 5 )}$ & 0.8140 & 0.02032 & 0.8134 & 0.02080 & 0.8128 & 0.02132 & 0.8105 & 0.02201 & 0.8134 & 0.02080 & 0.8163 & 0.01948 & 0.8117 & 0.02151 & 0.8134 & 0.02080 & o. 8149 & 0.02013 \\
\hline$\nu \mathrm{N}_{f}(238)$ & 0.1298 & 0.03594 & 0. 1304 & 0.03546 & 0.1310 & 0.03489 & 0.1296 & 0.03790 & 0.1304 & 0.03546 & 0.1310 & 0.03326 & 0.1303 & 0.03649 & 0.1304 & 0.03546 & 0.1304 & 0.03448 \\
\hline$\alpha_{235}$ & 0.1 & & 0.1 & & o. 1 & & 0.17 & & 0.17 & & 0.17 & & 0.17 & & 0.1 & & & 1790 \\
\hline$\alpha_{M 0}$ & 0.0 & & 0.0 & 027 & 0.0 & 021 & 0.04 & 1022 & 0.0 & & 0.0 & & 0.0 & & & 027. . & & 34031 \\
\hline$\alpha_{\mathrm{Fe}}$ & 0.0 & & 0.02 & 384 & 0.0 & 366 & 0.01 & 1736 & 0.02 & & 0.02 & & 0.02 & & & & & 32341 \\
\hline$\alpha_{\mathrm{Hg}}$ & 0.0 & & 0.0 & 237 & 0.0 & 5662 & 0.04 & 176 & 0.0 & 237 & 0.0 & & 0.02 & & 0.0 & & & 06034 \\
\hline $\bar{\nu}(235)$ & 2.5 & & 2.5 & & 2.5 & & 2. 51 & & 2.5 & & 2. 5 & & 2.51 & & 2.5 & & & 5188 \\
\hline $\bar{v}(238)$ & 2.6 & & 2.6 & & 2.6 & & 2. 60 & & 2.6 & & 2.6 & & . 2.60 & & 2.6 & & & 6059 \\
\hline$\Delta y^{\prime}$ & 0.3 & & 0.3 & & 0.3 & & 0.31 & & 0.3 & & 0.3 & & 0.31 & & 0.3 & & & 3066 \\
\hline BRI & 1.3 & & 1.3 & & 1.2 & & 1.31 & & 1.3 & & 1. 2 & & 1.3 & & $1: 3$ & 79 & & 2913 \\
\hline k & 1.0 & & 1.0 & & 1,0 & & 1.00 & & 1.0 & & 1.0 & & 1.0 & & 1.0 & & & 0000 \\
\hline$I_{n c}$ & 0.3 & & 0.3 & & 0.3 & & 0.33 & & 0.33 & & 0,3 & & 0.33 & & 0.3 & & & 3381 \\
\hline BRI & 1,2 & & 1. 2 & & 1.2 & & 1. 28 & & 1.2 & & 1. 1 & & 1.2 & & 1. 2 & & & 2080 \\
\hline
\end{tabular}

- The first two digits of the case number indicate the percent enrichment of the uranium in the core. 


\section{MERCURY COOLED BREEDER REACTOR}

\section{APPENDIX F \\ BASIS FOR MCBR MATERIALS SELECTION}

Much of the data employed in the MCBR analysis has been developed in connection with Argonne. National Laboratory (ANL) and Atomic Power Development Associates (APDA) fast breeder reactor projects. In addition, considerable information on metallic uranium fuels has been gathered as a result of both the United States and the United Kingdom gas-cooled reactor programs. All of this information has been extensively published over the past two years. It is the purpose of this discussion to review the pertinent facts rather briefly, drawing upon the published literature for supporting data.

1. Irradiation Effects on Uranium and Its Alloys

Since fuel selection for the MCBR has been initially restricted to metallic uranium, it is important to understand and to distinguish between two primary irradiation effects which limit burnup lifetime, namely, growth and swelling. Growth is an over-all change of shape associated with only minor changes in density which occur at temperatures up to about $500^{\circ} \mathrm{C}$. Depending upon fabrication history and composition, lengthening or contraction can occur in any dimension, and surface wrinkling and "orange peel" can take place. Swelling is the relatively large decrease in density which takes place above about $400^{\circ} \mathrm{C}$. Growth becomes less important at higher temperatures and higher burnups, while swelling becomes more important. In this respect, the two phenomena are somewhat complementary. Although swelling is the more important problem to be overcome for MCBR application, some generalizations are listed below for each effect to aid understanding of the behavior of uranium fuel materials under various conditions.

\section{a." Growth}

1) Growth is basically due to the anisotropic expansion properties of alpha uranium and is strongly influenced by the degree of preferred crystal orientation (texture) present as a result of fabrication history.

2) Growth is less pronounced at temperatures above about $350^{\circ} \mathrm{C}$ and disappears completely above about $500^{\circ} \mathrm{C}$.

3) The higher the fabrication temperature, the less the growth. (Grain size decreases with higher fabrication temperatures.)

4) Quenching from the beta phase, as well as beta-quenching followed by tempèring treatments, greatly reduces growth rate. 
5) The decrease in density during growth is about $3 \%$ per a/o burnup and appears to be independent of fabrication history or heat treatment.

6) In general, alloying additions and thermal treatment that cause grain-size refinement minimize surface roughening, and procedures that reduce preferred orientation decrease growth.

b. Swelling

1) Swelling is primarily due to segregation of the fission products xenon and krypton as bubbles within the metallic structure, and their subsequent expansion by gas pressure against the restraint of the surrounding uranium matrix.

2) Swelling increases slowly with increasing temperature to about $600^{\circ} \mathrm{C}$, after which it increases much more rapidly.

3) Swelling increases with increasing burnup, although in a nonlinear manner which becomes more marked beyond about $0.3 \mathrm{a} / \mathrm{o}$ burnup. The swelling rate apparently decreases with burnup at lower temperatures $\left(<400^{\circ} \mathrm{C}\right)$ but increases with burnup at elevated temperatures (compare Figures $F-1$ and $F-2$ ).

4) Swelling is not greatly affected by the addition of small amounts of alloying elements (up to $5 \mathrm{w} / \mathrm{o}$ ), but is greatly retarded by larger amounts of certain additions.

5) Thermal cycling during irradiation greatly enhances swelling.

6) In general, precise correlations between swelling and test conditions, microstructures, and alloy composition have not as yet been established.

\section{Unalloyed Uranium Metal}

Although unalloyed uranium metal would be the most desirable fuel for the MCBR, attainable burnup life is severely limited by swelling under irradiation; consequently, high fuel-cycle costs would result. Data from a large number of sources, in both the United States and the United Kingdom, have been summarized recently ${ }^{51}$ (Figure F-3). In this graph, a. band has been drawn bracketing a rather broad scattering of experimental points. The line D-D is used as the most reasonable prediction of the behavior of unalloyed uranium; the following Table ${ }^{51}$ presents the predicted maximum fuel lifetimes that produce a $10 \%$ volume increase for several irradiation temperatures. Here, temperature is interpreted to mean surface temperature. 


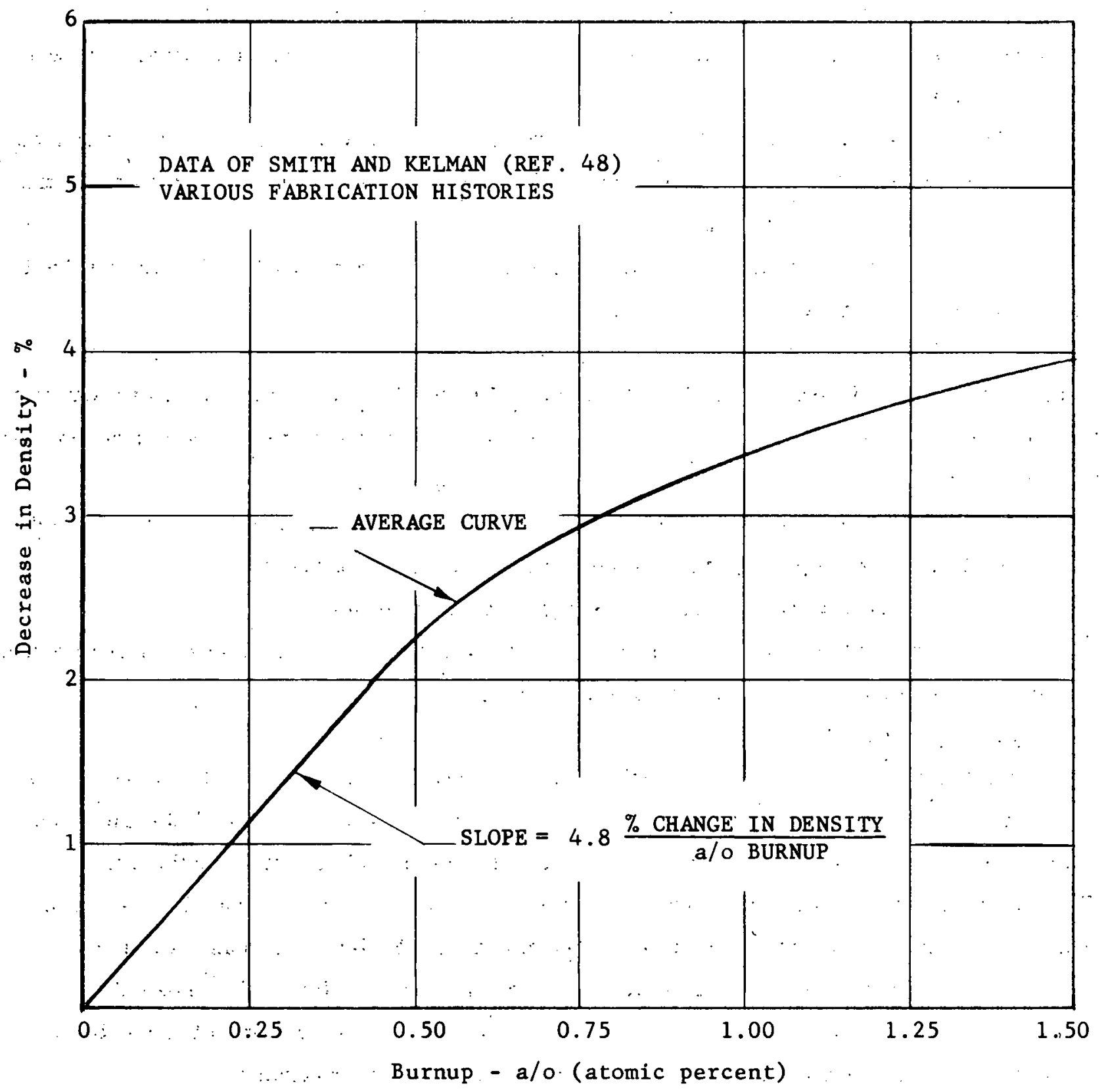

EFFECT OF RADIATION ON THE DENSITY OF URANIUM AT IRRADIATION TEMPERATURES BELOW $400^{\circ} \mathrm{C}$

FIGURE F-1 


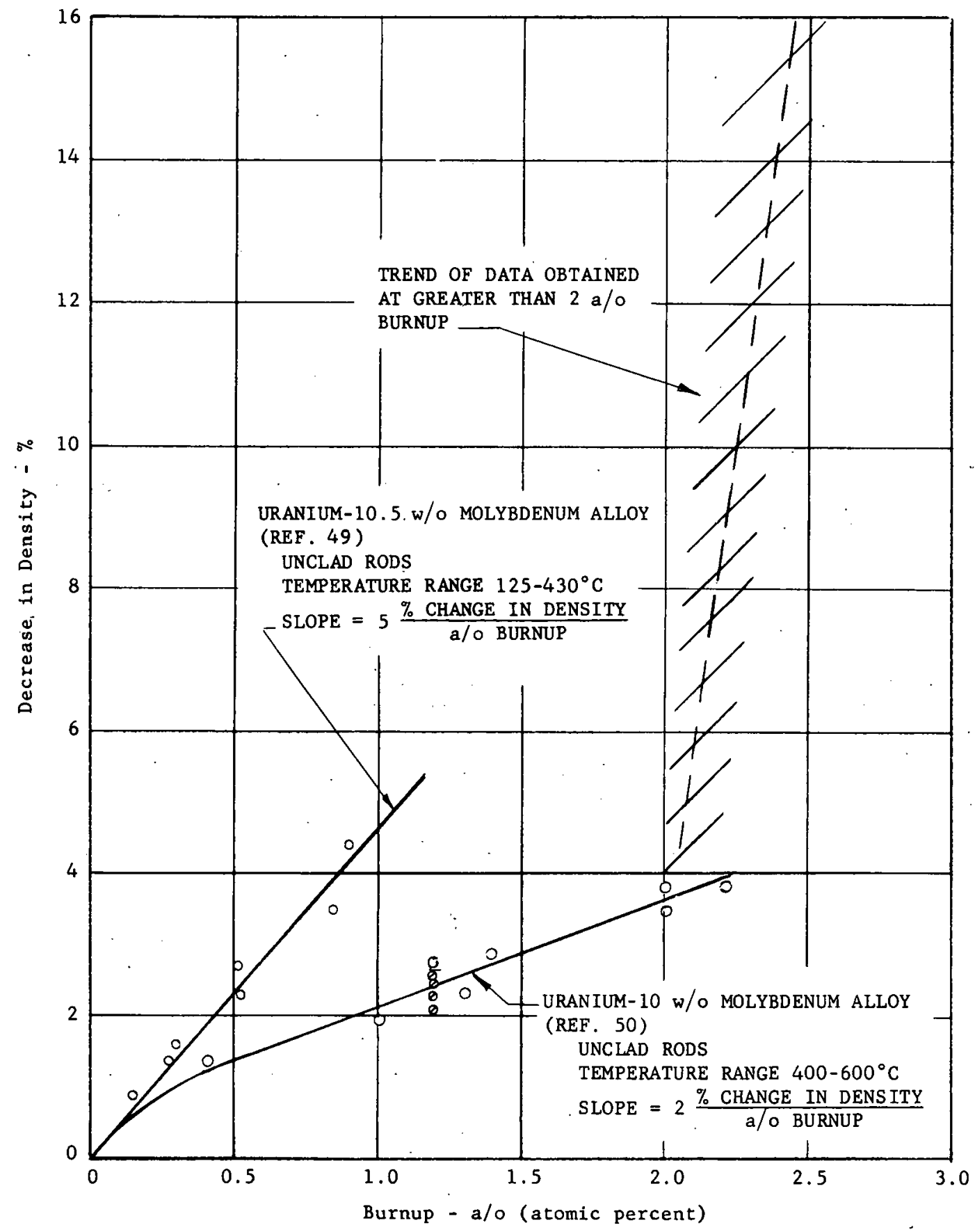

DENSITY CHANGE OF URANIUM-MOLYBDENUM ALLOYS DUE TO IRRADIATION IN VARIOUS TEMPERATURE RANGES

FIGURE F-2 


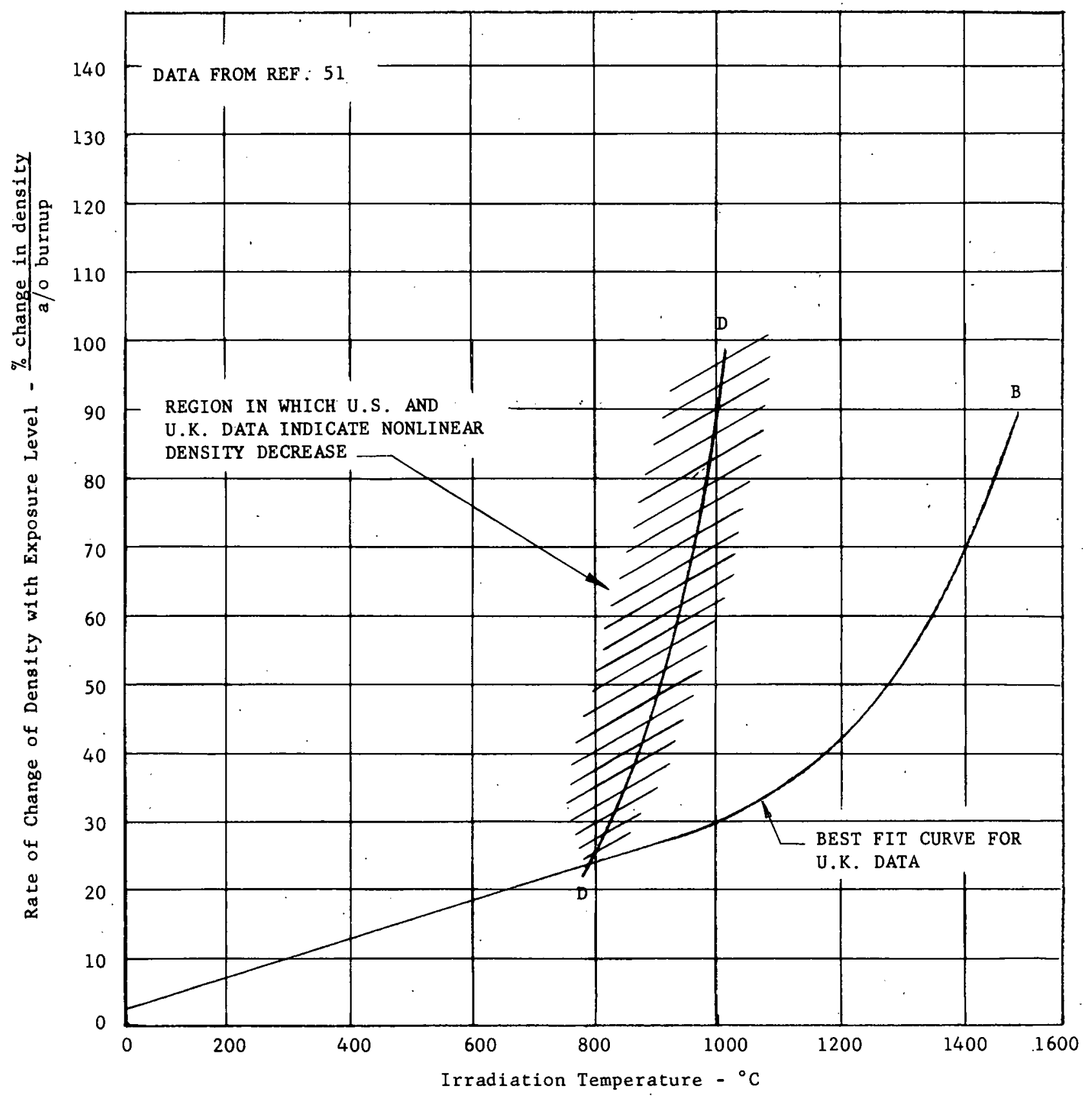

EFFECT OF IRRADIATION TEMIPERATURE ON STABILITY OF UNALLOYED URANIUM

FIGURE $F-3$ 
1

Irradiation Temperature

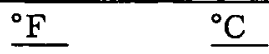

$752 \quad 400$

$797 \quad 425$

$842 \quad 450$

$887 \quad 475$

$932 \quad 500$

TABLE F-I

Exposure (for $10 \%$ Volume Increase) (mwd/metric ton) (a/o burnup)

$\begin{array}{ll}4000 & 0.40 \\ 3000 & 0.30 \\ 2000 & 0.20 \\ 1500 & 0.15 \\ 1000 & 0.10\end{array}$

It is clear that shorter life results from higher surface temperature. However, an additional limitation must not be overlooked when considering elevated temperature operation; namely, the . central metal temperature must not exceed the alpha $\rightarrow$ beta transition temperature or rapid failure from thermal stress cycling can occur. This limitation is $600^{\circ} \mathrm{C}$ central temperature.

Extensive data on unalloyed uranium is given in references 2 and 52 . It is of interest to note that thermal conductivity of uranium has been found to be practically unaffected by irradiation.

3. Uranium Alloys

Although a rather broad range of uranium alloys has been investigated for fuel element applications over the past several years, intensive effort has been limited to a few fairly promising materials. All other data are extremely spotty, so that conclusions regarding potential applicability of these alloys are considered tentative in nature. In addition, even though considerable information has been accumulated regarding the several more promising alloys, a number of uncertainties exist because of gaps in the experiments and because no actual service experience is available as yet. Therefore, caution must be exercised in interpreting available information and predicting power reactor performance. The following discussion will attempt to summarize the current state of the technology, with more detailed treatment reserved for those alloys which show particular promise for power reactor applications. Table F-II provides a brief summary of temperature and burnup limitations that are currently believed to apply to individual alloys. Table F-III presents typical irradiation data for various uranium alloys of interest to this study and indicates the difficulties associated with the attempt to develop correlations of any value at this stage of the technology.

\section{a. Zirconium-Uranium}

Considerable effort was expended on this system in connection with the EBR-I fuel element program when it was found that small amounts of zirconium impart radiation stability to uranium. Typical irradiation data for $2 \mathrm{w} / \mathrm{o} \mathrm{Zr}-\mathrm{U}$ alloy specimens of various histories is shown in Figure $\mathrm{F}-4$. 


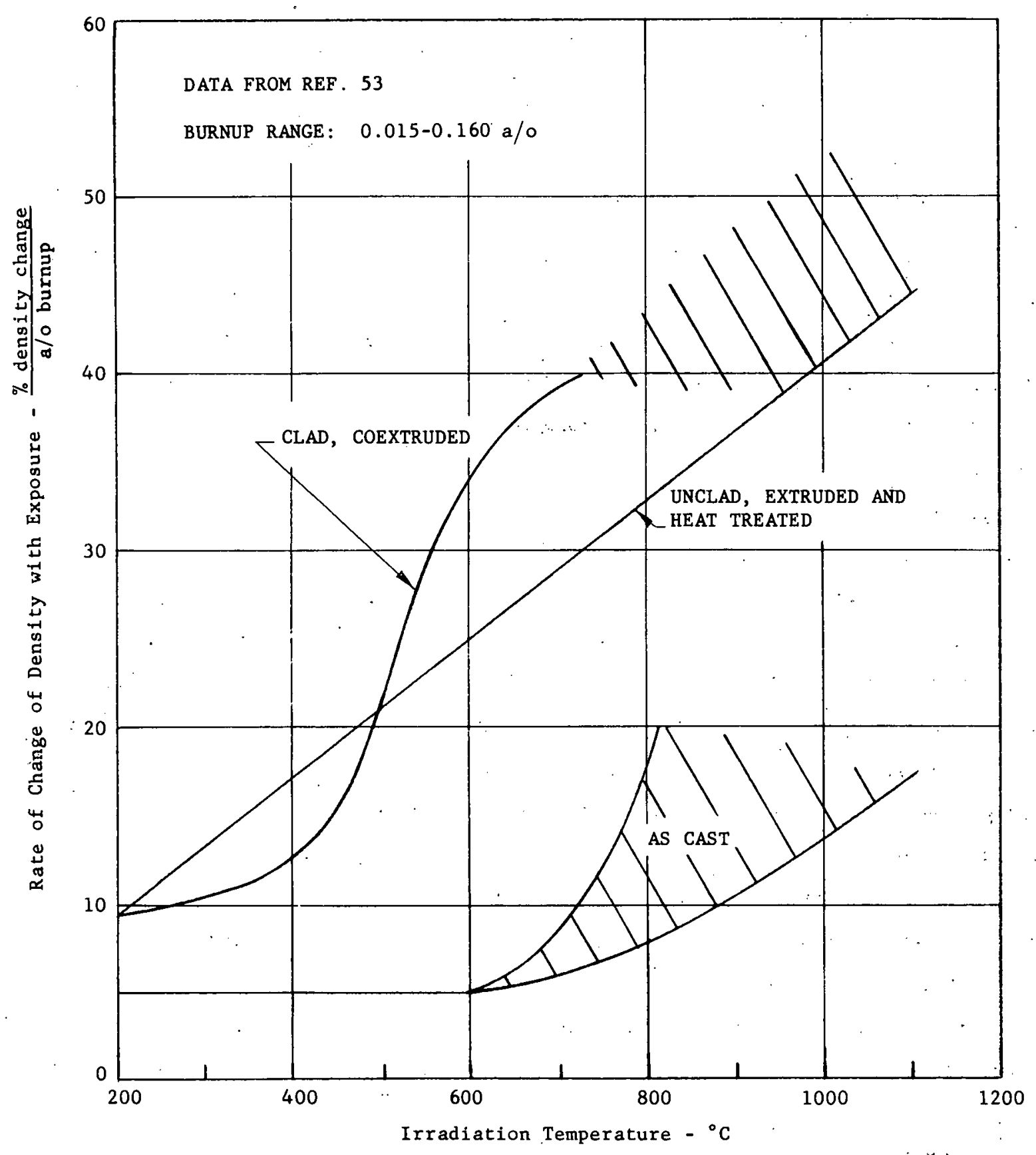

RATE OF DECREASE IN DENSITY OF URANIUM-2 $w / o$ ZIRCONIUM ALLOYS FIGURE $\mathrm{F}-4$ 
For wrought and heat-treated specimens, the effect of irradiation, temperature greatly outweighed the minor differences in behavior resulting from varying heat treatment. Higher temperatures tended toward lower growth rates, although the degree of swelling was considerably greater at elevated temperatures. Induction-cast specimens showed much higher resistance to swelling than heat-treated specimens, the rate of increase at $1250^{\circ} \mathrm{C}$ of induction-cast specimens being less than half that displayed by heat-treated specimens irradiated at $700^{\circ} \mathrm{C}$.

Results of this nature indicate that below $600^{\circ} \mathrm{C}, 2 \mathrm{w} / \mathrm{o} \mathrm{Zr}-\mathrm{U}$, as cast, is very stable under irradiation to at least 0.6 a $/ 0$ burnup. Occasional cycling above the alpha $\rightarrow$ beta transition temperature $\left(663^{\circ} \mathrm{C}\right)$ causes instability and consequent rapid failure. Specimens irradiated above $600^{\circ} \mathrm{C}$ to burnups of over 1 a/o undergo severe swelling of the specimen diameter.

Of the zirconium-uranium alloys, $1.6 \mathrm{w} / \mathrm{O} \mathrm{r}-\mathrm{U}$ has been found to possess the optimum resistance to growth. The reported growth rate is 8 to $10 \%$ per a/o burnup at low irradiations, with an average growth of $5 \%$ at 1 a/o burnup. Irradiation stability of $1.62 \mathrm{w} / \mathrm{o} \mathrm{Zr}$ alloy castings has been found to depend strongly on temperature. Below $350^{\circ} \mathrm{C}$, burnups of $0,0.18,0.67,1.1$, and $1.6 \mathrm{a} / \mathrm{o}$ produced closely similar irradiation effects. Maximum elongation was $6.3 \%$, or $3.8 \%$ per a/o burnup. Above $600^{\circ} \mathrm{C}$, however, very large volume increases resulted (see Figure F-4).

\section{b. Zirconium-Niobium-Uranium (Ternary)}

This group, particularly the $5 \mathrm{w} / \mathrm{o} \mathrm{Zr}-1 \frac{1}{2} \mathrm{w} / \mathrm{o} \mathrm{Nb}-\mathrm{U}$ alloy, is mentioned briefly because of recent application to the EBWR initial core loading. Experimental work in connection with fuel selection for the EBWR has shown that this alloy performs well to moderate burnups at moderate temperatures. Severe dimensional changes have been observed at burnups above about $0.35 \mathrm{a} / \mathrm{o}$ (approximately 4000 megawatt-days per metric ton) at temperatures below $400^{\circ} \mathrm{C}$. Above $400^{\circ} \mathrm{C}$, swelling limits burnup to between 3000 and $4000 \mathrm{mwd} / \mathrm{t}$, and this alloy probably behaves much like unalloyed uranium at these temperatures. At $1000^{\circ} \mathrm{F}\left(538^{\circ} \mathrm{C}\right)$, percent density change per a/o burnup equals about 300 . Therefore, the irradiation limits for this material are $600^{\circ} \mathrm{C}$ to prevent cycling through the alpha $\rightarrow$ beta transformation temperature and $4000 \mathrm{mwd} / \mathrm{t}\left(<400^{\circ} \mathrm{C}\right)$ due to growth. Above $400^{\circ} \mathrm{C}$, limitations due to swelling are about the same as those shown in Table F-I for unalloyed uranium. 


\section{MERCURY COOLED BREEDER REACTOR}

c. Chromium-Uranium

Very small chromium additions for grain refinement were investigated, and larger chromium additions (eutectic) were made to develop a low melting casting alloy that would be particularly advantageous for remote refabrication of fuel elements.

1) Small additions such as $0.03,0.07$, or $0.22 \mathrm{w} / \mathrm{oCr}$ alloys, alpha-annealed and betaquenched, are very similar in behavior under irradiation to unalloyed uranium of comparable treatment. A series of 0.1 and $0.4 \mathrm{w} / \mathrm{o} \mathrm{Cr}$ alloys, isothermally transformed in the high alpha region, showed similar or worse response under irradiation than beta-quenched unalloyed uranium specimens. The $0.4 \mathrm{w} / \mathrm{o} \mathrm{Cr}$ alloy was less stable than the $0.1 \mathrm{w} / \mathrm{o} \mathrm{Cr}$ alloy.

2) Larger chromium additions, such as the $5 \mathrm{w} / \mathrm{o} \mathrm{Cr}$ eutectic alloy, cast, were investigated by APDA as a potential low melting $\left(860^{\circ} \mathrm{C}\right)$ fuel for remote refabrication. Irradiation to burnups ranging to $0.65 \mathrm{a} / \mathrm{o}$ resulted in a severely roughened surface due to large grain size. There has been a loss of interest in this alloy since it was discarded by APDA several years ago; consequently, considerable work would be required before the optimum conditions for this alloy could be established.

\section{d. Niobium-Uranium}

This alloy system has been found to offer no improvement over unalloyed uranium as far as radiation resistance is. concerned. Low-addition alloys such as $3 \mathrm{w} / \mathrm{o}$ niobium have demonstrated poor radiation stability. High additions such as $10 \mathrm{w} / \mathrm{o}$ niobium have not appeared promising. For example, a density decrease of $25 \%$ was observed at 0.69 a/o burnup ( $36 \%$ decrease per a/o burnup) at $800^{\circ} \mathrm{C}$.

\section{e. Silicon-Uranium}

Major effort has concentrated on the cast and heat treated $3.8 \mathrm{w} / \mathrm{o}$. Si-U alloy $\left(\mathrm{U}_{3} \mathrm{Si}\right.$, intermetallic-compound, epsilon-phase alloy), which has demonstrated excellent dimensional stability over the temperature range 280 to $860^{\circ} \mathrm{C}$ up to $0.71 \mathrm{a} / \mathrm{o}$ burnup $(6000 \mathrm{mwd} / \mathrm{t})$. Length changes were between 1 and $2 \%$ over the whole temperature range.

Both cast and extruded epsilonized $\mathrm{U}_{3} \mathrm{Si}$ specimens have been irradiated in other experiments. Cast specimens showed excellent surface smoothness and dimensional stability at lower temperatures with growth values ranging from -3 to $+4 \%$ elongation per a/o burnup. However, one cast specimen, irradiated to approximately $0.8 \mathrm{a} \%$ burnup at about $600^{\circ} \mathrm{C}$, increased in diameter by 33\%. Extruded specimens show good surface but elongate greatly. Extruded specimens elongated with an average growth of $30 \%$ per a/o burnup at low temperatures. 


\section{MERCURY COOLED BREEDER REACTOR}

The chief obstacle to utilization of this material currently arises from the very incomplete state of technology in connection with both fabrication and irradiation stability. Considerable work is required before a satisfactory degree of understanding of the metallurgy and irradiation behavior of this material can be achieved. After this development has been carried out, the Si-U system may prove to be an important fuel material.

f. Plutonium-Uranium and Plutonium-Fissium-Uranium ${ }^{*}$

Considerable work is in progress at ANL in development of fuel materials for the EBR-II fast breeder reactor. Fuel specifications for that project call for $2 \mathrm{a} / \mathrm{o}$ burnup $(20,000 \mathrm{mwd} / \mathrm{t})$ maximum at $700^{\circ} \mathrm{C}$ maximum operating temperature. Also, $20 \mathrm{w} / \mathrm{o}$ plutonium is specified for optimum breeding gain. Of the whole spectrum of alloys of the above systems investigated, the following showed the most favorable behavior:

1) $20 \mathrm{w} / \mathrm{o} \mathrm{Pu}-\mathrm{U}^{\circ}$ - Cast or extruded specimens irradiated to 0.7 a/o burnup exhibited good dimensional stability and surface smoothness. However, this alloy is extremely brittle and unstable in the as-cast condition and lacks resistance to thermal cycling.

2) $20 \mathrm{w} / \mathrm{o} \mathrm{Pu}-5 \mathrm{w} / \mathrm{O} \mathrm{Fs}-\mathrm{U}$ - Cast specimens are expected to show good stability to as high as $1 \mathrm{a} / \mathrm{o}$ burnup. For example, after experiments in the temperature range 450 to $560^{\circ} \mathrm{C}$ and 0.33 to 0.42 a/o burnup, density decreases of only 0.28 to $0.91 \%$ were observed $(0.85$ to $2.2 \%$. decrease per a/o burnup). Molybdenum may be substituted for fissium in this alloy with equally good results.

3) $20 \mathrm{w} / \mathrm{o} \mathrm{Pu}-5 \mathrm{w} / \mathrm{O} \mathrm{Mo}-\mathrm{U}$ - This alloy is similar to (2) above. At 120 to $340^{\circ} \mathrm{C}$ range and $0.43 \mathrm{a} / \mathrm{o}$ burnup, density decrease of $1.5 \%$ was noted (3.5\% decrease per a $/$ o burnup).

4) $20 \mathrm{w} / \mathrm{O} \mathrm{Pu}-10.8 \mathrm{w} / \mathrm{O} \mathrm{Fs}-\mathrm{U}$ - Cast specimens are expected to show good stability to as high as 1 a/o burnup. Excellent stability was observed at $1000^{\circ} \mathrm{F}\left(540^{\circ} \mathrm{C}\right)$ and $0.5 \mathrm{a} / \mathrm{o}$ burnup, where an elongation rate of $1.8 \%$ increase per a/o burnup was measured. Temperature limitation is expected to be the alpha-beta transformation temperature $\left(663^{\circ} \mathrm{C}\right)$, while exposures in excess of

* These alloys represent pyrometallurgically reprocessed fuels. Fissium (Fs) is a mixture of metals and has metallurgical properties similar to those expected for the residual fission products in recycled fast breeder fuel. Typical analysis of fissium includes: $4.6 \mathrm{w} / \mathrm{o} \mathrm{Zr}$, $25.9 \mathrm{w} / \mathrm{o} \mathrm{Mo}, 39.8 \mathrm{w} / \mathrm{o} \mathrm{Ru}, 6.5 \mathrm{w} / \mathrm{o} \mathrm{Rh}$, and $23.2 \mathrm{w} / \mathrm{o} \mathrm{Pd}$. It should be noted that these are all gamma phase stabilizing alloying elements and might therefore be expected to improve radiation stability to some degree corresponding to results obtained with individual additions such as molybdenum. 


\section{MERCURY COOLED BREEDER REACTOR}

$8000 \mathrm{mwd} / \mathrm{t}$ are expected. For example, cast specimens were irradiated in the temperature range 280 to $310^{\circ} \mathrm{C}$ to 0.81 to 0.92 a/o burnup, with only 0.18 to $1.29 \%$ density decrease $(0.22$ to $1.4 \%$ decrease per a/o burnup).

5) $5 \mathrm{w} / \mathrm{O}$ Fs $-\mathrm{U}$ - Experimental results have shown that this alloy is stable at central temperatures from 700 to $1000^{\circ} \mathrm{F}\left(370\right.$ to $\left.540^{\circ} \mathrm{C}\right)$ and burnup to $0.76 \mathrm{a} / \mathrm{o}$. Limitations are expected to be similar to those shown under (4) above. The addition of 2.5 and $7.5 \mathrm{w} / \mathrm{o}$ Mo to cast U-5 w/o Fs alloys increased surface smoothness, and radiation stability. was found to be independent of prior heat treatment. Maximum stability was achieved by gamma quenching.

A number of unknowns exist before these alloys will be employed with confidence. Thermal expansion studies by ANL of Pu-F'S-U alloys have revealed erratic behavior when heated above. $500^{\circ} \mathrm{C}$ for Fs alloys having a molybdenum content of $5 \mathrm{w} / \mathrm{o}$ Mo. Phase change starting at $541^{\circ} \mathrm{C}$, cycling above this to $713^{\circ} \mathrm{C}$, and shrinkage of about 0.003 inch occurred in 0.5 inch. After shrinkage, growth occurred on thermal cycling.

Experience in the EBR-II reactor will clarify the importance of these alloys as nuclear fuels, especially for fast reactors. It is particularly worthy of note that ANL believes the cast materials containing fissium are the best uranium alloys ever tested by that laboratory.

Recent data on a group of cast $20 \mathrm{w} / \mathrm{O} \mathrm{Pu}-10 \mathrm{w} / \mathrm{O} \mathrm{Fs}-\mathrm{U}$ alloys, irradiated to burnups to $3.5 \mathrm{a} / \mathrm{o}$ and temperatures up to $840^{\circ} \mathrm{C}$ (calculated), showed large volume increases (40\% density decrease) from swelling. This temperature is well above EBR-II operating requirements, and good dimensional stability is expected with fissium alloys for 2 a/o burnups at approximately $600^{\circ} \mathrm{C}$.

Extensive information on these alloys is given in reference 54.

\section{g. Molybdenum-Uranium}

These alloys have been under investigation for some time, and the radiation stability of a. number of alloys has been determined.

1) Alloys containing less than $7 \mathrm{w} / \mathrm{o}$ molybdenum have not shown appreciable benefits over unalloyed uranium. For example, $1.2 \mathrm{w} / \mathrm{o}$ Mo-U powder compact exhibited relatively poor radiation stability at center temperatures in the range 750 to $1250^{\circ} \mathrm{F}\left(400\right.$ to $675^{\circ} \mathrm{C}$ ) and burnups of 0.4 a/o. Diameter increases of 8 to $12 \%$ were measured. ANL has investigated compositions in the range of 1 to $3.5 \mathrm{w} / \mathrm{o}$. Mo in the form of powder compacts, wrought, and cast material. Burnups to $0.5 \mathrm{a}$ /o have been employed at moderate temperatures. Results ranged from essentially no improvement for cold pressed and sintered powder compacts to essentially complete resistance to growth for cast material. Growth of wrought material was very sensitive to heat treatment, varying 


\section{MERCURY COOLED BREEDER REACTOR}

from the behavior of beta-quenched wrought uranium to that of cast material. The effect of elevated temperature irradiation would be similar to results on unalloyed uranium.

2) $10 \mathrm{w} / \mathrm{o}$ Mo-U alloys represent the best available radiation-resistant alloy, based on all information obtained to date. Investigations conducted in connection with the PWR project, earlier, and the Enrico Fermi project, currently, have provided the bulk of the data shown in Figure F-2. PWR data were confined to temperatures below $800^{\circ} \mathrm{F}$ and burnups less than 0.5 a/o. Maximum density decreases of $4.4 \%$ at $8800 \mathrm{mwd} / \mathrm{t}$ and temperatures below $428^{\circ} \mathrm{C}$ were found in bare specimens. Decreases ranged to $4.3 \%$ at $28,200 \mathrm{mwd} / \mathrm{t}$ and irradiation temperatures to $654^{\circ} \mathrm{C}$ in clad specimens. Recent APDA data at elevated temperatures, shown in Figures F-5 and F-6, are particularly useful. Density changes for irradiation to $2.7 \mathrm{a} / \mathrm{o}$ burnup and to temperatures of $745^{\circ} \mathrm{C}$ are shown. The gamma-quenched condition exhibited smaller changes than partially or fully transformed conditions. Cracking is observediabove $2 \mathrm{a} / \mathrm{o}$ burnup, the severity increasing with cladding thickness. From the available data, it can be assumed that this alloy is satisfactory for average exposures around $1 . \mathrm{a} / \mathrm{o}$ burnup $(10,000 \mathrm{mwd} / \mathrm{t})$ at center temperatures around $600^{\circ} \mathrm{C}$.

This is the fuel alloy chosen for the Enrico Fermi Power Reactor initial core loading (27\% enriched). In this reactor, the increase in critical mass and decrease in breeding ratio resulting from the high percent of molybdenum is believed to be offset by longer burnup and cheaper fuel reprocessing.

The effect of irradiation on the thermal conductivity of rolled $10 \mathrm{w} / \mathrm{O}$ Mo-U alloy has been studied to some extent at relatively low temperature $\left(200^{\circ} \mathrm{C}\right)$. Changes in the value of thermal conductivity after burnups to 1.2 a/o were within experimental error $( \pm 10 \%)$ and are therefore considered to be indicative of negligible difference due to irradiation. Detailed physical property data for this alloy have been published rather extensively (references 55 and 56, Figure F-7). 


\section{MERCURY COOLED BREEDER REACTOR}

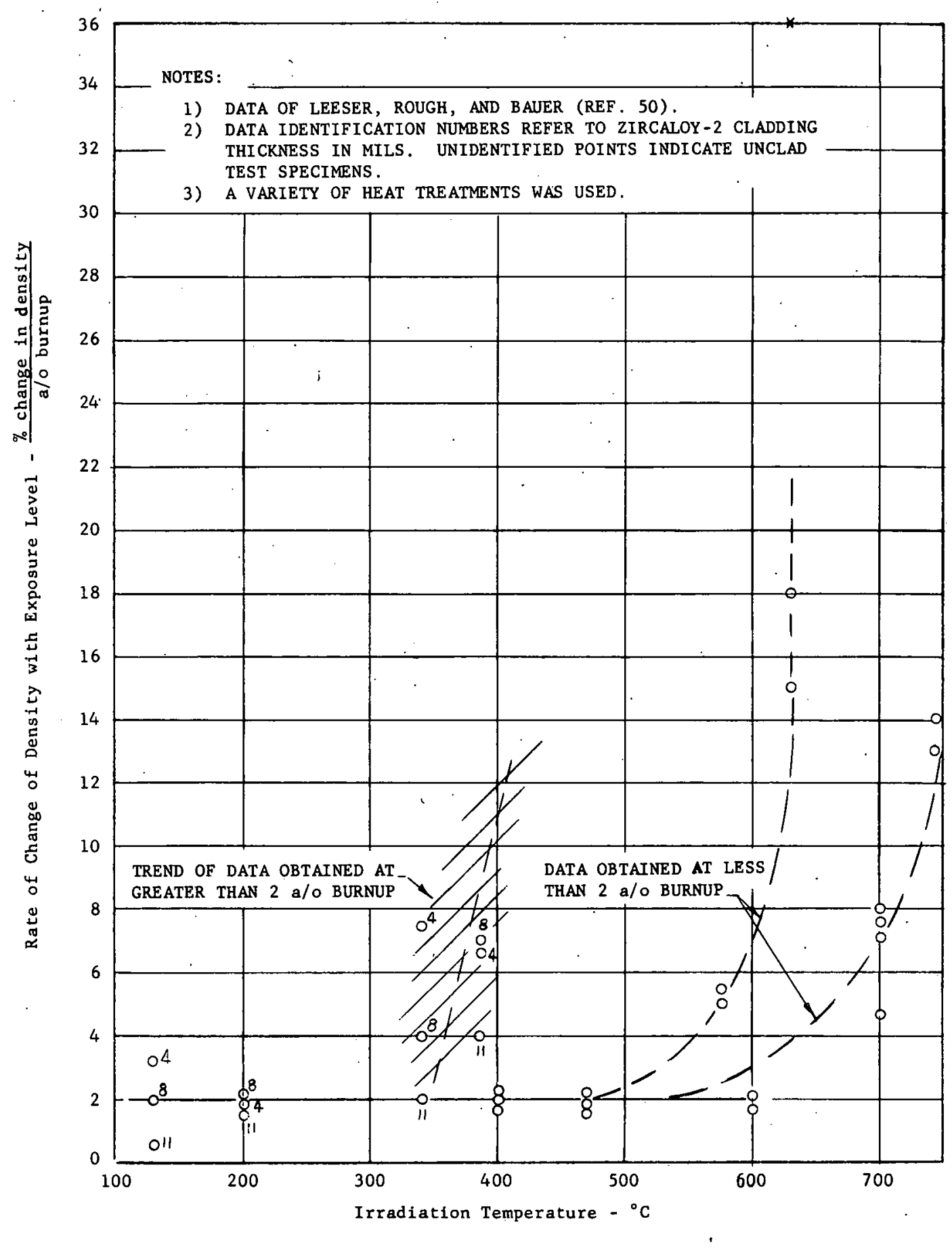

RATE OF DENSITY DECREASE OF

URANIUM-10 $w / o$ MOLYBDENUM ALLOYS

AT VARIOUS IRRADIATION TEMPERATURES

FIGURE $F-5$ 


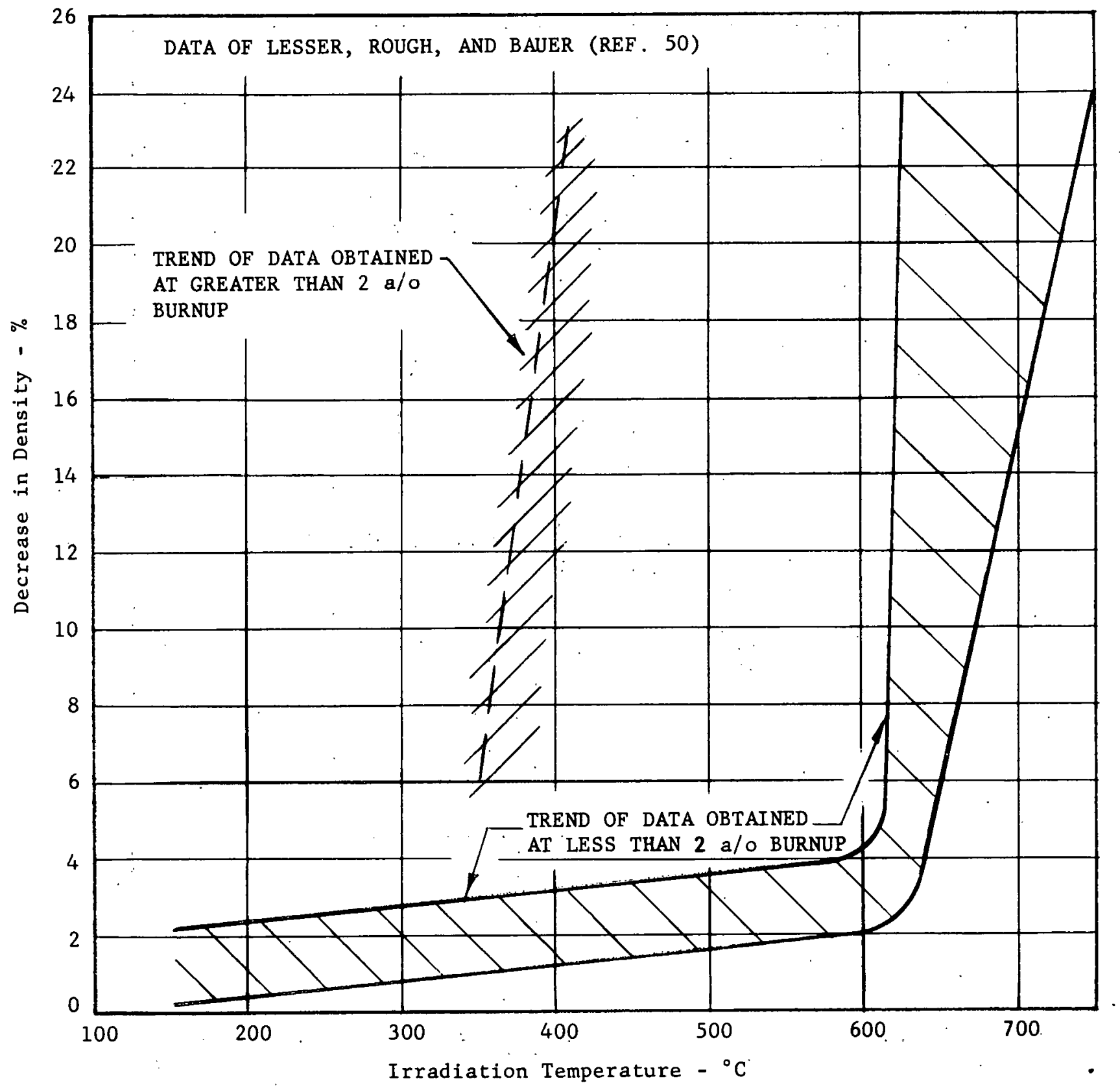

DENSITY CHANGE OF URANIUM-10 $\mathrm{w} / \mathrm{O}$ MOLYBDENUM ALLOY IRRADIATED AT VARIOUS TEMPERATURES AND

TO VARIOUS EXPOSURE LEVELS

FIGURE F-6 


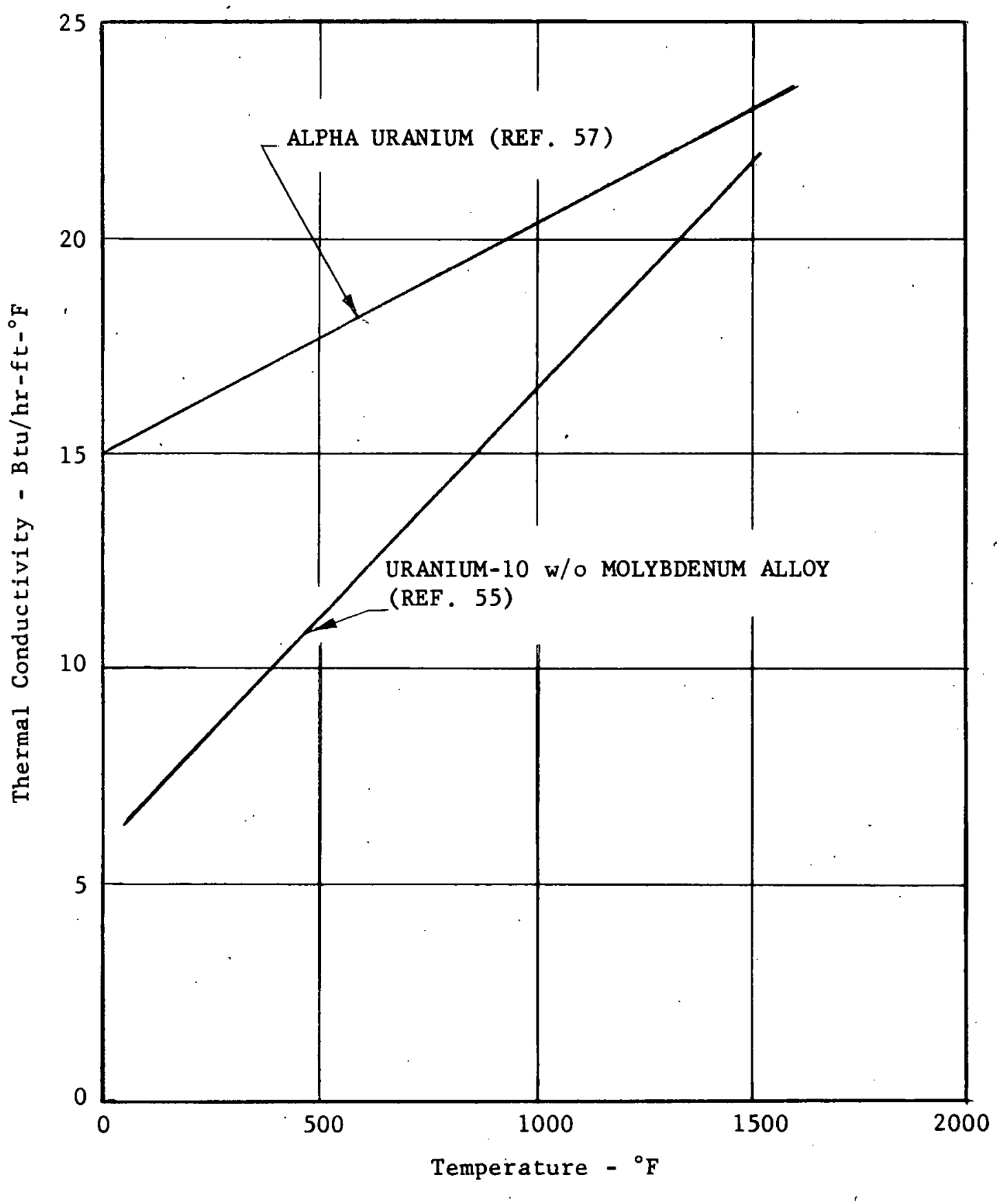

THERMAL CONDUCTIVITY OF

URANIUM-10 w/o MOLYBDENUM ALLOY AND ALPHA URANIUM

FIGURE $F-7$ 
TABLE F-II

APPROXIMATE TEMPERATURE AND

BURNUP LIMITATIONS OF URANIUM ALLOYS

\section{Composition}

$(w / 0)$

$2 \mathrm{Zr}$

$5 \mathrm{Zr}-1 \frac{1}{2} \mathrm{Nb}$

$5 \mathrm{Cr}$

3. $8 \mathrm{Si}\left(\mathrm{U}_{3} \mathrm{Si}\right)$

$20 \mathrm{Pu}-10.8 \mathrm{Fs}$

$20 \mathrm{Pu}-5 \mathrm{Fs}$

$20 \mathrm{Pu}-5 \mathrm{Mo}$

5 Fs

$10 \mathrm{Mo}$
Maximum Burnup

$(\mathrm{a} / \mathrm{o})(\mathrm{mwd} / \mathrm{t})$

0.6

6,000

0.35

4,000

0.5

5,000

600

$\begin{array}{r}\text { Maxim } \\ \left({ }^{\circ} \mathrm{C}\right)\end{array}$
600
400

$0.7 \quad 7,000$

600

600

1

10,000

2

20,000
Remarks

As-cast

These limits due to growth; swelling limits approximately same as Table F-I.

As-cast; badly wrinkled surface occurs even at very low exposures.

Difficult to fabricate; many unknowns; cast and heat treated condition preferred.

EBR-II; more testing required; cast and gamma quenched.

Enrico Fermi; best alloy available; cast or wrought and heat treated. 
TABLE F-III

COMPARISON OF RADIATION STABILITY OF

METALLIC URANIUM FUELS

(TYPICAL DATA)

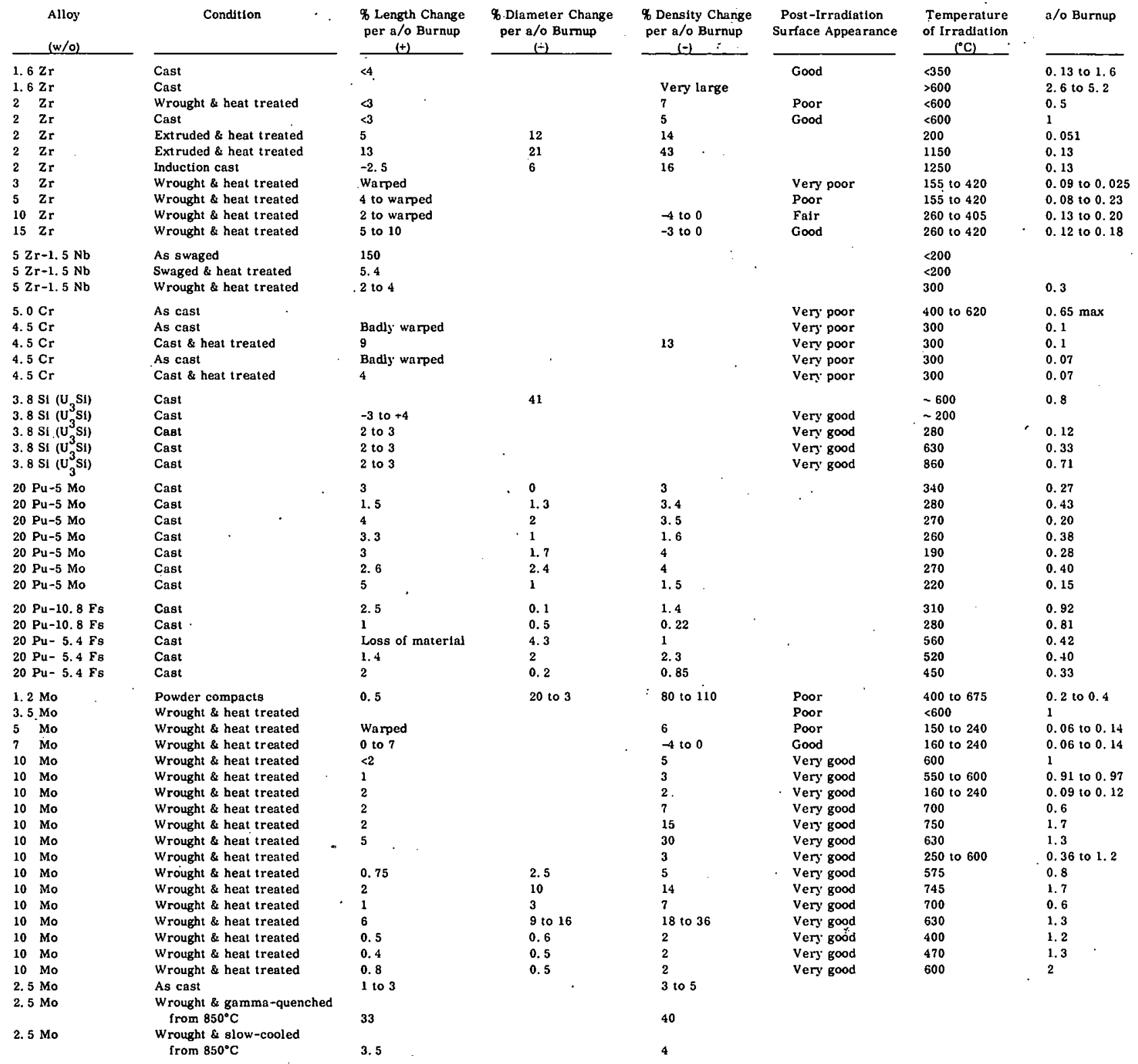




\section{Compatibility of Fuel-Element Materials}

The high operating temperatures desired in liquid-metal-cooled reactors require that compatibility of solid- and liquid-phase materials be investigated.

a. Fuel-Cladding Compatibility Temperature Limit

Uranium vs Zircaloy-2 $600^{\circ} \mathrm{C}$ - interdiffusion

Uranium vs Steel, Stainless Steel, Chromium, Manganese, or other ferrous materials

$$
\begin{aligned}
& 750-850^{\circ} \mathrm{C} \text { - low melting eutectics } \\
& 350^{\circ} \mathrm{C} \text { - intermetallic compounds }
\end{aligned}
$$

b. Fuel versus Thermal Bonding Medium

Uranium vs Mercury Extensive solubility of $\mathrm{U}$ in $\mathrm{Hg}$

Uranium vs Sodium or $\mathrm{NaK}$ $600^{\circ} \mathrm{C}$ maximum

Up to about $600^{\circ} \mathrm{C}$ in oxygen-free sodium or $\mathrm{NaK}$, the corrosion rate of uranium is quite small; however, as little as 1 or $2 \%$ oxygen can increase corrosion rate by a factor of 10 . If the liquid metal bond can be kept free of oxygen, negligible corrosion effects should be experienced.

Following current practice, a 5-mil annulus would be needed to facilitate fuel element fabrication.

c. Coolant versus $\mathrm{Na}$ or $\mathrm{NaK}$

The compatibility of liquid sodium or $\mathrm{NaK}$ and mercury is important from the standpoint of the potential consequence of a cladding failure. A number of compounds from $\mathrm{Na}{ }_{3} \mathrm{Hg}$ to $\mathrm{NaHg}_{4}$ and from $\mathrm{KHg}$ to $\mathrm{KHg}_{8}$ are formed, all of which possess negative heats of formation (exothermic reactions):

Sodium-mercury compounds which occur are:

$\begin{array}{lcc}\mathrm{Na}_{3} \mathrm{Hg} & 11.8 \pm 0.5 & \mathrm{kcal} / \mathrm{mole} \\ \mathrm{Na}_{5} \mathrm{Hg}_{2} & 23.0 \pm 1.0 & " \\ \mathrm{Na}_{3} \mathrm{Hg}_{2} & 23.0 \pm 1.0 & " \\ \mathrm{NaHg} & 10.2 \pm 0.5 & " \\ \mathrm{NaHg}_{2} . & 18.3 \pm 1.0 & " \\ \mathrm{NaHg}_{4} . & 20.0 \pm 1.5 & "\end{array}$

These compounds are completely miscible above $353^{\circ} \mathrm{C}$ in liquid phase. 


\section{MERĆURY COOLED BREEDER REACTOR}

Potassium-mercury compounds occurring are:

$\begin{array}{lcc}\mathrm{KHg} & 13.4 \pm 1.0 & \mathrm{kcal} / \mathrm{mole} \\ \mathrm{KHg}_{2} & 18.5 \pm 1.5 & " \\ \mathrm{KHg}_{3} & 20.0 \pm 2.0 & " \\ \mathrm{KHg}_{4} & 21.5 \pm 2.0 & " \\ \mathrm{KHg}_{8} & 25.0 \pm 2.5 & "\end{array}$

These compounds are completely miscible above $270^{\circ} \mathrm{C}$ in liquid phase.

Under MCBR conditions, it is not believed that $\mathrm{Hg}-\mathrm{Na}$ or $\mathrm{NaK}$ reactions present any problem.

\section{Cladding Material}

The chief requirement for the cladding material is resistance to corrosion by the boiling mercury environment and adequate mechanical strength at temperatures around $1000^{\circ} \mathrm{F}$.

a. A $5 \mathrm{w} / \mathrm{O} \mathrm{Cr}$ Steel appears to be most applicable for the MCBR, based on past experience in mercury systems and upon elevated temperature behavior required for the MCBR. Although wall thickness of about 0.008 to 0.010 inch and outside diameters of less than 0.5 inch may be required, tubing is generally obtainable on special order. Mechanical properties of this material may be found in the ASME Codes; allowable stresses shown there are recommended for design purposes. Fabricability is less than ideal; however, sufficient experience is available to permit handling of such problems with ease. A typical analysis of this steel 'is $5 \mathrm{w} / \mathrm{o} \mathrm{Cr}, 1.5 \mathrm{w} / \mathrm{o} \mathrm{Si}, 0.5 \mathrm{w} / \mathrm{o} \mathrm{Mo}, 0.1$ w/o C, balance Fe. Conventional additive practice is assumed with regard to mercury treatment to minimize mass transfer.

b. Stainless steel offers no technical advantages over $5 \mathrm{w} / \mathrm{oCr}$ Steel under MCBR conditions, and actually much less is known about the resistance of stainless steel to mercury corrosion effects.

c. Zirconium and zirconium alloys are not recommended for service in high-temperature mercury. It is reported ${ }^{11}$ that zirconium has only limited resistance to attack by mercury at elevated temperatures. Also, zirconium forms a distinct amalgam layer on exposure to static mercury for 330 hours at $600^{\circ} \mathrm{F}\left(316^{\circ} \mathrm{C}\right)$. A review of the $\mathrm{Zr}-\mathrm{Hg}$ equilibrium diagram reveals that several-intermetallic compounds exist. Equilibrium solubility varies from $5 \mathrm{ppm}$ at $350^{\circ} \mathrm{C}$ to $16 \mathrm{ppm}$ at $550^{\circ} \mathrm{C}$. In addition, the affinity of zirconium for oxygen, hydrogen, and nitrogen above about $500^{\circ} \mathrm{C}$ is well known and would impose additional problems with regard to over-all system design. 
d. Low-carbon steels have good resistance to attack by flowing mercury below about $400^{\circ} \mathrm{C}$, limited resistance up to about $540^{\circ} \mathrm{C}$, and poor resistance at higher temperatures. The presence of inhibitor wetting agent combinations ( $\mathrm{Ti}-\mathrm{Mg}$, for example) has been found to reduce the attack on low-carbon steel to very small rates at temperatures up to $650^{\circ} \mathrm{C}$. However, factors such as mechanical properties and microstructural stability militate against the use of plain carbon steel for cladding or structural parts above about $450^{\circ} \mathrm{C}$. 


\section{MERCURY COOLED BREEDER REACTOR}

\section{APPENDIX G \\ PRELIMINARY ECONOMIC EVALUATION}

A preliminary estimate of the MCBR fuel-cycle costs was made in order to assess the economic potential of the system and thus to guide the selection of the size (power level) of the reactor to be used as the basis for the conceptual design and detailed cost estimate. It should be emphasized that the estimate is a preliminary one and includes values and assumptions which are not entirely reliable. Nonetheless, it is adequate to establish meaningful trends and give an approximate indication of the fuel-cycle costs for various power levels.

\section{Basis for Fuel-Cycle Cost Estimate}

The fuel-cycle cost estimate is based on the results of the technical feasibility evaluation presented in the body of this report, although the estimate was completed before all the data presented there were available. A cylindrical-core geometry was assumed, consisting of pin-type fuel rods arranged in closely packed bundles such that the coolant volume fraction is uniform in all parts of any single core. A uniform blanket was assumed to surround the core, preserving the cylindrical geometry.

An allowable head loss across the core of 5 feet of liquid mercury ( 31 psi) was assumed. This value was selected because it represents a compromise, primarily between high thermal performance and low thermal efficiency. A maximum allowable fuel-element surface temperature of $1000^{\circ} \mathrm{F}$ and a maximum fuel-element centerline temperature of $1112^{\circ} \mathrm{F}$ were assumed.

A range of fuel-element outside diameters was selected $(0.2$ to $0.35 \mathrm{inch})$, so that element diameter was the independent variable for the purpose of estimating fuel-cycle costs. The maximum permissible power density could then be obtained from Figure 4, as well as the corresponding fuel-element pitch-to-diameter ratio for each selected value of element diameter. The pitch-to-diameter ratio implies a unique coolant volume fraction in the core. With a value of

$2.0 \mathrm{gm} / \mathrm{cm}^{3}$ for the average mercury density, corresponding conservatively to a maximum saturation temperature of $1000^{\circ} \mathrm{F}$ and an exit quality of 0.30 , the basic core parameters were specified for each element diameter. From Figures 5 through 10 , the critical masses and breeding ratios were obtained and the core volume and dimensions determined.

Average power density was developed from the values obtained from Figure 4 by dividing by an assumed radial peak-to-average flux ratio of 2.2. With average power density and core volume determined, the operating power level was fixed for each value of fuel-element diameter selected. 
Thus, each diameter corresponds to a specific power level, and the reactor configuration for that power level is such that maximum allowable performance is achieved under the assumptions employed.

The mass of fabricated fuel was calculated from the critical mass, the coolant volume fraction, and estimates of the structure-fuel alloy volume ratios prepared for the purpose. An exposure level of 10,000 megawatt-days per metric ton of uranium in the core and 1;000 mwd/t of uranium in the blanket was specified because of uranium growth limitations on exposure level. (These exposure levels are comparable to those of the Enrico Fermi core.) Final uranium enrichment in this initial calculation was approximated by assuming that no plutonium was fissioned. The exposure level then determined the total uranium burnup, from which final enrichment was calculated. The error in fuel-cycle cost created by such a procedure is partially offset by the unrealistically high plutonium credit used. For a plutonium value of $\$ 12$ per gram and a uranium value of about $\$ 16$ per gram, the calculated fuel-cycle costs are higher than would be realistically predicted; the opposite would be true for a plutonium value of $\$ 30$ per gram.

The unit costs for various items of the fuel cycle were obtained largely from published data made available by the Atomic Energy Commission for the Atomic Power Development Association in connection with the Enrico Fermi Atomic Power Plant. These unit costs are summarized in Table G-I. For comparison, the values for the Enrico Fermi plant are included.

\section{Results of Fuel-Cycle Cost Estimate}

Table G-II shows the important quantities and calculated values which.led to the total fuel-cycle cost in mils per electrical kilowatt hour. The fuel-cycle cost calculated values are presented in Figure G-1 as a function of electrical power output. The curves show the normal unit cost reductions as total design capacity is increased but indicate further that little cost incentive remains for increasing plant size beyond about 100 electrical megawatts. The high costs at low power levels reflect the dominance of uranium inventory charges and interest on working capital. At higher power levels, corresponding to higher power densities, the fabrication, conversion, and reprocessing costs are chiefly significant; these costs, when expressed in mils per kilowatt hour, are functions of exposure level only: Being constant for a fixed exposure level, they produce the nearly level portions of the curves when they dominate the totals.

The effect of uranium enrichment also is indicated by the graph. Since the basis for the analysis actually was fuel-element diameter, and since the diameters cover a realistic range, the limits of the curves represent approximate limits in power level and cost associated with the 


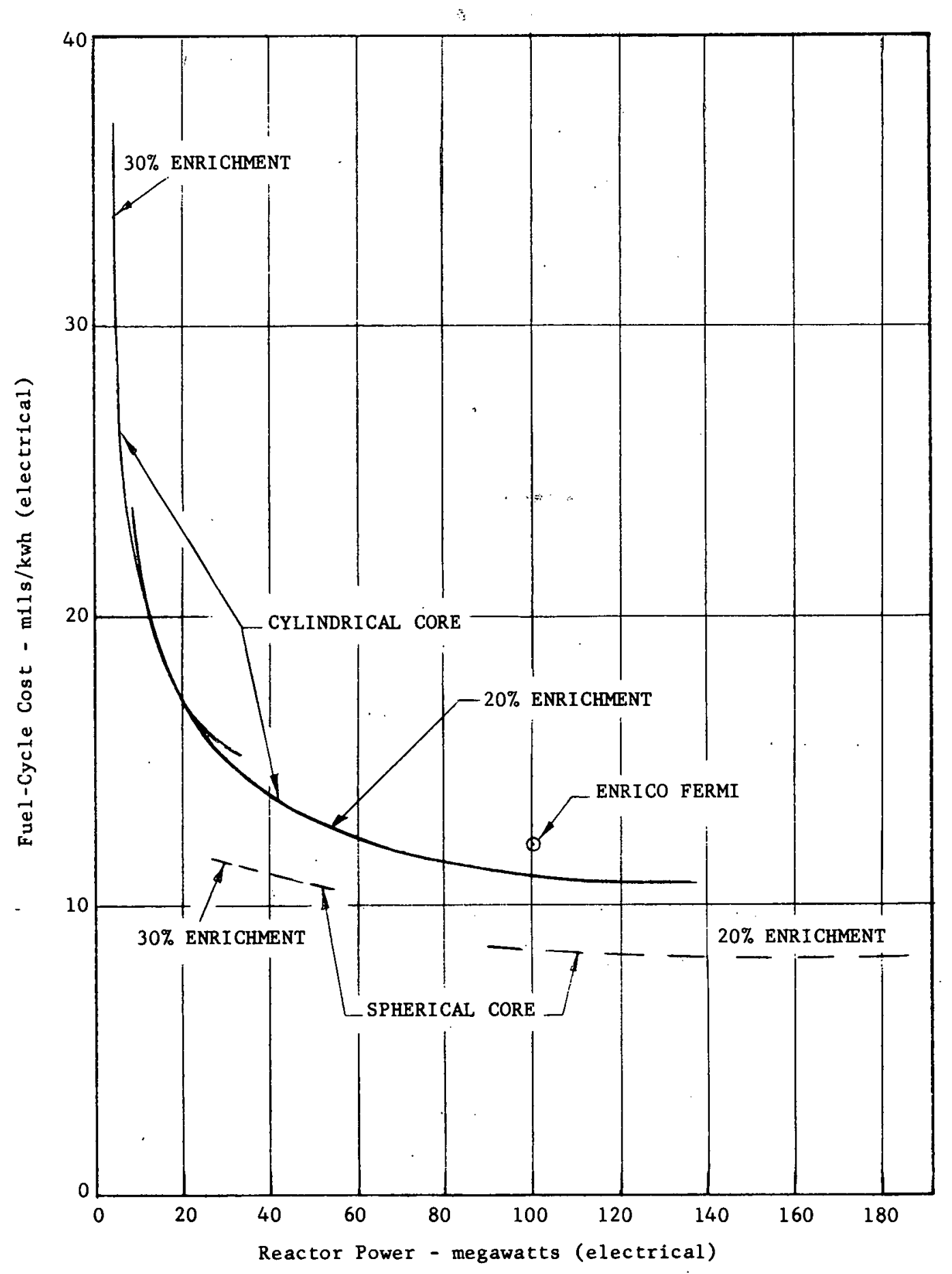

MCBR FUEL-CYCLE COSTS AT VARIOUS POWER LEVELS (PRELIMINARY ESTIMATE) (PLUTONIUM CREDIT AT \$12 PER GRAM)

FIGURE G-1 
various enrichments shown. The curves reveal that high enrichments are required for low-power systems, and vice-versa, and suggest that an economic optimum uranium enrichment exists for any reactor power level.

Two short dotted lines labeled "Spherical Core" lie slightly below the solid lines labeled "Cylindrical Core." These dotted lines represent the effect of the substantially improved power density achievable with a relaxation of the pressure-drop limitation imposed by conventional fuelelement designs. The spherical-core notation refers to a specific core configuration involving a spherical array of tapered fuel elements. The arrangement permits an expanding flow channel, which materially reduces the pressure gradient, thereby improving thermal performance. Note that the fuel-cycle costs are estimated to be approximately 2 mils per kilowatt hour lower than for a corresponding conventional core. The difference stems largely from the reduction in uranium inventory and working capital interest charges, but also partly from a reduction in the total blanket cost arising from the lower leakage characteristic of the spherical-core shape.

The estimated fuel-cycle cost for the sodium-cooled Enrico Fermi plant is indicated at its design power level of 100 electrical megawatts. The preliminary MCBR estimate is not sufficiently accurate to warrant a conclusion regarding the relative magnitudes or the difference between the two cost estimates. A subsequent MCBR fuel-cost estimate indicates that 13.3 mils per kilowatt hour is more realistic than the value shown at 100 megawatts. Future core designs will certainly result in lower fuel-cycle costs for both the MCBR and sodium-cooled reactor systems such as the Fermi plant. 
TABLE G-I

COMPARISON OF UNIT FUEL-CYCLE COSTS

Case

Core geometry.

P1tch-to-d1ameter ratio

Coolant fraction (by vol.)

Structure-fuel alloy ratio (by vol.)

Puel fraction (by vol.

Average power density* (kw/11ter)

Puel enrichment (\%)

Crittcal mass ( $\mathrm{kg})$

Gross reactor power

Therm. mw
Elect. mit

Total fuel mass (kg)

Total $U$ in core $(\mathrm{kg}$

Speclfic power (therm.mw/met. ton)

Puel cycle thmett
Core radius $(\mathrm{cm})$

Blanket outer radius $(\mathrm{cm})$.

Volume of blanket and core (11ters)

Blanket volume (11ters)

Blanket U mass (kg)
Blanket U cost ( $\$$ /cycle $\left.\times 10^{-6}\right)$

Plutonlum produced (gm Pu/kg U-cycle)

Pu at $\$ 12$

Puel $\cos t \cdot(\$ / \mathrm{kg} U)$

Inventory \& working cap1tal charge ( $\$ / \mathrm{kg} \mathrm{U})$

Net fuel cost $(\$ / \mathrm{kg} U)$

$$
\begin{aligned}
& \text { Pu at } \$ 12 \\
& \text { Pu at } \$ 30
\end{aligned}
$$

Net fuel cost ( $\$ 1000 /$ year)

$$
\text { Pu at } \$ 12
$$

Blanket cost ( $\$ 1000 /$ year)

Puel cycle cost ( $\$ /$ year)

$$
\begin{aligned}
& \text { Pu at } \$ 12 \\
& \text { Pu at } \$ 30
\end{aligned}
$$

Fuel cycle coot (m118/kwh)

Pu at $\$ 12$

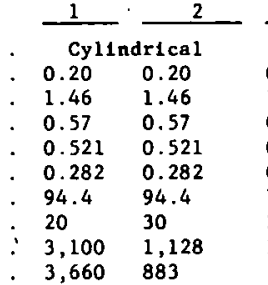

\begin{tabular}{l}
\multicolumn{1}{c}{3} \\
\hline 0.25 \\
1.34 \\
0.48 \\
0.416 \\
0.368 \\
72.7 \\
20 \\
1,537 \\
1.390
\end{tabular}

$345.5 \quad 83.4$

$138.1 \quad 33.4$

$15,800 \quad 4,180$

$\begin{array}{ll}15,500 & 3,760 \\ 22.25 & 22.20\end{array}$

$\begin{array}{ll}563 & 563 \\ 83.4 & 50.9\end{array}$

83.450 .9

$\begin{array}{ll}14,920 & 6,450 \\ 11,260 & 5,567\end{array}$

$11,260 \quad 5,567$

$7,320 \quad 3,620$

$\begin{array}{ll}137,000 & 67,600 \\ 28.75 & 14.18\end{array}$

$1.06 \quad 1.15$

$12.50 \quad 13.59$

$\begin{array}{ll}131.30 & 142.60 \\ 356.50 & 387.00\end{array}$

$\begin{array}{ll}631.38 & 688.16 \\ 358 & 533\end{array}$

$858.08 \quad 1,078.51$

$\begin{array}{ll}8,610 & 2,620 \\ 6,350 & 2,020\end{array}$

$\begin{array}{ll}6,350 & 2,020 \\ 1,860 & 917\end{array}$

$\begin{array}{ll}10,470 & 3,537 \\ 8,210 & 2,937\end{array}$

$\begin{array}{ll}10.8 & 15.1 \\ 8.5 & 12.52\end{array}$

101.0
40.4

8,530

7,680

950

60.3
110.3

110.3
8,490
7,100
4,600

4,610

86,300
24.40

1.15
$.59 \quad 14.5$

$\begin{array}{llll}.60 & 152.50 & 148.40 & 158.80\end{array}$

\begin{tabular}{|c|c|}
\hline \multicolumn{2}{|c|}{ Cyl1ndrical } \\
\hline 0.35 & 0.35 \\
\hline 1.15 & 1.15 \\
\hline 0.32 & 0.32 \\
\hline 0.297 & 0.297 \\
\hline $\begin{array}{l}0.525 \\
44.0\end{array}$ & $\begin{array}{l}0.525 \\
44.0\end{array}$ \\
\hline 20 & 30 \\
\hline
\end{tabular}

\begin{tabular}{l}
$43.50 \quad 403.50 \cdot 431.00$ \\
\hline
\end{tabular}

$\begin{array}{llll}631.38 & 688.16 & 631.38 & 688.16 \\ 515 & 763 & 730 & 1,080\end{array}$

$\begin{array}{ll}20 & 30 \\ 736- & 368\end{array}$

$\begin{array}{ll}20.6 & 6.88 \\ 8.23 & 2.79\end{array}$

$8,090 \quad \ldots 1,360$
3,680

$\begin{array}{ll}3,680 & 1,225 \\ 5.60 & 5.63\end{array}$

$2230 \quad .2230$

$\begin{array}{ll}42.0 & 29.1 \\ 42.0 & 79.1\end{array}$

$\begin{array}{ll}4,900 & 3,110 \\ 4,434 & 2,955\end{array}$

$2,880 \quad 1,920$

$\begin{array}{ll}53,900 & 35,900 \\ 28.40 & 18.92\end{array}$

$\begin{array}{ll}1.23 & 1.31 \\ 14.51 & 15.48\end{array}$

162.20

$\begin{array}{llll}403.50 & 431.00 & 387.00 & 413.50\end{array}$

$\begin{array}{llllll}1,035 & -688.16 & 631.38 & 688.16 & 631.38 & 688.16 \\ 1,527 & 226 & 339 & 194 & 292\end{array}$

$\begin{array}{lllllllllll}1,003.28 & 1,298.66 & 1,212.98 & 1,609.76 \\ 888.88 & 1,037.66 & 957.88 & 1,337.56 & 1,513.98 & 2,053.16 & 708.73 & 868.46 & 682.28 & 827.41 \\ 1,252.88 & 1,774.36 & 453.63 & 596.26 & 437.88 & 566.41\end{array}$

$\begin{array}{llllllllll}2,965 & 1,102 & 1,537 & 629 & 910 & 411 & 4,615 & 1,750 & 9,285 & 3,260\end{array}$ $\begin{array}{llllll}2,325 & 881 & 1,212 & 523 & 754 & 356 \\ 938 & 545 & 625 & 397 & 464 & 310\end{array}$

$\begin{array}{lllllll}3,903 & 1,647 & 2,162 & 1,026 & \cdot 1,374 & 721\end{array}$

$\begin{array}{ll}13.8 & 20.1 \\ 11.55 & 17.4\end{array}$

17.9

27.25

$23.8 \quad 37.0$

NOTBS

* Adjusted for peak-to-average ratio $=3.5$.

etry (cylindrical cases only)

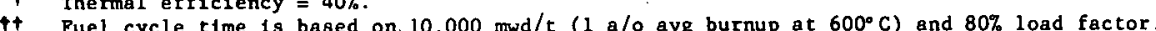

1 Rlanket urantum volume various alze cores. Average taken as $65 \%$. 
TABLE G-II

CASE STUDIES - VARIOUS MCBR CORE CONFIGURATIONS

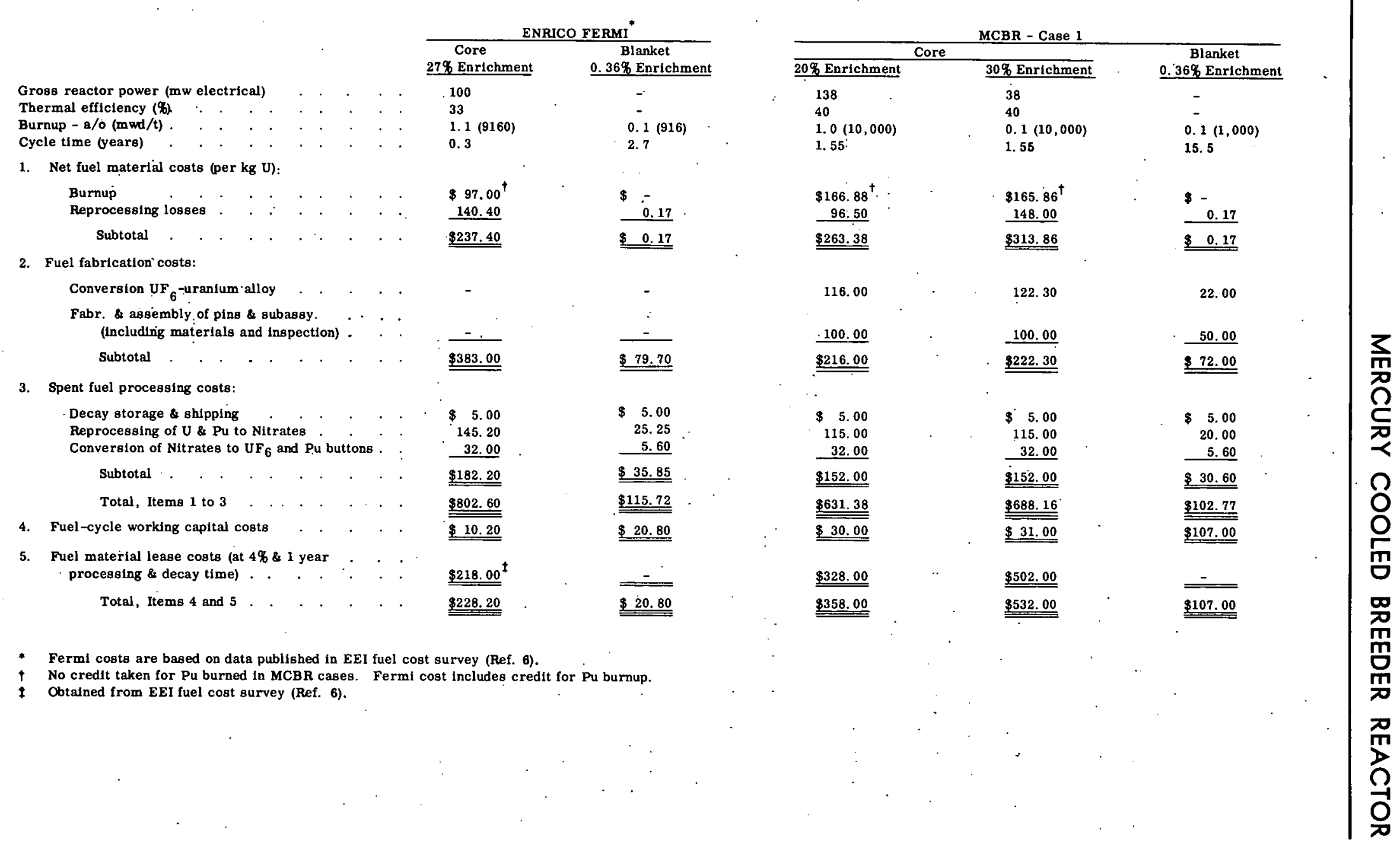




\section{APPENDIX H \\ CAPITAL COST ESTIMATE \\ 1959 Basis}

A detailed breakdown of the capital cost estimate for the $100 \mathrm{mw}(\mathrm{e}) \mathrm{MCBR}$ power plant is presented in Tables H-I, H-II, and H-III. Presentday values have been used for the estimates of material costs. The labor rates and productivity are representative of the midwest U.S.A.

For the major items of equipment, estimates or approximate quotes were obtained from manufacturers and fabricators with specific experience. The Chicago Bridge and Iron Company supplied an estimate for the erected cost of containment shell and air locks. Yuba Consolidated Steel Corporation furnished a preliminary quote on the pressure vessel and indicated that their shop could handle the job, including annealing, with no difficulty. Yuba indicated that they are well experienced in the fabrication of such vessels using the $5 \%$ chromium steel specified. The Industrial Division of American-Standard provided the basis for the cost estimate of the doublewalled heat exchanger. Other manufacturers and suppliers provided help and assistance in obtaining cost information. All such help is gratefully acknowledged.

The drawings describing this plant are preliminary and incomplete in that they represent a conceptual design. They have been used as the basis for this estimate in that the individual items in the Tables were taken from them.

The turbine-generator portion of the plant has been estimated on a $\$ / \mathrm{kw}$ basis from statistical data taken from actual costs of various electrical power plants of similar capabilities in the U.S.A. ${ }^{6}$ Costs have been escalated to date.

Auxiliary services for the reactor plant have been held to a minimum, since the design and estimate are intended to reflect the cost of a typical plant, not of the first experimental version. The cask car of the Enrico Fermi plant has been omitted from capital costs, and it is contemplated that its function will be fulfilled by a maintenance subcontract. Also, it has been assumed that the shop building and its equipment will be supplied from the $\$ / \mathrm{kw}$ estimated for the turbine-generator portion of the plant and that no additive space or equipment will be required for reactor operation.

The site has been assumed to be on relatively level ground with good soil conditions; average climatic conditions in the midwest have been assumed. The cost of land and land rights, Federal Power Commission Account Number 310 , is estimated to be. $\$ 186,000$. 


\section{TABLE H-I: \\ DETAILED BREAKDOWN \\ FEDERAL POWER COMMISSION ACCOUNT NUMBER 311}

Reactor Plant Structures \& Improvements Reactor Containment Vessel-75 OD $\times 115^{\prime}$,

Field Assistance to Subcontractor.

On \& Off Charges

Testing \& Inspection

Detail Allowance
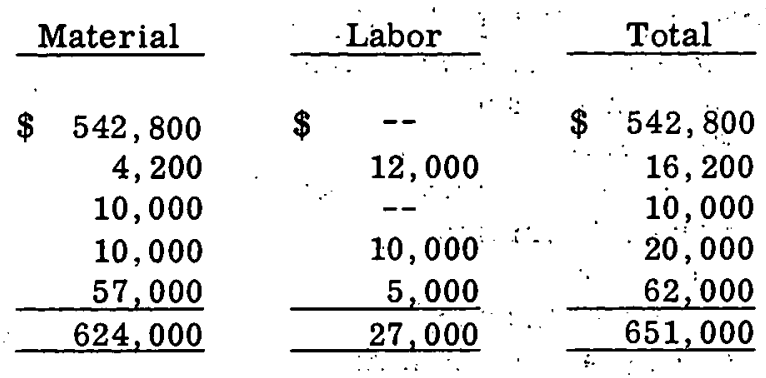

Structural Steel in Containment Vessel.

Reactor Vessel;', Supports, Elevator Shaft, Crane Supports

Stairs, Handrails, Platforms

Grating

Misc. Structural Steel

Detail Allowance

\section{$\underline{\text { Subtotal }}$}

33,000

7,500

5,000

7,500

8,000

61,000

Structural Concrete in Containment Vessel

Containment Vessel Foundations

\section{Inside Base}

Slabs \& Walls

Imbedded Iron

Internal Finishing

Hardware \& Specials

Détail Allowancé

$$
\because \text { Subtotal }
$$

\section{Excavation - Machine}

$$
\text { - Rock }
$$$$
\text { - Hand }
$$

Disposal

Backfill

"Imported Fill

Concrete

Special-Support Structural Steel

$$
\because \text { : Subtotal. }
$$

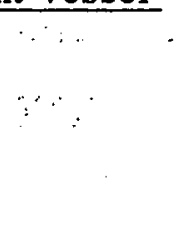

$\therefore$

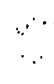

$\because \because \quad \because$ Subtotal
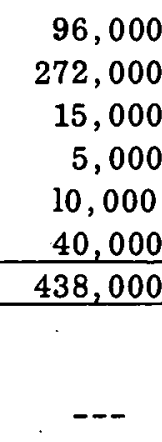

---

$--$

$---$

$---$

10,000

102,000

2,000

114,000

$$
\begin{aligned}
& 5,500 \quad 38,500 \\
& 2,500 \therefore 10,000 \\
& 1,000 \quad 6,000 \\
& 7,500 \\
& 15,000 \\
& 16,000 \\
& \frac{8,000}{24,000} \\
& 85,500
\end{aligned}
$$

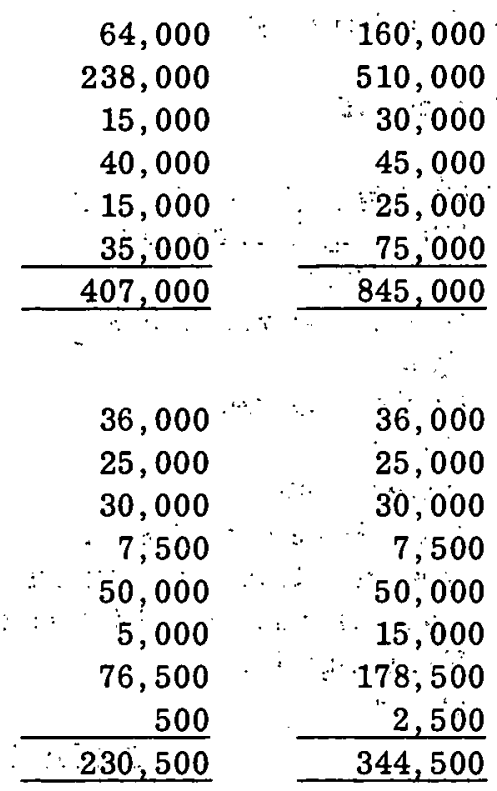


TABLE H-I

(Contunued)
Containment Vessel Facilities

Exhaust Stack \& Foundation

Air Intake Stack

Electrical

Painting \& Protection (outside)

Paint \& Trim (inside)

Floor Finish

Drains \& Plumbing

Heating and Ventilating

Other

\section{$\underline{\text { Subtotal }}$}

Waste Disposal Building - $30^{\prime} \times 40^{\prime}$

Heating \& Hoist

Foundation Concrete

Subtotal

${ }^{*}$ Control Room $-20^{\prime} \times 20^{\prime}$

*Office Building

Passageway

\section{*Yard Services \& Facilities}

Clearing \& Exchange

Fine Grading

Roads \& Paved Areas

Spur

Curbs \& Gutters

Fence

Water System

Fire Protection System

Sewers - Sanitary \& Storm

Underground Yard Electrical

Yard Lighting

Other

Subtotal

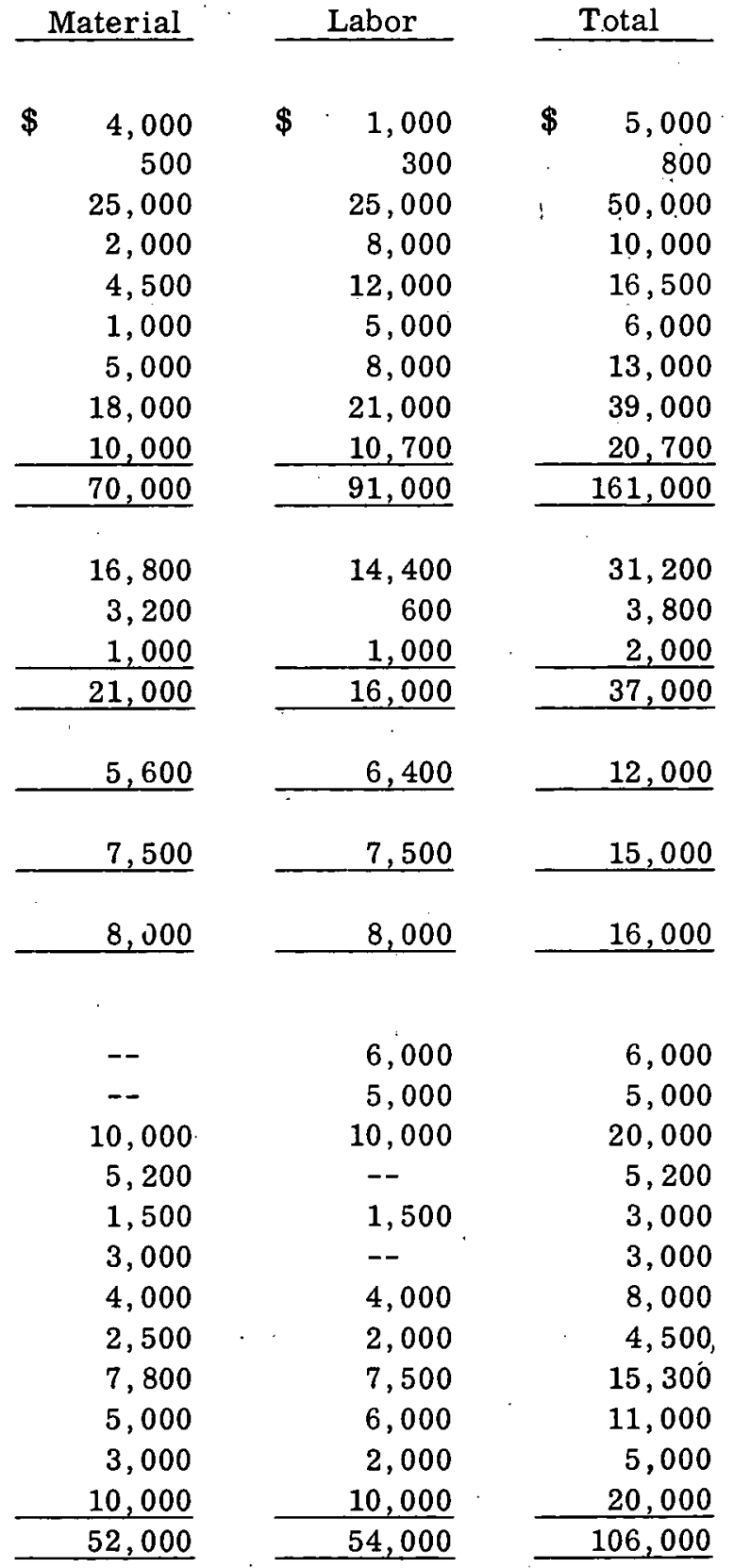


TABLE H-I

(Concluded)

Direct Field Costs

Prorates

Total Field Costs

\begin{tabular}{|c|c|c|}
\hline Material & Labor & Total \\
\hline$\$ 1,401,100$ & $\$ \cdot 871,900$ & $\$ 2,273,000$ \\
\hline 70,200 & 697,500 & 767,000 \\
\hline$\$ 1,471,300$ & $\$ 1,569,400$ & $\$ 3,040,700$ \\
\hline
\end{tabular}

219,000

717,000

$3,976,800$

795,200

$\$ 4,772,000$

TOTAL - Account 311

*Incremental costs only over "conventional" power station. 


\section{MERCURY COOLED BREEDER REACTOR}

\section{TABLE H-II \\ DE TAILED BRE AKDOWN \\ FEDERAL POWER COMMISSION ACCOUNT NUMBER 312}

\section{Reactor Plant Equipment}

Reactor Vessel.

Shell, Flanges, Nozzles, Shield Plates,

Support Plates, Poison Elements,

Distribution Ring, Control-Rod Thimbles

Holddown Assembly \& Top Shield Plate

Test and Special Cleanup

Detail Allowance

\section{Subtotal}

Other Vessels and.Tanks

Sand/Water Shield Tank

Reactor Plant Vessels: D-1 to D-6

Waste Disposal Vessels:

Hot Cell

Water Tank, Demineralizer, Low-Level Waste Tank

Autoclave with Vacuum Pumps, Solid-

Waste Storage Tank

Test \& Special Cleanup

$\underline{\text { Subtotal }}$

Condenser and Coolers

$\mathrm{E}-1 \mathrm{~A}, 1 \mathrm{~B}, 1 \mathrm{C}$ Condenser Boilers

(including Spare Bundle)

E-2 Shutdown Cooler

E-3A \& 3B Shield Coolant Coolers

E-4 Relief Condenser

E-5 Mercury Recovery Condenser

E-6 Water Removal Condenser

Detail Allowance

Subtotal

$\underline{\text { Heaters }}$

H-1A \& 1B Startup Heaters

H-2 Mercury Recovery Furnace

H-3 Cleanup Drum Heater

H-4 Sump Heater

Miscellaneous

$\underline{\text { Subtotal }}$

\section{Material}

$\$ 165,000$

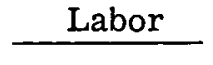

$\$ \quad 11,000$

$\$ 176,000$

$.105,000$

17,500

$-\quad 2,000$

28,500

318,000

$\begin{array}{r}9,000 \\ 2,500 \\ 10,000 \\ 1,500 \\ \hline 34,000 \\ \hline\end{array}$
$\therefore \quad 114,000$
20,000
12,000
- 30,000 .
352,000

85,000

64,400

42,500

12,200

14,000

12,300

5,000

9,600

1,000

179,000

$$
8,000
$$

7,000

5,000

87,000

127,500

76,600

26,300

13,000

16,600

6,000

266,000

$1,095,000$

20,000

$.1,115,000$

50,000

4,000

96,000

500

300

249,200

$1,495,000$

$$
2,500
$$

800

16,000

100

100

3,500

43,000

$$
\begin{array}{r}
52,500 \\
4,800 \\
112,000 \\
600 \\
400 \\
252,700 \\
\hline 1,538,000 \\
\hline
\end{array}
$$

$, 2,200$

1,000

300

300

200

4,000
3,200

1,500

500

500

300

6,000 
TABLE H-II

(Continued)

Pumps and Drivers

P-1A, 1B, 1C Mercury Recirculating Pumps

P-2 Mercury Shutdown Pump

P-3A \& 3B Auxiliary Mercury Pumps

P-4 Mercury Sump Pump

P-5A \& 5B Shield Coolant Pumps

P-6 Reactor Evaculation Pump

Test, Align, Special Cleanup

Detail Allowance

\section{Subtotal}

Machinery

K-1 Fuel Decay Storage Tank

50-Ton Bridge Crane

Equipment Hoist

Fuel Transfer Mechanism \& Cask (2 req'd)

Fuel Transfer Indexing Plate

Manipulators for Hot Cell

Other Machinery

Miscellaneous Hoists, Dollies, Davits

Control Rods \& Dirives

Subtotal

\section{Instrumentation}

Instruments (excluding nuclear)

Nuclear Instruments \& Steam Circuit

Instrument Board \& Console

Transmitters

Mercury Detectors

Control-Rod Position Indicators

Flow-Ratio Controllers \& Special Instruments

Health Physics, Equipment: Hand \& Fast Counter, Gate Monitor, Constant Air Monitor, Sample Counter, Health

Physics Instruments and other

Relief Valves

Control Valves - MC Valves with Piping

Other Materials: Tubing, Small Valves, Racks

Test \& Special Cleanup

Detail Allowance

\section{Subtotal}

$\begin{array}{r}\text { Material } \\ \hline \$ 60,000 \\ 10,000 \\ 10,000 \\ 7,000 \\ 2,000 \\ 5,000 \\ 1,000 \\ 9,200 \\ \hline 104,200 \\ \hline\end{array}$

$\begin{array}{r}\text { Labor } \\ \hline \$ \quad \\ 9,000 \\ 2,000 \\ 2,400 \\ 600 \\ 600 \\ 500 \\ 2,000 \\ 1,700 \\ \hline 18,800 \\ \hline\end{array}$

\begin{tabular}{|c|c|}
\hline & otal \\
\hline & \\
\hline$\$$ & 69,000 \\
\hline & 12,000 \\
\hline & 12,400 \\
\hline . & 7,600 \\
\hline & 2,600 \\
\hline & 5,500 \\
\hline & 3,000 \\
\hline & 10,900 \\
\hline & 123,000 \\
\hline
\end{tabular}

10,000

55,000

40,000

156,000

39,000

30,000

90,000

275,000

695,000

$\begin{array}{r}5,000 \\ 10,000 \\ 5,000 \\ 3,000 \\ 2,000 \\ 10,000 \\ \\ 10,000 \\ 75,000 \\ \hline 120,000 \\ \hline\end{array}$

65,000

31,200

26,600

10,500

4,500

18,100

5,000

18,000

19,000

5,000

50,000

5,000

25,000

283,000
19,500

16,000

5,000

3,500

4,500

7,800

1,000

.

$$
4,200
$$

2,000

500

40,000

15,000

12,000

131,000
15,000

65,000

45,000

159,000

41,000

40,000

100,000

350,000

815,000

84,500 :

47,200

31,600

14,000

9,000

26,000

6,000

22,200

21,000

5,500

90,000

20,000

37,000

414,000 


\section{MERCURY COOLED BREEDER REACTOR}

TABLE H-II

(Continued)

Mercury Vapor and Liquid Piping Systems

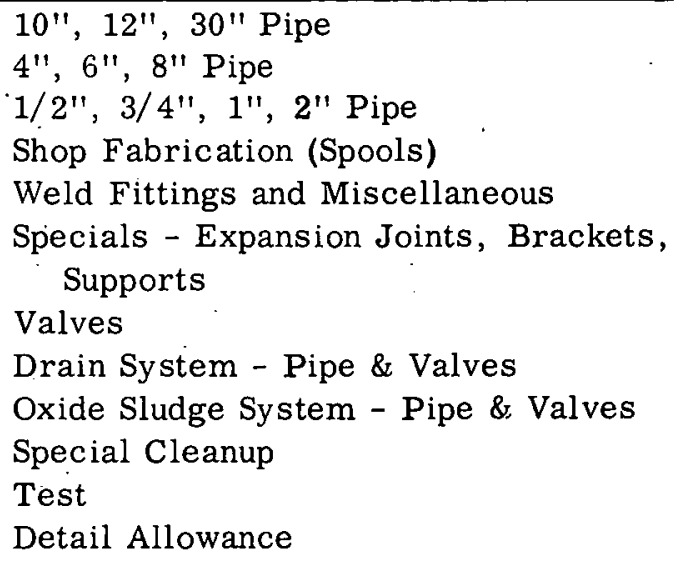

Weld Fittings and Miscellaneous

Specials - Expansion Joints, Brackets, Supports

Valves

Drain System - Pipe \& Valves

Oxide Sludge System - Pipe \&. Valves

Special Cleanup

Test

Detail Allowance

\section{$\underline{\text { Subtotal }}$}

Demineralized Water Piping System

$2-1 / 2$ " Sch. 40 Pipe Coils

2-1/2" \& 3" Pipe \& Fittings

Valves

Specials \& Supports

Test

\section{$\underline{\text { Subtotal }}$}

Cooling Water Piping System

2" - 4" Sch. 40 Pipe \& Fittings

Valves

Small Valves, Fittings, Specials

Brackets \& Supports

Test

\section{$\underline{\text { Subtotal }}$}

Feedwater Piping System

4", 6", 10" Sch. 120 Pipe

Fittings, Bolts, Gaskets

Valves

Small Pipe, Valves, Fittings

Hangers, Expansion Joints, Specials

Test

$\underline{\text { Subtotal }}$

\section{Material}

$\$ 63,200$

37,300

6,800

86,700

80,000

20,000

98,000

7, 000

7,000

6,000

3,000

40,000

455,000

19,500

3,300

2,500

500

200

26,000

3,800

1,000

500

600

100

6,000

16,600

5,000

4,500

2,000

4,500

400

33,000
Labor

$\$ 17,800$

14,200

8,700

$--$

200,000

20,000

10,000

8,000

4,300

15,000

7,000

20,000

145,000

$\begin{array}{r}81,000 \\ 51,500 \\ 15,500 \\ 86,700 \\ 100,000 \\ \\ 40,000 \\ 108,000 \\ 15,000 \\ 11,300 \\ 21,000 \\ 10,000 \\ 60,000 \\ \hline 600,000 \\ \hline\end{array}$

7,500

1,200

300

500

500

10,000

$\begin{array}{r}27,000 \\ 4,500 \\ 2,800 \\ 1,000 \\ \quad 700 \\ \hline 36,000 \\ \hline\end{array}$

1,900

100

300

500

200

3,000

5,700

1,100

800

1,100

300

9,000

$\begin{array}{r}300 \\ 9,000 \\ \hline\end{array}$

3,100

19,700

6,000

5,000

500

2,000

4,000

8,000

900

1,300

44,000 
TABLE H-II

(Concluded)
Steam Piping System

$16^{\prime \prime} \times 1.88^{\prime \prime}$ Wall Forged \& Bored Pipe

$10^{\prime \prime} \times 1.25^{\prime \prime}$ Wall Forged \& Bored Pipe

Special Fittings

Valves

Small Pipe, Valves, : Fittings

Specials - Attemperator, Orifice Runs, etc.

Hangers, Supports, Expansions

Test

\section{Subtotal}

Other Direct Costs

Insulation

Miscellaneous Structural

Electrical

Painting

Direct Field Cost

Prorates

Total Field Cost

Contractor's Fee

Startup

Mercury (4750 flasks at $\$ 225)$

Engineering, Purchasing, Inspection, \& Hazards Survey

Total Without Contingency

Contingency

TOTAL - Account 312

\begin{tabular}{|c|c|c|c|c|c|}
\hline \multicolumn{2}{|c|}{ Material } & \multicolumn{2}{|c|}{ Labor } & \multicolumn{2}{|c|}{ Total } \\
\hline$\$$ & 40,800 & $\$$ & 5,000 & $\$$ & 45,800 \\
\hline & 12,000 & & 2,000 & & 14,000 \\
\hline & 20,000 & & -- & & 20,000 \\
\hline & 10,000 & & 1,500 & & 11,500 \\
\hline & 4,500 & & 4,000 & & 8,500 \\
\hline & 5,000 & & 1,000 & & 6,000 \\
\hline & 9,000 & & 9,000 & & 18,000 \\
\hline & 700 & & 2,500 & & 3,200 \\
\hline & 102,000 & & 25,000 & & 127,000 \\
\hline
\end{tabular}

$$
\begin{array}{r}
180,000 \\
70,000 \\
250,000 \\
30,000 \\
\hline 4,374,200 \\
218,800 \\
\hline \$ 4,593,000 \\
\hline
\end{array}
$$

340,000

114,000

455,000

170,000

$5,693,000$

$1,274,000$

$6,967,000$

502,000

168,000

$1,069,000$

$1,680,000$

$10,386,000$

$2,077,000$

$\$ 12,463,000$ 


\section{MERCURY COOLED BREEDER REACTOR}

\section{TABLE H-III \\ DETAILED BREAKDO'WN \\ FEDERAL POWER COMMISSION ACCOUNT NUMBERS 314, 315, 316, ÁND PORTIONS OF 311}

Turbine-Generator : Portion of Plant

$\therefore$ Including Turbine-Generator Units;

- Accessory Electrical Units, Miscellaneous

$\therefore$ Power Plant Equipment, Turbinè-Generator

Building, Water. Treatment Equipment and

Building and Site Grading for this Portion

of Plant.

$\$ 12,700,000$

These cases were estimated on an over-all basis by extracting cost data from Tables IX and XV of Reference 58 to obtain an average cost per kilowatt of installed generating capacity. Investment costs have been reduced by the amounts given for the steam boiler plant equipment; the resultant investmant costs have been escalated to 1959 .

\begin{tabular}{|c|c|c|c|c|c|c|c|c|c|c|}
\hline $\begin{array}{l}\text { Station } \\
\quad \text { No. : }\end{array}$ & $\begin{array}{c}\text { First } \\
\text { Operation } \\
\text { Year }\end{array}$ & $\begin{array}{l}\text { Press. } \\
\text { (psi) }\end{array}$ & $\begin{array}{c}\therefore \\
\text { Temp. } \\
\left({ }^{\circ} \mathrm{F}\right)\end{array}$ & $\begin{array}{l}\text { Total } \\
\text { Station } \\
\text { Exclud. } \\
\text { Switch } \\
\text { Yards } \\
(\$ / \mathrm{kw})\end{array}$ & $\begin{array}{l}\text { Land } \\
(\$ / \mathrm{kw})\end{array}$ & $\begin{array}{l}\text { Equip. } \\
(\$ / \mathrm{kw})\end{array}$ & $\begin{array}{l}\text { Boiler } \\
\text { House } \\
(\$ / \mathrm{kw})\end{array}$ & $\begin{array}{l}\text { Power } \\
\text { Gener. } \\
(\$ / \mathrm{kw})\end{array}$ & $\begin{array}{l}\text { Escal. } \\
\text { Factor }\end{array}$ & $\begin{array}{l}\text { 1959-60 } \\
\text { Power } \\
\text { Gener. } \\
(\$ / \mathrm{kw})\end{array}$ \\
\hline 264 & 1952 & 1260 & 900. & 115.15 & 1.86 & 38.42 & 0.30 & 74.57 & 1.55 & 115 \\
\hline 267 & 1950 & 1325 & 950 & 106.84 & 0.16 & 42.17 & 0.30 & 64.21 & 1.75 & 112 \\
\hline 270 & 1952 & 1350 & 900 & 120.30 & 1. 31 & 40.91 & 0.30 & 77.78 & 1.55 & 120 \\
\hline 271 & 1946 & 1350 & 905 & 116.61 & 1.40 & 47.70 & 0.30 & 67.21 & 2. 14 & 143 \\
\hline 272 & 1953 & 1450 & 1000 & 200.75 & 4.56 & 7.8 .20 & 0.30 & 117.69 & 1.52 & 178 \\
\hline 273 & 1951 & 1492 & 1000 & 104.14 & - & 42.84 & 0.30 & 61.00 & 1.59 & 97 \\
\hline Average & & & & & $\underline{\underline{1.86}}$ & & & & & 127 \\
\hline
\end{tabular}




\section{APPENDIX J}

\section{MERCURY AVAILABILITY AND PRICE}

The mercury requirement for the $100 \mathrm{mw}(\mathrm{e}) \mathrm{MCCBR}$ plant has been estimated at 360,000 pounds, or 4750 flasks ( 1 flask $=76$ pounds of mercury). An investigation has been made to verify the availability of such a quantity of mercury and to establish a reasonable presentday price.

The total world production of mercury in 1958 was 248,000 flasks, of which 38,067 were produced in the United States. $^{59}$ Similar data for selected years from 1877 to 1958 are reproduced ${ }^{60}$ in Table J-I. In recent years; it is seen that the United States has contributed an average of about $10 \%$ of the world production. In addition to domestic production, imports into the United States totaled 47,316 flasks in 1956, 42,005 flasks in 1957, and 30,158 flasks in 1958, so that combined production and imports for the past three years average approximately 72,000 flasks per year. As can be seen, the mercury requirement for a $100 \mathrm{mw}(\mathrm{e}) \mathrm{MCBR}$ is about $6.5 \%$ of the average annual United States consumption during the past three years. Since the normal consumption and production in the United States have varied considerably more than $6.5 \%$ over the past few years, it may be concluded that mercury in sufficient quantity to fill the requirements of many large MCBR power plants constructed over the next few decades is readily available.

The price of mercury is governed largely by world demand but is not entirely free of influences from large government purchases and price support programs. ${ }^{60}$ An attempted acquisition of several thousand flasks at one time would produce significant price elevation, and the required quantity would not be available on short notice, since suppliers customarily do not maintain large inventories. The price of mercury over the past several years is shown in Figure $J-1$. Note that a large and rapid price increase occurred in 1951 and again in 1954. These fluctuations coincide with large United States Government purchases for a classified AEC project and for strategic stockpiling. The total quantities involved in these purchases have not been disclosed, but the fractions reported were of the order of 50,000 flasks. 60 . The known quantities are themselves well in excess of the MCBR requirements.

In addition to the price data shown in Figure $J-1$, quotations were obtained from several United States mercury producers in an effort to establish. a presentday mercury price for estimating purposes. Table J-II summarizes the quotations received. All prices are for technical-grade, prime, virgin mercury ( $99.9 \%$ pure) and assume that mercury will be purchased carefully in small lots over a period of many months. 
TABLE. J-I

PRIMARY MERCURY: UNITED STATES AND WORLD PRODUCTION, SELECTED YEARS 1877 to 1957

(In flasks containing 76 pounds)

\begin{tabular}{|c|c|c|c|c|c|c|}
\hline Year & $\begin{array}{l}: \\
: \\
: \\
:\end{array}$ & $\begin{array}{l}\text { United } \\
\text { States }\end{array}$ & $\begin{array}{l}\vdots \\
: \\
\vdots \\
\vdots\end{array}$ & World & $\begin{array}{l}: \\
: \\
\vdots \\
:\end{array}$ & $\begin{array}{l}\text { Ratio of } \\
\text { United States } \\
\text { to world } \\
\text { production }\end{array}$ \\
\hline & $:$ & Flasks & & Flasks & $:$ & Percent \\
\hline 1877 & $:$ & 79,917 & : & 135,000 & : & 59.2 \\
\hline 1882 & $:$ & 53,079 & : & 116,200 & : & $45 . .7$ \\
\hline 1921 & $:$ & 6,256 & : & 62,742 & : & 10.0 \\
\hline 1928 & $:$ & 17,870 & $:$ & 149,083 & : & 12.0 \\
\hline 1933 & $:$ & 9,669 & $:$ & 59,828 & : & 16.2 \\
\hline 1936 & : & 16,569 & : & 123,878 & : & 13.4 \\
\hline 1937 & $:$ & 16,508 & $:$ & 130,661 & : & 12.6 \\
\hline 1938 & : & 17,991 & : & 150,000 & : & 12.0 \\
\hline 1939 & $:$ & 18,633 & : & 145,000 & : & 12.8 \\
\hline 1940 & $:$ & 37,777 & : & 210,000 & : & 18.0 \\
\hline 1941 & $:$ & 44,921 & $:$ & 275,000 & : & 16.3 \\
\hline 1942 & $:$ & 50,846 & : & 265,000 & $:$ & 19.2 \\
\hline 1943 & $:$ & 51,929 & : & 236,000 & : & 22.0 \\
\hline 1944 & $:$ & 37,688 & : & 163,000 & : & 23.1 \\
\hline 1945 & : & 30,763 & $:$ & 131,000 & : & 23.5 \\
\hline 1946 & : & 25,348 & $:$ & 154,000 & : & 16.5 \\
\hline 1947 & : & 23,244 & : & 168,000 & $:$ & 13.8 \\
\hline 1948 & : & 14,388 & : & 107,000 & : & 13.4 \\
\hline 1949 & : & 9,930 & : & 121,000 & : & $8 . .2$ \\
\hline 1950 & $:$ & 4,535 & $\because$ & 144,000 & : & 3.1 \\
\hline 1951 & : & 7,293 & : & 147,000 & : & $5.0^{\circ}$ \\
\hline 1952 & : & 12,547 & : & 151,000 & : & 8.3 \\
\hline 1953 & $:$ & 14,337 & $:$ & 160,000 & : & 9.0 \\
\hline 1954 & $:$ & 18,543 & : & 182,500 & $:$ & 10.2 \\
\hline 1955 & $:$ & 18,955 & : & 191,500 & : & 9.9 \\
\hline 1956 & : & 24,177 & : & 217,000 & : & 11.1 \\
\hline 1957 & : & 34,625 & $:$ & 237,500 & $:$ & 14.6 \\
\hline 1958 & $:$ & 38,067 & $:$ & 248,000 & $:$ & 15.4 \\
\hline
\end{tabular}

Source: Compiled from official statistics of the U. S. Bureau of Mines.

* This table is presented as Table 15, Reference 60. It is reproduced here in complete form, with the 1958 entry added. 


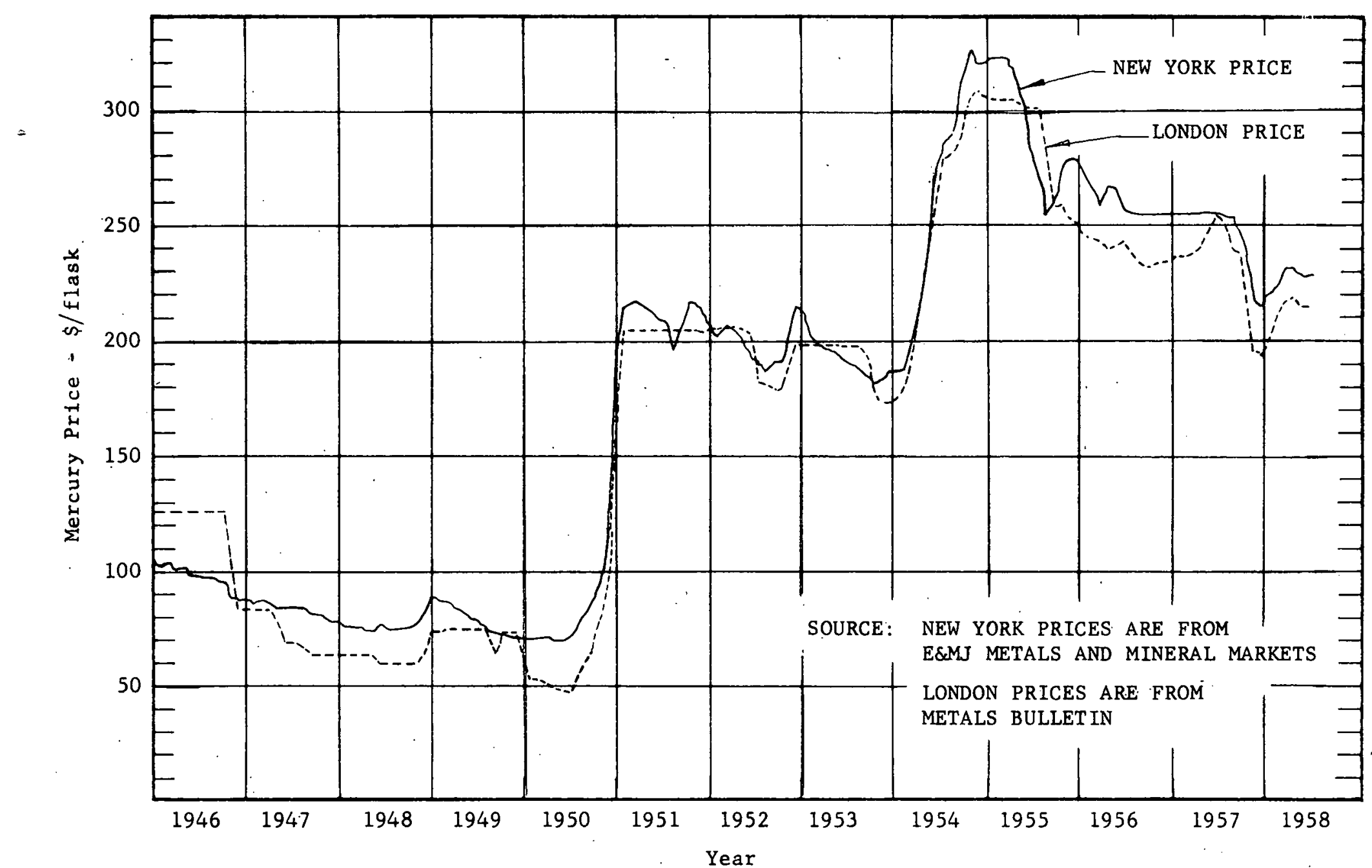

NOTE: THIS GRAPH IS PRESENTED AS CHART 2 IN "MERCURY (QUICKS ILVER)", UNITED STATES TARIFF COMMISS ION REPORT ON INVESTIGATION NO. 23, WASHINGTON, D.C., 1958 (REFERENCE 60). 


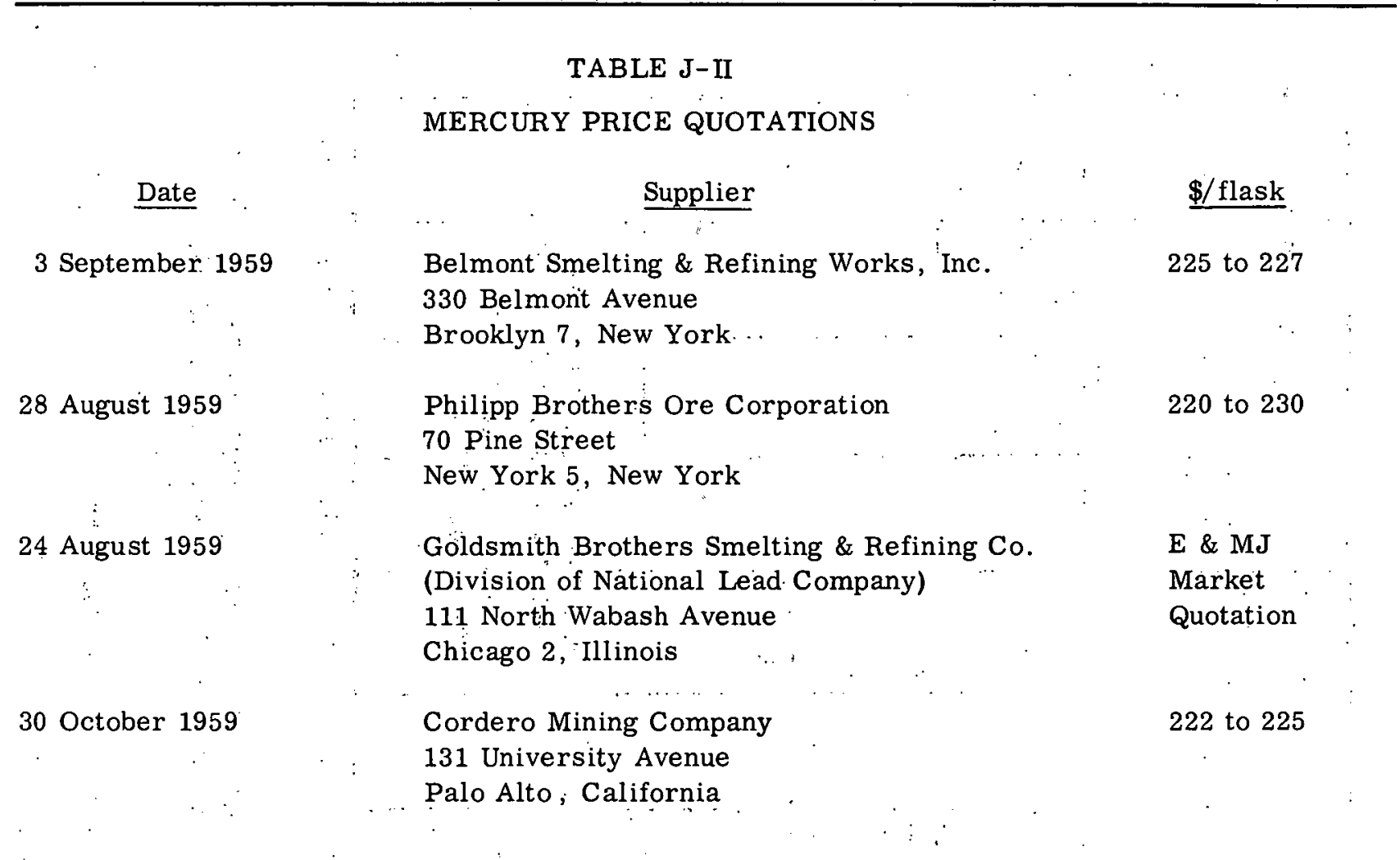

The actual price paid for large orders of mercury bought in the United States is usually determined by bargaining between sellers and buyers, with the New. York price quotation as the basis. On sales through brokers, an additional fee of 1 or $2 \%$ is added. ${ }^{60}$ A reasonable presentday price is assumed to be $\$ 225$ per flask. 


\section{APPENDIX K}

\section{EQUIPMENT DESIGN DATA - REACTOR PLANT}

Process and mechanical design data for the major process equipment comprising the reactor portion of the MCBR Nuclear Power Plant are summarized in Tables K-I through K-IV. Data on the reactor plant equipment are grouped under the following classifications:

$$
\begin{array}{ll}
\text { Table K-I } & \text { - Vessels, } \\
\text { Table K-II } & \text { - Heat Exchangers } \\
\text { Table K-III } & \text { - Pumps and Drivers } \\
\text { Table K-IV } & \text { - Heaters }
\end{array}
$$

For data on miscellaneous mechanical equipment, e.g., cranes, hoists, and fuel handling and storage equipment, refer to the Power Plant Description section of this report. 
TABLE K-I

VESSELS DESIGN DATA

\begin{tabular}{|c|c|c|c|c|c|c|c|c|c|}
\hline Item No. & $\mathrm{R}-1$ & $D-1$ & $\mathrm{D}-2$ & $D-3$ & $\mathrm{D}-4$ & D-5 & D-6 & & - \\
\hline Service & Reactor Vessel & $\begin{array}{l}\text { Mercury Cleanup } \\
\text { Drum }\end{array}$ & Mercury Sump & $\begin{array}{l}\text { Titanium Injection } \\
\text { Chamber }\end{array}$ & $\begin{array}{l}\text { Magnesium Injection } \\
\text { Chamber }\end{array}$ & $\begin{array}{l}\text { Shleld Coolant } \\
\text { Drum }\end{array}$ & $\begin{array}{l}\text { Mercury Level } \\
\text { Drum }\end{array}$ & \multicolumn{2}{|c|}{$\begin{array}{l}\text { Containment Vessel } \\
\text { Drum }\end{array}$} \\
\hline Position & Vertical & Horizontal & Horizontal & Vertical & Vertical & Horizontal & Vertical & \multicolumn{2}{|l|}{ Vertical } \\
\hline Material & $5 \%$ Cr, $\frac{1}{2} \%$ MoSteel & $5 \%$ Cr. $\frac{1}{2} \%$ Mo Steel & $5 \% \mathrm{Cr}, \frac{1}{2} \%$ Mo Steel & $5 \%$ Cr, $\frac{1}{2} \%$ Mo Steel & $5 \%$ Cr, & Carbon Steel & $5 \% \mathrm{Cr}, \frac{1}{2} \%$ Mo Steel & \multicolumn{2}{|c|}{ Carbon Steel } \\
\hline Shell OD (ft) & 10 & 2.5 & 6 & 0.5 & 0.5 & 3.5 & 75 & \multicolumn{2}{|l|}{2} \\
\hline Length (ft). & $20 \div-8 "$ (a) & 9 (b) & 18 (b) & 1 (c) & 2 (c) & 10 (b) & 10 (c) & \multicolumn{2}{|l|}{115 (c) } \\
\hline Shell Thlckness (in.) & 2.00 & 0.625 & 0.875 & Sch. 40 Pipe & Sch. 40 Pipe & 0.25 & Sch. 40 Pipe & \multicolumn{2}{|l|}{0.50} \\
\hline Corrosion Allowance & 0.12 & 0.013 & 0.013 & - & - & 0.125 & - & \multicolumn{2}{|l|}{-} \\
\hline $\begin{array}{l}\text { Head } \\
\text { Type } \\
\\
\text { Thickness (in.) }\end{array}$ & $\begin{array}{l}\text { Ellipsoidal } \\
1.88\end{array}$ & $\begin{array}{l}\text { Ellipeoidal } \\
0.625\end{array}$ & $\begin{array}{l}\text { Ellipsoldal } \\
0.875\end{array}$ & Flange & $\begin{array}{c}\text { Flange } \\
- \\
-\end{array}$ & $\begin{array}{l}\text { Ellipsoidal } \\
0.25\end{array}$ & Caps & \multicolumn{2}{|c|}{$\begin{array}{l}\text { Top: } \\
\text { Hemispherical } \\
\text { Bottom: } \\
\text { Ellipsoidal } \\
\text { Top: } 5 / 16 \\
\text { Btm: } \frac{1}{2} \text { with } \\
7 / 8 \text { knuckle } \\
\end{array}$} \\
\hline Design Press. (psig) & 210 & 225 & 190 & 225 & 225 & ATM & $157 \cdot$ & \multicolumn{2}{|c|}{15} \\
\hline Design Temp. ('F) & 1000 & 1000 & 1000 & 1000 & 1000 & 225 & 1000 & \multicolumn{2}{|l|}{ Amblent } \\
\hline PSV Setting (psig) & 125 & 210 & 115 & - & - & - & 125 & \multicolumn{2}{|l|}{-} \\
\hline Joint Eff. $(\%)$ & 100 & 90 & -90 & - & - & 90 & - & \multicolumn{2}{|l|}{100} \\
\hline $\begin{array}{l}\text { Nozzle } \\
\text { Size (in.) } \\
\text { Rating }\end{array}$ & See Remarks & $\begin{array}{l}4 \\
300\end{array}$ & $\begin{array}{l}4 \\
300\end{array}$ & $\begin{array}{l}1 \frac{1}{2} \\
300\end{array}$ & $\begin{array}{l}1 \frac{1}{2} \\
300\end{array}$ & $\begin{array}{l}4 \\
150\end{array}$ & $\begin{array}{l}12 \\
300\end{array}$ & \multicolumn{2}{|l|}{$\begin{array}{r}- \\
150\end{array}$} \\
\hline $\begin{array}{l}\text { Manways } \\
\text { Size (in.) } \\
\text { No. }\end{array}$ & - & $\begin{array}{l}20 \\
1\end{array}$ & $\begin{array}{l}20 \\
1\end{array}$ & - & - & $\begin{array}{l}20 \\
1\end{array}$ & - & $\frac{\text { Airlocks }}{2}$ & $\frac{\mid \text { Equip. Door }}{1}$ \\
\hline $\begin{array}{l}\text { Stress Relief } \\
\text { Hydrostatic Test Press. } \\
\text { (psig) }\end{array}$ & $\begin{array}{l}\text { Yes } \\
315\end{array}$ & $\begin{array}{l}\text { Yes } \\
338\end{array}$ & 285 & $\begin{array}{l}\text { No } \\
338\end{array}$ & $\begin{array}{l}\text { No } \\
338\end{array}$ & No & $\begin{array}{l}\text { No } \\
235\end{array}$ & \multicolumn{2}{|l|}{$\begin{array}{l}\text { No } \\
30\end{array}$} \\
\hline Remarks & See Dwg. F-182 & $\begin{array}{l}\text { 1. } 5^{\prime} \text { OD } \times 2^{\prime} \text { pot on } \\
\text { top. Settling time } \\
=10 \mathrm{~min} \text {. } \\
\text { Velocity }= \\
0.019 \mathrm{ft} / \mathrm{sec}\end{array}$ & $\begin{array}{l}2^{+} \mathrm{OD} \times x^{\prime} \text { pot on btm. } \\
\text { Flanged pump } \\
\text { connection on top. }\end{array}$ & $\begin{array}{l}\text { Shell - capped pipe. } \\
\text { Top closure - quick- } \\
\text { opening flange. }\end{array}$ & $\begin{array}{l}\text { Shell - capped pipe. } \\
\text { Top closure-quick- } \\
\text { opening flange. }\end{array}$ & ASME Code Vessel & Capped steel pipe. & \multicolumn{2}{|c|}{$\begin{array}{l}\text { ASME Code Veasel } \\
\text { See Dwg8. F-185, F-186, } \\
\text { F-187. ASME 201, } \\
\text { Grade B steel. }\end{array}$} \\
\hline
\end{tabular}

NOTES: (a) Over-all (excluding control rod thimbles)

(b) Tangent-to-tangent length

- 
TABLE K-II

HEAT EXCHANGERS DESIGN DATA

\begin{tabular}{|c|c|c|c|c|c|c|c|c|c|}
\hline Item No. & \multicolumn{3}{|c|}{$E-1 \mathrm{~A}, 1 \mathrm{~B}, 1 \mathrm{C}^{*}$} & \multicolumn{2}{|l|}{ E-2 } & $E-3 A, 3 B^{*}$ & $E-4$ & $E-5$ & $E-6$ \\
\hline Service & \multicolumn{3}{|c|}{ Condenser-Boiler } & \multicolumn{2}{|c|}{ Shutdown Cooler } & $\begin{array}{l}\text { Shield Coolant } \\
\text { Cooler }\end{array}$ & Relief Condenser & $\begin{array}{l}\text { Mercury-Recovery } \\
\text { Condenser }\end{array}$ & $\begin{array}{l}\text { Water-Removal } \\
\text { Condenser }\end{array}$ \\
\hline Type & \multicolumn{3}{|c|}{$\begin{array}{l}\text { Vertical Tube in } \\
\text { Shell }\end{array}$} & \multicolumn{2}{|l|}{ Air Fin } & Tube in Shell & Coil in Box & $\begin{array}{l}\text { Cooling Coil in } \\
\text { Shell }\end{array}$ & $\begin{array}{l}\text { Cooling Coil in } \\
\text { Shell }\end{array}$ \\
\hline Duty $(\mathrm{Btw} / \mathrm{hr})$ & \multicolumn{3}{|c|}{$318,000,000$} & \multicolumn{2}{|l|}{$12,000,000$} & 716,000 & $16,100,000$ & 150,000 & 115,000 \\
\hline $\begin{array}{l}\text { Shell Side: } \\
\text { Fluid Flowing } \\
\text { Flow Rate }(\mathrm{lb} / \mathrm{hr}) \\
\mathrm{T}_{\text {in }}\left({ }^{\circ} \mathrm{F}\right) \\
\mathrm{T}_{\text {out }}\left({ }^{\circ} \mathrm{F}\right) \\
\Delta \mathrm{P}(\mathrm{psi}) \\
\text { Design Press. (psig) } \\
\text { Design Temp. }\left({ }^{\circ} \mathrm{F}\right) \\
\text { Materials }\end{array}$ & $\begin{array}{l}\text { Cond } \\
2,57 \\
920 \\
920 \\
3 \\
125 \\
1000 \\
5 \% 0\end{array}$ & $\begin{array}{l}\text { insing } M \\
.000 \\
, \frac{1}{2} \% \mathrm{MC}\end{array}$ & $\begin{array}{l}\text { ercury } \\
\text { Steel }\end{array}$ & $\begin{array}{l}\text { Air } \\
90 \\
100 \\
- \\
- \\
\text { Carbon Stee }\end{array}$ & 1 & $\begin{array}{l}\text { Demineralized Water } \\
12,000 \\
180 \\
120 \\
3 \\
50 \\
210 \\
\text { Carbon Steel }\end{array}$ & $\begin{array}{l}\text { Cooling Water } \\
7,700,000 \\
965 \\
955 \\
8 \\
125 \\
1000 \\
\text { Concrete }\end{array}$ & $\begin{array}{l}\text { Condensing Mercury } \\
1200 \\
680 \\
680 \\
- \\
10 \\
750 \\
5 \% \mathrm{Cr}, \frac{1}{2} \% \text { Mo Steel }\end{array}$ & $\begin{array}{l}\text { Contaminated Water } \\
110 \\
212 \\
120 \\
\quad- \\
10 \\
250 \\
\text { Carbon Steel }\end{array}$ \\
\hline $\begin{array}{l}\text { Tube Side: } \\
\text { Fluid Flowing }\end{array}$ & \multicolumn{3}{|c|}{ Water \& Steam } & $\begin{array}{l}\text { Condensing } \\
\text { Mercury }\end{array}$ & $\begin{array}{l}\text { Liquid } \\
\text { Mercury }\end{array}$ & Cooling Water & Condensing Mercury & Cooling Water & Cooling Water \\
\hline $\begin{array}{l}\text { Flow Rate }(\mathrm{lb} / \mathrm{hr}) \\
\mathbf{T}_{\text {in }}\left({ }^{\circ} \mathrm{F}\right) \\
\mathbf{T}_{\text {out }}\left({ }^{\circ} \mathrm{F}\right) \\
\Delta \mathrm{P}(\mathrm{psi}) \\
\text { Design Press. (psig) } \\
\text { Design Temp. }\left({ }^{\circ} \mathrm{F}\right) \\
\text { Materials } \\
\end{array}$ & $\begin{array}{l}340, \\
450 \\
900 \\
10 \\
1900 \\
1000 \\
5 \% \mathrm{C} \\
\end{array}$ & 00 & teel & $\begin{array}{lr}770,000 \\
920 \\
920 \\
2 & \\
& 300 \\
& 1000 \\
5 \% \mathrm{Cr}, \frac{1}{2} \% \mathrm{M} \\
\end{array}$ & $\begin{array}{l}360,000 \\
920 \\
200 \\
5 \\
\\
0 \text { Steel } \\
\end{array}$ & $\begin{array}{l}36,000 \\
80 \\
100 \\
3 \\
50 \\
210 \\
\text { Admiralty. } \\
\end{array}$ & $\begin{array}{r}- \\
100 \\
212 \\
- \\
5 \% \mathrm{Cr}, \frac{1}{2} \% \text { Mo Steel } \\
\end{array}$ & $\begin{array}{l}7500 \\
80 \\
100 \\
- \\
50 \\
150 \\
5 \% \mathrm{Cr}, \frac{1}{2} \% \text { Mo Steel } \\
\end{array}$ & $\begin{array}{l}5500 \\
80 \\
100 \\
\quad- \\
50 \\
150 \\
\text { Admiralty }\end{array}$ \\
\hline LMTD & $\begin{array}{l}\text { Pre. } \\
380\end{array}$ & Evap. & $\begin{array}{l}\text { Super. } \\
103\end{array}$ & & & 58 & 800 & 580 & 65 \\
\hline$U_{0}$ & 264 & 537 & 102 & & & 150 & 75 & 75 & 500 \\
\hline Area $\left(\mathrm{ft}^{2}\right)$ & 585 & 1060 & 8660 & & & 82 & 16,000 & 3.5 & 3.5 \\
\hline Tube Size (in.) & $\frac{\text { Inne }}{5 / 8}$ & & $\frac{\text { uter }}{1 / 4}$ & & & $5 / 8$ & 2 OD G-Fin & $\frac{1}{2}$ & $\frac{1}{2}$ \\
\hline Tube Wall (in.) & 0.06 & & 049 & & & 16 BWG. & 0.083 & 0.065 & 0.065 \\
\hline Tube Length (ft) & 16 & 1 & & & & 6 & 12 & 26 & 26 \\
\hline Shell oD (ft) & 8 & 8 & & & & 1 & $13 \times 13 \times 13$ & 2 & 2 \\
\hline Remarks & $\begin{array}{l}\text { Doub } \\
\text { tube } \\
\text { shee } \\
=10\end{array}$ & $\begin{array}{l}\text { e-wall } \\
\text { Double } \\
\text { 30. Area } \\
305 \mathrm{ft}^{2} \text {. }\end{array}$ & $\begin{array}{l}\text { raight } \\
\text { tube } \\
\text { unit }\end{array}$ & $\begin{array}{l}\text { Air f in coo } \\
\text { adjustable } 1 \\
\text { two-speed } f\end{array}$ & $\begin{array}{l}\text { ler w/ } \\
\text { ouvers \& } \\
\text { an. }\end{array}$ & & $\begin{array}{l}\text { Finned sections in } \\
\text { box. }\end{array}$ & $\begin{array}{l}\text { Pipe shell w/ } \\
\text { cooling coil. }\end{array}$ & $\begin{array}{l}\text { Pipe shell. w/ } \\
\text { cooling coil. }\end{array}$ \\
\hline
\end{tabular}

* Data shown applicable to each unit. 
TABLE K-III

PUMPS AND DRIVERS DESIGN DATA

\begin{tabular}{|c|c|c|c|c|c|c|}
\hline Item No. & $\mathrm{P}-1 \mathrm{~A}, 1 \mathrm{~B}, 1 \mathrm{C}$ & P-2 & $P-3 A \& 3 B$ & P-4 & $P-5 A \& 5 B$ & P-6 \\
\hline Service & Mercury. Recirculating. & Mercury Shutdown & Auxillary Mercury & Mercury Sump & Shield Coolant & Reactor Evacuation \\
\hline Pump Type & Vertical Centrifugal & Vertical Centrifugal & Centrifugal & Sump & Ćentrifugal & Vacuum \\
\hline Driver - . & Motor & Motor & Motor & Motor & Motor & Motor \\
\hline Fluid Pumped & Mercury & Mercury & Mercury & Mercury & $\begin{array}{l}\text { Demineralized } \\
\text { Water }\end{array}$ & $\begin{array}{l}\text { Noncondensable } \\
\text { Gases. }\end{array}$ \\
\hline Temperature $\left({ }^{\circ} \mathrm{F}\right)$ & 920 & 920 & $70-920$ & $70-920$ & 100 & 200 \\
\hline Sp. Gr. at P.T. & 12.4 & $12: 4$ & $' 13.5-12.4$ & $13.5-12.4$ & $1: 0$ & 1.0 (air) \\
\hline Viscosity at P.T. (lb/ft-sec) & 1.8 & 1.8 & $3.7-1.8$ & $: 3.7-1.8$ & $1 \mathrm{cp}$ & - \\
\hline Vapor Press. at P.T. (psia) & 110 & 110 & 110 & 110 & 1. & - \\
\hline Pump Speed (rpm) & 1000 & 1750 & 17.50 & 1750 & 1750 & 360 \\
\hline Rated Capacity P. T. (gpm) & 1855 & 390 & 100 & $80:$ & $50 \cdots$ & $60 \mathrm{cfm}$ \\
\hline Differential Press. (psi) & 150 & 190 & 75 & 485 & 39 & $755 \mathrm{~mm} \mathrm{Hg}$ \\
\hline Differential Head (ft) & 27 & 35. & 14 & 90 & 90 & - \\
\hline Suction Press. (psia) & 170 & 250 & $90-265$ & $15-42$ & 16 & $5 \div 760 \mathrm{~mm} \mathrm{Hg}$ \\
\hline Discharge Press. (psia) & 320 & 440 & $.165-340$ & $500-527$ & 55 & 14.7 \\
\hline NPSH $(\mathrm{ft})$ & 12 & 25 & 15 & - & 30 & - \\
\hline Efficiency at Rating (\%) & 75 & 70 & 56 & 50 & 45 & - \\
\hline BHP at Rating & $215 \cdots$ & $60^{\circ}$ & $8.6 \cdots$ & 50 & 2.5 & 15 \\
\hline Material & $5 \% \mathrm{Cr}, 0: 5 \%$ Mo Steel & $5 \%$ Cr, $0.5 \%$ Mo Steel & $5 \%$ Cr, $0.5 \%$ Mo Steel & $5 \% \mathrm{Cr}_{\mathrm{r}}, 0.5 \%$ Mo Steel & Carbon Steel & Cärboñ Steel \\
\hline
\end{tabular}

$5 \%$ Cr, $0.5 \%$ Mo Steel $5 \%$ Cr, $0.5 \%$ Mo Steel

$\therefore$ 
TABLE K-IV

HEATERS DESIGN DATA

\begin{tabular}{|c|c|c|c|c|}
\hline Item No. & $\mathrm{H}-1 \mathrm{~A} \& 1 \mathrm{~B}^{*}$ & $\mathrm{H}-2$ & $\mathrm{H}-3$ & $\mathrm{H}-4$ \\
\hline Service & Startup Heater & $\begin{array}{l}\text { Mercury Recovery } \\
\text { Furnace }\end{array}$ & $\begin{array}{l}\text { Cleanup Drum } \\
\text { Heater }\end{array}$ & Sump Heater \\
\hline Type & Circulation Heater & Electric Retort & Immersion & Immersion \\
\hline Fluid & Mercury & Mercury & Mercury & Mercury \\
\hline$T_{\text {in }}\left({ }^{\circ} \mathrm{F}\right)$ & $70-920$ & 70 & - & - \\
\hline $\mathrm{T}_{\text {out }}\left({ }^{\circ} \mathrm{F}\right)$ & $95-920$ & 680 & - & - \\
\hline Heat Rate (Btw/hr) & 200,000 & 19,000 & 34,150 & 34,150 \\
\hline Power (kw) & 60 & 6 & 10 & 10 \\
\hline Design Temp. $\left({ }^{\circ} \mathrm{F}\right)$ & 1000 & 750 & 1000 & 1000 \\
\hline Design Press. (psig) & 325 & 50 & 225 & 190 \\
\hline
\end{tabular}

* Data shown applicable to each unit. 


\section{NOMENCLATURE}

(Arranged alphabetically by symbols)

Symbol

a

a/o

B

BRI

BRII

$\mathrm{c}_{\mathrm{p}}$

$\mathrm{C}_{\mathrm{c}}$

$\mathrm{C}_{\mathrm{c}}^{\prime}$

$\mathrm{C}_{\mathrm{f}}$

$\mathrm{C}_{\mathrm{i}}$

$\mathrm{C}_{\mathrm{r}}$

D

$D_{f}$

$\mathrm{D}_{\mathrm{h}}$

$\mathrm{D}_{\mathrm{h}}$

$\mathrm{D}_{\mathrm{hl}}$

$\mathrm{D}_{\mathrm{i}}$

D

e,

(e)

E

$E_{\text {L }}$ $\underline{\text { Definition }}$

Unit

abundance of isotope

atomic percent

$\%$

proportionality constant

breeding ratio

theoretical maximum breeding ratio

specific heat at constant pressure

unit fuel cost

unit fuel cost

unit power cost associated with the capital required for fuel-element fabrication

unit power cost associated with uranium inventory

unit revenue rate

diameter

fuel-pin diameter

equivalent diameter of coolant channel in core (defined as four times the flow area divided by the wetted perimeter)

equivalent diameter of coolant channel in upper blanket

equivalent diameter of coolant channel in lower blanket

internal diameter

fuel-element outside diameter

uranium enrichment

electrical

exposure level at discharge

lower boundary of energy group $\mathrm{ft}$

$\mathrm{Btw} / \mathrm{lb}-{ }^{\circ} \mathrm{F}$

mils/kwh(e)

mils/kwh(t)

mils/kwh(e)

mils/kwh(e)

mils/kwh(e)

ft

$\mathrm{ft}$

$\mathrm{ft}$

$\mathrm{ft}$

$\mathrm{ft}$

$\operatorname{kg~U~235/kg~U~}$

$\mathrm{mwd} /$ metric ton $\mathrm{U}$

$\mathrm{Mev}$ 
Symbol

f

fo

$F_{1}$

g

$\mathrm{g}_{\mathrm{c}}$

G

$G_{f}$

$\mathrm{h}$

$\Delta \mathrm{h}$

$\Delta \mathrm{h}_{\text {acc }}$

$\Delta \mathrm{h}_{\mathrm{f}}$

$\Delta \mathrm{h}_{\text {hyd }}$

$i_{i}$

$i_{f}$

$I_{\text {fc }}$

$I_{r}$

j

$\mathrm{k}$

k

$\mathrm{k}_{\mathrm{c}}$

$\mathbf{k}_{\mathbf{f}}$

$\Delta \mathrm{k} / \mathrm{k}\left({ }^{\circ} \mathrm{C}\right)$

$\Delta \mathrm{k} / \mathrm{k}\left(\mathrm{gm} / \mathrm{cm}^{3}\right)$

$\mathbf{K}$
Definition

Unit fluid friction factor [defined as $\left(\frac{d h}{d L}\right)\left(2 g D / V^{2}\right)$ ]

friction factor for liquid flow (Appendix D)

plant load factor

acceleration of gravity

gravitational conversion constant

mass flux

fuel-element geometry factor

unit thermal conductance

head difference

acceleration head difference

friction head loss

hydrostatic head

uranium inventory charge rate

interest on working capital required for fuel element fabrication

total fixed charges

rate of return on investment

energy group

neutron multiplication

thermal conductivity

thermal conductivity of fuel-element cladding

thermal conductivity of fuel

temperature coefficient of reactivity

density coefficient of reactivity

air in mixture $\mathrm{ft} / \mathrm{hr}^{2}$

$\mathrm{lb}-\mathrm{ft} / \mathrm{hr} \mathrm{r}^{2}-\mathrm{lb}$ force

$\mathrm{lb} / \mathrm{hr}-\mathrm{ft}^{2}$

$\mathrm{lb} / \mathrm{ft}^{2}$

$\mathrm{Btu} / \mathrm{hr}-\mathrm{ft}^{2}-{ }^{\circ} \mathrm{F}$

$\mathrm{ft}$ of liquid

$\mathrm{ft}$ of liquid

$\mathrm{ft}$ of liquid

$\mathrm{ft}$ of liquid

years $^{-1}$

years $^{-1}$

$\$ /$ unit time

$\$ /$ unit time

$\mathrm{Btu} / \mathrm{hr}-\mathrm{ft}^{2}\left({ }^{\circ} \mathrm{F} / \mathrm{ft}\right)$

$\mathrm{Btu} / \mathrm{hr}-\mathrm{ft}^{2}\left({ }^{\circ} \mathrm{F} / \mathrm{ft}\right)$

$\mathrm{Btu} / \mathrm{hr}-\mathrm{ft}^{2}\left({ }^{\circ} \mathrm{F} / \mathrm{ft}\right)$

$\left({ }^{\circ} \mathrm{C}\right)^{-1}$

$\left(\mathrm{gm} / \mathrm{cm}^{3}\right)^{-1}$ 


\section{MERCURY COOLED BREEDER REACTOR}

\begin{tabular}{|c|c|c|}
\hline Symbol & $\underline{\text { Definition }}$ & Unit \\
\hline $\mathrm{L}$ & length & $\mathrm{ft}$ \\
\hline $\mathrm{L}_{\mathrm{b}}$ & thickness of upper blanket & $\mathrm{ft}$ \\
\hline $\mathrm{L}_{\mathrm{bl}}$ & thickness of lower blanket & $\mathrm{ft}$ \\
\hline $\mathrm{L}_{\mathrm{c}}$ & boiling length of core & $\mathrm{ft}$ \\
\hline $\mathrm{L}_{\mathrm{nc}}$ & leakage from core & \\
\hline M & mass of uranium in core & $\mathrm{kg}$ \\
\hline$M_{c}$ & mass of $U 235$ in core & $\mathrm{kg}$ \\
\hline $\mathrm{M}_{\mathrm{t}}$ & total mass of $U 235$ required for operation of reactor & \\
\hline $\mathrm{n}_{\mathrm{f}}$ & fraction of fuel in fabrication & \\
\hline$n_{s}$ & fraction of fuel in storage & \\
\hline$N_{c}$ & total number of captures in core and blanket & \\
\hline $\mathrm{N}_{\mathrm{f}}$ & total number of fissions in core and blanket & \\
\hline $\mathrm{p}$ & pressure & psia \\
\hline$p_{c}$ & critical pressure & psia \\
\hline$\Delta p_{\text {acc }}$ & acceleration pressure difference & psi \\
\hline$P_{d}$ & power density & $\mathrm{kw} / \mathrm{liter}$ \\
\hline $\mathrm{P}_{\mathrm{e}}$ & net station power & $k w(e)$ \\
\hline$P_{S}$ & average specific power & $\mathrm{kw}(\mathrm{t}) / \mathrm{kg} \mathrm{U}$ \\
\hline$P_{t}$ & reactor thermal power & $k w(t)$ \\
\hline q & heat transfer rate & $\mathrm{Btu} / \mathrm{hr}$ \\
\hline$q^{\prime}$ & heat transfer rate per unit length & $\mathrm{Btu} / \mathrm{hr}-\mathrm{ft}$ \\
\hline$q / A$ & heat flux & $\mathrm{Btu} / \mathrm{hr}-\mathrm{ft}^{2}$ \\
\hline$q / A_{\max }$ & maximum heat flux & $\mathrm{Btu} / \mathrm{hr}-\mathrm{ft}^{2}$ \\
\hline
\end{tabular}




\begin{tabular}{|c|c|c|}
\hline Symbol & $\underline{\text { Definition }}$ & Unit \\
\hline$q / A_{0}$ & cladding outside surface heat flux & $\mathrm{Btu} / \mathrm{hr}-\mathrm{ft}^{2}$ \\
\hline $\mathrm{q} / \mathrm{A}_{\text {avg }}$ & average heat flux & $\mathrm{Btu} / \mathrm{hr}-\mathrm{ft}^{2}$ \\
\hline$q / A_{\text {avg }}$ & average heat flux in coolant channels & $\mathrm{Btu} / \mathrm{hr}-\mathrm{ft}^{2}$ \\
\hline $\mathbf{r}$ & acceleration pressure drop multiplier & \\
\hline $\mathbf{R}$ & thermal resistance & $\left(\mathrm{Btu} / \mathrm{hr}-\mathrm{ft}^{2}-{ }^{\circ} \mathrm{F}\right)^{-1}$ \\
\hline $\begin{array}{c}\mathrm{R}_{\mathrm{B}}, \mathrm{R}_{\mathrm{H}}, \mathrm{R}_{\mathrm{L}} \\
\mathrm{R}_{\mathrm{LM},},{ }^{\mathrm{R}}{ }_{\mathrm{M}}\end{array}$ & two-phase friction multipliers & \\
\hline $\mathrm{R}_{\mathrm{Hg}}$ & $\begin{array}{l}\text { electrical resistance of mercury core (Heat Transfer } \\
\text { Experiment) }\end{array}$ & ohms \\
\hline$R_{w}$ & $\begin{array}{l}\text { electrical resistance of tube wall (Heat Transfer } \\
\text { Experiment) }\end{array}$ & ohms \\
\hline$\overline{\mathbf{R}}$ & length-average friction multiplier & \\
\hline $\mathbf{S}$ & pitch (centerline to centerline) & $\mathrm{ft}$ \\
\hline$s_{f}$ & fuel-element fabrication cost & $\$ / \mathrm{kg} \mathrm{U}$ \\
\hline$S_{h}$ & $\begin{array}{l}\text { ratio of heat generated in tube wall to total heat } \\
\text { (Heat Transfer Experiment) }\end{array}$ & \\
\hline $\mathbf{S}_{\mathrm{i}}$ & value of uranium & $\$ / \mathrm{kg} \mathrm{U}$ \\
\hline $\mathrm{t}$ & cladding thickness & $\mathrm{ft}$ \\
\hline$(\mathrm{t})$ & thermal & \\
\hline $\mathrm{T}$ & temperature, absolute & ${ }^{\circ} \mathrm{R}$ \\
\hline $\mathrm{T}_{\mathrm{CL}}$ & fuel-pin centerline temperature & ${ }^{\circ} \mathrm{R}$ \\
\hline $\mathrm{T}_{\mathrm{L}}$ & liquid temperature & ${ }^{\circ} \mathbf{R}$ \\
\hline $\mathrm{T}_{\mathrm{s}}, \mathrm{T}_{\text {sat }}$ & saturation temperature & ${ }^{\circ} \mathrm{R}$ \\
\hline$\Delta \mathrm{T}$ & temperature difference & ${ }^{\circ} \mathrm{R}$ \\
\hline$\Delta \mathrm{U}$ & group lethargy interval & \\
\hline $\mathrm{v}$ & specific volume & $\mathrm{ft}^{3} / \mathrm{lb}$ \\
\hline
\end{tabular}




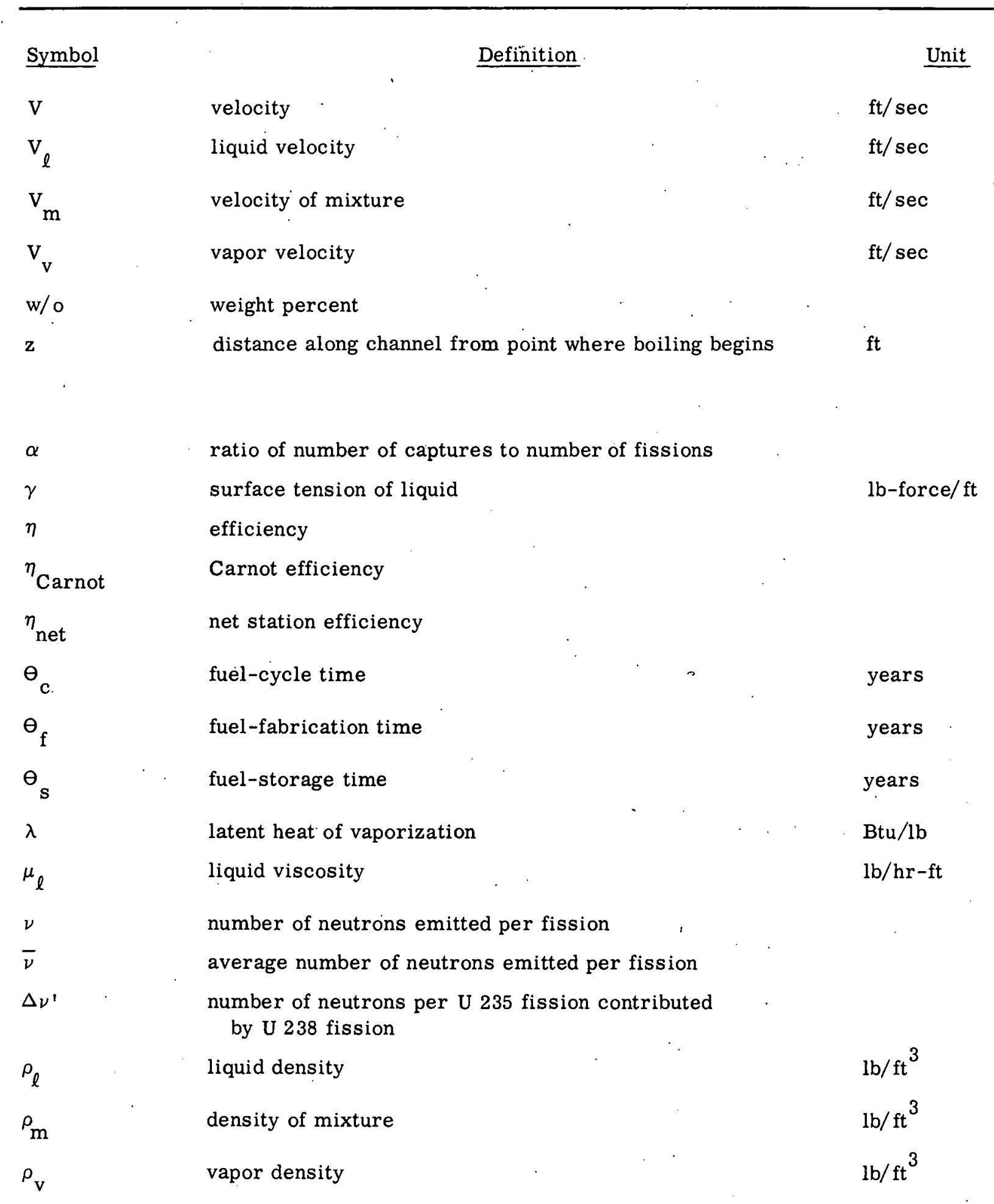


Symbol

$\bar{\rho}$

$\sigma$

$\sigma_{c}$

$\sigma_{\text {ef }}$.

$\sigma_{\mathrm{f}}$

$\sigma_{\text {if }}$

$\sigma_{\text {in }}$

$\sigma_{\text {it }}$

$\sigma_{\operatorname{tr}}$

$\phi t$

$x$

$\chi$

$x_{e}$

$\Omega$

\section{Definition}

liquid/vapor density

slip ratio

parasitic neutron absorption cross section

cross section of element for fast neutron capture

fission cross section

cross section of isotope for fast neutron capture

cross section for neutrons removed from energy

group by inelastic scattering

cross section of isotope for thermal neutron capture

transport cross section

integrated flux

vapor quality, ratio of mass flow rate of vapor to mass flow rate of total coolant

fission spectrum (fraction of fission neutron born into each group) - Appendix $F$

quality at channel exit

electrical resistance $\underline{\text { Unit }}$

$\mathrm{lb} / \mathrm{ft}^{3}$

barns

barns

barns

barns

barns

barns

barns

neutrons $/ \mathrm{cm}^{2}$

ohms 


\section{REFERENCES}

1. H. N. Hackett and D. Douglass, "Modern Mercury-Unit Power-Plant Design," Transactions of the ASME, January $1950, \mathrm{p} 89$.

2. J. R. Dietrich and W. H. Zinn, Solid Fuel Reactors, Reading, Mass., Addison-Wesley (1958), "Fuel and Fuel Element Materials," p 495.

3. "Development, Growth and State of the Atomic Energy Industry, " Hearings before the Joint Committee on Atomic Energy, Congress of the United States, February 1959.

4. "Report on the Fluid Fuel Reactors Task Force," U. S. Atomic Energy Commission, Oak Ridge, TID-8507, February 1959.

5. "Cost of Nuclear Power, "U. S. Atomic Energy Commission, Office of Operations Analysis, TID-8506, July 1959.

6. "Survey of Initiál Fuel Costs of Large U. S. Nuclear Power Stations, " Edison Electric Institute, EEI Publication No. 59-150, December 1958.

7. Hearings before the Joint Committee on Atomic Energy, U. S. 86th Congress, First Session on AEC Authorizing Legislation, FY 1960.

8. Hearings before the Joint Committee on Atomic Energy, U. S. 86th Congress, Section 202 of Act, FY 1960.

9. Electrical World, 151, No. 5, June 22, 1959, pp 64-77.

10. Nucleonics, 16, No. 4, April 1958, pp 53-72.

11. Liquid Metals Handbook, The U. S. Atomic Energy Commission in conjunction with U. S. Department of the Navy, NAVEXOS P-733, 2nd Edition, 1 June 1952.

12. T. B. Douglas, A. F. Ball, D. C. Grinnings, "Heat Capacity of Liquid Mercury Between 0 and $450^{\circ} \mathrm{C}$; Calculation of Certain Thermodynamic Properties of the Saturated Liquid and Vapor," Journal of Research of the National Bureau of Standards, $\underline{46}$, No. 4, NBS-2204, April 1951, p 334.

13. C. T. Ewing, et al, "Thermal Conductivity of Mercury and Two Sodium-Potassium Alloys," The Journal of Physical Chemistry, $\underline{59}$; No. 6, June 1955, p 524.

14. V. A. Veltishcheva, N. A. Kalakutskaya, N. A. Nikolskiy, "The Thermal Conductivity of Mercury," (in Russian), Teploenergetika, No. 10, 1958, p 80 (abstract in PB 141089T-10, U. S. Dept. of Congress, OTS, Washington, D. C.).

15. S. S. Kutateladze, et al, "Liquid Metal Heat Transfer Media," Translated from Russian Consultants Bureau, Inc., New York, 1959 (Supplement No. 2 of Soviet Journal of Atomic Energy, Atomnaia Energiia, Atomic Press, Moscow, 1958).

16. A. R. Smith and E. S. Thompson, "The Mercury-Vapor Process, "Transactions of the ASME, October 1942, p 625.

17. "Geneva Reviews Reactor Progress," Nucleonics, 16, No. 9, Sept. 1958, p 27. 
18. O. Wood, General Electric Company, personal communication.

19. H. N. Hackett, "Mercury for the Generation of Light, Heat, and Power," Transactions of the ASME, October 1942, p 647.

20. M. I. Korneev, "Heat Transfer in Mercury and Magnesium Amalgams During Boiling Under Conditions of Free Convection," (Translation) Teploenergetika, 2, No. 4, 1955, p 44.

21. C. F. Bonilla, J. S. Busch, A. Stalder, N. S. Shaikmahmud, A. Ramachandran, "Pool Boiling Heat Transfer with Mercury, "Reactor Heat Transfer Conference, November 1-2, 1956, New York, N. Y. (Nuclear Development Corporation of America, 5 New Street, White Plains, New York).

22. R. E. Lyon, A. S. Froust, D. L. Katz, "Boiling Heat Transfer with Liquid Metals," Chemical Engineering Symposium Progress Series, 51, No. 17, p 41.

23. Heat Transfer, a Symposium, University of Michigan (1953).

24. M. I. Korneev and B. N. Puganov, "An Investigation of Heat Exchange in Horizontal Pipes Carrying a Vapor-Liquid Mixture," (Translation) Teploenergetika, $\underline{3}$, No. 6, p 39.

25. N. Zuber and M. Tribus, "Further Remarks on the Stability of Boiling Heat Transfer," Department of Engineering, University of California at Los Angeles, Report No. 58-5, June 1958.

26. C. F. Bonilla, Editor, Nuclear Engineering, New York, McGraw-Hill Book Co. (1957).

27. W. M. Rohsenow and P. Griffith, "Correlation of Maximum Heat Flux Data for Boiling of Saturated Liquids," AICAE Meeting, Louisville, Kentucky, March 1955.

28. P. Griffith, "The Correlation of Nucleate Boiling Burnout Data," ASME Paper No. 57-HT-21.

29. B. Lubarsky and S. J. Kaufman, "Review of Experimental Investigation of Liquid-Metal Heat Transfer, " NACA Report No. 1270, 1956.

30. S. S. Kutateladze, V. J. Subbotin, V. M. Borishansky, P. L. Kirilloy, "Heat Transfer in Liquid Metal Pipe Flowing," Proceedings of the Second United Nations International Conference on the Peaceful Uses of Atomic Energy, A/Conf. 15/P/2210 (1958).

31. C. L. Rickard, O. E. Dwyer, D. Dropkin, "Heat Transfer Rates to Cross-Flowing Mercury in a Staggered Tube Bank - II," ASME Paper No. 57-HT-11.

32. B. Misra and C. F. Bonilla, "Heat Transfer in the Condensation of Metal Vapors: Mercury and Sodium up to Atmospheric Pressure, "Heat Transfer - Louisville Chemical Engineering Progress Symposium Series No. 18, American Institute of Chemical Engineers, $\underline{52}$ (1956).

33. L. I. Gel'man, "Heat Exchange During Dropwise Condensation of Mercury Vapor," Teploenergetika, No. 3, 1958, pp 45-50.

34. R. C. Martinelli and D. B. Nelson, "Prediction of Pressure Drop During Forced-Circulation Boiling of Water," Transactions of the ASME, August 1948, p 695.

35. P. A. Lottes, et al, "Experimental Studies of Natural Circulation Boiling and Their Application to Boiling Reactor Performance, " Argonne National Laboratory, Lemont, Illinois. 
36. B. Carlson and G. I. Bell, "Solution of the Transport Equation by the $S_{N}$ Method, "Proceedings of the International Conference on the Peaceful Uses of Atomic Energy, Paper No. P/2386 (1955).

37. D. Okrent, R. Avery, H. Hummel, "A Survey of the Theoretical and Experimental Aspects of Fast Reactor Physics, "Proceedings of the International Conference on the Peaceful Uses of Atomic Energy, Vol. 5, P/609 (1955).

38. R. Avery, "Fast Reactor Physics Calculations," Argonne National Laboratory, ANL-5492 (1956).

39. W. B. Loewenstein and D. Okrent, "The Physics of Fast Power Reactors, a Status Report," Proceedings of the Second United Nations International Conference on the Peaceful Uses of Atomic Energy, Paper No. P/637 (1958).

40. G. J. Habetler, "One-Space-Dimensional Multigroup for the IBM-650, Part I Equations," Knolls Atomic Power Laboratory, KA.PL-1415, Dec. 1, 1955.

41. V. A. Walbran, "One-Space-Dimensional Multigroup for the IBM-650, Part II Machine Program," Knolls Atomic Power Laboratory, KAPL-1531, April 10, 1956.

42. D. J. Hughes and R. B. Schwarz, "Neutron Cross Section," Brookhaven National Laboratory, BNL-325, July 1, 1955.

43. B. C. Diven, H. C. Martin, R. F. Taschek, "Multiplicities of Fast Neutrons," Physic. Rev., 101 , No. 3, Feb. 1, 1956, p 1012.

44. R. B. Leachman, "Emission of Prompt Neutrons From Fission," Physic. Rev., 101, No. 3, Feb. 1, 1956, p 1005.

45. B. C. Diven, "Radioactive Capture," Proceedings of the Second United Nations International Conference on the Peaceful Uses of Atomic Energy, Vol. 15, P/667 (1958).

46. J. K. Long, "Fast Neutron Power Reactor Studies with ZPR-III," Proceedings of the Second United Nations International Conference on the Peaceful Uses of Atomic Energy, P/598 (1958).

47. R. E. Canter and J. R. Beyster, "Inelastic Collision Cross Sections for Fission Spectrum Neutrons," Physic. Rev., 90, No. 2, April 15, 1953, p 3899.

48. K. F. Smith and L. R. Kelman, "Irradiation of Cast Uranium-Plutonium Base Alloys," Argonne National Laboratory, ANL-5677, May 1957.

49. M. L. Bleiberg, J. D. Eichenberg, R. H. Fillnow, L. J. Jones, "Development and Properties of Uranium-Base Alloys Corrosion Resistant in High-Temperature Water, Part IV, Radiation Stability of Uranium-Base Alloys, "Westinghouse Atomic Power Division, WAPD-127, May 1957.

50. D. O. Lesser, R. A. Rough, A. H. Bauer, "Radiation Stability of Fuel Elements for the Enrico Fermi Power Reactor, " Proceedings of the Second United Nations International Conference on the Peaceful Uses of Atomic Energy, A/Conf. 15/8/622, June 1958.

51. "Gas-Cooled Power Reactor, Preliminary Design 55,000 kw Prototype," Kaiser Engineers and Nuclear Products - Erco Division of ACF Industries, IDO-2021, Rev. 1, April 1, 1958, p 47. 


\section{MERCURY COOLED BREEDER REACTOR}

52. J. H. Kittel and S. H. Paine, "Effect of Irradiation on Fuel Materials, " Proceedings of the Second United Nations International Conference on the Peaceful Uses of Atomic Energy, A/Conf. 15/8/1890, June 1958.

53. "Metallurgy Division Quarterly Report for July, August, and September, 1957, " Argonne National Laboratory, ANL-5797, October 1958.

54. J. R. Dietrich and W. H. Zinn, Solid Fuel Reactors, Reading, Mass., Addison-Wesley (1958), "Fuel Performance (EBR-II), " p 210.

55. J. R. Dietrich and W. H. Zinn, Solid Fuel Reactors, Reading, Mass., Addison-Wesley (1958), "Fuel and Blanket Materials (Enrico Fermi Power Reactor)," p 366.

56. A. Del Grosso, "Compilation of Uranium-10 w/o Molybdenum Fuel Alloy Properties," The U. S. Atomic Energy Commission, AECU-3679, June 7, 1957.

57. E. L. Francis, Compiler, "Uranium Data Manual," The U. S. Atomic Energy Research Authority, IGR-R/R 287, May 1958.

58. A. Puishes, et al, "Comparison of Calder Hall and PWR Reactor Types," Atomic Energy Division of American-Standard, Report S-1, 1 November 1956.

59. Minerals Yearbook, Metals and Minerals, Vol. 1, Bureau of Mines, Department of the Interior, Washington (1958).

60. "Mercury (Quicksilver)," Report of Investigation No. 23, United States Tariff Commission, Washington, D. C. , November 1958. 


\section{DISTRIBUTION}

No. of Copies

3

1

1

1

2

2

1

1
Aberdeen Proving Ground Aerojet-General Corporation

Aerojet-General, San Ramon (IOO-880)

AFPR, Lockheed, Marietta

Air Force Special Weapons Center

ANP Project Office, Convair, Fort Worth

Alco Products, Inc.

Allis-Chalmers Manufacturing Company

Argonne National Laboratory

Army Ballistic Missile Agency

Army Chemical Center

Army Signal Research and Development Laboratory

AEC Scientific Representative

AEC Scientific Repres entative, Belgium

AEC Scientific Representative, Japan

Atomic Energy Commission, Washington

Atomics International

Babcock and Wilcox Company (NYOO-1940)

Battelle Memorial Institute

Bettis Plant

Brookhaven National Laboratory

Brush Beryllium Company

Bureau of Medicine and Surgery

Bureau of Ships (Code 1500)

Bureau of Yards and Docks

Chicago Operations Office

Chicago Patent Group

Combustion Engineering, . Inc.

Convair-General Dynamics Corporation, San Diego

Defence Research Member

Denver Research Institute

Department of the Army, G-2

duPont Company, Aiken

duPont Company, Wilmington

Edgerton, Germeshausen and Grier, Inc. , Las Vegas

Frankford Arsenal

General Atomic Division

General Electric Company (ANPD)

General Electric Company, Richland

General Nuclear Engineering Corporation

Gibbs and Cox, Inc.

Grand Junction Operations Office

Iowa State University

Jet Propulsion Laboratory 
No. of Copies

2

4

1

1

1

1

1

1

1

1

1

1

3

1

2

1

1

1

10

2

1

1

1

1
Knolls Atomic Power Laboratory

Los Alamos Scientific Laboratory

Mallinckrodt Chemical Works

Maritime Administration

Martin Company

Massachusetts Institute of Technology (Hardy)

Monsanto Chemical Company

Mound Laboratory

National Aeronautics and Space Administration, Cleveland

National Bureau of Standards

National Bureau of Standards (Library)

National Lead Company of Ohio

Naval Research Laboratory

New Brunswick Area Office

New York Operations Office

Nuclear Development Corporation of America

Nuclear Metals, Inc.

Oak Ridge Institute of Nuclear Studies

Office of Naval Research

Office of Naval Research (Code 422)

Office of Ordnance Research

Office of the Chief of Naval Operations

Office of the Surgeon General

Ordnance Tank-Automotive Command

Patent Branch, Washington

Phillips Petroleum Company (NRTS)

Picatinny Arsenal

Power Reactor Development Company

Pratt and Whitney Aircraft Division

Public Health Service

Sandia Corporation, Albuquerque

Schenectady Naval Reactors Operations Office

Stevens Institute of Technology

Sylvania Electric Products, Inc.

Tennessee Valley Authority

Texas Nuclear Corporation

Union Carbide Nuclear Company (ORGDP)

Union Carbide Nuclear Company (ORNL)

USAF Project RAND

U. S. Geological Survey, Albuquerque

U. S. Geological Survey, Denver

U. S. Geological Survey (Stringfield)

U. S. Naval Ordnance Laboratory

U. S. Naval Postgraduate School

U. S. Naval Radiological Defense Laboratory

U. S. Patent Office

University of California, Berkeley

University of California, Livermore 
No. of Copies

1
1
75
75
725

University of Puerto Rico

University of Rochester

University of Rochester (Marshak)

Walter Reed Army Medical Center

Watertown Arsenal

Westinghouse Electric Corporation (Schafer)

Wright Air Development Center

Yankee Atomic Electric Company

Technical Information Service Extension

Office of Technical Services, Washington

San Francisco Operations Office

Chief, Evaluation \& Planning Branch, DRD, Washington, D. C.

Advanced Technology Laboratories

675 